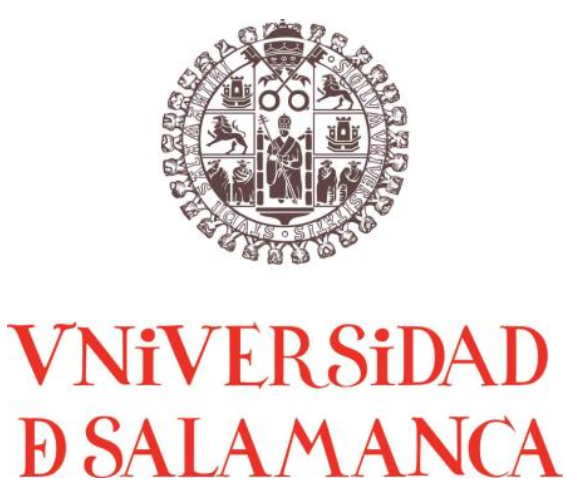

FACULTAD DE ECONOMÍA Y EMPRESA

Departamento de Administración y Economía de la Empresa

TESIS DOCTORAL

\title{
Los factores organizacionales y del entorno como moderadores de la relación entre innovación y desempeño empresarial: diferencias entre pequeñas y grandes empresas
}

\author{
Doctoranda: \\ EVELYN GARCÍA ZAMORA \\ Directores: \\ DR. D. ÓSCAR GONZÁLEZ BENITO \\ Catedrático de Comercialización e Investigación de Mercados \\ DR. D. PABLO A. MUÑOZ GALLEGO \\ Catedrático de Comercialización e Investigación de Mercados
}







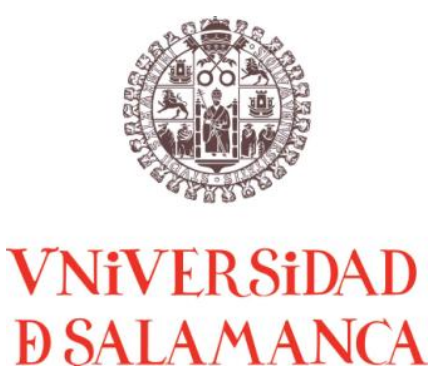

DEPARTAMENTO DE ADMINISTRACIÓN Y ECONOMÍA DE LA EMPRESA

PROGRAMA DE DOCTORADO EN

ECONOMÍA DE LA EMPRESA

TESIS DOCTORAL

\section{Los factores organizacionales y del entorno como moderadores de la relación entre innovación y desempeño empresarial: diferencias entre pequeñas y grandes empresas}

Tesis Doctoral que se presenta para la obtención del título de grado de doctor por la Universidad de Salamanca

Doctoranda:

EVELYN GARCÍA ZAMORA

Directores:

DR. D. ÓSCAR GONZÁLEZ BENITO

DR. D. PABLO A. MUÑOZ GALLEGO

Salamanca, 2012 

Los factores organizacionales y del entorno como moderadores de la relación entre innovación y desempeño empresarial: diferencias entre pequeñas y grandes empresas

Dedicado a Daniel. 

Los factores organizacionales y del entorno como moderadores de la relación entre innovación y desempeño empresarial: diferencias entre pequeñas y grandes empresas

\section{Agradecimientos}

Agradezco a mis Directores de Tesis Doctoral, Dr. Óscar González Benito y Dr. Pablo A. Muñoz Gallego, por su tiempo y dedicación para que esta Tesis Doctoral se culminara. 



\section{DEPARTAMENTO DE ADMINISTRACIÓN}

Y ECONOMÍA DE LA EMPRESA

\section{VNiVERSiDAD \\ DSALAMANCA}

\section{AUTORIZACIÓN \\ DE LOS DIRECTORES DE LA TESIS DOCTORAL \\ PARA SU PRESENTACIÓN}

Dr. Óscar González Benito y Dr. Pablo A. Muñoz Gallego, como Directores de la Tesis Doctoral "Los factores organizacionales y del entorno como moderadores de la relación entre innovación y desempeño empresarial: diferencias entre pequeñas y grandes empresas", realizada por $D^{\mathrm{a}}$. Evelyn García Zamora en el Departamento de Administración y Economía de la Empresa de la Universidad de Salamanca, autorizan su presentación a trámite dado que reúne las condiciones necesarias para su defensa.

Y para que conste a los efectos oportunos, se firma la presente en Salamanca a 04 de julio de 2012.

Fdo. Óscar González Benito

Fdo. Pablo A. Muñoz Gallego 



\section{Índice de contenidos}

1. Introducción ..........................................................................................................................................................25

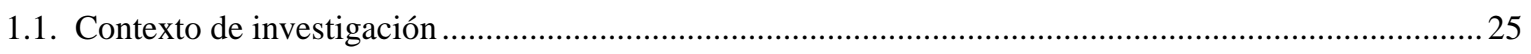

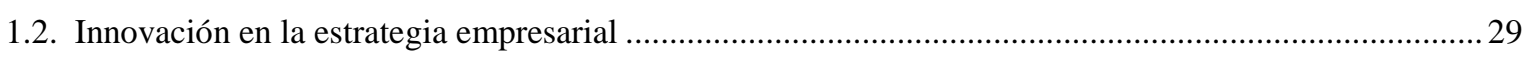

1.2.1. Elección de la estrategia .......................................................................................................2 29

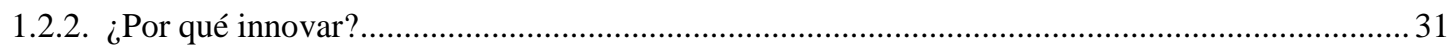

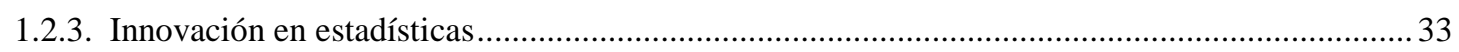

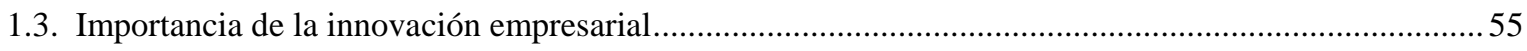

1.3.1. Innovación y desempeño empresarial ................................................................................... 57

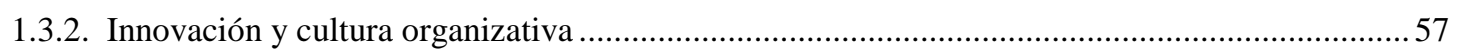

1.3.3. Innovación y tamaño empresarial ……………………………………………………….... 58

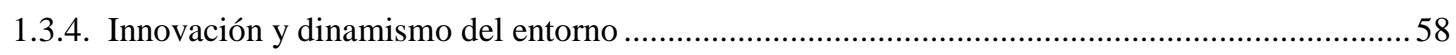

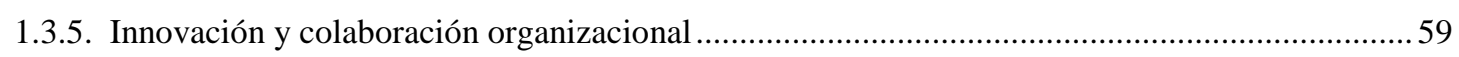

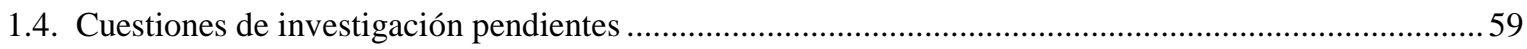

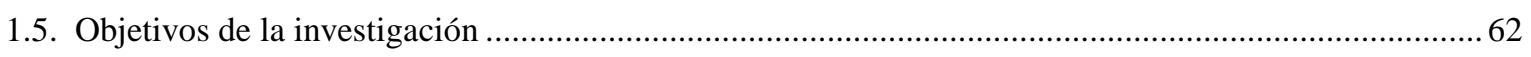

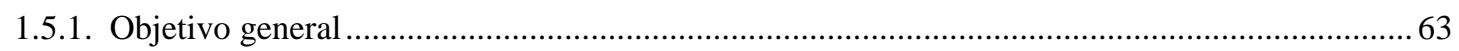

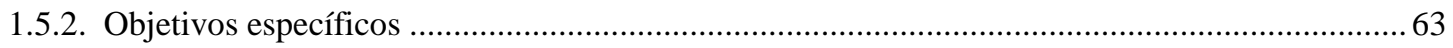

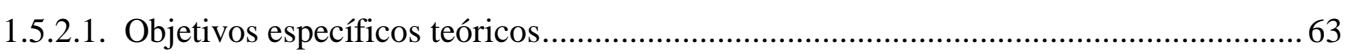

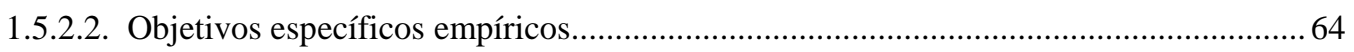

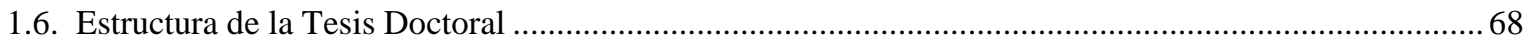

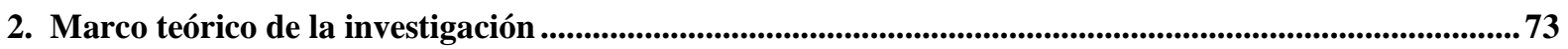

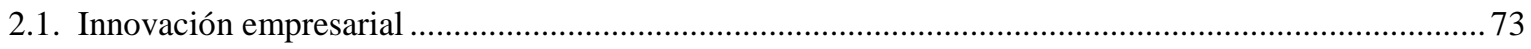

2.1.1. Innovación incremental, operativa y multidimensional ......................................................... 79

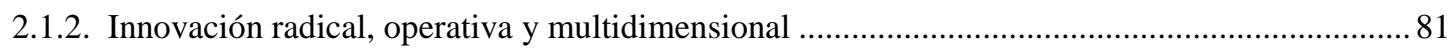

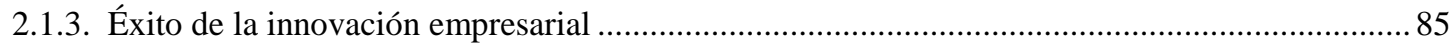

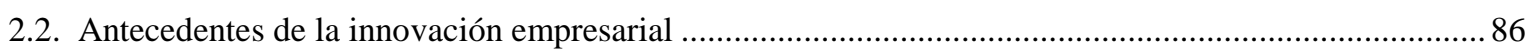

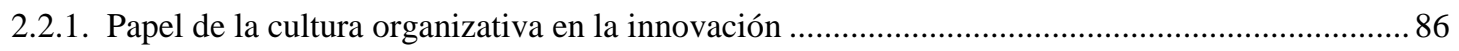

2.2.1.1. Papel de la orientación al mercado en la innovación ........................................................ 87

2.2.1.2. Papel de la orientación emprendedora en la innovación ............................................... 95

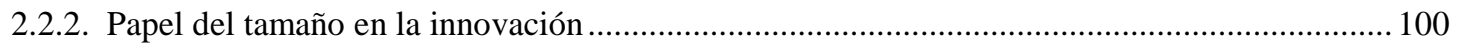

2.2.3. Papel del tamaño en la cultura organizativa ............................................................................... 106

2.2.4. Papel del tamaño: relación entre cultura organizativa e innovación ............................................ 107

2.3. Efecto de la innovación en el desempeño empresarial y sus moderadores ............................................ 111

2.3.1. Innovación: aportación al desempeño empresarial.................................................................. 111

2.3.2. Factores empresariales claves del éxito innovador …………………………………………..... 113

2.3.2.1. Factores organizacionales: cultura organizativa y tamaño empresarial ....................... 115

2.3.2.2. Papel de la cultura organizativa en el desempeño empresarial ..................................... 116 
2.3.2.3. Papel de la cultura organizativa: relación entre innovación y desempeño empresarial 118

2.3.2.4. Papel del tamaño en el desempeño empresarial ........................................................ 119

2.3.2.5. Papel del tamaño: relación entre innovación y desempeño empresarial ..................... 121

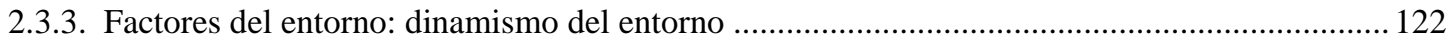

2.3.3.1. Papel del dinamismo del entorno en la innovación................................................. 123

2.3.3.1.1. Papel de la turbulencia del entorno: relación entre innovación y desempeño empresarial

2.3.3.1.2. Papel de la intensidad competitiva: relación entre innovación y desempeño empresarial 128

2.3.4. Factores de interacción con el entorno: colaboración organizacional 131

2.3.4.1. Teoría de redes sociales en el ámbito empresarial ............................................... 133

2.3.4.2. Teoría basada en los recursos y su influencia en la teoría de redes sociales 136

2.3.4.3. Papel de la colaboración organizacional en la innovación: diferencias entre grandes y pequeñas empresas .................................................. 139

2.3.4.3.1. Innovación y colaboración organizacional .............................................................. 141

2.3.4.3.2. Colaboración con los proveedores, clientes, y competidores ................................ 143

2.3.4.3.3. Colaboración con consultores y universidades ....................................................... 143

2.3.4.3.4. Innovación y colaboración: diferencias entre grandes y pequeñas empresas............ 144

2.3.4.4. Papel de colaboración organizacional en la relación entre innovación y desempeño empresarial: diferencias entre grandes y pequeñas empresas ................................. 146

2.3.4.4.1. Colaboración y desempeño empresarial.............................................................. 146

2.3.4.4.2. Colaboración con los proveedores, clientes, y competidores................................. 147

2.3.4.4.3. Colaboración con consultores y universidades ................................................... 147

2.3.4.4.4. Colaboración y desempeño empresarial: diferencias entre

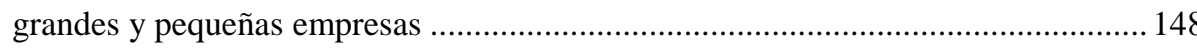

2.3.4.4.5. Papel de la colaboración en la relación entre innovación y desempeño................... 149

2.3.4.4.6. Papel de la colaboración en la relación entre innovación y desempeño empresarial: diferencias entre grandes y pequeñas empresas

3. Metodología general .163

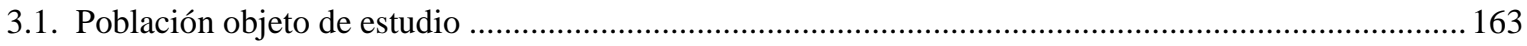

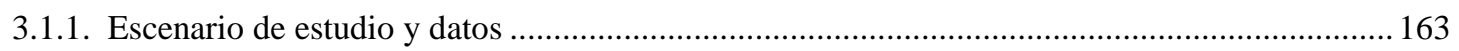

3.1.2. Perfil de la población y la muestra ................................................................................ 165

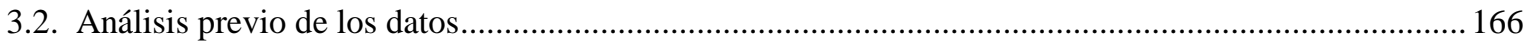

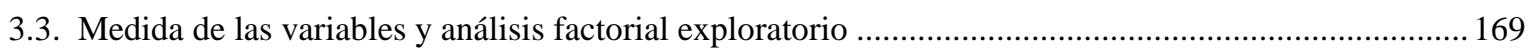

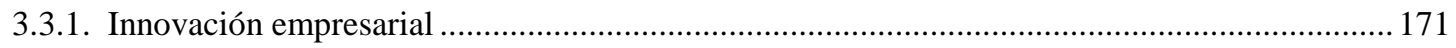

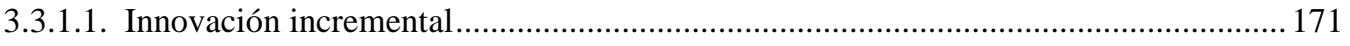

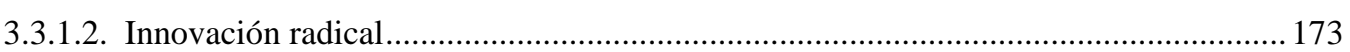


3.3.2. Desempeño empresarial 176

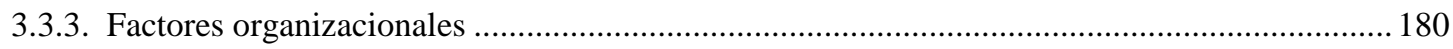

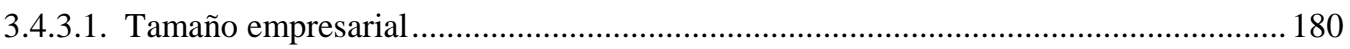

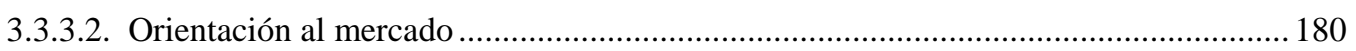

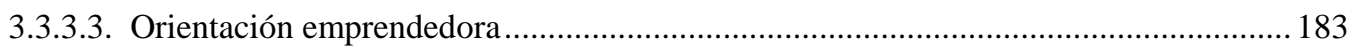

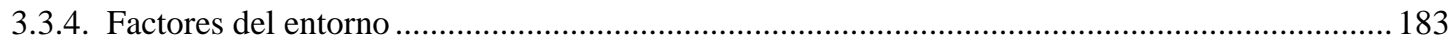

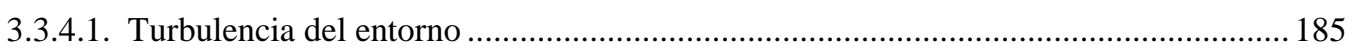

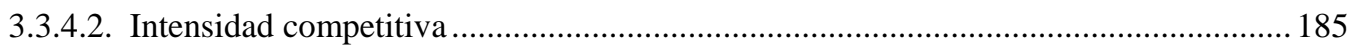

3.3.4.3. Colaboración organizacional .............................................................................. 188

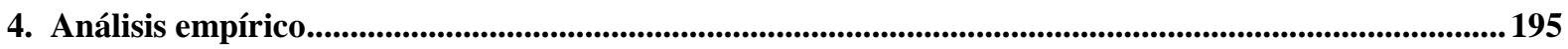

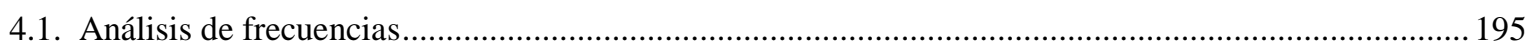

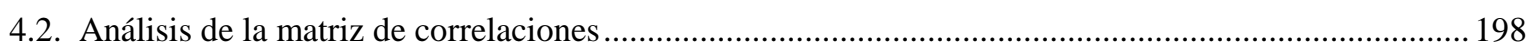

4.2.1. Matriz de correlaciones: modelo explicativo I ................................................................ 198

4.2.2. Matriz de correlaciones: modelo explicativo II ................................................................ 200

4.2.3. Matriz de correlaciones: modelo explicativo III .................................................................. 203

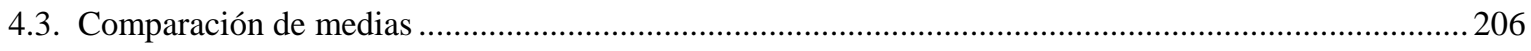

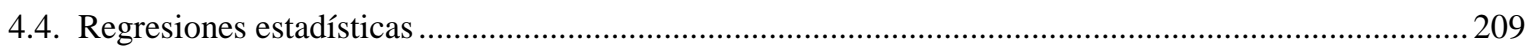

4.4.1. Emprendedorismo y orientación al mercado como precursoras de la innovación: papel del tamaño empresarial (modelo explicativo I) ......................................... 209

4.4.1.1. Papel de la cultura organizativa en la innovación ................................................... 209

4.4.1.2. Papel del tamaño: relación cultura organizativa e innovación ................................... 211

4.4.2. Factores organizacionales y del entorno como moderadores de la relación entre innovación multidimensional y desempeño empresarial (modelo explicativo II) ..................... 222 4.4.2.1. Innovación: aportación al desempeño empresarial ................................................. 222

4.4.2.2. Efectos moderadores de los factores organizacionales y del entorno ...................... 229

4.4.3. El papel de la colaboración en el éxito de la innovación: diferencias entre grandes y pequeñas empresas (modelo explicativo III) .............................................. 246

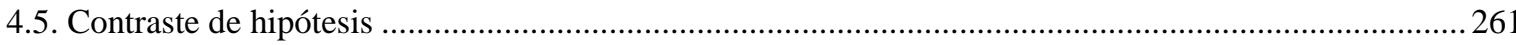

5. Conclusiones.

5.1. Emprendedorismo y orientación al mercado como precursoras de la innovación: papel del tamaño empresarial (modelo explicativo I) ........................................................................ 269

5.1.1. Implicaciones en la práctica empresarial..

5.2. Factores organizacionales y del entorno como moderadores de la relación entre innovación multidimensional y desempeño empresarial (modelo explicativo II) 273 5.2.1. Implicaciones en la práctica empresarial 
5.3. El papel de la colaboración en el éxito de la innovación: diferencias entre grandes y pequeñas empresas (modelo explicativo III) 278

5.3.1. Implicaciones en la práctica empresarial................................................................................28 280

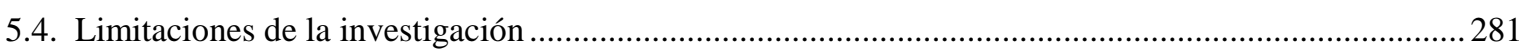

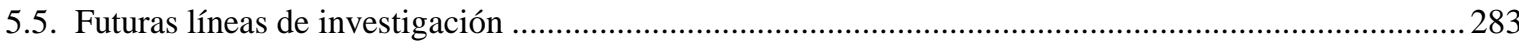

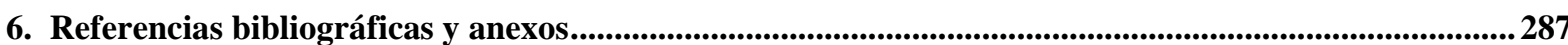

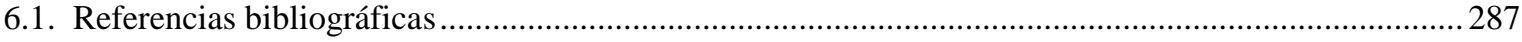

6.2. Anexo: instrumento de medida los distintos variables implicadas en el análisis de la muestra ..............322 


\section{Índice de tablas}

1 Empresas según estrato de asalariados y porcentaje total, en España y

en la U27, 2010

$2 \quad$ Líderes del crecimiento innovador en la Unión Europea 34

3 Solicitud y concesión de patentes (EPO y UPSTO) 40

4 Solicitudes y concesiones de patentes en España por Comunidades 42 Autónomas. 1995-2008

$5 \quad$ Recursos humanos en investigación z desarrollo / ciencia y tecnología 43

6 Gastos y equipo en I+D en el sector empresarial. 1995-2008 45

7 Proporción de empresas innovadoras con introducción de nuevos productos 46 a otros mercados o propios, desarrollos de procesos innovadores. 2008

8a Empresas españolas con innovaciones no tecnológicas de organización. 49 2006-2008

8b Empresas españolas con innovaciones no tecnológicas de marketing. 49 2006-2008

9 Empresas con innovaciones no tecnológicas según lugar dónde se realiza la 51 innovación y tamaño de la empresa. 2006-2008

10 Colaboración en innovación de las empresas según tipo de agente y tamaño 54 de la empresa. 2008

11 Objetivos específicos teóricos de la Tesis Doctoral 66

12 Objetivos específicos empíricos de la Tesis Doctoral 67

13 Estudios que evidencian que la orientación al mercado tiene un efecto en la 92 innovación: según tipo de innovación y tamaño de la empresa

14 Estudios que evidencian que la orientación emprendedora tiene un efecto en 99 la innovación: según tipo de innovación y tamaño

15 Tipo de relación entre el tamaño de la empresa y la innovación 104

16 Tipo de contribución de la colaboración a la innovación e interacción con el 145 tamaño

17 Tipo de contribución de la colaboración al desempeño empresarial: 154 interacción colaboración y tamaño

18 Hipótesis planteadas por el modelo teórico 157

19 Características de la población y de la muestra 166

20 Mínimo $\mathrm{R}^{2}$ según el tamaño de la muestra y las variables utilizadas 169

21 Escala de medida de la innovación incremental 174 
22 Escala de medida de la innovación radical

23 Clasificación de las dimensiones de desempeño

24 Escala de medida de las variables de desempeño

25 Escala de medida de la orientación al mercado

26 Escala de medida de la orientación emprendedora

27 Escala de medida del turbulencia del entorno

28 Escala de medida de la intensidad competitiva

29 Escala de medida de la colaboración para la innovación radical

30 Escala de medida de la colaboración para la innovación incremental

31 Características estructurales de la muestra según tamaño de la empresa

32 Tipo de innovación realizada según tamaño de la empresa

33 Correlaciones entre las variables del modelo explicativo I y II

34 Correlaciones entre las variables del modelo explicativo III

35 Comparación de medias tomando como base de comparación el tamaño de la empresa

36a Regresiones: la innovación incremental en relación con la cultura organizativa y el dinamismo del entorno

36b Regresiones: la innovación radical en relación con la cultura organizativa y el dinamismo del entorno

37 Regresiones: la innovación incremental y radical en relación con el tamaño de la empresa

38 Regresiones: la innovación (incremental y radical) y la cultura organizativa en relación con el dinamismo del entorno y el tamaño de la empresa

39a Regresiones: efecto moderador del tamaño en la relación entre la cultura organizativa y la innovación incremental

39b Regresiones: efecto moderador del tamaño en la relación entre la cultura organizativa y la innovación incremental

39c Regresiones: efecto moderador del tamaño en la relación entre la cultura organizativa y la innovación radical

40a Regresiones: la innovación incremental en relación con la rentabilidad

40b Regresiones: la innovación incremental en relación con la respuesta 234 del mercado

40c Regresiones: la innovación incremental en relación con el valor en 235 el mercado 
40d Regresiones: la innovación incremental en relación con el éxito de 236 nuevos productos

41a Regresiones: la innovación radical en relación con la rentabilidad

41b Regresiones: la innovación radical en relación con la respuesta del mercado

41c Regresiones: la innovación radical en relación con el valor en el mercado

41d Regresiones: la innovación radical en relación con el éxito de 240 nuevos productos

42a Regresiones: efectos moderadores de los factores organizacionales y del entorno en la relación entre innovación incremental y desempeño empresarial

42b Regresiones: efectos moderadores de los factores organizacionales y del entorno en la relación entre innovación radical y desempeño empresarial

43 Regresiones: relación entre la colaboración organizacional y la innovación: papel del tamaño de la empresa

44 Regresiones: relación entre la colaboración organizacional y el desempeño empresarial

45a Regresiones: efecto moderador de la colaboración organizacional en la relación entre innovación incremental y desempeñoempresarial: papel de tamaño como doble moderador

45b Regresiones: efecto moderador de la colaboración organizacional en la relación entre innovación incremental y desempeñoempresarial: papel de tamaño como doble moderador

46a Regresiones: efecto moderador de la colaboración organizacional en la relación entre innovación radical y desempeñoempresarial: papel de tamaño como doble moderador

46b Regresiones: efecto moderador de la colaboración organizacional en la relación entre innovación radical y desempeño empresarial: papel de tamaño como doble moderador

47a Regresiones: efecto moderador de la colaboración organizacional en la relación entre innovación incremental y desempeño empresarial según tamaño de la empresa

47b Regresiones: efecto moderador de la colaboración organizacional en la relación entre innovación incremental y desempeño empresarial según tamaño de la empresa 
48a Regresiones: efecto moderador de la colaboración organizacional en la 259 relación entre innovación radical y desempeño empresarial según tamaño de la empresa

48b Regresiones: efecto moderador de la colaboración organizacional en la 260 relación entre innovación radical y desempeño empresarial según tamaño de la empresa

49 Contraste de las hipótesis planteadas del modelo teórico 261

$50 \quad$ Instrumento de medida de las variables de la muestra 


\section{Índice de figuras}

1a Resultados de la innovación en la Unión Europea 34

1b Proporción de empresas innovadoras en la Unión Europea 35

2 El esfuerzo en I+D en los países industrializados. Gasto total en I+D en 36 porcentaje del PIB en 2000, 2006, 2007 y 2008

$3 \quad$ Gasto en I+D en empresas según el \% del PIB 37

4 Gasto en I+D por comunidades autónomas en porcentaje del PIB regional 38 en 2009. (Entre paréntesis datos de 2008). PIB base 2000

$5 \quad$ Solicitudes de patentes PCT por billón del PIB 41

$6 \quad$ Empleo en actividades de conocimiento intensivo (\% del total de empleo) 44

7 PYMEs: introducción de innovaciones de producto o procesos según \% de 47 PYMEs

$8 \quad$ Ventas de innovaciones a nuevos mercados (\% de facturación) 47

9 PYMEs: introducción de innovaciones de organización o marketing según 48 $\%$ de PYMEs

10 Empresas españolas con innovaciones no tecnológicas según tipo de 50 innovación y tamaño de la empresa. 2006-2008

11 PYMEs: innovaciones propias según \% de PYMEs 51

12 Empresas con innovaciones no tecnológicas según lugar dónde se realiza la 52 innovación y tamaño de la empresa. 2006-2008

13 Estados miembros según los resultados de colaboraciones y 53 emprendedorismo

14 PYMEs: innovaciones en colaboración con otros según \% de PYMEs 54

15 Colaboración en innovación de las empresas según tipo de agente. $2008 \quad 55$

16 Modelo de análisis I: el emprendedorismo y la orientación al mercado como 110 precursoras de la innovación: papel del tamaño empresarial

17 Modelo de análisis II: los factores organizacionales y del entorno como 130 moderadores de la relación entre innovación multidimensional y desempeño empresarial

18 Innovación abierta

19 Modelo de análisis III: el papel de la colaboración en el éxito de la 156 innovación: diferencias entre grandes y pequeñas empresas

20 Modelo explicativo integrado 



\title{
Primer capítulo
}

\author{
Introducción
}





\section{Introducción}

\subsection{Contexto de investigación}

La U.E. ha priorizado sus políticas de desarrollo productivo, especialmente, a aquellas regiones que muestren un cierto desfase sobre la media en producción o rentas, de forma que se aminore, en la medida de lo posible, la diferencia entre el bienestar entre las regiones o países en Europa. Es relevante en este sentido conocer el modo en el que operan las empresas localizadas en estas zonas más desfavorecidas para identificar las principales prácticas que mejor se adecuan a este entorno y para enfocar con más acierto los fondos públicos destinados a las mismas. Estructuralmente las regiones entre Castilla \& León y Extremadura presentan dificultades añadidas a la hora de alcanzar un desarrollo empresarial que permita enriquecer un tejido productivo especialmente centrado en las actividades agrícolas y ganaderas (Muñoz-Gallego, 1992; Molinero et al. 2002; Cescyl, 2006).

Subyace en este planteamiento que las empresas localizadas en regiones "periféricas" y/o de pequeña dimensión pueden diferir en su comportamiento competitivo de aquellas otras localizadas en regiones empresarialmente más desarrolladas y/o que dispongan de un mayor tamaño de población. Sobre esta última premisa es que suelen centrarse mayormente los estudios sobre competitividad empresarial tanto a nivel nacional como internacional.

Las barreras a la creación y desarrollo empresarial en zonas desfavorecidas son de índole multidimensional: cultural, dinámica social, desarrollo personal, formativo, a lo que debe sumarse el papel, no siempre tan relevante como a priori se puede pensar, de las infraestructuras (viarias, ferroviarias, suelo industrial, telecomunicaciones y energía) o de las fuentes de financiación disponibles. La existencia y la competitividad de las empresas es un activo a promover pese a las dificultades que ello entrañe en estos territorios periféricos (Muñoz-Gallego, 1992; Cescyl, 2006; Sanz y Fernández, 2006).

Tal interés, ha ocupado a los investigadores en profundizar sobre los tópicos que explican la competitividad, comportamiento innovador y desempeño en el sector de las pequeñas empresas. No obstante, se ha dado una escasa atención a la competitividad de empresas en zonas desfavorecidas o periféricas, probablemente por la mayor dificultad para 
acceder por los investigadores a las mismas o por la menor relevancia de estas situaciones en el marco de las experiencias de competitividad de empresas en zonas con mayor tejido empresarial.

Las pequeñas empresas y medianas empresas son el motor de crecimiento de las economías emergentes y ejercen un rol dinámico en el desarrollo de las economías domésticas (Morris y Brennan, 2000; Morrison et al., 2003). Muchos países son conscientes de estas premisas e insisten en la creación de proyectos para su fortalecimiento con el objetivo de que se desarrollen y crezcan (Robson y Bennett, 2000; Barau y Osteryoung, 2001). Uno de los objetivos importantes de la acción pública de los países y regiones es alcanzar un desarrollo equilibrado y armónico del territorio, particularmente en lo concerniente a zonas desfavorecidas.

Dentro de los factores importantes para el éxito y el crecimiento de las pequeñas empresas, la ubicación geográfica o localización de estas es un elemento determinante por su fuerte influencia en el crecimiento de la empresa. Existe evidencia empírica que muestra que el desarrollo y consolidación de las firmas está conectado al entorno local y que la localización tiene una gran significancia para la explicación de la supervivencia o nosupervivencia de la firmas (Armstrong y Taylor, 1985; Storey, 1994; Spilling, 1996, Currya y Webberb, 2012), no obstante, Almus y Nerlinger (1999), concluyeron en su estudio que la localización no afectaba dramáticamente en el crecimiento para las empresas.

Liedholm (2002); Storey (1994) y Fotopoulos y Louri (2000) coinciden en sus estudios que las firmas localizadas en centros rurales o periféricas crecen menos que las ubicadas en bases urbanas, por otro lado, McPherson (1992) deduce que las empresas que operan en parques industriales o distritos comerciales muestran un marcado y mayor crecimiento que aquellas que tiene base SOHO (Small Ofiice-Home Oficce). Según el estudio realizado por Liedholm (2002), la mayoría de las pequeñas empresas se encuentran en centros y áreas rurales, sin embargo, los programas de ayuda están enfocados en empresas ubicadas en áreas urbanas, donde se tiene más acceso y es más sencillo centrar los estudios de investigación. 
No hay que dejar de lado, que las ventajas que provee una localización urbana con respecto a la rural o periférica, es que en la primera se cuenta con una estructura productiva sólida, interacción empresarial, mayor competitividad y por ende, mejoramiento en las habilidades organizaciones, acceso a fuentes de información del mercado, etc. En las zonas rurales o periféricas, al no contar con estos factores, es importante desarrollar una red informal (informal network) que de acuerdo a la teoría de redes - network theory - (Low y MacMillan, 1988; Mintzberg and van Der, 1999), una red empresarial informal, se basa en relaciones personales, familiares, contactos de negocios y del canal, lo que permite la relación interactiva dentro del entorno local, permitiendo el desarrollo del éxito y la flexibilidad dentro de las empresas (Littunen, 2000).

De la misma forma, Skuras et al. (2000), admite que uno de los tantos factores que limitan las empresas rurales, es la falta de infraestructura pública en las zonas desfavorecidas, sumado al ambiente económico externo desfavorable que se prolonga por la falta de planes de control y regulación. Además, añaden, que una forma de incentivar las zonas periféricas marginadas es crear planes de negocio, acciones reguladoras y proyectos de infraestructura que permitan a las pequeñas empresas competir, así como lo han provisto a las incubadoras de empresas y a los polígonos industriales. Aunque es cierto que en áreas geográficas donde existe un alto grado de creación de nuevas empresas, tienen a la vez un alto ratio de cierre de las mismas (Storey, 1994; Littunen et al., 1998; Currya y Webberb, 2012). El alto grado de creación de nuevas empresas se debe principalmente un entorno especial que ofrece buenas oportunidades para la innovación y la diferenciación, y donde las barreras del mercado son bajas (Littunen, 2000).

Como se recalcó anteriormente, a lo largo de los últimos años ha aumentado el interés por investigar las pequeñas empresas debido a su papel en el crecimiento económico y a su contribución en la generación de empleo (Kwoka y White, 2001; Audretsch, 2002; Liedholm, 2002). Son muchos los tópicos que se han explorado y analizado. Pero antes de analizar los temas que conciernen, específicamente al propósito de este estudio, es necesario hacer referencia a las principales líneas de investigación que se han examinado en los últimos años asociadas alrededor de la pequeña y mediana empresa. 
Dentro de la literatura de estrategia de management para pequeña empresa, existe una vasta referencia hacia el enfoque del comportamiento estratégico relacionado con diversas teorías y conceptos. Entre ellas, la asociación del enfoque estratégico con la teoría de recursos y capacidades y su relación con las ventajas competitivas de la empresa (Rangone, 1998; Santos et al., 2002). Por otra parte, se ha profundizado en la investigación de la innovación y la transferencia tecnológica, los mecanismos organizativos y la planificación estratégica (Menkveld y Thurik, 1999; Freel, 2000; Entrialgo et al., 2001; McCann et al., 2001; Perry, 2001; Upton et al., 2001; Barth, 2003).

Del mismo modo, se ha es estudiado ampliamente la personalidad del empresario (Roper, 1998; Kickul y Gundry, 2002; Hult et al, 2003; Beugelsdij y Noorderhaven, 2003; O’Gorman et al., 2005), la estructura de mercado y la estructura organizativa (Pelham y Wilson, 1996; Aragón y Sánchez, 2005), como también, la supervivencia, el fracaso y el éxito de la pequeñas empresas (Headd, 2003; Lussier y Pfeifer, 2001; Reid y Smith, 2000).

Asimismo, existen numerosos estudios que han destacado resultados importantes en temas como el entorno turbulento (van Gelderen et al., 2000; Freel, 2005), el aprendizaje organizativo (Santos et al., 2002; van Gelderen et al., 2005), la orientación al mercado (Kara et al., 2005; Verhess y Meulenberg, 2004; Pelham y Wilson, 1996), la orientación emprendedora (Mintzberg, 1989; Naman y Slevin, 1993; Lumpkin y Dess, 1996; Entrialgo et al., 2001; Messenghen, 2003; Hult y Ketchen, 2001) y la actividad sectorial (Santos y González-Benito, 2000), entre otros. En definitiva, los autores han tratado de demostrar por diversos medios metodológicos para demostrar que el comportamiento estratégico e innovador está ligado a otros factores y dependiendo de la relación existente se dará un mejor o menor desempeño en los resultados de las empresas. Esto lo sintetiza la Comisión Europea de la siguiente manera:

"la capacidad de innovación y adaptación permanente a los cambios económicos es lo que proporcionará a las regiones gran parte de las bazas necesarias para incrementar su competitividad, con vistas a alcanzar el objetivo de reducir las diferencias y crear empleo de calidad. Se trata de encontrar y difundir las mejores prácticas innovadoras, incitando a las autoridades políticas 
regionales y a las autoridades gestoras a fomentarlas. Las acciones innovadoras son un laboratorio cuyo objeto es la evolución de la política regional europea y su adaptación a los nuevos retos" (Comisión Europea, 2001).

\subsection{Innovación en la estrategia empresarial}

\subsubsection{Elección de la estrategia}

La elección de la estrategia, según Norman (1976) y Sandberg y Hofer (1986) debe estar diseñada para usar las capacidades directivas y administrativas y así cumplir con los objetivos de la empresa, de lo contrario son pocas las posibilidades de alcanzar el éxito en el sector industrial (Porter, 1980). En la misma línea, Littunen (2000), demostró que la estrategia de una firma tiene un efecto directo y moderador en su éxito.

Las organizaciones con una orientación estratégica hacia las acciones innovadoras, son aquellas que continuamente recogen información y la analizan con el propósito de aprovechar las nuevas oportunidades de mercado, a través de procesos de innovación, y desarrollo de productos (Aragón y Sánchez, 2005).

Acercándose al estudio de la aproximación del comportamiento innovador es obligatorio analizar las estrategias de innovación desarrolladas por las empresas. La tipología de la estrategia formulada por Miles y Snow (1978) considera importantes implicaciones en la organización, porque depende de la orientación estratégica que se adopte. Existen en la teoría dos clases de estrategias tecnológicas claves, la estrategia proactiva y la estrategia reactiva. La tipología clasifica el comportamiento estratégico como líder en el mercadoproactiva, y como seguidora-reactiva y se dirigen a todo el mercado (Ansoff, 1965); si es dirigido solo a un segmento del mercado las estrategia son ofensivas, defensivas, dependiente y oportunista (Sidro-Cazador, 1988).

Estudios previos se han encargado de investigar sobre la relación de la estrategia de innovación y el desempeño empresarial (Jaworski y Kohli, 1993; Slater y Narver, 1994; 
Pelham y Wilson, 1996; Pelham, 2000; van Gelderen et al., 2000; Aragón y Sánchez, 2005). Por un lado, Camison (1997) dedicó su estudio a la relación y concluyó que el tipo de organización que era más rentable y productiva era aquella que adoptaba estrategias proactivas en su comportamiento e integraba grupos orientados hacia la innovación de productos, procesos de calidad y satisfacción del cliente. Aragón y Sánchez (2005) deducen que la estrategia innovadora (estrategia proactiva) tiene resultados positivos para la empresa.

Los líderes en el mercado siguen una política agresiva de innovación dirigida a desarrollar actividades de investigación y desarrollo, a introducir nuevos productos o procesos para cubrir las necesidades y gustos de los consumidores y satisfacer la demanda de los nuevos mercados. Esta conducta estratégica suele propiciar ventajas competitivas al diferenciarse $\mathrm{u}$ obtener el liderazgo en costes marcando un posicionamiento fuerte en el mercado que proporciona crecimiento en las ventas, la obtención de la lealtad de los consumidores, etc., a pesar del riesgo de cambio y los altos costes financieros para desarrollar e implantar innovaciones de nuevos productos y procesos o la creación de nuevos mercados.

Las empresas que deciden adoptar una estrategia reactiva, estarán atentas a las innovaciones de los líderes para imitarlas rápidamente, y suelen comercializarlas a un precio más bajo, ahorrándose tiempo, costes y riesgos. Estas empresas realizan actividades de innovación aunque no basadas en las $\mathrm{I}+\mathrm{D}$, porque también pueden adquirir licencias o establecer alianzas o acuerdos para el transito de conocimiento.

Las estrategias ofensivas normalmente representan a empresas pequeñas relacionadas al desarrollo de la innovación para segmentos de mercado específicos. Así que para González et al. (1997: 98) "la empresa actúa como líder innovador, con la continua introducción de productos y la apertura de mercados, requiriendo que la unidad económica posea una gran capacidad tecnológica impulsada a través del mantenimiento de elevados gastos en I+D y una importante capacidad financiera para lanzar al mercado las innovaciones".

Las estrategias defensivas normalmente las acogen empresas seguidoras del líder, y además genera innovaciones incrementales para asemejar el producto al de la competencia pero añadiendo valor añadido; usualmente, lo consiguen a través de licencias para utilizar la tecnología y se dirigen a conocer las exigencias de los clientes para adaptarlas a sus gustos y 
necesidades. Estas empresas incurren en mayores gastos que las empresas seguidoras u ofensivas pero no tan altos como lo líderes tecnológicos.

La estrategia dependiente obtiene licencias, y depende como subsidiaria del propietario de la tecnología. El propietario le impone un sin número de restricciones que le impedirán la apropiación de la innovación. Los que siguen la estrategia oportunista, investigan sobre nichos de mercado menos atractivos y "consiguen entendimientos satisfactorios explotando el error que cometen los competidores al no dirigir los nuevos productos a todo el mercado sino sólo a aquellos segmentos que perciben como interesantes" (González et al., 1997: 98).

Ahora bien, las empresas para desarrollar su estrategia innovadora requieren tomar el camino de desarrollar por si mismo, por medio de actividades de $\mathrm{I}+\mathrm{D}$, a través de compra de licencias, patentes, adquisición de empresas con potencial tecnológico, o por medio de alianzas de colaboración, pero ¿por qué innovan las empresas?

\subsection{2. ¿Por qué innovar?}

Ahora entonces surge la pregunta ¿por qué innovar? La innovación ha alcanzado una importancia clave en la estrategia empresarial, surge de la necesidad de adaptarse a los cambios del entorno, e incluso ser participe de esos cambios con políticas agresivas de innovación. Por esta razón, innovar es una actividad imprescindible para la obtención de ventajas competitivas sostenibles, básica en los planes estratégicos y moderadora de la competitividad en el tejido empresarial.

Pero, retomando a las pequeñas empresas pertenecientes a las zonas desfavorecidas comentadas, surgen al respecto algunas preguntas sobre cómo están eligiendo e introduciendo una estrategia acertada; entonces:

(1) ¿qué opciones tienen las pequeñas empresas para alcanzar una mayor competitividad?, 
(2) ¿qué estrategias organizativas deben seguir para alcanzar el éxito?,

(3) ¿son capaces de implantar acciones innovadoras?,

(4) ¿están mas dirigidas hacia las innovaciones incrementales o radicales?,

(5) ¿es el tamaño de la empresa una condicionante para alcanzar el éxito innovador?,

(6) ¿es el sector al que pertenece un determinante para innovar más?,

(7) ¿qué tipo de acciones innovadoras implantan con mejores resultados?,

(8) ¿qué elementos culturales debieran de adoptar o potenciar para mejorar su estrategia competitiva?,

(9) ¿están más orientadas al mercado?,

(10) ¿más orientación al mercado conlleva a una mayor innovación?,

(11) ¿son más emprendedoras a la hora de introducir innovaciones incrementales y/o radicales?,

(12) ¿un espíritu emprendedor aumenta la capacidad innovadora?,

(13) ¿cómo afectan los factores del entorno a la hora de alcanzar las metas de crecimiento?,

(14) ¿es necesaria la colaboración externa para asegurar el éxito innovador?,

(15) ¿aprovecharán mejor la colaboración externa las pequeñas las empresas? 


\subsubsection{Innovación en estadísticas}

La población de pequeñas y medianas empresas españolas (menos de 250 empleados) constituye la mayor parte de la industria nacional con el casi 99, 9\% del total y brindan más del 50\% de empleo generado (ver Tabla 01). Esta evidencia porcentual es aún más categórica para las regiones de Castilla \& León y Extremadura, donde su estructura industrial es superior a la media nacional (Muñoz-Gallego, 1992).

Tabla 01

Empresas según estrato de asalariados y porcentaje total, en España y en la U27, 2010

\begin{tabular}{|c|c|c|c|c|c|c|c|}
\hline & Micro & Micro & Pequeñas & Medianas & Pyme & Grandes & Total \\
\hline & sin asalariados & $1-9$ & $10-49$ & $50-250$ & $0-249$ & $>250$ & \\
\hline España & 1.793 .878 & $1.297,971$ & 130,448 & 20,888 & $3.243,185$ & 3,801 & $3.246,989$ \\
\hline$\%$ & 55,20 & 40,0 & 4,00 & 0,60 & 99,90 & 0,10 & 100,00 \\
\hline UE27 \% & 92,1 & & 6,60 & 1,10 & 99,80 & 0,20 & 100,00 \\
\hline
\end{tabular}

Fuente: DIRCE, 2011 (datos de enero 2011) y Comisión Europea (2011b) "Annual report on EU small and medium sized enterprises 2010/2011 . Estimaciones para 2010.

La situación de España con el resto de la Unión Europea la cantidad de pequeñas y medianas empresas es superior en comparación a la media europea $(99,80 \%)$, solo cercana a países como Grecia, Dinamarca o Italia. Aunque, actualmente, la dínamo de una región se mide mejor por su dinamismo económico, que depende en gran medida, de su capacidad de innovación. En el estudio de Innovation Union Scoreboard de la Comisión Europea (2011), muestra la posición de resultados de los países miembros, en la Tabla 02 se puede observar el caso de España que se encuentra en una posición de innovación moderada y con bajo crecimiento. 
Tabla 02

Líderes del crecimiento innovador en la Unión Europea

\begin{tabular}{|c|c|c|c|c|}
\hline $\begin{array}{c}\text { Grupo de } \\
\text { innovadores }\end{array}$ & Crecimiento & $\begin{array}{l}\text { Lideres de } \\
\text { Crecimiento }\end{array}$ & $\begin{array}{l}\text { Moderado en } \\
\text { crecimiento }\end{array}$ & $\begin{array}{c}\text { Bajos en } \\
\text { crecimiento }\end{array}$ \\
\hline Líderes & $1,09 \%$ & Finlandia & Alemania & Dinamarca, Suecia \\
\hline Seguidores & $2,4 \%$ & $\begin{array}{l}\text { Chipre, Estonia, } \\
\text { Eslovenia }\end{array}$ & $\begin{array}{l}\text { Chipre, Estonia, } \\
\text { Eslovenia }\end{array}$ & $\begin{array}{l}\text { Luxemburgo, Reino } \\
\text { Unido }\end{array}$ \\
\hline Moderados & $2,5 \%$ & Malta, Portugal & Malta, Portugal & Grecia, España \\
\hline Modestos & $4,4 \%$ & Bulgaria & Bulgaria & Lituania \\
\hline
\end{tabular}

Fuente: European Commission (2011b)

La Figura 01-a, ilustra los resultados de la innovación en la región. El crecimiento del éxito innovador ha sido calculado para cada país y por datos de la EU27 sobre un periodo de cinco años. España se encuentra por debajo de la media en crecimiento innovador $(5,5 \%)$ y se mantiene dentro del grupo de "moderado crecimiento".

Figura 01-a

Resultados de la innovación en la Unión Europea

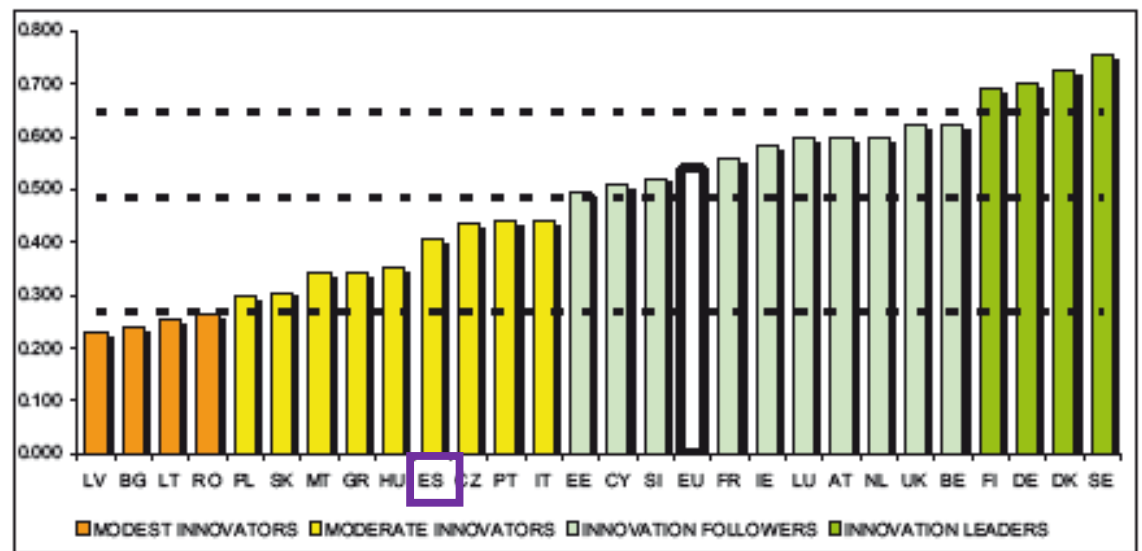

Note Average performance is measured using a composite indicator bulding on data for 24 indcators going from a lowest possible performance of 0 to a maximum possble performance of 1 . Average performance in 2011 reflacts performance in 20092010 due to a lag in data avallabiluty.

Fuente: European Commission (2011):7

La Figura 01-b muestra que el $48 \%$ de las empresas españolas son innovadoras, esta cifra posiciona al país en la segunda mitad de la tabla en el ámbito europeo. La tasa de empresas innovadoras en España se mantiene sólo dos puntos por debajo de la media de la 
Unión Europea (50\%), pero tan solo el 43,5\% de las empresas españolas del sector industrial y servicios realizó actividades de innovación entre 2006 y 2008, frente al 51,6\% de promedio comunitario, según un informe de Eurostat (2011). Es urgente fomentar aún más la innovación empresarial para logar ser competitivos en el entorno europeo, puesto que países como Alemania rondan el $77 \%$ de empresas que introducen innovaciones tecnológicas o no tecnológicas.

Figura 01-b

\section{Proporción de empresas innovadoras en la Unión Europea}

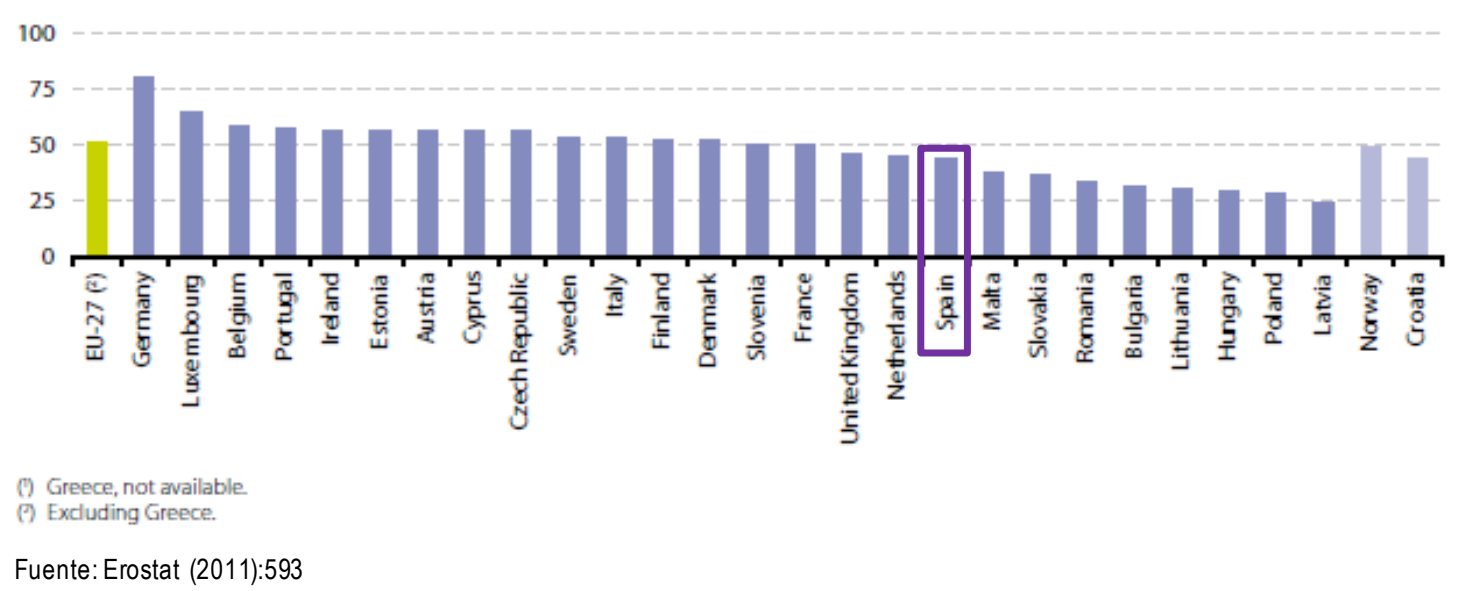

Esta capacidad innovadora, tecnológica o no tecnológica, de los países, apoya especialmente, los esfuerzos dirigidos a estimular la investigación y el desarrollo, la capacidad de obtener tecnologías, enriquecer los conocimientos, y adquirir equipos tecnológicos en el exterior, a la vez, contar con capital humano especializado y dedicado a la I+D, y por último, que es parte del interés de este estudio, el aprovechamiento que hacen las empresas e instituciones de las oportunidades para emprender.

Uno de los principales objetivos del gobierno español ha sido mantener el ritmo de crecimiento en el gasto de I+D para conseguir los objetivos impuesto por la Unión Europea, o sea; 3\% del Producto Interior Bruto (PIB) y, de este, que el 70\% proviniera de la iniciativa privada (es decir, que la I+D privada debería representar un $2 \%$ del PIB) y el $30 \%$ de la iniciativa pública (esto es, que la I+D pública debería representar un $1 \%$ del PIB). El alcance de este objetivo, según el Instituto de Estadística, estuvo muy por debajo de lo esperado, 
donde solo se alcanzó un 1,35\% del PIB y el 48,8\% correspondió al sector público para el 2008 (ver Figura 02).

Figura 02

\section{El esfuerzo en I+D en los países industrializados. Gasto total en I+D en porcentaje del PIB en 2000, 2006, 2007 y 2008}

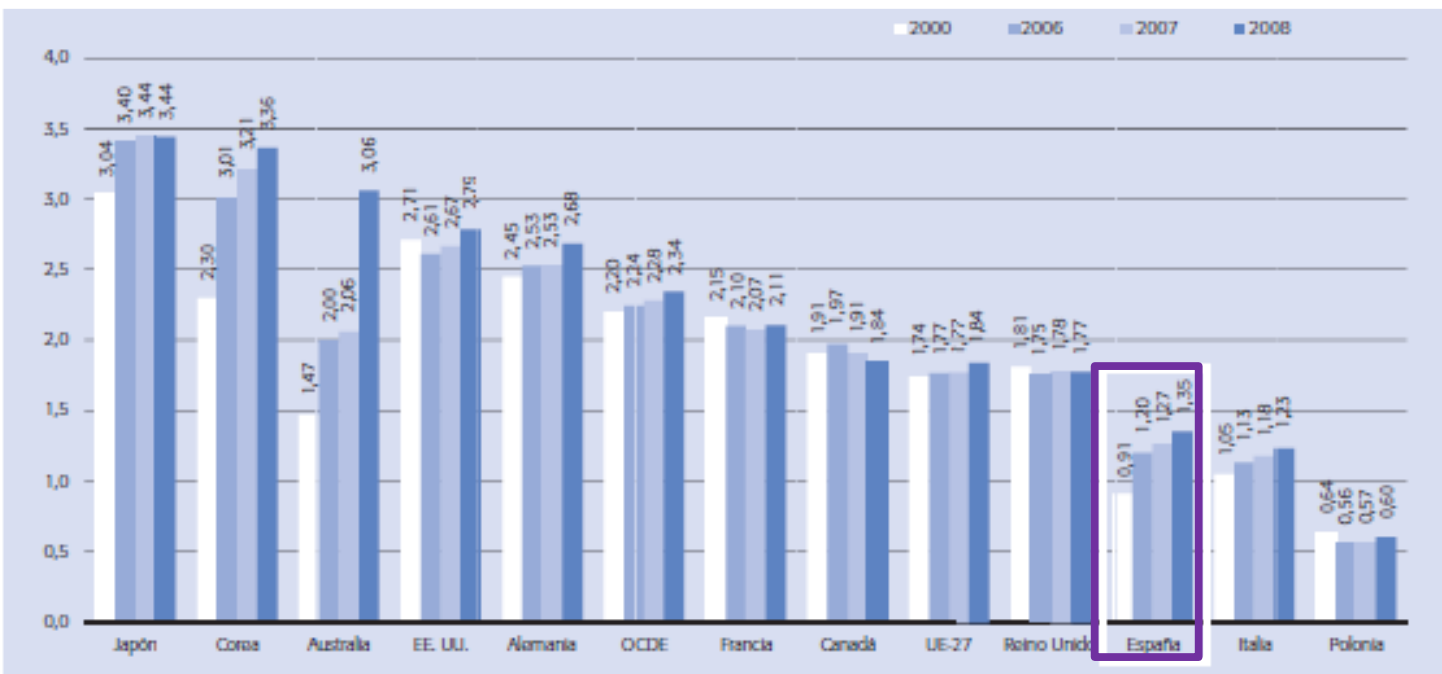

Fuente: COTEC (2011):25

No obstante, para el año 2011, las repercusiones de la crisis económica han causado una baja considerable en el gasto en actividades de investigación y desarrollo en el ámbito empresarial con respecto al porcentaje del producto interno bruto. La media europea descendió a un 1,25\% y España decreció de un $1,35 \%$ al $0,75 \%$ respecto al 2008 (ver Figura 03).

Este decrecimiento puede ser explica por la falta de control en las políticas promoción de la innvoación, esto lo refuerza García-Romero (2012) al opinar que:

"el desafortunado término de I+D+i que se ha acuñado en nuestro país ha podido ser causa de algunos de nuestros males en materia de innovación. Al mismo tiempo, también puede ser un síntoma de que no hemos sido capaces de plantear políticas eficaces capaces de generar retorno socioeconómico a partir la inversión en I+D”. 
Figura 03

Gasto en I+D en empresas según el \% del PIB

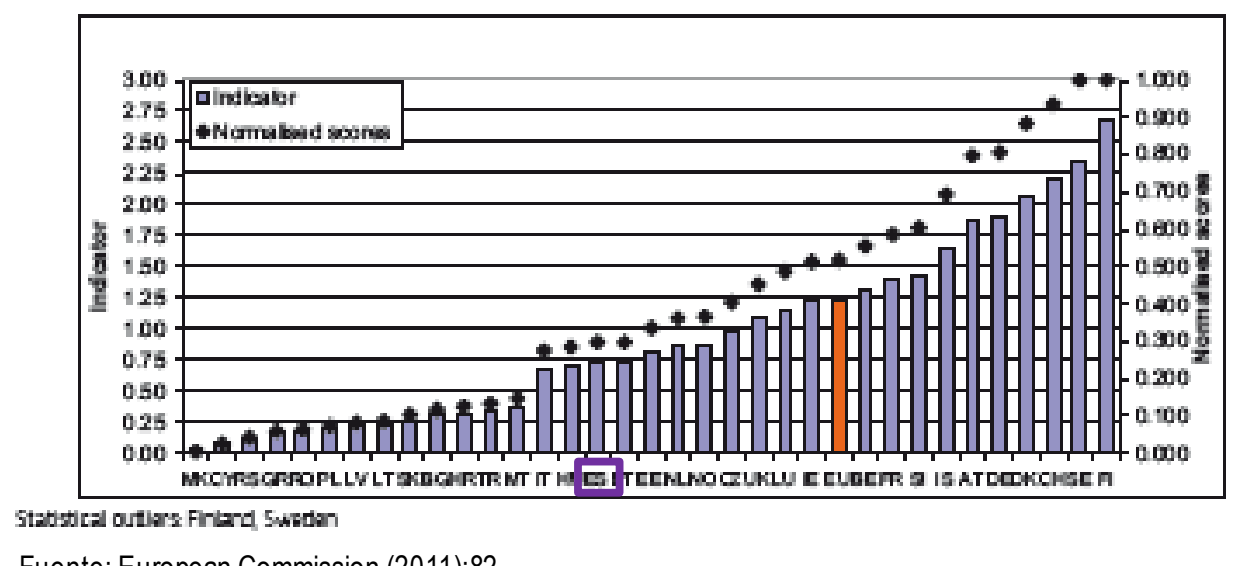

Fuente: European Commission (2011):82

La situación del esfuerzo de I+D por regiones para el 2009 varía dependiendo la comunidad autónoma, por ejemplo la Comunidad de Navarra representa el 2,14\%, siendo la más alta y las Islas Baleares con el 0,38\% la más baja. Respecto a las comunidades periféricas de Castilla \& León el esfuerzo en la inversión en I+D fue del 1,12\% y Extremadura del 0,88\% (ver Figura 04). Las proporciones de la inversión para el sector público y privado se asemejan a la media nacional. Las cifras significan que en términos de gasto por habitante es de 246euros por habitante en la región castellana-leonesa y 140 euros para la comunidad extremeña.

Los datos ponen de manifiesto que tanto el sector público como el sector privado se enfrentan al mismo desafío, es decir, mejorar y desarrollar el sistema de innovación español para que no siga reduciendo, como ha pasado en el 2008 al 2009, resultado de la crisis económica que está atravesando el país y de la reducción del presupuesto destinado a este objetivo.

Si bien es cierto, a lo largo del tiempo, el número de empresas que realizan $\mathrm{I}+\mathrm{D}$ poco a poco ha ido en aumento, pero aún así siguen siendo pocas las empresas que realizan $\mathrm{I}+\mathrm{D}$ de manera estructurada y sistemática. El gobierno propone el Plan Nacional de I+D+i que regula y centraliza los campañas para mejorar, fomentar y sistematizar el sistema español de cienciatecnología-empresa (CTE) y así optimar la competitividad empresarial. Para ello se han creado distintos organismos públicos de investigación (OPI) para fortalecer la creación de 
parques científicos y técnicos (PCT) que pretenden promover la cooperación y la canalización de recursos para su financiación.

\section{Figura 04}

\section{Gasto en I+D por comunidades autónomas en porcentaje del PIB regional en 2009. (Entre paréntesis datos de 2008). PIB base 2000}

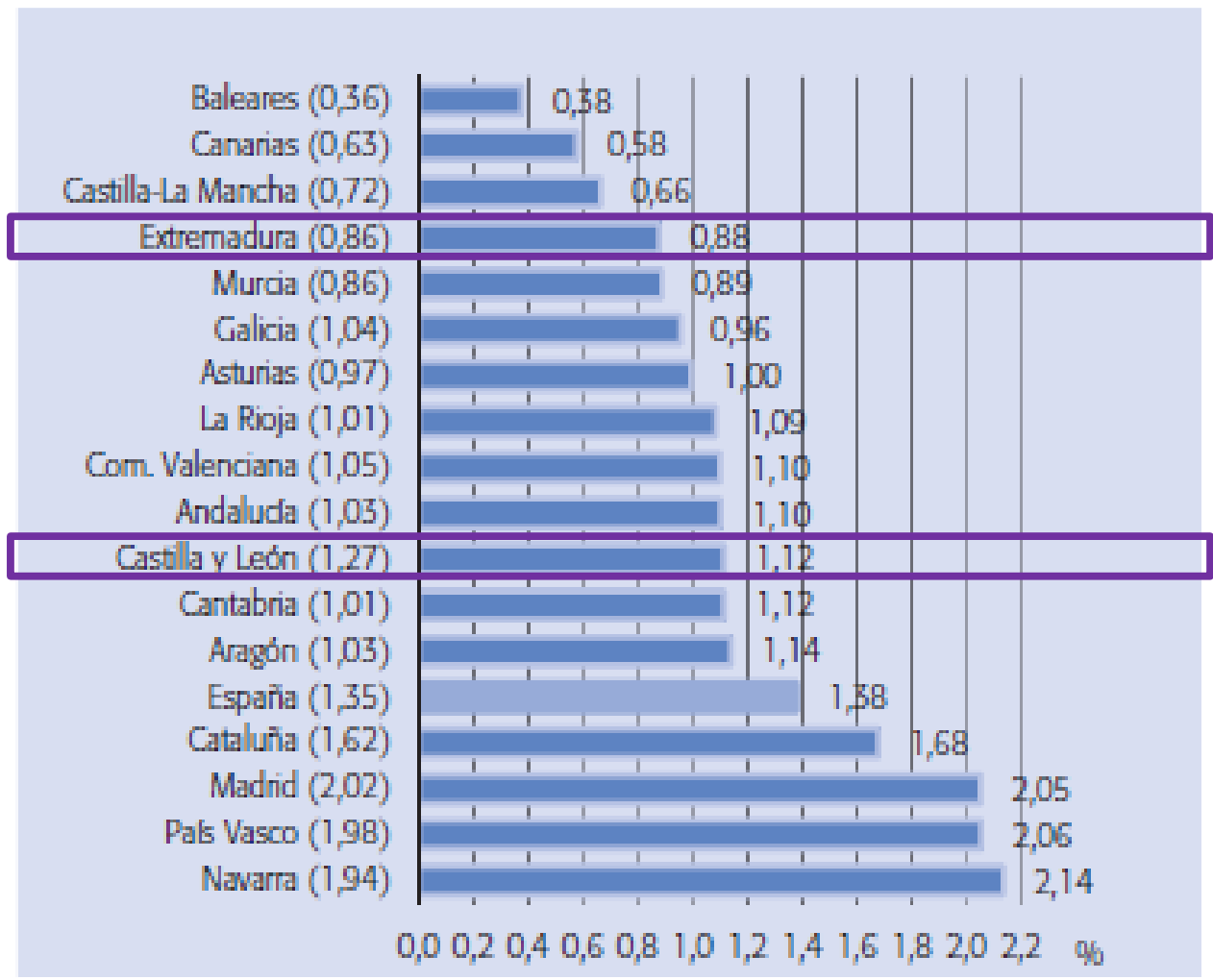

Fuente: COTEC (2011): 23.

Por poner un ejemplo, según el Boletín de Noticias Asebio (2010) "la financiación del Consejo de Administración del Centro para el Desarrollo Tecnológico Industrial (CDTI) a proyectos de $\mathrm{I}+\mathrm{D}$ se realiza por medio de ayudas parcialmente reembolsables a tipo de interés cero que pueden cubrir hasta el $75 \%$ del presupuesto total del proyecto y con una parte no reembolsable (sobre el crédito concedido) que puede llegar hasta el $15 \%$ en el caso de que los proyectos sean desarrollados por empresas de forma individual; hasta el $25 \%$ cuando se subcontrata a organismos de investigación y hasta el 33\% en el caso de que estos proyectos sean realizados mediante un consorcio de empresas o procedan de cooperación internacional. Para la devolución de la ayuda, existe un periodo de carencia de dos a tres años y un plazo de amortización de hasta 10 años". 
Dejando de lado lo anterior, ahora corresponde conocer en cifras el papel de las empresas españolas sobre la creación de innovación en los distintos niveles, tanto tecnológicos como tradicionales. Bajo cualquier comparación, de las grandes empresas con las pequeñas, se podría decir que las últimas, dadas sus escasos recursos y capacidad financiera, no cumplen con las características adecuadas para lograr un comportamiento innovador exitoso, aunque si bien es cierto, la fuerte figura centrada en el empresario puede permitirles a las empresas pequeñas ser flexibles y dinámicas a la hora de innovar y así mejorar su posición competitiva. Las siguientes tablas y figuras muestran más detalladamente el comportamiento competitivo en varias áreas de la innovación para los dos tamaños empresariales.

Centrándose en el análisis de las diversas magnitudes para caracterizar el comportamiento innovador de las empresas en los diferentes tipos se puede observar el siguiente comportamiento a través de las siguientes gráficas. En el caso de las patentes, en España son reducidos los sectores que tienen una fuerte estrategia de protección industrial e intelectual, los datos disponibles en la Tabla 03, muestran la débil posición de España de 32,6 solicitudes de patente europeas por millón de habitantes, comparado con la media europea de 116, 5 solicitudes. Considerando las patentes de alta tecnología la posición relativa es más baja de 2,2 frente a 11,5, y de patentes concedidas de 5,0 a 32,3. Este retraso es reflejo de la poca propensión empresarial para impulsar las innovaciones de desarrollo de productos y procesos, y las actividades de I+D que son el "input" generador del “output" patentes. 
Tabla 03

Solicitud y concesión de patentes (EPO y UPSTO)

\begin{tabular}{|c|c|c|c|c|c|c|c|c|c|}
\hline & \multicolumn{3}{|c|}{$\begin{array}{l}\text { Patent applications } \\
\text { to the EPO }\end{array}$} & \multicolumn{3}{|c|}{$\begin{array}{l}\text { High technology patent } \\
\text { applications to the EPO }\end{array}$} & \multicolumn{3}{|c|}{$\begin{array}{l}\text { Patents granted by the US } \\
\text { Patent \& Trademark Office }\end{array}$} \\
\hline & \multicolumn{2}{|c|}{$\begin{array}{l}\text { (number of patent } \\
\text { applications) }\end{array}$} & \multirow{2}{*}{$\begin{array}{l}\text { (per } \\
\text { million } \\
\text { inhab.) } \\
2007 \\
\end{array}$} & \multicolumn{2}{|c|}{$\begin{array}{l}\text { (number of patent } \\
\text { applications) }\end{array}$} & \multirow{2}{*}{$\begin{array}{c}\text { (per } \\
\text { million } \\
\text { inhab.) } \\
2007 \\
\end{array}$} & \multicolumn{2}{|c|}{$\begin{array}{c}\text { (number of patents } \\
\text { granted) }\end{array}$} & \multirow{2}{*}{$\begin{array}{c}\text { (per } \\
\text { million } \\
\text { inhab.) } \\
2004 \\
\end{array}$} \\
\hline & 2002 & 2007 & & 2002 & 2007 & & 1999 & 2004 & \\
\hline EU-27 & 50462 & 57725 & 116.5 & 10964 & 5684 & 115 & 31172 & 15775 & 323 \\
\hline Belgium & 1287 & 1472 & 1390 & 333 & 231 & 21.8 & 794 & 395 & 380 \\
\hline Bulgaria & 15 & 29 & 38 & 2 & : & : & 10 & 48 & 6.2 \\
\hline Crech Republic & 68 & 162 & 75.8 & 6 & 9 & 09 & 37 & 49 & 4.8 \\
\hline Denmark & 935 & 1057 & 1941 & 230 & 110 & 20.2 & 564 & 246 & 455 \\
\hline Germany & 21503 & 23929 & 290.7 & 3823 & 2098 & 25.5 & 12799 & 6874 & 833 \\
\hline Estonis & 6 & 23 & 174 & 1 & 7 & 5.2 & 5 & 4 & 2.8 \\
\hline Ireland & 224 & 288 & 66.8 & 65 & 38 & 8.8 & 214 & 156 & 38.8 \\
\hline Greece & 74 & 109 & 98 & 18 & 6 & a6 & 18 & 20 & 18 \\
\hline Spain & 938 & 1457 & 326 & 148 & 96 & 22 & 381 & 210 & 5.0 \\
\hline France & 7321 & 8427 & $\mathrm{~B} 2.4$ & 1821 & 1128 & 17.7 & 4616 & 2344 & 376 \\
\hline Italy & 4168 & $5 \mathrm{NOP}$ & 86.4 & 489 & 253 & 4.3 & 1938 & 1049 & 18.1 \\
\hline Cyprus & 7 & 9 & 115 & 2 & 5 & 6.0 & 4 & 1 & 1.6 \\
\hline Latvia & 6 & 19 & 8.4 & 2 & 2 & 1.0 & 2 & 2 & 09 \\
\hline Lithuanis & 3 & 8 & 24 & 0 & 2 & 0.7 & 7 & 19 & 55 \\
\hline Luxembourg & 61 & 110 & 2302 & 4 & 5 & 99 & 39 & 38 & 835 \\
\hline Hungary & 120 & 173 & 172 & 17 & 19 & 19 & 76 & 39 & 19 \\
\hline Malta & 4 & 8 & 205 & 1 & : & $=$ & 3 & $z$ & $=$ \\
\hline Netherlands & 3442 & 3656 & 2235 & 1160 & 348 & 21.3 & 1535 & 938 & 577 \\
\hline Austria & 1269 & $1 \not 97$ & 2170 & 216 & 149 & 18.0 & 640 & 366 & 449 \\
\hline Poland & 81 & 146 & 3.8 & 12 & 24 & 0.6 & 31 & 40 & 1.0 \\
\hline Portugal & 41 & 121 & 11.4 & 5 & 29 & 27 & 15 & 14 & 1.4 \\
\hline Romanis & 11 & 21 & 10 & 3 & 7 & 0.3 & B & 13 & 06 \\
\hline Slovenia & 76 & No3 & 515 & 12 & 14 & 7.0 & 15 & 8 & 4.2 \\
\hline Slovakia & 24 & 42 & 78 & 7 & 4 & 0.7 & 7 & 6 & 1.7 \\
\hline Finland & 1257 & 1323 & 250.8 & 598 & 209 & 397 & 1169 & 544 & 1043 \\
\hline Sweden & 2002 & 2719 & 298.4 & 463 & 331 & 36.4 & 1796 & 509 & 56.8 \\
\hline United Kingdom & 5500 & 5422 & 892 & 1527 & 558 & 9.2 & 4451 & 1936 & 324 \\
\hline Iceland & 35 & 28 & 906 & 10 & 3 & 9.8 & 33 & 25 & 85.2 \\
\hline Liechtenstein & 26 & 31 & 895.4 & 2 & 1 & 28.4 & 15 & 13 & 377.2 \\
\hline Norway & 377 & SIS & 1100 & B1 & 16 & 3.5 & 300 & 149 & 327 \\
\hline Switzerland & 2641 & 3224 & 4293 & 404 & 222 & 29.6 & 1520 & 78 & 1035 \\
\hline Croatia & 37 & 32 & 72 & 4 & 2 & 0.5 & 9 & 10 & 23 \\
\hline Turkey & 60 & 220 & 32 & $z$ & 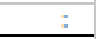 & $z$ & 16 & 9 & 0.7 \\
\hline Japan & 20218 & 20657 & 161.7 & 7111 & 3675 & 28.3 & 39467 & 29149 & 228.1 \\
\hline United States & 31171 & 31908 & 105.8 & 10919 & 3686 & 12.2 & 103966 & 80322 & 273.8 \\
\hline
\end{tabular}

Fuente: Eurostat (2011): 598

European Patent Office (EPO)

United States Patent and Trademark Office (USPTO)

La Figura 05 muestra gráficamente los datos principales sobres solicitudes de patentes. La media europea es de 4 solicitudes de patentes por cada billón del PIB; marcan una gran diferencia los países como Suecia y Finlandia con una media de 9. En el caso de España la media es de 1,2 solicitudes. 
Figura 05

\section{Solicitudes de patentes PCT por billón del PIB}

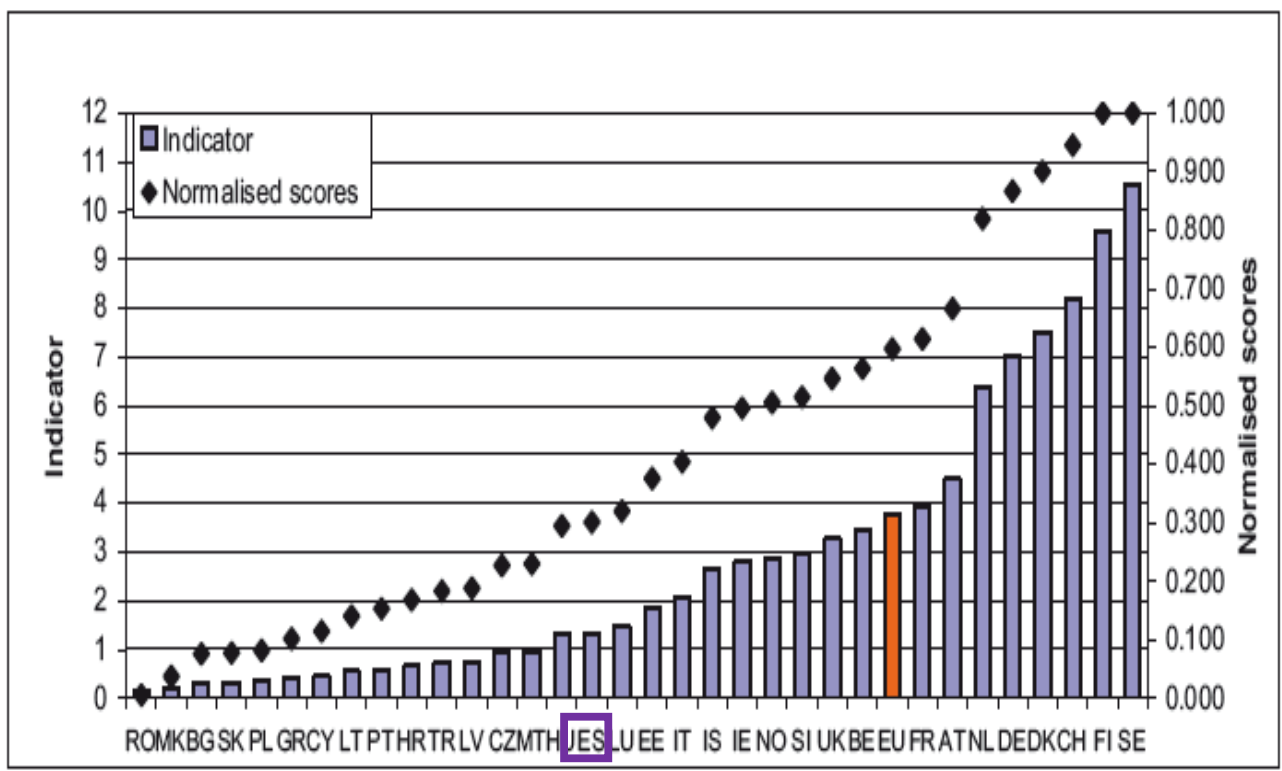

No data for Serbia. Statistical outliers: Finland, Sweden. Indicator skewed and a square-root transformation has been used for deriving the normalised scores

Fuente: European Commission (2011): 87

PCT: Patent Cooperation Treaty

En la Tabla 04 puede observarse el aumento de solicitudes por comunidad autónoma difiere según el desarrollo de la región; por ejemplo, se observa que la comunidad de Navarra encabeza la lista con 178,9 solicitudes por cada millón de habitantes, mientras que la comunidad de Castilla \& León solicita 52,9 y la comunidad extremeña tan solo 29,2 solicitudes. Sobre las patentes concedidas, la comunidad de Navarra lidera los ratios con 122,5. Pero en términos absolutos, la comunidad de Madrid es la que más número de patentes solicita (797) y recibe concesión (344). 
Tabla 04

\section{Solicitudes y concesiones de patentes en España por Comunidades Autónomas. 1995-2008}

En relación al número de habitantes (1) $\mathrm{y}$ al total nacional

\begin{tabular}{|c|c|c|c|c|c|c|}
\hline \multirow[b]{2}{*}{ Comunidedes Auténomss } & \multicolumn{3}{|c|}{ Solkitudes } & \multicolumn{3}{|c|}{ Concestones } \\
\hline & Múmero & $\begin{array}{l}\text { N sebre Total } \\
\text { nacional }\end{array}$ & $\begin{array}{l}\text { Ratio sollettudead } \\
\text { Mullikn habitantes }\end{array}$ & Número & $\begin{array}{l}\text { S sebre Total } \\
\text { naclonal }\end{array}$ & $\begin{array}{l}\text { Ratlo conceslones/ } \\
\text { Milikn habitantes }\end{array}$ \\
\hline Andalucía & 433 & 12,03 & 52,8 & 200 & 9,92 & 24,4 \\
\hline Aragion & 204 & 5,67 & 153,7 & 97 & 4,81 & 73,1 \\
\hline Aeturias (Principado de) & $\infty$ & 1,67 & 55,5 & 27 & 1,34 & 25,0 \\
\hline Bslears (tlies) & 53 & 1,47 & 49,4 & 17 & 0,84 & 15,8 \\
\hline Canarias & 59 & 1,64 & 28,4 & 28 & 1,39 & 13,5 \\
\hline Cactabris. & 22 & 0.61 & 37.8 & 20 & 0.99 & 34.4 \\
\hline coctillay ledin. & 108 & 3,00 & 529 & 73 & 3.62 & 35.7 \\
\hline Cartilla-La Mancha & $\infty 0$ & 1,67 & 23,5 & 42 & 2,08 & 16,4 \\
\hline Cataluha & 756 & 21,01 & $1 \infty 2,7$ & 523 & 25,93 & 71,0 \\
\hline Comunitat: Yalenctans & 394 & 10.56 & 78.3 & 232 & 11.50 & that 1 \\
\hline Extremadura & 32 & 0.89 & 29.2 & 16 & 0,79 & 14,6 \\
\hline Gallicla & 176 & 4,89 & 63,2 & 93 & 4,61 & 33,4 \\
\hline Madrid (Comunidad de) & 797 & 22,15 & 127,1 & 344 & 17,06 & 54,9 \\
\hline Murcla (Regyón de) & $\pi 0$ & 1,94 & 49,1 & 36 & 1,78 & 25,2 \\
\hline Narama (Comunidad Foral) & 111 & 3,08 & 178,9 & 76 & $3, \pi 7$ & 122,5 \\
\hline Pais Vasco & 230 & 6,39 & 106,6 & 169 & 8,38 & 78,3 \\
\hline Bboja (La) & 27 & 0,75 & 85,0 & 17 & 0,34 & 53,5 \\
\hline Ceuta y Metilla & 2 & 0,06 & 13,4 & 0 & $0, \infty$ & 0,0 \\
\hline No consta & 5 & 0,14 & . & 7 & 0,35 & . \\
\hline Total & 3.599 & 100,00 & 78,0 & 2.017 & 100,00 & 43,7 \\
\hline
\end{tabular}

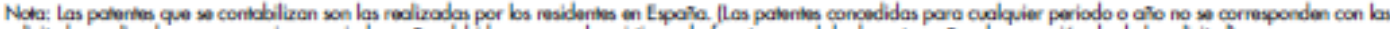

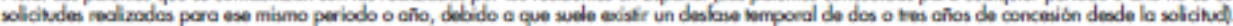

(1) Sé toma camo base de pobloción el padrón municipol octudizado od 1 de enero.

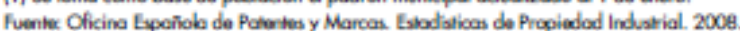

Fuente: ICONO (2010): 68

Los "inputs" de la innovación, que se trataron anteriormente, son generadores de patentes y fomentan actividades empresariales creadoras del éxito empresarial, sumamente necesarios para mantener la competitividad en entornos turbulentos y de alta intensidad tecnológica y competitiva. Un indicador primordial es el esfuerzo empresarial relacionado a las actividades $\mathrm{I}+\mathrm{D}$, especialmente en personal cualificado dedicado exclusivamente a estas actividades. En la Tabla 05 se muestra el porcentaje de empleados que trabajan en áreas dedicadas a las ciencias y la tecnología. España se aleja tan solo del 5,6\% de la media europea, obteniendo una adecuada puntuación en este rango innovador. 
Tabla 05

Recursos humanos en investigación y desarrollo / ciencia y tecnología

\begin{tabular}{|c|c|c|c|c|c|c|c|c|c|c|}
\hline & \multicolumn{5}{|c|}{$\begin{array}{l}\text { People working in an } \\
\text { S\&T occupation }\end{array}$} & \multicolumn{5}{|c|}{$\begin{array}{l}\text { People who have a tertiary education } \\
\text { and work in an S\&T occupation }\end{array}$} \\
\hline & \multirow{2}{*}{$\begin{array}{c}(1000) \\
2008\end{array}$} & \multicolumn{4}{|c|}{ ( 96 of total employment) } & \multirow{2}{*}{$\begin{array}{c}(1000) \\
2008\end{array}$} & \multicolumn{4}{|c|}{ (\% of total employment) } \\
\hline & & 2005 & 2006 & 2007 & 2008 & & 2005 & 2006 & 2007 & 2008 \\
\hline EU-27 $(2)$ & 65120. & 292 & 297 & 298 & $=$ & 37378. & 16.6 & 170 & 17.1 & $\therefore$ \\
\hline Belgium & 1441 & 32.7 & 329 & 330 & 325 & 1018 & 22.6 & 23.1 & 236 & 22.9 \\
\hline Bulgaria (f) & 710 & 23.2 & 21.5 & 219 & : & 531 & 16.8 & 16.2 & 163 & : \\
\hline Gech Republic & 1687 & 326 & 32.6 & 33.3 & 33.8 & 591 & 113 & 11.6 & 115 & 11.8 \\
\hline Denmark (J) & 1117 & 366 & 36.8 & 360 & 39.1 & 699 & 24.2 & 24.6 & 21.9 & 24.5 \\
\hline Germany & 14181 & 36.1 & 36.5 & 36.3 & 365 & 7130 & 17.9 & 17.7 & 179 & 18.4 \\
\hline Estonis & 175 & 27.4 & 269 & 27.2 & 267 & 117 & 18.3 & 183 & 18.0 & 179 \\
\hline Ireland & 494 & 232 & 22.4 & 23.3 & 235 & 384 & 17.1 & 170 & 17.7 & 18.3 \\
\hline Greece & 1061 & 21.9 & 22.8 & 23.1 & 233 & 829 & 16.7 & 175 & 179 & 18.2 \\
\hline Spsin & 5119 & 23.8 & 239 & 24.2 & 253 & 3965 & 18.2 & 16.8 & 187 & 196 \\
\hline France & 8338 & 312 & 31.8 & 31.8 & 320 & 5225 & 1900 & $19 J$ & 196 & 20.1 \\
\hline Italy & 7347 & 295 & 31.1 & 319 & 315 & 3050 & 11.4 & 11.9 & 125 & 13.1 \\
\hline Cyprus & 104 & 25.7 & 26.1 & 27.0 & 27.2 & 83 & 19.1 & 19.9 & 21.3 & 21.8 \\
\hline Latvis & 350 & 245 & 27.0 & 297 & 31.1 & 194 & 13.9 & $14 B$ & 157 & 17.2 \\
\hline Lithuania & 443 & 26.1 & 25.7 & 269 & 29.2 & 311 & 177 & 178 & 190 & 20.5 \\
\hline Luxembourg & 84 & 38.4 & 390 & 39.5 & 415 & 56 & 255 & 23.9 & 2.3 & 279 \\
\hline Hungary & 1078 & 26.1 & 26.6 & 26.5 & 27.8 & 634 & $14 B$ & 15.1 & 15.4 & 16.3 \\
\hline Malta & 45 & 25.6 & 2.7 & 27.3 & 28.2 & 23 & 11.9 & 13.1 & 136 & 14.5 \\
\hline Netherlands & 3187 & 37.1 & 360 & 37.2 & 37.4 & 1895 & 21.8 & 21.1 & 21.8 & 22.3 \\
\hline Austria & 1218 & 30.6 & 305 & 297 & 299 & 480 & 120 & 117 & 115 & 11.8 \\
\hline Poland $(A)$ & 3908 & 25.9 & 26.2 & 26.2 & $=$ & 2429 & 15.3 & 15.8 & 160 & : \\
\hline Portugal & 943 & 17.4 & 17.7 & 17.6 & 185 & 588 & 10.4 & 10.8 & 109 & 11.5 \\
\hline Romania & 1813 & 178 & 18.6 & 18.6 & 193 & 1094 & 9.7 & 10.4 & 10.8 & 117 \\
\hline Slovenia (9) & 300 & 30.7 & 31.6 & 30.6 & $=$ & 172 & 16.3 & 17.4 & 176 & : \\
\hline Slovakia & 707 & 295 & 297 & 29.3 & 290 & 298 & 12.0 & 125 & 12.1 & 12.2 \\
\hline Finland & 882 & 335 & 34.1 & 34.5 & 34.8 & 621 & 22.4 & 228 & 23.1 & 24.5 \\
\hline Sweden (") & 1780 & 39.2 & 39.1 & 39.2 & : & 1083 & 23.2 & 235 & 239 & : \\
\hline United Kngdom & 7847 & 26.1 & 269 & 26.8 & 268 & 5281 & 175 & 18.0 & 180 & 18.0 \\
\hline Iceland & 64 & 312 & 327 & 33.4 & 362 & 36 & 179 & 13.8 & 189 & 20.5 \\
\hline Norway & 940 & 36.2 & 36.4 & 369 & 37.4 & 661 & 24.6 & 25.2 & 259 & 26.3 \\
\hline Switzerland & 1704. & 38.3 & 389 & 39.4 & 405 & 909. & 19.1 & 195 & 203 & 21.6 \\
\hline Crostia ${ }^{\circ}$ ) & 406 & 23.8 & 24.4 & 240 & 249 & 248 & 145 & 14.7 & 146 & 15.3 \\
\hline FYR of Macedonis ( $)$ & 122 & : & 21.1 & 207 & : & 77 & : & 13.0 & 13.1 & : \\
\hline Turkey & 2748 & $\therefore$ & 12.5 & 12.5 & 12.8 & 1768 & 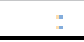 & 7.4 & 77 & 8.2 \\
\hline
\end{tabular}

Fuente: Eurostat (2011): 587

Este indicador de la Figura 06 revela datos sobre el empleo caracterizado por conocimiento intensivo en actividades de media y alta tecnología, y en servicios. Los datos confirman que España mantiene una correspondencia del 12\%, mostrando una leve caída en relación a la media europea (14\%) del total de empleados ubicados en actividades de investigación y desarrollo respecto al total del empleo nacional según los datos del 2011. 
Figura 06

Empleo en actividades de conocimiento intensivo ( $\%$ del total de empleo)

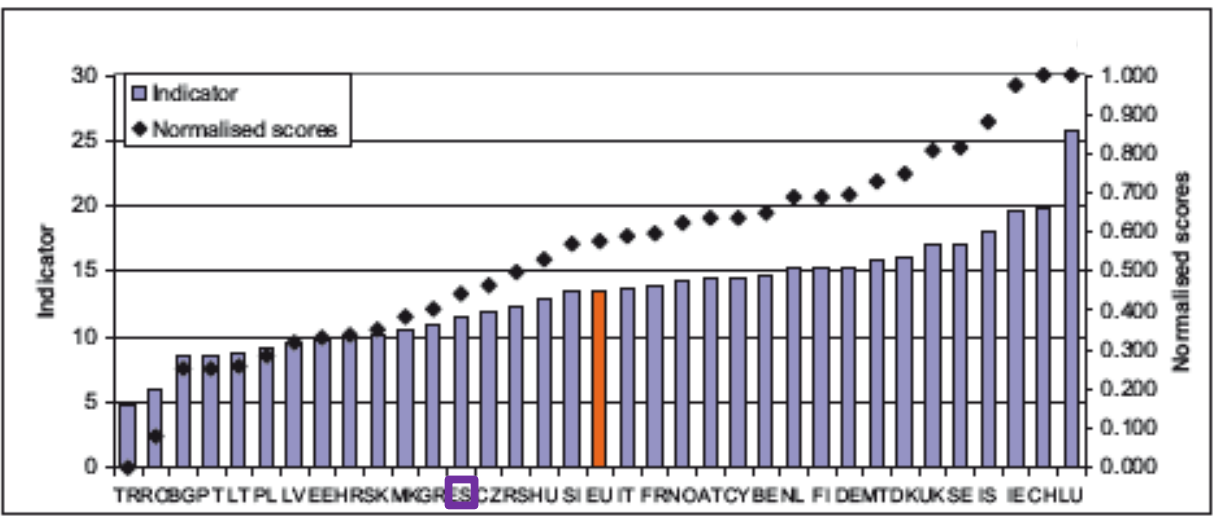

Statistical cutlier. Lxembourg

Fuente: European Commission (2011):93

Centrándose específicamente en el campo nacional se puede observar el comportamiento desglosado de la implicación de recurso humano en las actividades de I+D. En la Tabla 06 se observa que el asombroso incremento de las empresas participantes en actividades de I+D, de 1.804 empresas en 1995 a 15.049 en el 2008; el personal empleado en I+D ha aumentado desde 1995 al 2008, 3,45 veces; en cambio el porcentaje de los gastos corrientes y de capital se mantienen en el mismo nivel. En total los gastos de I+D han aumentado 4,7 veces durante ese período. No obstante, aunque este crecimiento es fundamental en el entorno nacional, no es comparable con los indicadores de la región europea como se observó en las tablas anteriores. 
Tabla 06

Gastos y equipo en I+D en el sector empresarial. 1995-2008

\begin{tabular}{|c|c|c|c|c|c|c|c|c|c|c|c|c|c|c|}
\hline & 1995 & 1996 & 1997 & 1998 & 1999 & 2000 & 2001 & 2002 & 2003 & 2004 & 2005 & 2006 & 2007 & 2008 \\
\hline$N^{0}$ de empresas que realizan $1+D$ & 1.804 & - & 1.872 & - & 2.267 & - & 2.790 & 6.204 & 7.963 & 9.719 & 10.953 & 12.575 & 14.669 & 15.049 \\
\hline Personal empleado en I+D (EJC) & 27.555 & 29.430 & 30.023 & 34.667 & 38.323 & 47.055 & 46.465 & 56.337 & 65.032 & 71.123 & 75.345 & 82.870 & 87.543 & 95.207 \\
\hline Investigadores (\%) & 39,2 & 37,7 & 46,4 & 40,1 & 39,6 & 44,3 & 40,8 & 43,7 & 42,4 & 45,1 & 46,5 & 48,2 & 48,1 & 48,7 \\
\hline Otro personal (\$) & - & - & 20,1 & - & 22,4 & - & 19,6 & 56,3 & 57,6 & 54,9 & 53,5 & 51,8 & 51,9 & 51,3 \\
\hline Mujeres dedicadas a $1+D$ (EJC) & - & - & - & - & 8.608 & - & 9.129 & 15.716 & 17.793 & 20.194 & 21.351 & 24.194 & 26.451 & 28.652 \\
\hline Investigadoras ( $(\%)$ & - & - & - & - & $\cdot$ & - & $\cdot$ & 40,8 & 41,4 & 43,4 & 44,7 & 46,5 & 46,4 & 47,5 \\
\hline Otro personal $(\%)$ & $\cdot$ & - & $\cdot$ & - & - & - & $\cdot$ & 59,2 & 58,6 & 56,6 & 55,3 & 53,5 & 53,6 & 52,5 \\
\hline Gastos internos en I+D (miles de $\epsilon$ ) & 1.712 .229 & 1.862 .621 & 1.970 .851 & 2.457.184 & 2.597 .099 & 3.068 .994 & 3.261 .0313 & 3.926.338 & 4.443 .438 & 4.864 .931 & 5.485 .033 & 6.557 .529 & 7.453 .902 & 28.073 .521 \\
\hline \multicolumn{15}{|l|}{ A. Por naturaleza del gasto (\%) } \\
\hline Gastos corrientes & 83,3 & 86,2 & 81,8 & 79,4 & 80,0 & 84,1 & 79,6 & 86,5 & 83,3 & 86,0 & 83,3 & 81,6 & 80,1 & 81,2 \\
\hline Gastos de capital & 16,8 & 13.7 & 18.2 & 20.6 & 20,0 & 15.9 & 20,4 & 13.5 & 16.7 & 14.0 & 16,7 & 18.4 & 19.9 & 18.8 \\
\hline \multicolumn{15}{|l|}{ B. Por origen de los fondos (*) } \\
\hline Fondos propios & 80,3 & 83,0 & 80,2 & 83,1 & 81,7 & 88,8 & 78,6 & 73,8 & 75,9 & 74,9 & 73,3 & 72,6 & 68,0 & 69,0 \\
\hline De otras empresas & 4,0 & 3,7 & 4,6 & 5,9 & 5,0 & - & 3,8 & 10,2 & 7,6 & 7,2 & 6,7 & 6,4 & 7,1 & 6,6 \\
\hline De la Administración Pública & 9,2 & 7,9 & 8,7 & 6,5 & 8,5 & 7,2 & 9,5 & 9,5 & 11,1 & 12,5 & 13,6 & 14,4 & 16,3 & 17,9 \\
\hline De universidades & 0,03 & 0,01 & 0,01 & 0,1 & 0,1 & 0,2 & 0,2 & 0,4 & 0,02 & 0,1 & 0,03 & 0,04 & 0,03 & 0,0 \\
\hline De IPSFL & 0,04 & 0,2 & 0,1 & 0,1 & 0,1 & - & 0,2 & 0,2 & 0,2 & 0,2 & 0,6 & 0,2 & 0,1 & 0,2 \\
\hline Del extranjero & 6,4 & 5,2 & 6,3 & 4,2 & 4,5 & 3,8 & 7,7 & 5,9 & 5,2 & 5,1 & 5,8 & 6,3 & 8,4 & 6,3 \\
\hline Gastos externos en I+D (miles de $\epsilon$ ) & 360.944 & - & 497.920 & - & 787.849 & & 1.015 .165 & - & 1.410 .800 & 1.568 .287 & 1.792 .179 & 1.862 .963 & 2.171 .416 & 61.694 .960 \\
\hline
\end{tabular}

Fuente: ICONO (2010): 49

En relación a las innovaciones tecnológicas en producto y procesos, se puede notar en la Tabla 07 que las empresas grandes tienden a innovar más que las pequeñas empresas. Según la Unión Europea "...la medida de innovación tecnológica se mide a través de la introducción de nuevos productos y procesos, y se considera la clave de la innovación para las actividades manufactureras, puesto que altos índices de innovación tecnológica debería reflejar un alto nivel de actividades innovadoras" (European Commision, 2011: 92).

Las nuevas o mejoras significativas de los productos contribuyen a una pequeña proporción relativa del total de facturación entre las empresas en 2008 acerca del 6,4\% para la EU27. El patrón que sigue España así como el resto de países, es que las grandes empresas han tenido más probabilidades de aportar nuevos productos al mercado que las pequeñas empresas; algo similar sucede con las innovaciones en procesos. 
Tabla 07

Proporción de empresas innovadoras con introducción de nuevos productos a otros mercados o propios, desarrollos de procesos innovadores (2008)

\begin{tabular}{|c|c|c|c|c|c|c|c|c|}
\hline & \multicolumn{4}{|c|}{$\begin{array}{c}\text { Process innovations: } \\
\text { developed by the enterprise or group }\end{array}$} & \multicolumn{4}{|c|}{$\begin{array}{c}\text { Product innovationsz } \\
\text { new to market }\end{array}$} \\
\hline & Total & $\begin{array}{l}\text { With } \\
10 \text { to } 49 \\
\text { employees }\end{array}$ & $\begin{array}{l}\text { With } \\
50 \text { to } 249 \\
\text { employees }\end{array}$ & $\begin{array}{c}\text { With } \\
\geq 250 \\
\text { employees }\end{array}$ & Total & $\begin{array}{c}\text { With } \\
10 \text { to } 49 \\
\text { employees }\end{array}$ & $\begin{array}{c}\text { With } \\
50 \text { to } 249 \\
\text { employees }\end{array}$ & $\begin{array}{c}\text { With } \\
\geq 250 \\
\text { employees }\end{array}$ \\
\hline Belgium & 422 & 427 & 393 & 475 & 475 & 47.1 & 45.5 & 59.3 \\
\hline Bulgaris & 413 & 407 & 43.8 & 38.1 & 259 & 233 & 308 & 30.8 \\
\hline Crech Republic & 390 & 40.1 & 35.4 & 41.2 & 39.1 & 34.0 & 47.0 & 54.1 \\
\hline Denmark & : & : & : & : & 44.4 & 44.1 & 423 & 54.1 \\
\hline Germany & 30.1 & 27.1 & 35.6 & 420 & 260 & 232 & 295 & 43.7 \\
\hline Estonis & 405 & 379 & 44.3 & 560 & 25.8 & 24.2 & 280 & 36.1 \\
\hline Ireland & : & $=$ & $=$ & $=$ & $=$ & : & $=$ & : \\
\hline Gresce & - & $=$ & - & - & - & + & - & 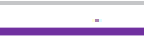 \\
\hline Spain & 507 & 506 & 49.4 & 57.4 & 215 & 18.0 & 28.1 & 43.6 \\
\hline France & 50.8 & 50.8 & 49.1 & 550 & 432 & 399 & 46.3 & 600 \\
\hline Italy & 44.9 & 440 & 487 & 479 & 477 & 45.5 & 55.5 & 61.4 \\
\hline Cyprus & 50.9 & 535 & 473 & 227 & 268 & 24.0 & 336 & 40.9 \\
\hline Latvia & 33.9 & 313 & 36.1 & 506 & 234 & 22.7 & 21.5 & 35.6 \\
\hline Lithuanis & 51.8 & 550 & 47.3 & 464 & 372 & 40.2 & 28.8 & 47.1 \\
\hline Luxembourg & 517 & 480 & 53.2 & 697 & 406 & 35.3 & 47.6 & 55.8 \\
\hline Hungary & 248 & 250 & 21.0 & 326 & 33.1 & 312 & 320 & 45.2 \\
\hline Malta & 477 & 469 & 46.9 & 550 & 39.1 & 383 & 327 & 600 \\
\hline Netherlands & 23.4 & 220 & 257 & 294 & 492 & 48.1 & 51.3 & 536 \\
\hline Austris & 376 & 349 & 413 & 45.8 & 495 & 46.3 & 52.1 & 66.4 \\
\hline Poland & 437 & 45.8 & 407 & 427 & 41.5 & 40.1 & 41.6 & 475 \\
\hline Portugal & 520 & 524 & 507 & 522 & 35.6 & 33.1 & 417 & 53.7 \\
\hline Romanis & 660 & 670 & 64.4 & 637 & 248 & 23.0 & 26.8 & 31.4 \\
\hline Slovenia & 372 & 36.2 & 38.8 & 387 & 513 & 513 & 48.1 & 59.5 \\
\hline Slovakis & 342 & 346 & 31.3 & 397 & 35.7 & 34.2 & 33.4 & 48.0 \\
\hline Finland & 392 & 40.4 & 35.1 & 400 & 373 & 35.5 & 35.9 & 57.7 \\
\hline Sweden & 335 & 33.1 & 330 & 395 & 50.4 & 483 & 536 & 62.8 \\
\hline United Kingdom & $:$ & $\Sigma$ & $\therefore$ & 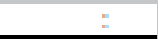 & $\therefore$ & : & $\therefore$ & : \\
\hline Norway & 274 & 280 & 25.1 & 290 & 345 & 36.8 & 285 & 34.6 \\
\hline Croatis & 37.4 & 369 & 393 & 36.0 & 37.4 & 36.7 & 38.5 & 39.1 \\
\hline
\end{tabular}

Fuente: Eurostat (2011): 594

En el caso de las pequeñas y medianas empresas de la Unión Europea poco a poco van incrementando la introducción de nuevos productos o nuevos procesos, la media europea se estable al casi $34 \%$ de las pymes innovadoras de la región. En este caso, Alemania y Suiza lideran los porcentajes con un $50 \%$ de empresas que introducen estas innovaciones. Relativo a esto, España mantiene un porcentaje del $27 \%$ en este rango, por debajo de la media europea (ver Figura 07). 
Figura 07

PYMEs: introducción de innovaciones de producto o procesos según \% de PYMEs

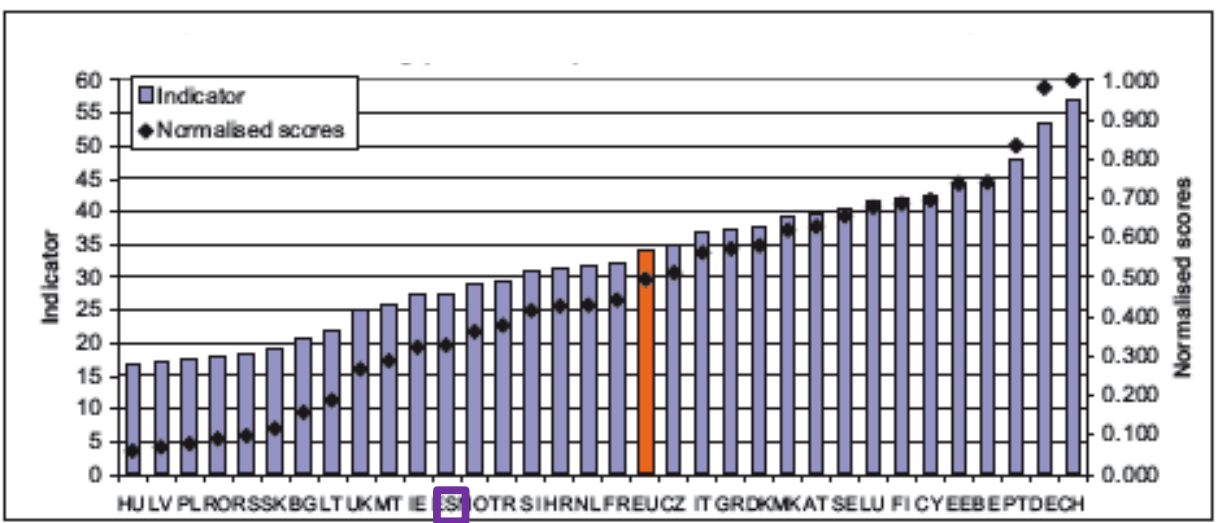

No data for Iceland Statistical cutlier. Switzerland

Fuente: European Commission (2011):92

Se observa en la Figura 08 que el indicador muestra el ratio sobre las ventas de productos mejorados pero nuevos para la empresa o productos nuevos para el mercado según el porcentaje de facturación anual. En este caso, España está por encima de la media europea (13\%) con el 17\%. De manera que, a nivel nacional, se está tratando de introducir innovaciones incrementales y radicales dentro del ámbito empresarial nacional.

Figura 08

Ventas de innovaciones a nuevos mercados (\% de facturación)

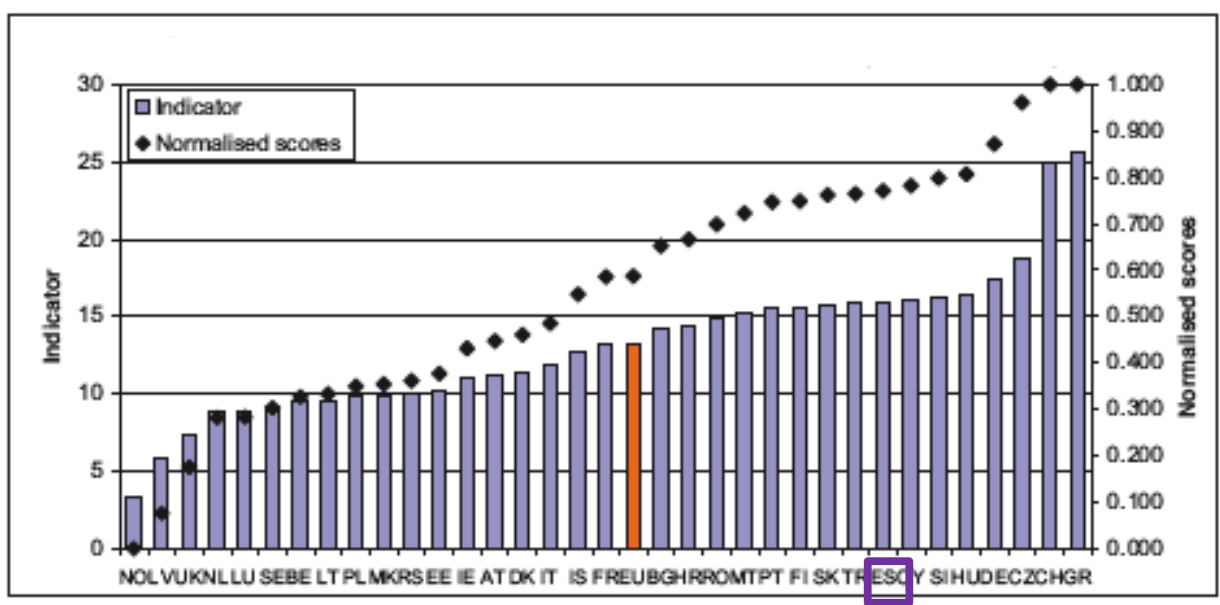

Statistical cutliers: Greece, Norway, Switzerland

Fuente: European Commission (2011):97 
Los indicadores anteriores sobre patentes registradas y concedidas, las actividades de I+D, y nuevos productos y procesos, están más relacionadas con innovaciones tecnológicas, no obstante, se halla una serie de acciones emprendedoras no relacionadas al entorno tecnológico, las llamadas - no tecnológicas.

Muchas de las empresas, sobre todo en los sectores de comercio y servicios no introducen innovación tradicionales (producto o procesos) más bien introducen innovaciones de organización o de marketing. Aproximadamente el $40 \%$ de las pequeñas y medianas empresas de EU27 afirman que han introducido alguna innovación de organización o marketing. De la misma forma, Alemania encabeza los porcentajes con el $60 \%$ de estas empresas que innovan en alguno de estos dos rubros. En el caso de España cuenta con un $30 \%$ de empresas pequeñas y medianas que son innovadoras no tecnológicas (ver Figura 09).

Figura 09

PYMEs: introducción de innovaciones de organización o marketing según \% de PYMEs

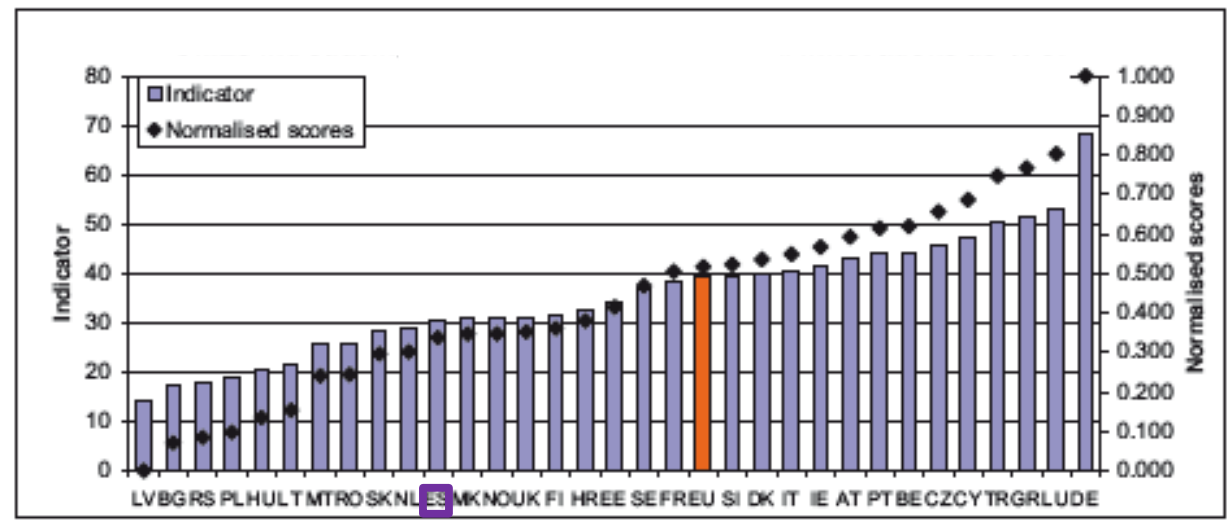

No data for Iceland and Switzerland.

Fuente: European Commission (2011):92

Estrictamente en el ámbito nacional, la Tabla 8-a muestra que las empresas grandes son las que más desarrollan innovaciones no tecnológicas. Las que tienen que ver con las innovaciones organizacionales, introducen nuevas prácticas empresariales en la organización del trabajo $(38,60 \%)$, nuevos métodos de organización de los lugares de trabajo $(36,67 \%)$ y nuevos métodos de gestión de las relaciones externas $(18,15 \%)$. 
Tabla 08-a

Empresas españolas con innovaciones no tecnológicas de organización. 2006-2008

\begin{tabular}{l|r|r|r|r}
\multicolumn{1}{c|}{ Innovación de organización } & \multicolumn{2}{c|}{ Pyme } & \multicolumn{2}{c}{ Grandes } \\
\hline Total de empresas nacional & \multicolumn{2}{|c|}{3243185} & \multicolumn{2}{|c}{3801} \\
\hline Nuevas prácticas empresariales en la organización del trabajo & 34211 & $1.05 \%$ & 1467 & $38.60 \%$ \\
Nuevos métodos de organización de los lugares de trabajo & 37348 & $1.15 \%$ & 1394 & $36.67 \%$ \\
Nuevos métodos de gestión de las relaciones externas & 13476 & $0.42 \%$ & 690 & $18.15 \%$
\end{tabular}

Fuente: ICONO (2010)

Algo similar sucede con la introducción de innovaciones de comercialización o marketing de la Tabla 8-b. Estas innovaciones están caracterizadas según por modificaciones significativas del diseño o el envasado del producto (10.87\%), nuevas técnicas o canales para la promoción del producto (12.79\%), nuevos métodos para el posicionamiento del producto en el mercado (9.92\%) y nuevos métodos para el establecimiento de los precios del producto $(8.71 \%)$. Las grandes empresas que realizan estas innovaciones rondas las 1.606 contra 43.350 pymes. La Figura 10 ilustra las tablas que se han analizado.

Tabla 08-b

Empresas españolas con innovaciones no tecnológicas de marketing. 2006-2008 Innovación de marketing

Total de empresas nacional

Modificaciones significativas del diseño o el envasado del producto Nuevas técnicas o canales para la promoción del producto

Nuevos métodos para el posicionamiento del producto en el mercado

Nuevos métodos para el establecimiento de los precios del producto

\begin{tabular}{|r|r|r|r}
\multicolumn{2}{|c|}{ Pymes } & \multicolumn{2}{l}{ Grandes } \\
\hline \multicolumn{2}{|c|}{$\mathbf{3 2 4 3 1 8 5}$} & \multicolumn{2}{|c}{$\mathbf{3 8 0 1}$} \\
\hline 8217 & $0.25 \%$ & 413 & $10.87 \%$ \\
14427 & $0.44 \%$ & 486 & $12.79 \%$ \\
8905 & $0.27 \%$ & 377 & $9.92 \%$ \\
11803 & $0.36 \%$ & 331 & $8.71 \%$
\end{tabular}

Fuente: ICONO (2010) 
Figura 10

Empresas españolas con innovaciones no tecnológicas según tipo de innovación y tamaño de la empresa.2006-2008

Número de empresas

Innovaciones organizativas

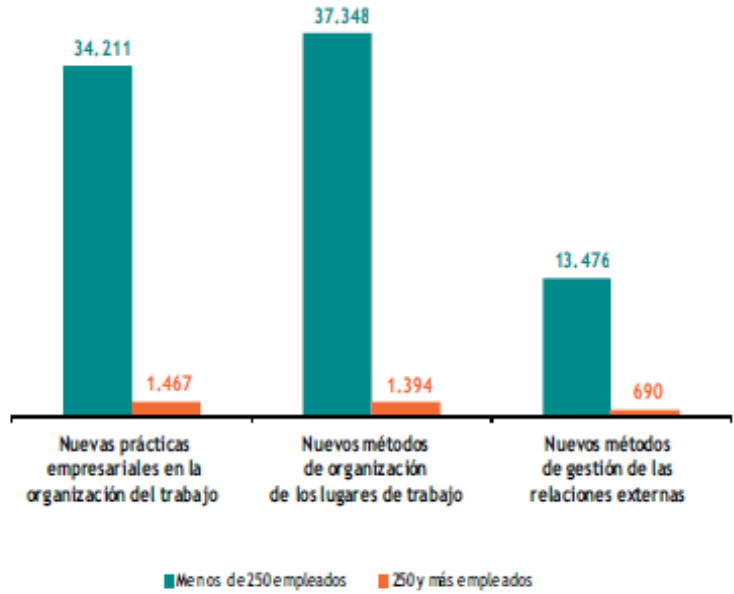

Imovaciones de comercialización

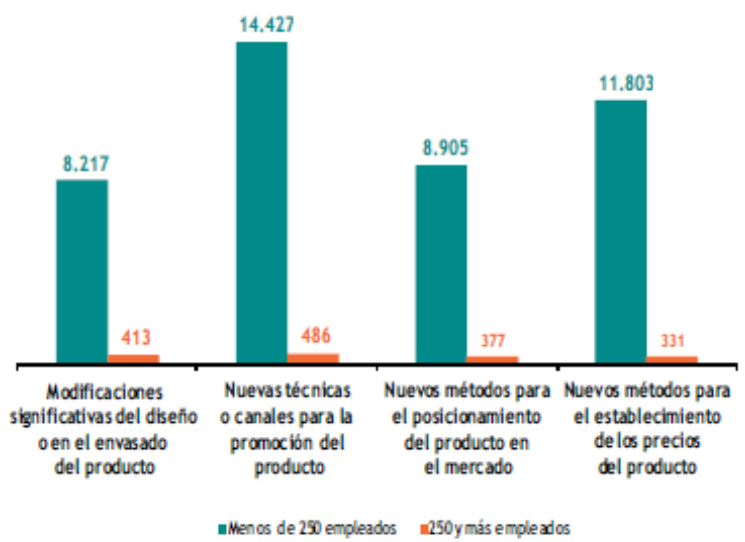

Fuente: ICONO (2010): 62

Ahora bien, es importante destacar, cuáles de las innovaciones tecnológicas que introducen las pequeñas y medianas empresas son desarrolladas e implantadas por ellos mismo o en colaboración de otros agentes. Según la Comisión Europea, el indicador se limita a las pyme, ya que casi todas las grandes empresas innovan y porque los países con una estructura industrial enfocada a las empresas más grandes tienden a hacerlo mejor. Cerca del $30 \%$ de las pymes han innovado con sus propios recursos y capacidades. Liderando en este caso Alemania con el 30\%, mientras que el $22 \%$ de las pymes españolas lo hacen internamente (ver Figura11). 
Figura 11

PYMEs: innovaciones propias según \% de PYMEs

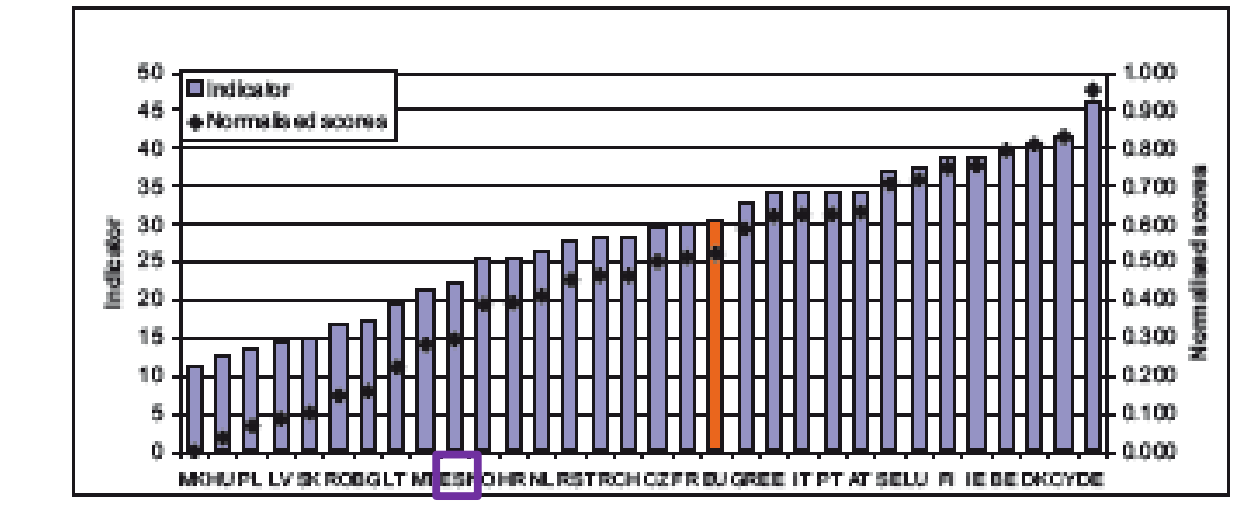

Na data for lad and Slowsria ard Lw.

Fuente: European Commission (2011):84

Por otra parte, alejándonos del ámbito europeo y acercándonos al nacional, se muestra en la Tabla 09 las empresas españolas (por tamaño) con innovaciones no tecnológicas pero dependiendo del lugar dónde realizan la innovación. Por un lado, sigue la tendencia de que el número de introducción de innovaciones de organización es mayor, en todos los ámbitos, que la introducción de innovaciones de comercialización.

Tabla 09

Empresas con innovaciones no tecnológicas según lugar dónde se realiza la innovación y tamaño de la empresa. 2006-2008

\begin{tabular}{|c|c|c|c|c|c|c|c|c|}
\hline \multirow{3}{*}{ Total empresas } & \multicolumn{4}{|c|}{ Innovación de organización } & \multicolumn{4}{|c|}{ Innovación de marketing } \\
\hline & \multicolumn{2}{|c|}{ Pyme } & \multicolumn{2}{|c|}{ Grandes } & \multicolumn{2}{|c|}{ Pymes } & \multicolumn{2}{|c|}{ Grandes } \\
\hline & \multicolumn{2}{|c|}{3243185} & \multicolumn{2}{|c|}{3801} & \multicolumn{2}{|c|}{3243185} & \multicolumn{2}{|c|}{3801} \\
\hline Desarrollo interno & 37739 & $1.16 \%$ & 1242 & $32.68 \%$ & 19842 & $0.61 \%$ & 644 & $16.94 \%$ \\
\hline Colaboración & 8755 & $0.27 \%$ & 447 & $11.76 \%$ & 2745 & $0.08 \%$ & 159 & $4.18 \%$ \\
\hline Subcontratación & 2843 & $0.09 \%$ & 52 & $1.37 \%$ & 1187 & $0.04 \%$ & 16 & $0.42 \%$ \\
\hline
\end{tabular}

Fuente: ICONO (2010)

Por otra parte, prevalece la tendencia europea de desarrollar las innovaciones dentro de la empresa, sobre todo, en su mayoría las empresas grandes innovadoras (33\%). La introducción de innovaciones, tanto de organización como de marketing en colaboración con 
Figura 12

\section{Empresas con innovaciones no tecnológicas según lugar dónde se realiza la innovación y tamaño de la empresa. 2006-2008}

Número de empresas

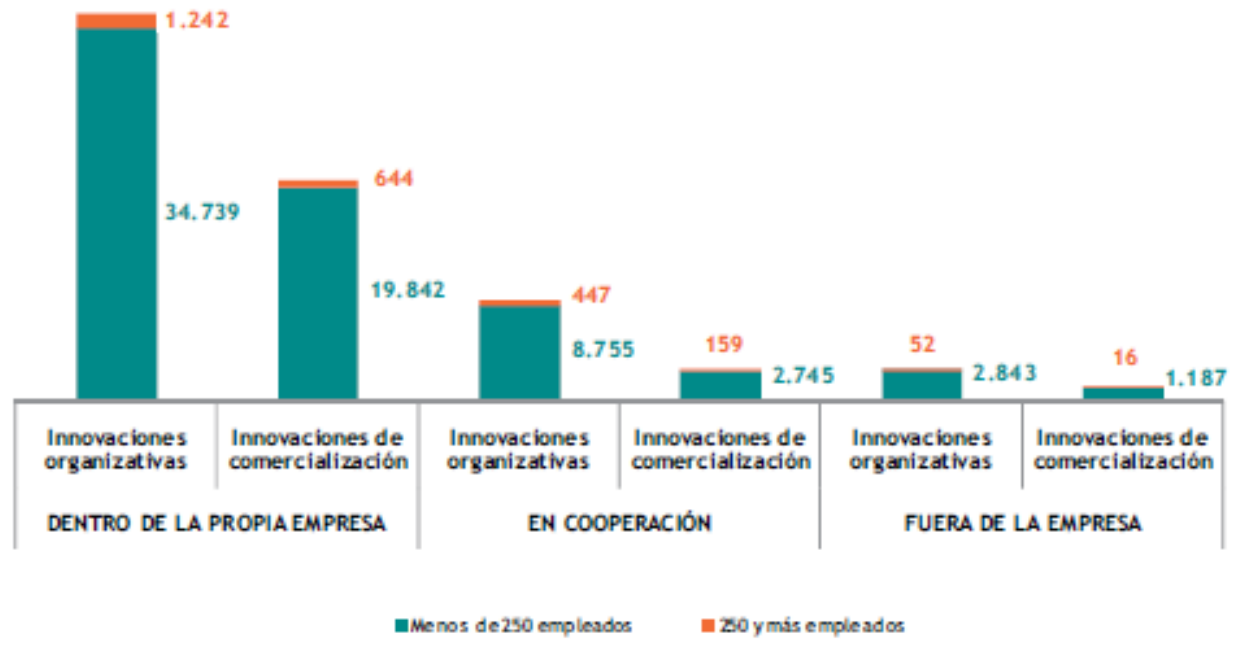

Fuente: ICONO (2010): 61

otros actores del entorno, prevalece la misma tendencia de crecimiento, son las grandes empresas (12\%) las que optan por esta vía, aunque es muy pequeña en comparación con el desarrollo interno. Por último, con un margen menor, se subcontrata las innovaciones no tecnológicas a terceros, pero igual en este ámbito sigue la misma tendencia de las dos anteriores $(1 \%)$. La introducción de innovaciones de marketing en la empresa grande se desarrolla prioritariamente a nivel interno de la empresa (17\%). Por lo anterior, se puede decir que ni la colaboración ni la subcontratación son estrategias habituales en los procesos de innovación de las empresas españolas, por tanto, no son abundantes las empresas de los distintos sectores empresariales que estén orientados a innovación, habiendo, incluso, disminuido en fechas recientes las empresas dedicadas a las actividades de I+D. La Figura 12 ilustra la tabla que se ha estudiado.

La tendencia de introducir innovaciones, tanto tecnológicas como no tecnológicas es un comportamiento que poco a poco ha ido tomando mayor actividad, sobre todo en sectores más dinámicos y de alta tecnología como es el caso del sector automovilístico. En primera instancia se puede observar en la Figura 13 el comportamiento de trabajo en cooperación para 
introducir la innovación a nivel europeo. Sobre este tema de colaboración, la encuesta realizada por Dirección General de Innovación de la CE (European Commission, 2011), que dicta que el $45 \%$ de las empresas europeas cooperan habitualmente para la innovación, mientras que el porcentaje de las empresas españolas con esta estrategia es el $27 \%$. El porcentaje de empresas que no contemplan la cooperación entre sus estrategias de innovación es un $37 \%$, frente al $27 \%$ de media de la UE. Ambas cifras sitúan a España entre los países de la UE que menos uso hacen de las posibilidades de la colaboración.

Figura 13

Estados miembros según los resultados de colaboraciones y emprendedorismo

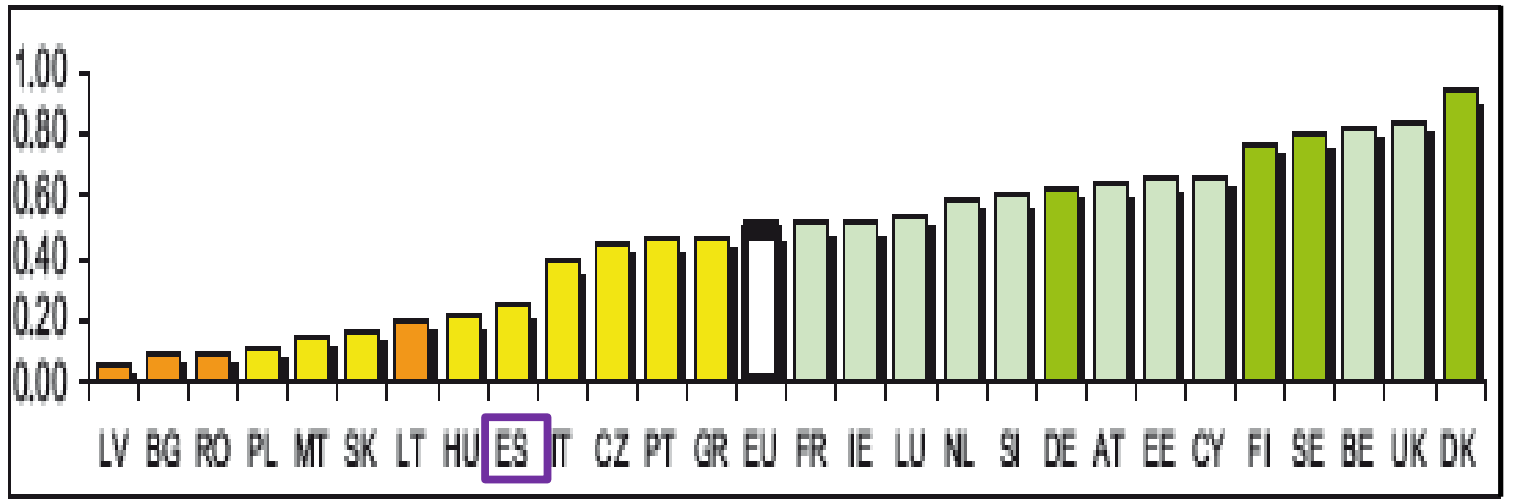

Fuente: European Commission (2011):16

El indicador de la Figura 14 mide el grado por el cual las pequeñas y medianas empresas se involucran en la innovación por medio de la colaboración, normalmente estas colaboraciones rigen en sectores de alta tecnología, normalmente dependen en la capacidad de recurrir a diversas fuentes de información y conocimiento, o para colaborar en el desarrollo de una innovación. Este indicador mide el flujo de conocimientos entre las instituciones de investigación públicas y empresas privadas y entre éstas y otras empresas. El indicador se limita a las pymes, ya que casi todas las grandes empresas están implicadas en la cooperación en innovación. Cerca del 11\% de EU27 son empresas pequeñas colaboradoras junto con otras empresas. En el caso de España el porcentaje ronda el 5\%, ubicada por debajo de la media europea y muy por debajo de los líderes innovadores (European Commission, 2011: 85). 
Figura 14

PYMEs: innovaciones en colaboración con otros según \% de PYMEs

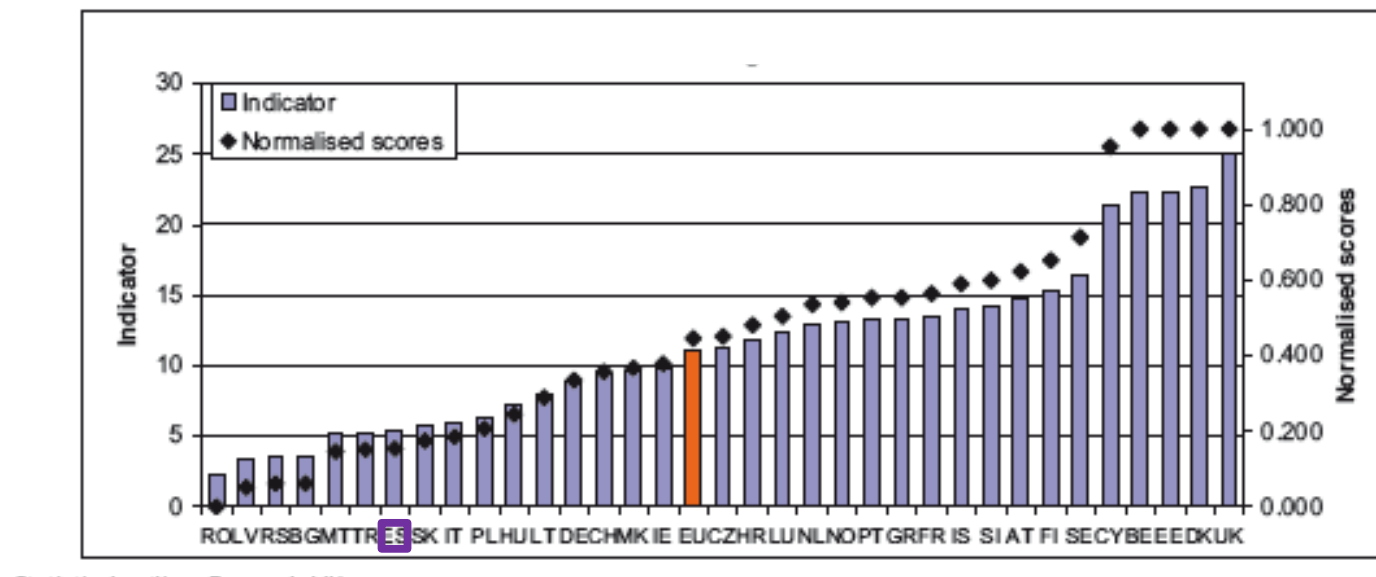

Statistical cutliers: Dermark UK

Fuente: European Commission (2011):85

La Tabla 10 muestra la distribución porcentual de los distintos agentes de colaboración que usualmente utilizan las empresas españolas para introducir innovaciones tecnológicas y no tecnológicas; incrementales y radicales. Las empresas grandes llevan la delantera sobre este tipo de colaboraciones, liderando las que se llevan a cabo con los proveedores seguidamente con las otras empresas del mismo grupo y tercero, con las universidades. Para las pequeñas y medianas empresas las colaboraciones más habituales son con los proveedores y con la universidad. En el caso de las pymes, el reparto de la colaboración con los distintos agentes está más equilibrado que las grandes empresas que se enfocan casi dos terceras partes de la colaboración con sus propios proveedores.

Tabla 10

Colaboración en innovación de las empresas según tipo de agente y tamaño de la empresa. 2008

\begin{tabular}{|c|c|c|c|c|}
\hline \multirow{2}{*}{ Total de empresas } & \multicolumn{2}{|c|}{ Pymes } & \multicolumn{2}{|c|}{ Grandes } \\
\hline & \multicolumn{2}{|c|}{6682} & \multicolumn{2}{|c|}{814} \\
\hline Otras empresas del mismo grupo & 1191 & $18 \%$ & 394 & $48 \%$ \\
\hline Proveedores & 2124 & $32 \%$ & 479 & $59 \%$ \\
\hline Clientes & 1482 & $22 \%$ & 236 & $29 \%$ \\
\hline Competidores /empresas del sector & 1229 & $18 \%$ & 206 & $25 \%$ \\
\hline Consultores /Licenciadores /Laboratorios comerciales & 1612 & $24 \%$ & 295 & $36 \%$ \\
\hline Centros tecnológicos & 1576 & $24 \%$ & 292 & $36 \%$ \\
\hline Universidades & 1946 & $29 \%$ & 375 & $46 \%$ \\
\hline Organismos públicos de investigación & 998 & $15 \%$ & 222 & $27 \%$ \\
\hline
\end{tabular}

Fuente: ICONO (2010) 
Sobre estos datos, ilustrados en la Figura 15, se concluye que las colaboraciones más habituales entre las empresas españolas se orientan hacia los proveedores $(46,60 \%)$ y con las universidades $(31,40 \%)$. La colaboración que menos se incentiva para la introducción de innovaciones incrementales y radicales es con los organismos públicos de investigación.

Figura 15

\section{Colaboración en innovación de las empresas} según tipo de agente. 2008

Distribución porcentual

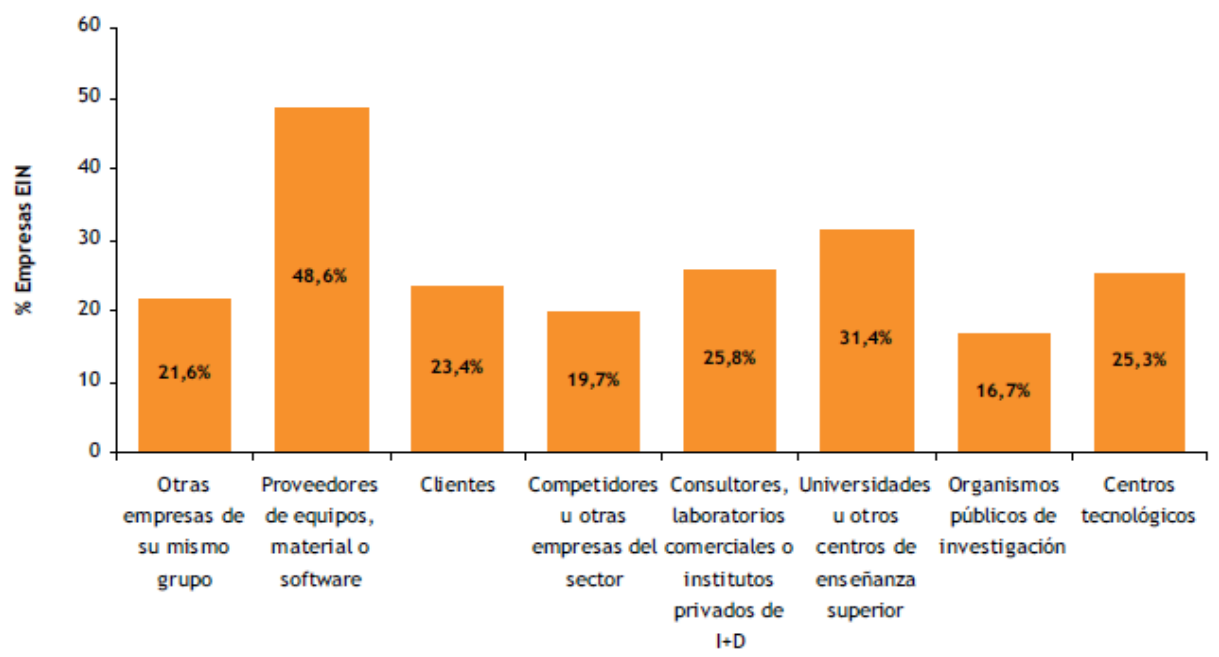

(*) Para las empresas denominadas EIN = Empresas innovadoras en el periodo 2006-2008 o con innovaciones en curso o no exitosas. Una empresa puede cooperar con más de una unidad.

Fuente: ICONO (2010): 59

\subsection{Importancia de la innovación empresarial}

Distintos autores han planteado que la innovación es importante para la empresa porque genera ventajas competitivas que la diferencian del resto de la competencia. La innovación permite conocer a sus clientes, mantener su competitividad y aprovechar las oportunidades del mercado (Cooper, 1996). Una empresa innovadora está capacitada para alcanzar una alta competitividad y elevados niveles de desempeño (Thomas, 1995).

Dentro de la economía global, no es suficiente participar en mercados altamente competitivos, lograr reestructuraciones, seguir estrategias de bajos costes o crear productos y 
procesos que sobrepasen las barreras tecnológicas. Se requiere de una competencia mayor: innovar (Vega-Vidal, 2010).

Aragón y Sánchez (2005) concluyen que el tipo de organización más rentable y productiva es aquella que adopta estrategias proactivas en su comportamiento e integra grupos orientados hacia la innovación. La adopción de la innovación como una estrategia proactiva responde a los cambios promovidos por el sector, la tecnología, la competencia, la exigencia de la demanda, los cambios del mercado, la escasez de recursos, las iniciativas de los altos mandos; con la aspiración última de diferenciarse y mejorar su desempeño empresarial (Jensen et al., 2006).

En los últimos años se ha intensificado la investigación sobre la innovación al convertirse en una disciplina básica en la misión de las empresas. Se han explorado distintas perspectivas con el objetivo de conocer su naturaleza. Últimamente, la tendencia del estudio multidimensional de la innovación ha desafiado el acercamiento unidimensional. Esto se debe a que cada tipo de innovación posee sus propias características. Al mismo tiempo, cada implantación es afectada por distintos factores organizacionales y del entorno (Jensen et al., 2006). Sin embargo, la tipología de la innovación no es un tema reciente, ya desde la década de los 70's se introducen distintas clasificaciones (Zaltman et al., 1973; Abernathy y Utterback, 1978) y no ha seguido un estándar único.

La distinción entre innovación de producto y procesos es el tipo de innovación que más se ha estudiado desde entonces. Más recientemente, se han incorporado la tecnológica y la administrativa (gestión y organización). Por ejemplo, Maravelakis et al. (2006) midió la innovación organizacional en tres áreas: producto, procesos y administrativo. Un año después, Lin y Chen (2007) incluyen la innovación de marketing y estratégica. Esta tendencia se debe, principalmente, a que las empresas están institucionalizando la innovación como parte de la cultura organizativa, dotándola de estructura, procesos, sistemas, valores e incentivos.

Po otro lado, la importancia de la innovación también radica en su relación con otros factores internos y externos de la empresa que conduce al éxito empresarial. A continuación mencionamos las relaciones más significativos para esta investigación. 


\subsubsection{Innovación y desempeño empresarial}

Una revisión de la literatura más relevante sobre innovación organizacional han investigado sobre la relación entre innovación y desempeño empresarial (Damanpour y Evan, 1984; Li y Atuahene-Gima, 2001; Roper y Love, 2002; Damanpour et al., 2009). Algunos de estas investigaciones encuentran una relación positiva e inducen a una generalización empírica. Sin embargo, existen excepciones que no han detectado dicha relación o incluso han observado un efecto inverso. La diversidad de estos resultados puede estar explicada por la heterogeneidad de metodologías, medidas, poblaciones; sin contar la variedad de las características de las empresas, sus estrategias, el sector de actividad, la estructura competitiva, el contexto en el que operan, el escenario socioeconómico, etc.

Pero si bien es cierto, para que se dé el desarrollo e introducción de las actividades de innovación son necesarias ciertas condiciones que las favorezcan, llamadas "posibilitadores", entre otras están los elementos característicos de la cultura organizativa, oportunidades del entorno o alianzas de colaboración ( Davenport, 1996)

\subsubsection{Innovación y cultura organizativa}

Estudios empíricos han confirmado la relación de la cultura organizativa con la innovación (Deshpandé et al., 1993). En particular, la orientación al mercado y la orientación emprendedora han acaparado gran atención. Estas orientaciones actúan no solo como cultura sino también como capacidades organizativas claves para contribuir en el corto o largo plazo a los resultados del negocio (Day, 1994; Pelham y Wilson, 1996; Santos et al., 2002) y de esta manera, crear ventajas competitivas sostenibles (Barney, 1991; Mahoney y Pandian, 1992; Peteraf, 1993; Grant, 1996).

Un primer objetivo de esta investigación es comprobar si la cultura organizativa antecede a la innovación. Entonces ¿actúan las orientaciones al mercado y emprendedora como determinantes de las acciones de innovación? Los resultados podrían ayudar a las empresas a determinar qué cultura organizativa fomentar o fortalecer para incrementar las acciones de innovación. 


\subsubsection{Innovación y tamaño empresarial}

El hecho de que las empresas más pequeñas tengan capacidades financieras y de recursos más reducidas no quiere decir que no desarrollan distintos tipos de innovación, aunque, si bien es cierto, muchas de ellas se encuentran con grandes barreras para su introducción. Las empresas son distintas entre si, en este caso por la característica organizacional del tamaño, y por lo tanto, su comportamiento innovador también lo es (Salavou et al. 2004).

Esta investigación pretende profundizar en el análisis de la relación entre la cultura organizativa y la innovación considerando el papel del tamaño empresarial. Estudios previos argumentan que el tamaño está relacionado con la orientación al mercado, la orientación emprendedora y la innovación. En consecuencia, ¿persiste la relación entre cultura organizativa e innovación cuando se considera el tamaño empresarial?

La mayor parte de las investigaciones que relacionan la innovación con los resultados y con otros factores empresariales se han enfocado en las grandes empresas y pocos han explorado el contexto de las pequeñas empresas (Shaffer, 2002; Zhou et al., 2005). Para ello, en este estudio se pretende analizar el papel de tamaño como moderador en distintas relaciones con la innovación. En otras palabras, ¿difiere las relaciones con la innovación según el tamaño empresarial? El principal aporte de este estudio es proporcionar evidencia cuantitativa tanto para grandes empresas como para pequeñas empresas.

\subsubsection{Innovación y dinamismo del entorno}

En particular, las características del entorno, y su papel moderador en la relación entre la innovación y el desempeño, también se han estudiado empíricamente, aunque los resultados no son del todo concluyentes (Özsomer et al., 1997; Messenghen, 2003; Souza et al., 2004, Carbonell y Rodríguez, 2005). Esto debido a que ciertas circunstancias empresariales y del entorno son de carácter más general. Con todo, la evidencia en cuanto a los efectos moderadores es más limitada. Por tanto, un análisis de estas circunstancias moderadoras de la relación puede ayudar, por un lado, a conocer hacia dónde 
dirigir los esfuerzos y recursos para una adecuada implantación de la innovación y, por otro lado, a puntualizar sobre los fenómenos que la potencian o la condicionan.

\subsubsection{Innovación y colaboración organizacional}

Algunos autores consideran que parte del éxito o fracaso de las empresas dependerá del aprovechamiento de las interacciones directas e indirectas con otros entes (Håkansson y Waluszewski, 2002; Tether, 2002a; Wilkinson y Young, 2002; Hoang y Antoncic, 2003). La literatura en gestión empresarial viene estudiando el impacto de las redes de colaboración en el desempeño empresarial. Se concluye que el papel de la colaboración permite mejorar los resultados empresariales (Iacobucci, 1996; Laage-Hellman, 1997; Naude y Turnbull, 1998; Combs y Ketchen, 1999; Sheth y Parvatiyar, 2000; Sarkar et al., 2001; Zaheer y Geoffrey, 2005; Gilsing et al., 2008). La innovación puede ser un vehículo para esta mejora; en otras palabras, la colaboración ayuda al éxito de la innovación.

Diversas investigaciones han concluido que la colaboración propicia la innovación y la creación de nuevos negocios (Kanter, 1989; Pennings y Harianto, 1992; Powell et al, 1996; Teece et al, 1997; van de Ven et al, 1999). Más aún, la colaboración propicia un mayor acierto en las acciones de innovación. "Altos niveles de cooperación genera mejor desempeño de nuevos productos que en niveles bajos de cooperación” (Olson et al., 2001: 269). De la misma manera, Wilkinson y Young (2002) advierten que las empresas que son capaces de trabajar juntas serán más capaces para adaptar mejor sus productos, sus servicios y sus procesos operacionales para satisfacer las necesidades y exigencias del mercado. Así, por medio de esta investigación se podrá conocer el efecto de la colaboración en el éxito innovador.

\subsection{Cuestiones de investigación pendientes}

El presente estudio se concentra en las pequeñas empresas de zonas desfavorecidas, y para ello, es necesario conocer en que consiste la competitividad en estas localizaciones. La literatura existente sobre la dinámica, la supervivencia, competitividad y el crecimiento de pequeñas empresas en regiones periféricas no relacionan directamente este factor con la elección de la estrategia desde el punto de vista de acciones innovadoras y los resultados 
empresariales para empresas localizadas en estas zonas (Skuras et al., 2000; Fotopoulos y Louri, 2000; Littunen, 2000; Niosi y Bas, 2001; Giner y Santa, 2002; Li y Hu, 2002; Liedholm, 2002; Hoogstra y Dijk, 2004; Johnson, 2005; Psaltopoulos et al., 2005). Esta situación favorece la pertinencia del estudio en cuestión, que tiene como objetivo conocer cuales son los factores determinantes del comportamiento innovador de la pequeña empresa en zonas periféricas y su comparación con otras empresas.

El fin de la revisión literaria es proveer un panorama general de la literatura sobre los pilares teóricos que fundamentan el estudio de esta investigación Todos estos pilares teóricos contienen constructos y variables que tienen indudables consecuencias sobre los diferentes resultados de las grandes y pequeñas empresas (zonas periféricas) y por ende en su comportamiento estratégico. El planteamiento de este estudio consiste en que las los factores internos de la empresa (como su tamaño o sus capacidades organizativas) junto con los factores del entorno (dinamismo del entorno, sector y la colaboración externa) pueden potenciar las acciones innovadoras como parte de la estrategia de la empresa, y estas acciones pueden influir positivamente en el éxito empresarial.

Más concretamente, la contribución de este estudio queda delimitada por los siguientes aspectos diferenciadores:

(1) La utilización de dos niveles de innovación: multidimensional y unidimensional. En la multidimensional: organización, marketing, producto y procesos productivos. En la unidimensional: incremental y radical. Esto permite estimar la relación de la innovación con los resultados desde varias perspectivas dimensionales. Se considera en el estudio la innovación radical e incremental. Dentro de la literatura de management, hay quienes han utilizado el elemento más específico de la innovación incremental, y concluyen que la colaboración de recursos tecnológicos mejoran la innovación empresarial (Baum et al., 2000; Stuart, 2000). Por otro lado, otros más dedicados al elemento radical de la innovación, aluden que aporta una fuerte evidencia de como los factores empresariales y la cooperación promueve el desarrollo de nuevos productos (Bond et al., 2004). En este estudio se tomarán en cuenta los dos tipos con el fin de observar sus diferencias. 
(2) Diferenciación en el desempeño organizativo: se plantea diferenciarlo, por un lado, indicadores de efectividad, eficiencia y adaptabilidad (Walker y Ruekert, 1987), y por otro lado, indicadores financieros y operativos (Venkatraman y Ramanujam, 1986). Esto permite valorar las consecuencias de la innovación y los efectos moderadores del en el desempeño global con una visión tanto a corto como a medio y largo plazo;

(3) La delimitación del papel moderador: se consideran dos vertientes a) los factores organizacionales como el tamaño y la orientación al mercado y b) los factores del entorno que parte del dinamismo del ambiente como un todo que integra el grado de volatilidad en la demanda, la rivalidad competitiva, incorporación de nuevos productos, los cambios en procesos y tecnologías, etc. Además, se añade un factor más específico centrado en la intensidad competitiva;

(4) La consideración de dos dimensiones de colaboración: aunque no sin matices, el alcance de las dimensiones de colaboración se puede interpretar conforme a dos clasificaciones: la colaboración del canal y la colaboración de asesoría. Raramente se ha estudiado la relación de cooperación de la proximidad (no geográfica) con la empresa. Por un lado, la colaboración del canal estará definida por el apoyo recibido de parte de los clientes, proveedores, los competidores y empresas del mismo grupo. La colaboración del canal proporciona beneficios más orientados a las cuestiones comerciales del mercado; por ejemplo, la colaboración en la cadena de valor (supply chain collaboration), además de otras contribuciones, aporta conocimiento y habilidades para conocer las necesidades de los consumidores (Narus y Anderson, 1996). La colaboración con otras firmas de la competencia aporta una fuerte reputación e imagen, crear potentes ofertas y acceso a nuevos mercados (Freeman et al., 2006; Swaminathan y Moorman, 2009). La colaboración con los clientes está más bien relacionada a la retroalimentación que dan sobre sus gustos y necesidades, la satisfacción e intención de re-uso (Bennett y Robson, 2005). Por otro lado, la colaboración de asesoría estará compuesta por el apoyo de asociaciones, consultores, licenciadores y universidades. Este tipo de colaboración aporta beneficios más orientados a la investigación y desarrollo, 
implantación de nuevas tecnologías, asesoría para desarrollar nuevos productos y abrir nuevos mercados, etc. (Nooteboom et al., 2005).

(5) El análisis empírico se centra en 440 empresas españolas (190 empresas grandes y 250 pequeñas empresas). Se realiza una distinción entre pequeñas y grandes empresas en la muestra. La idea es determinar las diferencias entre las empresas a la hora de aprovechar los factores internos y externos de la empresa, así como la colaboración en beneficio de la innovación y en la mejora de los resultados empresariales. Los resultados derivados podrían conllevar a un redireccionamiento de las normas y prácticas del apoyo externo (Freeman et al., 2006). Además, evaluar lo que actualmente se está realizando en el contexto de pequeñas empresas en zonas desfavorecidas, caracterizadas por su baja capacidad de gestión y su dificultad a la hora de obtener recursos. El énfasis de está investigación permite proveer tanto a las iniciativas públicas como privadas, y a las empresas situadas en zonas desfavorecidas, una orientación sobre los componentes exógenos y endógenos que afectan positiva o negativamente la elección estratégica y por ende, la competitividad de las pequeñas empresas (desempeño) de las zonas menos favorecidas.

(6) Se diferencian cuatro sectores de actividad principal: industria, construcción, agricultura y servicios-comercio. Puede esperarse que la pertenencia a un determinado sector de actividad implique mayores o menores oportunidades de crecimiento en función de la distinta coyuntura de mercado a la que se enfrenten. Para contrastar esto bastaría realizar una agregación de sectores lo más homogéneos posibles y establecer una regresión identificando cada sector con una variable dummy.

\subsection{Objetivos de la investigación}

Los objetivos, general y específicos, de esta investigación servirán para delimitar los cuestionamientos que han surgido del análisis contextual anterior. Además, estos objetivos cumplirán el propósito de dar respuesta a las hipótesis que se plantearán en el siguiente gran apartado. 


\subsubsection{Objetivo general}

La multiplicidad de elementos determinantes de la relación entre la innovación y el desempeño empresarial hace pertinente el objetivo general de este estudio el cual es medir la relación añadiendo distintos factores organizacionales (tamaño, orientación al mercado, orientación emprendedora) y del entorno (turbulencia del entorno, intensidad competitiva, colaboración empresarial), como condicionantes del éxito y/o moderadores, que interactúan en la implementación de la innovación.

\subsubsection{Objetivos específicos}

El objetivo general planteado anteriormente engloba una serie de objetivos específicos que cumplen la finalidad de sistematizar y estructurar tanto el desarrollo teórico como el desglose empírico de esta investigación.

\subsubsection{Objetivos específicos teóricos}

La primera bloque de objetivos pretende facilitar el entendimiento de elementos básicos de la literatura de management. Para ello será necesaria la revisión y profundización de determinados conceptos, sus determinantes y relaciones. Estos objetivos valdrán para justificar la argumentación, que posteriormente, permitirán plantear las hipótesis empíricas de la investigación. La Tabla 11 resume los objetivos específicos teóricos de la Tesis Doctoral y las secciones de la tesis en los que son abordados. Los objetivos específicos teóricos pueden desglosarse de la siguiente forma:

(1) analizar la definición, medición e interpretación del concepto de innovación, especialmente desde la perspectiva incremental; y radical.

(2) profundizar en el paradigma del éxito de la innovación desde la aportación de la innovación a los resultados empresariales.

(3) investigar sobre el papel del tamaño en la cultura organizativa.

(4) explorar en la literatura el papel del tamaño empresarial en el éxito de la innovación y el desempeño empresarial. 
(5) repasar la noción teórica de la orientación al mercado y su relación con la innovación y el desempeño empresarial.

(6) revisar el concepto y la estructura de la orientación emprendedora y su función determinante en la innovación.

(7) examinar en la literatura la importancia del dinamismo del entorno y su papel en la relación entre la innovación y el desempeño empresarial.

(8) considerar teóricamente el papel del sector en la innovación y el desempeño empresarial

(9) analizar la definición y significación de la colaboración empresarial y su comportamiento en el éxito de la innovación.

\subsubsection{Objetivos específicos empíricos}

A diferencia de los objetivos específicos teóricos, los empíricos están más enfocados en probar experimentalmente las distintas derivaciones que surgen de la relación principal entre la innovación y el desempeño empresarial. La Tabla 12 resume los objetivos específicos empíricos de la Tesis Doctoral y las secciones donde se desarrollan. Los objetivos específicos de partida de esta investigación se pueden sintetizarse en cinco partes, a continuación:

(1) aportar evidencia empírica de que la innovación conduce a la mejora del desempeño empresarial:

a. que la implementación de la innovación incremental de organización, marketing, producto y procesos conduce a la empresa a mejores resultados en cuanto a rentabilidad, crecimiento de las ventas, valor en el mercado, respuesta del mercado y éxito de nuevos productos,

b. que implementación de la innovación radical enfocada al registro de patentes, actividades I+D y desarrollo de nuevos productos y mercado, genera mejora del desempeño empresarial, en cuanto a rentabilidad, crecimiento de las ventas, valor en el mercado, respuesta del mercado y éxito de nuevos productos. 
(2) aportar evidencia empírica sobre el papel del tamaño de la empresa:

a. como condicionante de la innovación incremental y radical,

b. como condicionante de la cultura organizativa (orientación al mercado y orientación emprendedora),

c. como condicionante moderador de la relación entre la cultura organizativa y la innovación,

d. como condicionante de la innovación y el desempeño empresarial,

e. como condicionante moderador de la relación entre la innovación y el desempeño empresarial,

f. como papel moderador de la colaboración y la innovación,

g. observar si difiere con el tamaño de la empresa los resultados de los coeficientes de la cultura organizativa, el dinamismo del entorno, la colaboración y los resultados en relación a la innovación.

(3) aportar evidencia empírica sobre si el papel de la orientación al mercado y la orientación emprendedora conduce al éxito innovador y al desempeño empresarial:

a. que una empresa orientada al mercado tiende a mejorar sus implementaciones de innovación incremental y/o radical,

b. que la orientación al mercado en sinergia con la innovación puede potencial el éxito empresarial.

c. que una empresa emprendedora tiende a mejorar sus implementaciones de innovación incremental y/o radical,

(4) aportar evidencia empírica del papel moderador del dinamismo del entorno en el éxito innovador y empresarial:

a. que la turbulencia del entorno potencia el éxito innovador,

b. que la intensidad competitiva potencia el éxito innovador. 
(5) aportar evidencia empírica sobre el papel moderador de la colaboración empresarial en la innovación y el desempeño empresarial:

a. que la colaboración del canal potencia el éxito innovador,

b. que la colaboración de asesoría potencia el éxito innovador.

\section{Tabla 11}

\section{Objetivos específicos teóricos de la Tesis Doctoral}

\begin{tabular}{l}
\multicolumn{1}{c}{ Intensión } \\
\hline Profundizar, revisar e integrar la \\
literatura relevante que permita \\
establecer el marco teórico y \\
plantear los modelos explicativos \\
subyacentes al objetivo general \\
de la investigación.
\end{tabular}

\begin{tabular}{|c|c|}
\hline Objetivos & Secciones \\
\hline $\begin{array}{l}\text { Analizar la definición, medición e interpretación del } \\
\text { concepto de innovación, especialmente desde la } \\
\text { perspectiva incremental; y radical. }\end{array}$ & $\begin{array}{l}\text { Segunda parte - } \\
\text { sección } 2.1 .\end{array}$ \\
\hline $\begin{array}{l}\text { Profundizar en el paradigma del éxito de la innovación } \\
\text { desde la aportación de la innovación a los resultados } \\
\text { empresariales. }\end{array}$ & $\begin{array}{l}\text { Segunda parte - } \\
\text { sección 2.2. y } 2.3 \text {. }\end{array}$ \\
\hline $\begin{array}{l}\text { Investigar sobre el papel del tamaño en la cultura } \\
\text { organizativa. }\end{array}$ & $\begin{array}{l}\text { Segunda parte - } \\
\text { sección 2.4.1.5. }\end{array}$ \\
\hline $\begin{array}{l}\text { Explorar en la literatura el papel del tamaño empresarial en } \\
\text { el éxito de la innovación y el desempeño empresarial. }\end{array}$ & $\begin{array}{l}\text { Segunda parte - } \\
\text { sección 2.4.1.4., 2.4.1.7. } \\
\text { y 2.4.1.8. }\end{array}$ \\
\hline $\begin{array}{l}\text { Repasar la noción teórica de la orientación al mercado y su } \\
\text { relación con la innovación y el desempeño empresarial. }\end{array}$ & $\begin{array}{l}\text { Segunda parte - } \\
\text { sección } 2.4 .1 .1 .1 . \\
\text { 2.4.1.2. y } 2.4 .1 .3 .\end{array}$ \\
\hline $\begin{array}{l}\text { Revisar el concepto y la estructura de la orientación } \\
\text { emprendedora y su función determinante en la innovación. }\end{array}$ & $\begin{array}{l}\text { Segunda parte - } \\
\text { sección 2.4.1.1.2. }\end{array}$ \\
\hline $\begin{array}{l}\text { Examinar en la literatura la importancia del dinamismo del } \\
\text { entorno y su papel en la relación entre la innovación y el } \\
\text { desempeño empresarial. }\end{array}$ & $\begin{array}{l}\text { Segunda parte - } \\
\text { sección 2.4.2. }\end{array}$ \\
\hline $\begin{array}{l}\text { Considerar teóricamente el papel del sector en la } \\
\text { innovación y el desempeño empresarial }\end{array}$ & $\begin{array}{l}\text { Segunda parte - } \\
\text { sección 2.4.2.2. }\end{array}$ \\
\hline $\begin{array}{l}\text { Analizar la definición y significación de la colaboración } \\
\text { empresarial y su comportamiento en el éxito de la } \\
\text { innovación. }\end{array}$ & $\begin{array}{l}\text { Segunda parte - } \\
\text { sección 2.4.2.3. }\end{array}$ \\
\hline
\end{tabular}


Tabla 12

\section{Objetivos específicos empíricos de la Tesis Doctoral}

\begin{tabular}{|c|c|c|c|}
\hline Intensión & Objetivos & Desglose & Secciones \\
\hline \multirow[t]{5}{*}{$\begin{array}{l}\text { Desarrollar una } \\
\text { aplicación } \\
\text { empírica para } \\
\text { analizar las } \\
\text { relaciones } \\
\text { propuestas. }\end{array}$} & $\begin{array}{l}\text { Aportar evidencia empírica } \\
\text { de que la innovación } \\
\text { multidimensional conduce a } \\
\text { la mejora del desempeño } \\
\text { empresarial: }\end{array}$ & $\begin{array}{l}\text { a. que la implementación de la innovación } \\
\text { incremental de organización, marketing, producto } \\
\text { y procesos conduce a la empresa a mejores } \\
\text { resultados en cuanto a rentabilidad, crecimiento } \\
\text { de las ventas, valor en el mercado, respuesta del } \\
\text { mercado y éxito de nuevos productos, } \\
\text { b. que implementación de la innovación radical } \\
\text { enfocada al registro de patentes, actividades I+D } \\
\text { y desarrollo de nuevos productos y mercado, } \\
\text { genera mejora del desempeño empresarial, en } \\
\text { cuanto a rentabilidad, crecimiento de las ventas, } \\
\text { valor en el mercado, respuesta del mercado y } \\
\text { éxito de nuevos productos. }\end{array}$ & $\begin{array}{l}\text { Cuarta parte - } \\
\text { sección 4.4.2.1. }\end{array}$ \\
\hline & $\begin{array}{l}\text { Aportar evidencia empírica } \\
\text { sobre el papel del tamaño } \\
\text { de la empresa: }\end{array}$ & $\begin{array}{l}\text { a. como condicionante de la innovación incremental } \\
\text { y radical, } \\
\text { b. como condicionante de la cultura organizativa } \\
\text { (orientación al mercado y orientación } \\
\text { emprendedora), } \\
\text { c. como condicionante moderador de la relación } \\
\text { entre la cultura organizativa y la innovación, } \\
\text { d. como condicionante de la innovación y el } \\
\text { desempeño empresarial, } \\
\text { e. como condicionante moderador de la relación } \\
\text { entre la innovación y el desempeño empresarial, } \\
\text { f. como papel moderador de la colaboración y la } \\
\text { innovación, } \\
\text { g. observar si difiere con el tamaño de la empresa } \\
\text { los resultados de los coeficientes de la cultura } \\
\text { organizativa, el dinamismo del entorno, la } \\
\text { colaboración y los resultados en relación a la } \\
\text { innovación. }\end{array}$ & $\begin{array}{l}\text { Cuarta parte - } \\
\text { sección 4.4.1.2., } \\
\text { 4.4.2.3. y 4.4.3. }\end{array}$ \\
\hline & $\begin{array}{l}\text { Aportar evidencia empírica } \\
\text { sobre si el papel de la } \\
\text { orientación al mercado y la } \\
\text { orientación emprendedora } \\
\text { conduce al éxito innovador } \\
\text { y al desempeño } \\
\text { empresarial: }\end{array}$ & $\begin{array}{l}\text { a. que una empresa orientada al mercado tiende a } \\
\text { mejorar sus implementaciones de innovación } \\
\text { incremental y/o radical, } \\
\text { b. que la orientación al mercado en sinergia con la } \\
\text { innovación puede potencial el éxito empresarial. } \\
\\
\text { c. que una empresa emprendedora tiende a mejorar } \\
\text { sus implementaciones de innovación incremental } \\
\text { y/o radical, }\end{array}$ & $\begin{array}{l}\text { Cuarta parte - } \\
\text { sección 4.4.4.1. } \\
\text { y 4.4.2.3. }\end{array}$ \\
\hline & $\begin{array}{l}\text { Aportar evidencia empírica } \\
\text { el papel moderador la } \\
\text { dinamismo del entorno en el } \\
\text { éxito innovador y } \\
\text { empresarial: }\end{array}$ & $\begin{array}{l}\text { a. que la turbulencia del entorno potencia el éxito } \\
\text { innovador } \\
\text { b. que la intensidad competitiva potencia el éxito } \\
\text { innovador }\end{array}$ & $\begin{array}{l}\text { Cuarta parte - } \\
\text { sección 4.4.2.3. }\end{array}$ \\
\hline & $\begin{array}{l}\text { Aportar evidencia empírica } \\
\text { sobre el papel moderador } \\
\text { de la colaboración } \\
\text { empresarial en la } \\
\text { innovación y el desempeño } \\
\text { empresarial: }\end{array}$ & $\begin{array}{l}\text { a. que la colaboración del canal potencia el éxito } \\
\text { innovador } \\
\text { b. que la colaboración de asesoría potencia el éxito } \\
\text { innovador }\end{array}$ & $\begin{array}{l}\text { Cuarta parte - } \\
\text { sección 4.4.3. }\end{array}$ \\
\hline
\end{tabular}




\subsection{Estructura de la Tesis Doctoral}

Esta investigación es el compendio de tres estudios empíricos independientes, para ser publicados en revistas científicas del área, pero que guardan una relación explicativa lógica que sigue un plan previamente establecido. Para efectos de presentar la defensa de la tesis doctoral se ha optado por agrupar los tres artículos en bloques comunes. Aunque cada artículo contiene su propio marco lógico, se ha intentado aglomerar lo máximo posible para crear una estructura uniforme. No obstante, algunas partes no se podrán unir, como serán las explicaciones de los resultados empíricos y las conclusiones específicas. En total la estructura final corresponde a seis partes.

La primera parte está comprendida por la introducción. Las secciones que la integran tratan de explicar la manera como se ha abordado el problema que se ha planteado en la justificación y cuál será su contribución, o sea, la forma va a beneficiar la investigación a los ejecutores. También se aporta el interés, la utilidad y novedad del proyecto. Por otro lado, se plantean los objetivos de la investigación, subdividiendo en objetivos teóricos y empíricos, como soluciones concretas a las causas y consecuencias del problema que se ha planteado resolver. Por último explica la estructura lógica que seguirá la investigación.

La segunda parte establece las bases teóricas que esboza las investigaciones más sobresalientes y el marco conceptual que atañe al tema a investigar, además, se discuten los pilares teóricos y la revisión literaria sobre la adopción de la innovación, sus resultados y los efectos que la condicionan. Con la investigación preliminar sobre artículos científicos del área y libros, se ha podido diseñar el estudio empírico para poder orientar el análisis de los datos recolectados.

En este apartado se confluyen los pilares teóricos que han permitido formular y desarrollar los argumentos que apoyan el planteamiento de las hipótesis de trabajo y las cuestiones de investigación. De esta manera se abordan los objetivos específicos teóricos resultando la siguiente estructura. La sección [2.1.] analiza la definición, medición e interpretación del concepto de innovación multidimensional, especialmente desde la perspectiva incremental; y radical. La sección [2.2.] y [2.3.] profundizan en el paradigma del éxito de la innovación desde la aportación de la innovación a los resultados empresariales. El 
capítulo [2.4.] explora el papel los factores empresariales en el éxito de la innovación y el desempeño. La sub-sección [2.4.1.] repasa la noción teórica de los factores organizacionales de la cultura organizativa y el tamaño de la empresa y su relación con la innovación. La subsección [2.4.2.] examina la importancia del dinamismo del entorno y su papel en la relación entre la innovación y el desempeño empresarial. Por último, la sub-sección [2.4.2.3.] analiza la definición y significación de la colaboración empresarial y su comportamiento en el éxito de la innovación

La tercera parte, corresponde al diseño y metodología general de la investigación que permitirá por medio de un conjunto de procedimientos e instrumentos lograr los objetivos específicos empíricos de la investigación. La sección [3.1.] comprende la propuesta de tres modelos para el análisis y el desarrollo de las cuestiones de la investigación. La sección [3.2.] expone el escenario de estudio, el contexto y las fuentes de información; se detalla la forma en que se han obtenido los datos; y el perfil de la muestra. La sección [3.3.] introduce las distintas herramientas y técnicas de análisis. La sección [3.4.] expone la medición de las variables.

La cuarta parte presenta la derivación empírica de los datos y su interpretación. Está compuesta por cinco secciones, las tres últimas analizan cada parte del modelo explicativo. La sección [4.1.] contiene el análisis de frecuencias; la sección [4.2.] está integrada por las matrices de relaciones que detallas las posibles correlaciones entre las variables; la sección [4.3.] incluye un análisis de comparación de medias para verificar si las medias son iguales o distintas sobre todo con la variable tamaño de la empresa que dirige el eje principal de la relación; la sección [4.4.] analiza las regresiones que dan explicación a las relaciones planteadas; por último, la sección [4.5.] presenta el resumen del contraste de las hipótesis de la investigación.

En la quinta parte, expone las principales conclusiones y las implicaciones fruto del presente estudio. La sección [5.1.] analiza el emprendedorismo y la orientación al mercado como precursoras de la innovación tomando en cuenta el papel del tamaño empresarial; La sección [5.2.] analiza los factores organizacionales y del entorno como moderadores de la relación entre innovación multidimensional y el desempeño empresarial, y la sección [5.3.] 
analiza el papel de la colaboración en el éxito de la innovación tomando en cuenta diferencias entre grandes y pequeñas empresas. Las dos últimas secciones reúnen las principales limitaciones y proponen las posibles líneas de investigación futuras.

En la sexta parte, el último apartado de la investigación, se indican las referencias bibliográficas y los anexos. 
Segundo capítulo

Marco teórico de la investigación 



\section{Marco teórico de la investigación}

La innovación empresarial, durante las últimas décadas se ha cristalizado dentro de la estrategia empresarial como una variable de importancia dentro de su entorno interno como externo y debe estar diseñada para usar las capacidades organizativas y así cumplir con los objetivos de la empresa (Norman, 1976; Freeman, 1984; Sandberg y Hofer, 1986). La creciente demanda de cambio conlleva a las organizaciones a implementar dentro de sus planeamientos estratégicos políticas agresivas de innovación para alcanzar importantes ventajas competitivas que les permita operar dentro del contexto actual y obtener posibilidades de alcanzar el éxito en el sector (Porter, 1980).

En este contexto actual, las empresas están presionadas a replantearse su postura ante el entorno competitivo que las rodea. Reconducir las estrategias competitivas y su cultura organizativa les puede ayudar a garantizar el éxito innovador. A esto se suma la necesidad de comprender el papel de varios factores internos y externos a la empresa que pueden ofrecer garantías de éxito, como por ejemplo: la orientación al mercado, la orientación emprendedora, el dinamismo del entorno y la colaboración organizacional.

\subsection{Innovación empresarial}

La innovación es un factor vital en la actividad empresarial. La innovación ha marcado el ritmo de crecimiento y el éxito del negocio (Drucker, 1985). En la era actual, la innovación, más allá del área de la tecnología, significa estar un paso adelante en comparación a sus rivales.

En muchos casos suele confundirse el término de innovación con invención. Esta distinción la aclaran Minguella y Balañá (1989: 16) afirmando que "la invención aparece cuando la posibilidad de realizar un producto nuevo o de utilizar un procedimiento de fabricación original está admitida o demostrada. La innovación propiamente dicha se manifiesta cuando -por primera vez- una empresa vende un producto nuevo o utiliza un procedimiento original, que se convierte en éxito comercial". Parece ser que cuando la invención acarrea un éxito comercial se traduce en innovación; es decir, se puede tener grandes resultados en la fase creativa pero no se logra el éxito en la fase ejecutiva, se puede 
correr el riesgo de tener una invención óptima; pero no tener una innovación relevante. Como dice Kotler (1996: 348) "una innovación es una invención exitosa desde el punto de vista comercial".

La tercera edición del Manual de Oslo define la innovación como:

\begin{abstract}
"la introducción de un nuevo, o significativamente mejorado, producto (bien o servicio), de un proceso, de un nuevo método de comercialización o de un nuevo método organizativo, en las prácticas internas de la empresa, la organización del lugar de trabajo o las relaciones exteriores" (OECD, 2005).
\end{abstract}

El concepto más amplio y generalizado de innovación empresarial en la literatura empírica se sintetiza como: la adopción de una nueva idea o práctica que puede dar inicio a la generación y/o comercialización nuevos productos o procesos productivos, la introducción de cambios en la gestión- organizativos, comerciales, financieros, o cambios socialesadministrativos, que están más relacionados con el factor humano de la organización (Damanpour, 1996; Boer y During, 2001). Es importante aclarar que cuando tratemos el término producto aplica tanto para bienes tangibles o manufacturas, ideas y servicios.

El concepto de innovación es mucho más extenso, en el cual se incluyen diferentes tipos según actividades, o el tipo de cambio que afecta. Para detallar más la amplitud conceptual, la literatura sobre innovación empresarial marca algunas clasificaciones que ayudan a esquematizarlo.

(1) Innovación incremental o radical: esta clasificación consiste principalmente por el grado de novedad y originalidad de la innovación. La distinción entre estos dos tipos de innovación, según Nieto (2000), se refieren a dos materias distintas: (1) la naturaleza continua o discontinua del proceso de innovación, y (2) la magnitud del impacto que ejercen las innovaciones a su entorno.

La definición teórica de la innovación incremental la encontramos en el Manual de Oslo, OECD (2005) que dice: 
"Las innovaciones incrementales se refiere a cambios productos o procesos "insignificantes", menores o que no involucran un suficiente grado de novedad, refiriéndose esta novedad a la estética u otras cualidades subjetivas del producto, especialmente cuando se añade (o quita, o combina, o resta, o suplanta) una parte a un producto o servicio.; son innovaciones progresivas que alimentan de manera continua el proceso de cambio" (OECD, 2005).

La innovación incremental está relacionada a la mejora de las estructuras existentes de forma gradual y no modifican sustancialmente la capacidad competitiva de la empresa a largo plazo (Mole y Worral, 2001). Como afirma Arceo (2010);

\begin{abstract}
"Este tipo de innovación está marcada por pequeñas reformas y avances adaptados posiblemente son sólo nuevas para la empresa porque son innovaciones que han sido incorporadas a partir del proceso de difusión de ideas procedente de otras actividades que no involucran un suficiente grado de novedad pero que sí constituyen un marco de continuidad para la satisfacción del cliente y la mejora del desempeño en cuanto a la eficacia y eficiencia respecto a los productos (bienes o servicios). Se realizan dentro de estructuras existentes de forma gradual y no modifican sustancialmente la capacidad competitiva de la empresa a largo plazo".
\end{abstract}

La mayoría de las investigaciones científicas sobre la innovación se han enfocado a la innovación radical, más relacionada con las innovaciones tecnológicas de producto y de procesos, como grandes cambios que están ligadas a las grandes empresas por las inmensas capacidades y recursos con que cuentan. No obstante, poco a poco autores van enfatizando sobre la importancia de introducir al estudio la innovación incremental en caso de muestras de pequeñas empresas dado que este tipo de innovación es más habitual en ellas, tal como afirma Nieto (2000) que "las innovaciones incrementales aportan a las pequeñas otros tipos de innovaciones notecnológicas", como las organizativas y culturales, pero a la vez las pequeñas 
empresas, como dice Arceo (2010) "pueden ir dejando de lado la visión común de tratar las actividades de innovación como tareas especiales asignadas a equipos de proyecto o grupos de trabajo, puesto que la orientación estratégica marcada por una base innovadora incluye a toda la empresa y todo tipo de innovación”.

La definición teórica de la innovación radical la encontramos en el Manual de Oslo, que dice;

"Las innovaciones radicales incitan a nuevos productos y procesos, totalmente disímiles a los existentes; son novedosos y suponen un cambio de escenario y capaz de servir de inicio a una nueva trayectoria técnica, suponen aplicaciones fundamentalmente nuevas de una tecnología o una combinación original” (OECD, 2005).

La innovación radical consiste en aplicaciones fundamentalmente en el desarrollo de nuevos productos y procesos para nuevos mercados (Mole y Worral, 2001) es un variabilidad mayor que encubre un modelo tecnológico, contribuyendo a la creación de un nuevo modelo de comunicación deshabilitando a los anteriores por considerarse sus códigos inapropiados para su uso (Pedersen y Dalum, 2004); pueden generar grandes cambios que suponen una novedad para la empresa, para el sector y para el sistema económico porque puede suscitar nuevas estructuras sectoriales, ventajas competitivas abrumadoras, y además, causar nuevos formas de hacer las cosas o hasta nuevos tipos de industrias (Arceo, 2010).

(2) Innovación cultural u operativa: estas innovaciones van desde las iniciativas hasta la implementación de la innovación. El proceso de innovación cuenta con dos fases esenciales que permiten la implantación final de la innovación de un producto o proceso nuevo o mejorado y logre el éxito en el mercado: la fase creativa y la fase ejecutiva.

La innovación cultural, relacionada a la fase creativa, que es donde se generan y se gestan las ideas o decisiones, está más relacionada con el proceso creativo y pasan a ser innovaciones operativas cuando se implementan. La innovación cultural 
tiene impacto en distintas áreas funcionales de la empresa y en muchas personas y equipos disciplinarios dentro de ella porque estimula la aportación de ideas y la creatividad de las personas. La implementación efectiva de la innovación cultural consiste de "idea técnica" -mecanismos y criterios empleados para seleccionar y desarrollar ideas- con resultados predecibles, pero dependerá de los cambios progresivos en el know-how, en las capacidades y habilidades, y en las prácticas organizativas (Damanpour y Evan, 1984).

En cambio la innovación operativa, relacionada a la fase ejecutiva, se estructura para pasar de la idea al lanzamiento de un producto o servicio nuevo o mejorado, lo que incluye la definición detallada de las funciones, las especificaciones del producto, de sus partes y componentes de acuerdo con el proceso de montaje y fabricación y teniendo en cuenta su distribución y servicio postventa (Moorman y Miner, 1997).

(3) Innovación unidimensional y multidimensional: diversas investigaciones han estudiado la innovación de productos o procesos de forma unidimensional (Christensen y Bower, 1996; Baker y Sinkula, 2002). Dentro del esquema multidimensional, se entiende que las acciones de producto y procesos están más ligadas a la $\mathrm{I}+\mathrm{D}$ técnica $\mathrm{y}$; las acciones de organización y marketing están diseñadas por la I+D administrativa (Atuahene-Gima, 1995a). Del mismo modo, se ha medido la innova-ción como dos sub-componentes; la innovación técnica y la administrativa (Han et al., 1998; Damanpour y Evan, 1984). También, se han involucrado distintos componentes prácticos de la innovación como las acciones de organización marketing, producto y procesos (Atuahene-Gima, 1996; Lin y Chen, 2007). Por lo tanto, el desglose multidimensional implica que las empresas pueden ocuparse de distintas acciones de innovación para lograr el desempeño esperado (Lin y Chen, 2007).

Consecuentemente, los resultados de la empresa podrían depender de la congruencia entre distintos tipos de innovación más que de un solo tipo (Damanpour 1991; Cohen y Klepper, 1996b). De esta manera, como también lo afirma Mavondo et al. (2005), la creación una plataforma de innovación multidimensional puede 
proporcionar a las empresas nuevos caminos para el éxito tanto los resultados financieros y operacionales.

Según la clasificación de la innovación antes descrita, la innovación se puede alcanzar por diferentes vías o un conjunto de ellas, puede ser: (1) incluyendo pequeños cambios o cambios radicales que influyan en los procesos organizativos o productivos; (2) generando un clima organizacional de creatividad o llevando a la prácticas las ideas técnicas a la implementación y (3) introducirla por dimensiones (como la propuesta unidimensional o multidimensional). Ninguna es más importante o efectiva que la otra, lo esencial es convertir la idea en acción. No obstante, en este estudio se decanta por la innovación con elementos radicales y elementos incrementales, más orientada a la innovación operativa y maneja el concepto de uni y multidimensionalidad.

Aunque si bien es cierto que la innovación fomenta la competitividad de las empresas y les da vitalidad para sobrevivir en el mercado cambiante; existen factores que la determinan y barreras que la limitan (Barceló, 1994). En el caso de los factores determinantes del éxito de la innovación en la empresa, se advierte la existencia de tres tipos de factores: internos, estructurales y externos.

(a) Factores internos: se entiende como el conjunto de diversas características endógenas a la empresa, como pueden ser la comunicación interna rápida y efectiva; adecuada vigilancia tecnológica y comercial; integración y cooperación; métodos de control y planificación; reaccionar a las nuevas demandas del mercado, buen servicio técnico a los clientes, cualificación y cantidad de los recursos humanos, recursos financieros e infraestructura.

(b) Factores estructurales: dirección comprometida con el proyecto; dinámica abierta y aceptando el riesgo; estrategia innovadora; estructura organizativa flexible, dinámica.

(c) Factores del entorno: existencia de redes de servicio científico-tecnológicos; proximidad a parques o centros tecnológicos; red de cooperación con centros de investigación y universidades, captación de recursos humanos cualificados; 
políticas públicas de apoyo; adecuados sistemas de protección de la propiedad industrial; cooperación en I+D con otras empresas; y acceso a fuentes de financiación externas.

$\mathrm{Si}$ bien es cierto, existe una fuerte conciencia por parte de las empresas de la necesidad de innovar, pero muchas de ellas encuentran grandes barreras para desarrollar este tipo de actividades. Las barreras propician un clima negativo que inhibe a las empresas a desarrollar nuevos proyectos innovadores o desfavoreciendo el éxito en las fases intermedia del proceso. Relativo a las barreras que las empresas deben superar cuando deciden implantar procesos innovadores, se encuentran algunas modalidades que se encaminan en tres distintas direcciones: económicas, internas y externas.

(1) Barreras económicas: riesgo percibido, falta de financiación, alto coste de la innovación, retornos de la inversión a largo plazo.

(2) Barreras internas: poco personal cualificado, falta de información sobre la tecnología, cultura empresarial conservadora, falta de conocimiento del mercado.

(3) Barreras externas: legislación y normas, falta de oportunidades para cooperar, falta de conocimiento del mercado tecnológico, los clientes no desean los productos, facilidad de imitar o sustituir, falta de cooperación de los clientes.

\subsubsection{Innovación incremental, operativa y multidimensional}

El desglose multidimensional implica que las empresas pueden ocuparse de distintas acciones de innovación incremental para lograr el desempeño esperado. Los resultados de la empresa podrían depender de la congruencia entre distintos tipos de innovación más que de un solo tipo (Damanpour, 199; Cohen y Klepper, 1996b).

Dentro de este esquema multidimensional de la innovación incremental, el enfoque distingue entre: la innovación de organización, marketing, productos y procesos. 
(1) Innovación de organización: se refiere a las mejoras en los procesos de gestión y planeación de la empresa, cambios en la estructura organizativa y a los procesos administrativos, cambios en el sistema financiero y cambios sociales relacionados con el factor humano. Esos cambios afectan las políticas, la distribución de los recursos y otros factores asociados con la estructura social y organizacional (Daft, 1978; Damanpour, 1991; Afuah, 1998; Ravichandran, 2000; Zahra et al, 2000; OECD, 2005). En este caso la innovación de organización se relaciona específicamente con la estrategias, estructura, sistemas y personas -formación continua y la creación de un departamento de I+D. Por otra parte la innovación de organización busca externamente, la mejor estrategia de subcontratación, compra de licencias o patentes, fusiones con otras empresas, compra de empresas o bien, el establecimiento de colaboraciones tecnológicas con otras empresas.

(2) Innovación de marketing: aplica las nuevas tecnologías de la información para dirigir la introducción de cambios en los procesos de comercialización, relativo a las marcas, mercados, canales de distribución y aplicaciones de producto (Lin y Chen, 2007; OECD, 2005). En este caso la innovación de marketing compete a los cambios y mejoras en los componentes de la mezcla de marketing: producto, precio, promoción y plaza (Kotler y Armstrong, 1997; Afuah 1998); para aumentar el valor de los productos o para redefinir su comercialización.

(3) Innovación de producto: implica la introducción de cambios en algún momento del proceso de producción y comercialización del producto que pueden afectar al diseño, composición o presentación al mercado. Supone la mejora de la funcionalidad o singularidad del producto (funciones y especificaciones de sus partes y componentes), permitiendo aumentar el margen de la cuota de mercado (Storey, 1994; Utterback, 1994). Este tipo de innovación abarca diferenciación de productos mejorados, productos imitadores, productos sustitutos $\mathrm{y}$ complementarios. Los productos mejorados, que cumplen, ya sea con las exigencias del consumidor, o agregar algún valor agregado al producto. Los productos imitadores pueden que sean nuevos para la empresa pero ya conocidos en el mercado, pero desea aprovechar ese posicionamiento existente. Los productos sustitutos cumpliendo la misma función que algunos productos 
actualmente vigentes en el mercado pero con diferencias significativas o valor agregado; o sea, que puede ser consumido o usado en lugar del otro en alguno de sus posibles usos. Los productos complementarios son lo que poseen una relación de demanda directa.

(4) Innovación de procesos: representa las mejoras en las formas de producción del producto o servicio final que se ofrece (Utterback, 1994; Boer y During, 2001) o la adopción de una nueva idea que directamente influye en el resultado de producción (Daft, 1978) para disminuir costes de fabricación o tiempos de respuesta ante la demanda; o bien, una calidad más alta. Evalúa la incorporación de nuevas tecnologías y el desarrollo de nuevos métodos e instrumentos de gestión y de organización en sus procesos productivos para aumentar el valor de sus productos (Tidd et al., 2001). Afuah (1998) incluye la introducción de nuevos elementos en las operaciones tales como materiales de entrada, especificaciones de las tareas, mecanismos de flujo de tareas e información, y equipo usado para producir un producto o servicio.

\subsubsection{Innovación radical, operativa y multidimensional}

Dentro de este esquema multidimensional de la innovación radical, el enfoque distingue entre: el número de patentes registradas, actividad de I+D y el desarrollo de nuevos productos y nuevos mercados.

(1) Patentes registradas, es un indicador "output" de la actividad innovadora emprendida por las empresas o un país (Kemp et al., 2003). Se basa en la creación de tecnología propia y protegida a través de la propiedad industrial e intelectual. Normalmente están concentradas en determinados sectores específicos con estrategias de protección adecuadas. Arbussà et al. (2004) afirman que "las patentes distan de ser un instrumento perfecto y, en la práctica, su utilización es muy desigual entre sectores". Las limitaciones que puede presentar este "output" también consisten en que no todas las innovaciones son patentables, además, muchas patentes tienen un valor tecnológico y económico nulo, mientras que otras 
tienen un enorme valor (Pakes y Griliches, 1980; Scherer, 1983), aún así en el informe anual de la EIS (2006) la patente sigue viéndose como un indicador de la innovación.

(2) Actividades I+D, es un indicador "input" de la actividad innovadora emprendida por las empresas o un país (Kemp et al., 2003). Consiste en políticas investigación científica y desarrollo encaminada a la introducción de nuevos productos o procesos para satisfacer las necesidades en nuevos mercados. Se define como:

"el conjunto de trabajos creativos que se emprenden de modo sistemático a fin de aumentar el volumen de conocimientos, incluidos el conocimiento del hombre, la cultura y la sociedad, así como la utilización de esa suma de conocimientos para concebir nuevas aplicaciones (OECD, 2002).

Las estadísticas de I+D están relacionadas tanto a los gastos (corrientes y de capital) como al número del equipo implicado en estas actividades. Son los gastos en actividades de $\mathrm{I}+\mathrm{D}$ realizados en la empresa durante el año de referencia y sin importar el origen de los fondos. Estos gastos son tanto acarreados fuera o dentro de la empresa, siempre y cuando estén asociados al apoyo de las tareas de I+D. La página electrónica de Eustat (2012) clasifica los gastos de I+D de la siguiente manera.

Gastos de I+D: (1) gastos de personal: comprende el total de las remuneraciones del personal de cualquier tipo incluidos los seguros sociales a cargo de la empresa. (2) otros gastos corrientes: pequeño material y suministros diversos (gastos de material no considerados como bienes de equipo), energía (agua, gas, electricidad y cualquier otra fuente de energía), mantenimiento y pequeñas reparaciones, alquiler y limpieza de locales, compra de servicios (coste de utilización de ordenadores), retribución proporcional a la actividad del I+D del personal indirecto (seguridad, mantenimiento, etc.) y dietas de viaje. Se excluyen los gastos corrientes reales o imputados, en concepto de amortización. Gastos de capital: es la inversión bruta de capital en terrenos, edificios, trabajos importantes de mejora, material 
inventariable, instalaciones y equipo, realizada durante el período de referencia, por la empresa con destino a las actividades de $\mathrm{I}+\mathrm{D}$ cualquiera que sea la forma de financiación (Eustat, 2012).

Equipo de I+D: el capital humano dedicado a I+D constituye el fundamento del sistema de investigación e innovación. Cuando se aumenta la fuerza laboral destinada a las actividades I+D se robustece el pilar de la innovación empresarial. El objetivo en este caso debe centrarse en la creación y/o consolidación de departamentos estables de I+D en los centros de trabajo de las empresas, integrando a científicos y técnicos en la plantilla de la empresa, personas quienes finalmente ejecutan las actividades de $\mathrm{I}+\mathrm{D}$ y realicen actividades innovadoras. Para ello se debe tomar en cuenta que la formación es básica para potenciar el recurso humano y, además, provee talento innovador e investigador a la empresa. Hernani (2009:179) como bien expuso en su ensayo;

"La formación permite dotar a los profesionales de las capacidades necesarias en materia de innovación. De este modo, se articulan instrumentos para la formación en ámbitos tanto de gestión (como por ejemplo en la creación de patentes, internacionalización de la I+D, oportunidades públicas de financiación, etc.), como de especialización científico-tecnológica. Esta formación persigue dotar a las personas de una mayor empleabilidad respondiendo a los retos sociales actuales y a la estrategia de país entorno a la innovación".

Cabe mencionar como anexo a este punto que también se está profundizando en las empresas que introducen algún tipo de innovación pero sin contratar actividades de I+D conocidas como NID, o sea, no basadas en I+D. Santamaría et al. (2009) han estudiado las fuentes de innovación de estas empresas y han analizado el rol adoptado por otras actividades distintas a los procesos de $\mathrm{I}+\mathrm{D}$, como el diseño, la formación, la vigilancia tecnológica y el uso de tecnología avanzada. 
(3) Desarrollo de nuevos productos y mercados, es un indicador "output" de la actividad innovadora emprendida por las empresas o un país (Kemp et al., 2003).

Desarrollo de nuevos productos: consiste realmente en inventar e innovar en productos realmente únicos, que no existen sustitutos y que cumplen al máximo con las expectativas de los consumidores para lograr una adecuada competitividad en el mercado. Los ventajas resultantes de ser los precursores en el mercado competitivo son: el éxito de se el líder en la cuota de mercado, aumento en el crecimiento de las ventas, la obtención de la lealtad de los consumidores, entre otras (González et al. (1997). Las fases de la inventiva hasta la producción de un nuevo producto comprenden escalones progresivos, algunas de ellas pueden realizarse al mismo tiempo bajo una coordinación y sincronía apropiada. Estos escalones progresivos hacia el lanzamiento de un nuevo producto al mercado son: creación de ideas, selección de ideas o tamizado, análisis del negocio, desarrollo del producto, mercado de prueba, comercialización. No se profundizará en ellos porque no es el objetivo del estudio.

Desarrollo de nuevos mercado: Jaworski et al. (2000) exponen acerca de una composición conceptual para examinar la variedad de formas en que las empresas pueden dirigir o crear una forma de mercado; principalmente, los autores recomiendan cambiar dos ejes: la estructura y el comportamiento de los participantes. En la estructura: cambiando proactivamente la presencia de ciertos participantes, logrando alterar fundamentalmente los papeles y funciones desempeñados por uno o más agentes; y en el comportamiento: consiguiendo que los consumidores se centren en atributos del producto que antes no eran considerados o proporcionando ofertas totalmente nuevas para el mercado. Por lo tanto, la conformación de nuevos mercados abarca cambios en el producto, en el mercado y en la industria con el fin de crear un nuevo valor y señalar nuevas pautas en el mercado.

De la misma manera, Kumara et al. (2000) afirman que el éxito de las empresas precursoras en la creación de nuevos mercados han "revolucionado 
industrias existentes aplicando una innovación de negocio radical” en dos dimensiones: un impulso atributivo en la oferta de valor y la implementación de una técnica de negocio único. Esto se aplica a una adecuada filosofía sobre la conducción del mercado (market-driving) relacionada con "visión del emprendedor" o directivos.

\subsection{3. Éxito de la innovación empresarial}

La innovación puede alcanzar su valor de éxito cuando logra alinear la innovación con otros factores internos y externos a la empresa para que los resultados de la innovación no solo signifiquen avances futuristas sino que esté cerca de los clientes y estos estén dispuestos a aceptarlos y adquirirlos. En primer lugar, las empresas deben estar conscientes de sus posibilidades dependiendo de la magnitud de sus recursos y capacidades.

En segundo lugar, las empresas deben de tomar en cuenta la manera de adoptar una cultura organizativa que no sólo fomente la innovación sino su éxito a través de una plataforma orientada en las personas, orientada al cliente, con el fin de obtener su lealtad.

En tercer lugar, las empresas deben conocer, cómo puede canalizar su actitud emprendedora, una auténtica actitud innovadora, centrada en una mentalidad crítica, abierta y arriesgada, que ayude a detectar lo que ocurre en su entorno (consumidor, mercados, otros sectores, otros países, etc.) y estar dispuesto y preparado para adaptarse al cambio.

En cuarto lugar, es trascendente para el éxito de la innovación empresarial la constante supervisión de los cambios ocurridos en el entorno, aquellos que no se pueden controlar, relacionados con los procesos y técnicas de producción, cambios en la demanda, nuevos productos o estrategias innovadoras o políticas agresivas de la competencia.

En quinto y último lugar, es primordial que las empresas estén abiertas a la colaboración en los procesos de innovación. Una colaboración abierta que refuerce las fortalezas y mitigue las debilidades, que potencie sus recursos y brinde conocimiento. 
A continuación se tratan con detalle cada uno de estos pilares que determinan, condicionan o modifican el éxito innovador. Para ellos, se apoyan las distintas relaciones con base a la literatura teórica y empírica existente. El abordaje de esta sección da soporte teórico a las hipótesis de la investigación.

\subsection{Antecedentes de la innovación empresarial}

\subsubsection{Papel de la cultura organizativa en la innovación}

De acuerdo a los postulados de la teoría de recursos y capacidades (Barney, 1991; Grant, 1991; Mahoney y Pandian, 1992; Peteraf, 1993; Collis y Montgomery, 1995), los recursos, por sí mismos, no se consideran factores determinantes para generar una ventaja competitiva respecto a su competencia, es necesario que esos recursos se manejen de manera coordinada para lograr rendimientos superiores.

Los recursos organizativos requieren de las capacidades organizativas para que el conjunto de esos recursos se combinen. Una adecuada combinación de recursos puede generar ventajas competitivas (Peteraf, 1993; Santos et al., 2002). La orientación al mercado y la orientación emprendedora, actúan como capacidades organizativas claves para contribuir en el corto o largo plazo a los resultados del negocio (Pelham y Wilson, 1996; Santos et al., 2002; Day, 1994) y de esta manera, crear ventajas competitivas sostenibles (Barney, 1991; Grant, 1996; Mahoney y Pandian, 1992; Peteraf, 1993); es decir, estas capacidades permiten adoptar una orientación estratégica -hacia la innovación o - estrategia proactiva según la clasificación de la orientación estratégica de Miles y Snow (1978).

Las capacidades organizativas son por su naturaleza intangibles y residen dentro de la organización. Se caracterizan por su complejidad en conocimiento, habilidades, cultura y experiencia acumulada a lo largo del tiempo, las cuales, son necesarias para desarrollar distintas actividades en complejos procesos de coordinación y cooperación entre los individuos y los recursos (Grant, 1996; Peteraf, 1993). Asimismo, una empresa puede adquirir una ventaja competitiva sostenible sobre su competencia, si amplifica sus capacidades claves para el desarrollo de su negocio (Teece et al., 1997). 
Según Santos et al. (2002) a través de las capacidades claves (para lograr el desarrollo de las acciones innovadoras, incrementales y/o radicales), como parte integrante de la estrategia, pueden alcanzar una mayor competitividad, y por ende, mejores resultados dentro de la organización. Hult et al. (2003), llama a estas capacidades organizativas competitividades culturales que son el grado en el cual una organización está predispuesta a detectar y llenar las falencias en el momento en el que el 'mercado desea' y la 'oferta circula' dentro del mercado. Las competitividades culturales son capacidades que actúan como guía a los directivos para crear ventajas competitivas por medio de su énfasis estratégico (Hult et al. 2002). Dentro de esta interpretación, la orientación al mercado y la orientación emprendedora pueden considerarse capacidades claves para el desarrollo de la estrategia empresarial y su competitividad con el fin de lograr mejores resultados dentro de la organización (Narver y Slater, 1990; Deshpandé et al., 1993, Pelham y Wilson, 1996).

\subsubsection{Papel de la orientación al mercado en la innovación}

Existen diferentes conceptualizaciones de orientación al mercado y por tanto varían sus interpretaciones (Rapp et al., 2008). Sin embargo, el enfoque de la orientación al mercado que se establece en este estudio, es el señalado por Jaworski y Kohli (1990) y Narver y Slater (1990), refiriéndose a la orientación al mercado como una cultura organizativa que promueve valores relacionados con el seguimiento del mercado para poder ofrecer mayor valor a los clientes de la empresa. Para el objetivo de investigación, satisface el término de la orientación al mercado como una capacidad organizativa desde la óptica de la teoría de recursos y capacidades (Hunt y Morgan, 1996).

Dos enfoques han predominado en la conceptualización de la orientación al mercado. Por un lado, Narver y Slater (1990) proponen tres componentes clave en la orientación al mercado: orientación al consumidor, orientación a la competencia y coordinación interfuncional. Todo ello combinado con un énfasis en el beneficio y una visión a largo plazo. Por otro lado, Kohli y Jaworski (1990) desglosan las actividades vinculadas a la orientación al mercado conforme a tres finalidades: generación de inteligencia, diseminación de inteligencia y respuesta. La generación de inteligencia hace referencia a la recogida de información relevante del entorno de la organización. La diseminación de inteligencia se 
refiere a la distribución interna y análisis compartido de esta información entre las unidades funcionales implicadas. Finalmente, la respuesta hace referencia a la capacidad de reacción de la empresa adaptando sus estratégicas a las condiciones percibidas del entorno (tomado de: González-Benito y González-Benito, 2005).

La orientación al mercado es parte de la cultura organizativa que promueve valores relacionados con el seguimiento del mercado para poder crear y ofrecer mayor valor a los clientes (Llonch-Andreu y López, 1999). Como señalábamos anteriormente la orientación al mercado engloba un conjunto de valores, creencias, actividades, procesos y comportamientos derivados de la implantación del concepto de marketing (Kohli y Jaworski, 1990). Concretamente, cuando se habla de la orientación al mercado, se está enfocando al manejo de los recursos hacia la generación de inteligencia de mercado -market intelligence (Hult et al., 2003) que se construye a través de fuentes secundarias o contactos personales y se pueden potencial con el uso de las nuevas tecnologías de la información (Verhess y Meulenberg, 2004), esa información obtenida se usa para "desarrollar estrategias que permitan conocer las necesidades de los clientes e implementar esas estrategias para responder a los gustos y preferencias de los clientes" (Ruekert, 1992: 228), logrando de esta manera afectar los perfiles estratégicos de la innovación incremental y radical (Narver y Slater, 1990; Day, 1994; Hult et al. 2003).

La Tabla 13 muestra algunos estudios que relacionan la orientación al mercado con distintas acciones operativas de la innovación. Algunos autores afirman que la orientación al mercado actúa como precedente para alcanzar comportamientos innovadores, o sea, actividades de cambio de organización, marketing, producto y procesos (Day, 1994; Slater y Narver, 1994; Pelham y Wilson, 1996; Han et al. 1998; Pelham, 2000; Sin et al., 2000; Santos et al., 2002; Verhess y Meulenberg, 2004; Kara et al., 2005). De hecho, existen diversos estudios que han encontrado una relación cercana entre la orientación al mercado y la innovación (Slater y Narver, 1996; Appiah-Adu y Singh, 1998; Atuahene-Gima y Ko, 2001; Vázquez et al., 2001; Matear et al., 2002; Maydeu-Olivares y Lado, 2003), por lo que se deduce que la orientación al mercado afecta de manera positiva a las acciones de organización, procesos productivos, producto y marketing. 
No obstante, existe cierta controversia respecto esta relación, por hallarse un posible efecto negativo en las acciones de innovación; por ejemplo, Appiah-Adu y Ranchhod (1998) y Atuahene-Gima (1995b, 1996) encontraron que no existía una relación directa de la orientación del mercado y las acciones de innovación de producto. Por otra parte, Phelps 2010 et al. (2002) y Golden et al. (1995), no encontraron una relación directa de la orientación al mercado y las acciones de innovación de marketing (actividades de promoción, precios y enfoque en marca) o de-Luca et al. (2010) no encontró una relación significativa de la orientación al mercado y las actividades de I+D.

En resumen, se puede observar en la Tabla 13 que los investigadores han estudiado la orientación al mercado como antecedente de acciones innovadoras de organización, usualmente el efecto es positivo, excepto en Aldas-Manzano et al. (2005). De hecho, Pelham y Wilson (1996), consideraron en su modelo que la orientación al mercado influye de manera significativa en la estrategia de la empresa. Afirman los autores que una empresa que está orientada al mercado es fuerte externamente, porque se preocupa en las mejoras del producto para satisfacer al cliente y en las acciones del marketing, pero también es fuerte internamente porque mejora las acciones organizativas y los procesos productivos.

De la misma manera, la relación con las acciones innovadoras en marketing suele ser positiva excepto para Zhou et al. (2005). El mayor valor que logra una empresa orientada al mercado es la satisfacción del cliente, a través de la orientación al cliente, proporcionando, con antelación, el conocimiento del cliente en diversos procesos de innovación. Esta satisfacción se logra porque la empresa responde de manera positiva y rápida a la información que el cliente proporcione para enfocar la actividad de $\mathrm{I}+\mathrm{D}$ en proyectos viables. Al controlar la información que dan los consumidores y responder a sus necesidades se logra la retención y la fidelidad del cliente, logrando de esta manera, un efecto positivo en las ventas y en la cuota de mercado (Slater y Narver, 1994; Pelham y Wilson, 1996).

Por otra parte, esta fuente de estímulos, sirve para crear nuevas ideas que conlleven a nuevos proyectos de investigación y desarrollo (I+D) y nuevas patentes para la empresa (registradas, emitidas, vendidas o autorizadas por licencias) logrando a la vez, una alineación de distintos departamentos funcionales de la empresa, por medio de la coordinación 
interfuncional para mantener estrecha colaboración entre las subunidades de marketing e I+D (Narver y Slater, 1990; Santos y Vásquez, 1997; Li, y Calantone, 1998).

Como es de esperarse, la mayoría de las investigaciones relacionan esta cultura organizativa con la innovación incremental de producto y el desarrollo de nuevos productos. En general, el efecto de esa relación es positivo, excepto para Christensen y Bower (1996), Aldas-Manzano et al. (2005) y Keskin (2006) y muy débil para Salavou y Lioukas (2003). Cooper, 1984, afirmaba que la empresa orientada al mercado debe conocer el entorno de mercado en que se desempeña para reducir los fallos en la caracterización del producto. La orientación al mercado está relacionada con el producto porque promueve su éxito y mejora (Slater y Narver, 1994; Appiah-Adu y Singh, 1998).

Cuando se relaciona la orientación al mercado con la innovación de procesos, el efecto generalmente es positivo, aunque en algunos estudios es negativo (Atuahene-Gima, 1996; Lukas y Farrell, 2000; Aldas-Manzano et al., 2005; Keskin, 2006). Pelham y Wilson (1996), afirman que la orientación al mercado favorece las innovaciones en los procesos productivos por medio de la retroalimentación del mercado ya que la supervisión constante de los cambio en la demanda permite a la empresa innovar en costes de producción, tiempos de respuesta, y procesos más eficientes.

Entonces, ¿actúa la orientación al mercado como determinante de la innovación? Los conceptos de orientación al mercado e innovación son independientes pero potencialmente podrían interactuar (Berthon et al., 2004) porque la orientación al mercado requiere de respuestas innovadoras para las diferentes condiciones del mercado (Lee y Tsai, 2005).

Al parecer las empresas más orientadas al mercado son más innovadoras porque son más conscientes de las demandas de los clientes y pueden actuar rápidamente ante sus necesidades y adaptarse a sus gustos y preferencias (Jaworski y Kohli 1990; Narver y Slater, 1990; Deshpandé et al, 1993; Baker y Sinkula, 1999a y 1999b; Deshpandé y Farley, 1999a y 1999b). La evidencia anterior sobre la relación entre la orientación al mercado y la innovación hace plantear la formula hipotética: 
P1: ¿actúa la orientación al mercado como condicionante en la innovación empresarial?

H1: la orientación al mercado tiene un efecto positivo en la innovación, es decir, cuanto mayor es la orientación al mercado, mayor es la innovación empresarial.

H1a: la orientación al mercado está relacionada positivamente con la innovación incremental.

H1b: la orientación al mercado está relacionada positivamente con la innovación radical. 
Tabla 13

Estudios que evidencian que la orientación al mercado tiene un efecto en la innovación: según tipo de innovación y tamaño de la empresa

\begin{tabular}{|c|c|c|c|c|c|c|c|c|}
\hline \multirow{2}{*}{$\begin{array}{l}\text { Estudio } \\
\text { empírico }\end{array}$} & \multirow{2}{*}{ Población analizada } & \multicolumn{4}{|c|}{ Innovación incremental } & \multicolumn{3}{|c|}{ Innovación radical } \\
\hline & & $\begin{array}{l}\text { Innovación de } \\
\text { organización }\end{array}$ & $\begin{array}{l}\text { Innovación } \\
\text { de marketing }\end{array}$ & $\begin{array}{l}\text { Innovación } \\
\text { de producto }\end{array}$ & $\begin{array}{l}\text { Innovación } \\
\text { de procesos }\end{array}$ & $\begin{array}{l}\text { Patentes } \\
\text { registradas }\end{array}$ & $\begin{array}{l}\text { Actividades } \\
\text { de I+D }\end{array}$ & $\begin{array}{c}\text { Des. nuevos } \\
\text { productos y } \\
\text { mercados }\end{array}$ \\
\hline $\begin{array}{l}\text { Aldas-Manzano et } \\
\text { al. (2005) }\end{array}$ & $\begin{array}{l}\text { España, } 465 \text { grandes y pequeñas empresas de } \\
\text { textil }\end{array}$ & - & $x$ & - & - & $x$ & $x$ & $x$ \\
\hline $\begin{array}{l}\text { Atuahene-Gima } \\
(1995 b)\end{array}$ & Australia, grandes empresas, mixto sectores & $x$ & $x$ & + & $x$ & $x$ & $x$ & + \\
\hline $\begin{array}{l}\text { Atuahene-Gima } \\
\text { (1996) }\end{array}$ & Servicios, grandes empresas & + & + & + & - & $x$ & $x$ & + \\
\hline $\begin{array}{l}\text { Baker y Sinkula } \\
(2002)\end{array}$ & 400 grandes y pequeñas, industria y comercio & $x$ & $x$ & + & $x$ & $\mathrm{x}$ & + & + \\
\hline $\begin{array}{l}\text { Christensen y } \\
\text { Bower (1996) }\end{array}$ & Grandes y pequeñas, industria y comercio & $\mathrm{x}$ & $x$ & - & $x$ & $x$ & $x$ & - \\
\hline $\begin{array}{l}\text { de-Luca et al. } \\
(2010)\end{array}$ & Italia, 50 empresas high-tech & $x$ & + & + & $x$ & + & + & + \\
\hline $\begin{array}{l}\text { Deshpandè et al } \\
\text { (1993) }\end{array}$ & Japón, grandes y pequeñas empresas & + & $x$ & $\mathrm{x}$ & $x$ & $x$ & $x$ & $x$ \\
\hline $\begin{array}{l}\text { Gatignon y } \\
\text { Xuereb (1997) }\end{array}$ & USA, grandes empresas, industria y comercio & $\mathrm{x}$ & $x$ & + & $\mathrm{x}$ & $x$ & $x$ & + \\
\hline Han et al. (1998) & 134 grandes empresas, banca & + & + & + & + & $x$ & $x$ & + \\
\hline $\begin{array}{l}\text { Hernard y } \\
\text { Szymanski(2001) }\end{array}$ & $\begin{array}{l}\text { Grandes y pequeñas empresas, industria y } \\
\text { comercio }\end{array}$ & $x$ & $x$ & + & $x$ & $x$ & $x$ & + \\
\hline Hult et al. (2004) & 181 grandes empresas, industria y comercio & + & + & + & + & $x$ & $x$ & + \\
\hline
\end{tabular}




\begin{tabular}{|c|c|}
\hline $\begin{array}{l}\text { Hurley y Hult } \\
\text { (1998) }\end{array}$ & USA, servicios, grandes empresas \\
\hline $\begin{array}{l}\text { Jaworski y Kohli } \\
\text { (1993) }\end{array}$ & Grandes empresas, industria y comercio \\
\hline $\begin{array}{l}\text { Jaworski et al. } \\
(2000)\end{array}$ & Grandes empresas \\
\hline Keskin (2006) & Turquía, 157 pequeñas empresas, mixto sec. \\
\hline $\begin{array}{l}\text { Lado y } \\
\text { Maydeu/Olivares } \\
\text { (2001) }\end{array}$ & $\begin{array}{l}\text { Bélgica, España y USA, seguros, grandes y } \\
\text { pequeñas }\end{array}$ \\
\hline Lee y Tsai (2005) & $\begin{array}{l}\text { Taiwán, } 337 \text { grandes y pequeñas, manufactura } \\
\text { y servicios }\end{array}$ \\
\hline $\begin{array}{l}\text { Li y calantone } \\
\text { (1998) }\end{array}$ & Grandes y pequeñas empresas, mixto sec. \\
\hline $\begin{array}{l}\text { Low and Sloan } \\
(2007)\end{array}$ & $\begin{array}{l}\text { Australia, } 73 \text { pequeñas empresas, } \\
\text { industria/manufacturera }\end{array}$ \\
\hline $\begin{array}{l}\text { Lukas y Ferrell } \\
(2000)\end{array}$ & $\begin{array}{l}194 \text { pequeñas empresas, } \\
\text { industria/manufactura }\end{array}$ \\
\hline $\begin{array}{l}\text { Mavondo y Farrell } \\
\text { (2003) }\end{array}$ & $\begin{array}{l}\text { Zimbabue, } 176 \text { pequeñas empresas, } \\
\text { manufactura de alimentos }\end{array}$ \\
\hline $\begin{array}{l}\text { Mavondo et al. } \\
(2005)\end{array}$ & 227 pequeñas empresas, servicios de salud \\
\hline $\begin{array}{l}\text { Narver y Slater } \\
(1990,1998) \\
\text { Slater y Naver } \\
(1994 a, \\
\text { 1994b,1995, } 1998 \\
1999)\end{array}$ & Grandes empresas, industria y comercio \\
\hline $\begin{array}{l}\text { Narver et al. } \\
(2004)\end{array}$ & Grandes empresas, industria y comercio \\
\hline
\end{tabular}

\begin{tabular}{|c|c|c|c|c|c|}
\hline+ & + & + & + & $x$ & $x$ \\
\hline$x$ & $x$ & + & + & $x$ & $x$ \\
\hline$x$ & $x$ & + & + & $x$ & $x$ \\
\hline$x$ & $x$ & - & - & $x$ & $x$ \\
\hline & & & & $x$ & $x$ \\
\hline+ & + & + & $t$ & $x$ & $x$ \\
\hline$x$ & $x$ & + & + & + & + \\
\hline+ & $x$ & $x$ & $x$ & $x$ & $x$ \\
\hline$x$ & $x$ & - & $x$ & $x$ & $x$ \\
\hline+ & + & + & + & $x$ & $x$ \\
\hline+ & + & + & + & $x$ & $x$ \\
\hline & & & & + & + \\
\hline$x$ & $x$ & + & $x$ & & \\
\hline$X$ & $x$ & + & $x$ & $x$ & $X$ \\
\hline
\end{tabular}




\begin{tabular}{l|l}
$\begin{array}{l}\text { Rapp et al. (2008) } \\
\begin{array}{l}\text { Santos y Vásquez } \\
(1997)\end{array}\end{array}$ & $\begin{array}{l}\text { Bélgica, 369 grandes empresas, industria y } \\
\text { comercio }\end{array}$ \\
$\begin{array}{l}\text { Salavou y } \\
\text { Lioukas (2003) }\end{array}$ & Grecia, 69 pequeñas empresas \\
$\begin{array}{l}\text { Salavou et al. } \\
\text { (2004) }\end{array}$ & $\begin{array}{l}\text { Grecia, } 124 \text { pequeñas empresas; industria, } \\
\text { alimento, bebida y textil }\end{array}$ \\
$\begin{array}{l}\text { Verhees y } \\
\text { Meulenberg } \\
\text { (2004) }\end{array}$ & Holanda, 152 pequeña empresa, agrícola \\
Zhou et al. 2005) & China, 350 grandes y pequeñas, industria
\end{tabular}

\begin{tabular}{|c|c|c|c|c|c|c|}
\hline+ & $x$ & $X$ & $x$ & $x$ & $x$ & \\
\hline$x$ & $x$ & + & + & $x$ & + & + \\
\hline$x$ & $x$ & 0 & $x$ & $x$ & $x$ & \\
\hline$x$ & $x$ & + & $x$ & $x$ & + & + \\
\hline & & & & $x$ & $x$ & + \\
\hline$X$ & $x$ & + & $x$ & & & \\
\hline$x$ & - & $x$ & + & $x$ & $x$ & $\mathrm{x}$ \\
\hline
\end{tabular}

Fuente: elaboración propia.

(+) Efecto positivo de la orientación al mercado en la acción innovadora / (-) efecto negativo de la orientación al mercado en la acción innovadora / (x) no se toma en cuenta esa actividad innovadora / (0) no es significativa la relación 


\subsubsection{Papel de la orientación emprendedora en la innovación}

Según Entrialgo et al. (2001), el primer antecedente de la orientación emprendedora fue encontrado en el concepto de "empresario" de Schumpeter en 1942, donde este afirmaba que "los empresarios son los responsables de administrar y llevar a cabo nuevas combinaciones"; pero fue Cantillon en 1975, dice la autora, quien formalmente utilizó el término entrepreneurship.

La orientación emprendedora ha sido estudiada en numerosos estudios, con especial atención en el área del management (Covin y Slevin, 1989; Dess, Lumpkin y Covin, 1997; Mitchell y Smith, 2000). La orientación emprendedora o emprendedorismo es tradicionalmente entendida por la composición: orientación innovadora, propensión al riesgo y proactividad (Miller, 1983; Morris y Paul, 1987; Covin y Slevin, 1989; Davis et al., 1991; Miles y Arnold, 1991; Naman y Slevin, 1993; Covin y Miles, 1999; Slater y Narver, 2000; Kemelgor, 2002).

La orientación innovadora se interesa por promover nuevas ideas, experiencias y procesos creativos que podrían implantarse para el desarrollo o mejora de nuevos productos/servicios, tecnologías o procesos (Covin y Miles, 1999) y la diversificación de la empresa (Burgelman, 1991) y convertir las ideas en acciones colectivas (Chung y Gibbons, 1997). La propensión al riesgo es la actitud de asumir proyectos arriesgados aunque de manera calculada, es decir, habiendo valorado la probabilidad de fallo. La proactividad es un comportamiento pionero de cara al futuro tomando en cuenta las contingencias y reacciones de la competencia. El conjunto de estos tres tiene como objetivo promover y favorecer la introducción de innovaciones en la empresa y la búsqueda constante de nuevas oportunidades (Miller y Friesen, 1982).

Una empresa emprendedora es aquella que evalúa el riesgo para desarrollar y ejecutar proyectos creativos e innovadores para anticiparse a los cambios del entorno y a las acciones agresivas de la competencia y así aprovechar, explotar y comercializar las oportunidades para convertirlas en ventajas competitivas y buen desempeño (Zahra y Covin, 1995). Miller y Friesen (1982) resume el concepto diciendo que las empresas emprendedoras se animan a innovar con valentía y regularidad mientras toman riesgos considerables en sus estrategias de productos y de mercado. 
Desde el punto de vista de la teoría de recursos y capacidades, la orientación al mercado es un factor organizacional cultural clave para la acumulación y el apalancamiento de recursos que favorezcan los objetivos competitivos que fortalecen la posición de la empresa en el mercado (Covin y Miles, 1999).

La orientación emprendedora, afirma Hult et al. (2003), es una fuerza de disrupción dentro del equilibrio empresarial que promueve la creación y aplicación de nuevas combinaciones de recursos, por lo tanto, la orientación emprendedora es una capacidad organizativa que se encuentra en las empresas que llevar a cabo estrategias innovadoras y proactivas. La orientación emprendedora se convierte en una dimensión de la estrategia (Messenghen, 2003) por su fuerte relación con las acciones de innovación dentro de la orientación estratégica de la empresa.

Entonces ¿actúa el comportamiento emprendedor como antecedente de la innovación? Estudios previos sugieren que la orientación emprendedora dirige la actividad innovadora (Covin y Slevin, 1991; Russell y Russell, 1992; Kitchell, 1995).

La Tabla 14, muestra una selección de trabajos que han contrastado la relación entre emprendedorismo e innovación, y la gran mayoría ha llegado a la conclusión de que sí existe una relación significativa entre ambos constructos, por lo tanto, la orientación emprendedora antecede, promueve y es un importante conductor de las acciones de innovación, indistintamente del tipo que sea (Miller 1983; Slater y Narver 1995; Hult et al., 2004; McFadzean et al., 2007).

En muchos de estos estudios se ha utilizado el concepto de innovación unidimensional, enfocándose especialmente en acciones de innovación de producto y/o en procesos productivos (Drucker, 1985; Slater y Narver, 1995; Lumpkin y Dess, 1996; Salavou y Lioukas, 2003; Hsueh y Tu, 2004; Zhou et al. 2005; Lassen et al., 2006; Avlonitis y Salavou, 2007; Lee y Sukoco, 2007; McFadzean et al., 2007).

Liu et al. (2000) encontró evidencia de la relación entre la orientación emprendedora y los cambios en los procesos organizacionales y descubrieron la relación de la orientación emprendedora potencia las técnicas de gestión avanzada. 
Menos esfuerzos se han realizado por encontrar evidencia de la relación con la innovación de marketing (Lumpkin y Dess, 1996). Con la orientación emprendedora, el marketing se convierte en un medio útil para llevar a cabo las actividades de la empresa en el mercado y luchar por satisfacer las necesidades del cliente en medio de las acciones agresivas de la competencia (Morris y Paul, 1987; Hills y LaForge, 1992).

Por un lado, la relación de la orientación emprendedora y el producto está estrechamente enlazada a la unión entre la orientación emprendedora y el desarrollo o mejora de nuevos productos (Drucker, 1985; Lumpkin y Dress, 1996; Hsueh y Tu, 2004; Li et al., 2006). Esta relación permite que en un ambiente emprendedor se exploren y mejoren los productos para satisfacer las necesidades de los clientes, aunque esta inversión alberge riesgos (Biggadike, 1979).

El estudio de Messenghen (2003) contrastó la asociación entre orientación emprendedora y las características de la organización (específicamente en procesos de producción) y demostró que la relación es positiva y significativa.

Aunque mucho tienen que ver la importancia de un comportamiento emprendedor para generar actividades de investigación y desarrollo, poco se ha estudiado al respecto. Este tema los han analizado desde la óptica de las ciencias biotecnológicas y farmacéuticas. En el estudio de Frank et al. (2010) se remarca la importancia promover conductas empresariales orientadas acciones proactivas como catalizadoras y revitalizadoras de la productividad de $\mathrm{I}+\mathrm{D}$ y por ende a la creación de productos patentables.

Dada la evidencia empírica anteriormente señalada, se planten el siguiente conjunto de hipótesis;

P2: ¿actúa la orientación emprendedora como condicionante en la innovación empresarial?

H2: la orientación emprendedora tiene un efecto positivo en la innovación, es decir, cuanto mayor es la orientación emprendedora, mayor es la innovación empresarial. 
H2a: la orientación emprendedora está relacionada positivamente con la innovación incremental.

H2b: la orientación emprendedora está relacionada positivamente con la innovación radical. 
Tabla 14

Estudios que evidencian que la orientación emprendedora tiene un efecto en la innovación: según tipo de innovación y tamaño

\begin{tabular}{|c|c|c|c|c|c|c|c|c|}
\hline \multirow[b]{2}{*}{ Estudio empírico } & \multirow[b]{2}{*}{ Población analizada } & \multicolumn{4}{|c|}{ Innovación incremental } & \multicolumn{3}{|c|}{ Innovación radical } \\
\hline & & $\begin{array}{l}\text { Innovación de } \\
\text { organización }\end{array}$ & $\begin{array}{l}\text { Innovación } \\
\text { de marketing }\end{array}$ & $\begin{array}{l}\text { Innovación } \\
\text { de producto }\end{array}$ & $\begin{array}{l}\text { Innovación } \\
\text { de procesos }\end{array}$ & \begin{tabular}{|l} 
Patentes \\
registradas
\end{tabular} & $\begin{array}{c}\text { Actividades } \\
\text { I+D }\end{array}$ & $\begin{array}{c}\text { Des. nuevos } \\
\text { productos y } \\
\text { mercados }\end{array}$ \\
\hline Avlonitis y Salavou(2007) & Grecia,143 pequeñas empresas & $x$ & $x$ & + & + & $x$ & $\mathrm{x}$ & + \\
\hline Biggadike (1979) & Grandes empresas, industria y comercio & $x$ & + & $x$ & $x$ & $\mathrm{x}$ & $\mathrm{x}$ & $\mathrm{x}$ \\
\hline Covin y Miles (1999) & Grandes empresas, industria y comercio & $x$ & $x$ & + & + & $\mathrm{x}$ & $\mathrm{x}$ & + \\
\hline Covin y Slevin (1991) & USA, grandes empresa, industria/comercio & $x$ & $x$ & + & + & $\mathrm{x}$ & $\mathrm{x}$ & + \\
\hline Drucker (1985) & USA, grandes empresa, industria/comercio & $x$ & $x$ & + & + & $\mathrm{x}$ & $\mathrm{x}$ & + \\
\hline Frank et al. (2010) & USA, 26 estudios de caso, farmacéutica & $x$ & $x$ & + & $x$ & + & + & + \\
\hline Hills y LaForge (1992) & Grandes empresas, industria y comercio & $x$ & + & $x$ & $x$ & $\mathrm{x}$ & $\mathrm{x}$ & $x$ \\
\hline Hsueh y Tu, 2004 & Grandes y pequeñas empresas & $x$ & $x$ & + & + & $x$ & $x$ & + \\
\hline Hult et al. (2004) & 181 empresas, industria y comercio & + & $x$ & $x$ & $x$ & $\mathrm{x}$ & $\mathrm{x}$ & $x$ \\
\hline Johne y Snelson (1988) & USA, empresas grandes, manufactura & $x$ & $x$ & + & + & $x$ & $x$ & $x$ \\
\hline Kitchell (1995) & Grandes empresas, industria y comercio & $x$ & $x$ & + & + & $x$ & $\mathrm{x}$ & + \\
\hline Lassen et al. (2006) & 5 casos estudio, empresas high-tech & $x$ & $x$ & + & + & $x$ & $\mathrm{x}$ & $\mathrm{x}$ \\
\hline Lee y Sukoco (2007) & 152 grandes y pequeñas empresas & $x$ & $x$ & + & + & $x$ & $\mathrm{x}$ & $\mathrm{x}$ \\
\hline Liu et al. (2000 y 2002) & Grandes y pequeñas empresas & + & $x$ & $x$ & $x$ & $x$ & $x$ & $x$ \\
\hline Lumpkin y Dess (1996) & Grandes empresas, industria y comercio & $x$ & + & + & + & $x$ & $x$ & + \\
\hline McFadzean et al. (2007) & Grandes empresas, industria y comercio & $x$ & $x$ & + & + & $\mathrm{x}$ & $x$ & $\mathrm{x}$ \\
\hline Messenghen (2003) & Grandes empresas, industria y comercio & $x$ & $x$ & $x$ & + & $x$ & $x$ & $x$ \\
\hline Miller (1983) & Grandes empresas, industria y comercio & $x$ & $x$ & + & + & $\mathrm{x}$ & $x$ & $\mathrm{x}$ \\
\hline Miller y Friesen (1982) & Grandes empresas, industria y comercio & $x$ & $x$ & + & $x$ & $x$ & $x$ & + \\
\hline Morris y Paul (1987) & Grandes empresas, industria y comercio & $x$ & + & $x$ & $x$ & $x$ & $x$ & $\mathrm{x}$ \\
\hline Russell y Russell (1992) & Grandes empresas, industria y comercio & $x$ & $x$ & + & + & $x$ & $x$ & + \\
\hline Salavou y Lioukas (2003) & Grecia, 69 pequeñas empresas & $x$ & $x$ & + & + & $\mathrm{x}$ & $x$ & \\
\hline Slater y Narver (1995) & Grandes empresas, industria y comercio & $x$ & $x$ & + & + & $x$ & $x$ & + \\
\hline Zhou et al. (2005) & China, 350 empresas & $x$ & $\mathrm{x}$ & + & + & $\mathrm{x}$ & $x$ & + \\
\hline
\end{tabular}

Fuente: Elaboración propia.

(+) Efecto positivo de la orientación al mercado en la acción innovadora / ( $\mathrm{x}$ ) no se toma en cuenta esa actividad innovadora. 


\subsubsection{Papel del tamaño en la innovación}

En el contexto de la literatura tradicional de la economía y gestión, el tamaño de la empresa puede actuar como un determinante para la innovación. Existe una amplia evidencia empírica que justifica el efecto positivo de éste factor organizacional en la innovación (Ettlie, 1984; Acs y Audretsch, 1988; Yagüe, 1992; Cohen y Klepper, 1996a; Yin y Zuscovitch, 1998; Arias-Aranda et al, 2001; Rogers, 2004; Evangelista y Mastrostefano, 2006). Desde los estudios de Schumpeter (1934, 1944) y las hipótesis planteadas por Galbraith (1956), se presume que a mayor tamaño, mayor ventaja de innovación, o sea, un comportamiento más innovador.

Aunque también hay que mencionar que diversas investigaciones han demostrado que la relación entre el tamaño y la innovación es inversamente proporcional, concede ventajas a las a las pequeñas empresas (Abemathy y Utterback, 1978; Quinn, 1986; Salavou et al. 2004) Mientras que otros estudios comparativos entre empresas de distintos tamaños no obtuvieron resultados concluyentes en cuanto a ésta relación como en los casos de Hamberg (1966), y más recientemente, Avermaete et al. (2003).

Hay que tomar en cuenta los factores a favor de la ventaja innovadora para las pequeñas empresas son muy distintas que para las grandes. Por ejemplo, las pequeñas empresas, poseen ventajas de comportamiento pues son más emprendedoras, flexibles y rápidas (Abernathy y Utterback, 1976; Quinn, 1986; Fernández y Fernández, 1988); mientras, las grandes empresas poseen ventajas materiales porque cuentan economías de escala, curva de experiencia, recursos de marketing, recursos financieros, recursos tecnológicos y recursos humanos para desarrollar la innovación (Rothwell y Dodgson, 1994).

Es claro que la relación entre el tamaño de la empresa y la capacidad innovadora ha generado un amplio debate desde la década de los años 40's. Los trabajos empíricos realizados que estudian la relación entre dimensión e innovación no llegan a una conclusión única y definitiva puesto que existen argumentos a favor y en contra respecto a qué tipo de tamaño de empresa es más innovadora. La Tabla 15 muestra los tipos de relación entre el tamaño de la empresa y la innovación a través de la evidencia empírica de varios autores que han estudiado el tema en cuestión. 
Por un lado, existe evidencia que demuestra que las pequeñas empresas son más innovadoras que las grandes (Pavitt et al., 1987; Acs y Audretsch, 1991; Czarnitzki y Kraft, 2004; Salavou et al. 2004). Las posiciones en contra de la relación directa tamaño-innovación argumentan que las grandes empresas suelen ser más burocráticas, lo que crea una atmósfera desfavorable para la creatividad (Scherer, 1965; Cohen y Klepper, 1996b).

Las pequeñas empresas pueden alcanzar mayores niveles de innovación al poseer ventajas de comportamiento y de estructura organizativa, la cuales, las habilita a ser más emprendedoras, flexibles y rápidas a la hora de reconocer las oportunidades del entorno. Esa flexibilidad les permite tomar rápidas decisiones, realizar cambios en los planes, reestructurar las fases de implementación de un proyecto y ajustar los incentivos laborales para lograr un esfuerzo óptimo hacia la innovación (Roger, 2004). La desventaja de las pequeñas empresas es que no siempre cuentan con la financiación, experiencia y conocimiento para emprender una innovación costosa y asumir los contratiempos hasta contabilizar el retorno de la inversión (Rothwell y Dodgson, 1994; Ying-Chieh y Cipolla, 2007). Tal como afirman Zott y Amit (2009):
“...innovaciones precisan de una inversión considerable, por ejemplo, en $\mathrm{I}+\mathrm{D}$, recursos especializados y nuevos activos, o incluso en unidades empresariales completas y nuevas. En otras palabras, la innovación en productos y procesos puede ser cara y llevar su tiempo y, lo que es más, los futuros rendimientos de una inversión necesaria que se realiza por adelantado son inciertos."

Estos argumentos dejan patente que las pequeñas empresas encuentran limitaciones importantes a la hora de innovar, pero esto en ningún momento afirma que son empresas poco innovadoras o estancadas, es posible que les sea más difícil emprender grandes proyectos I+D, o sobre el impacto que la inversión de I+D puede tener sobre la rentabilidad (Cohen y Klepper, 1996b; Tsai y Wang, 2005), pero hay que tomar en cuenta que el concepto de innovación, como se ha tratado anteriormente, va más allá del I+D, pues incluyen acciones que propician avances, reformas o rupturas en cuanto a la introducción de nuevas iniciativas de gestión, comerciales, técnicos -producto o proceso (Fernández y Fernández, 1988). 
No obstante, se debe tomar en cuenta que las investigaciones donde las pequeñas empresas son más innovadoras, normalmente, corresponden a sectores high-tech o empresas que aplican normas de calidad o que están ubicadas en una concentración de mercado más propenso a la innovación.

Por el contrario, Zhou et al. (2005) afirman que las grandes empresas suelen tener un mejor resultado innovador que las pequeñas empresas porque cuanto más grande es la empresa, mayores son sus capacidades y recursos (investigación, tecnología, habilidades de marketing, autonomía financiera y equipos humanos experimentados) para desarrollar e implantar apropiadamente la innovación (Rothwell y Dodgson, 1994; Shaffer, 2002), o sea que, alcanzan un mayor éxito innovador (beneficios operativos y financieros). Éstas operan con economías de escala que distribuyen los costos de la innovación y maximizan los esfuerzos con el conocimiento y el capital humano del que disponen.

Aún aportando todos estos argumentos no es posible llegar a una conclusión final sobre la relación, como indica González et al. (1997: 96) "la mayor parte de las discrepancias sobre si son las grandes o las pequeñas empresas las más innovadoras proceden de la falta de homogeneidad en el concepto de innovación manejado, es decir, varía el concepto, su delimitación y aplicación, y la definición de empresa innovadora en cada uno de los estudios llevados a cabo, en función del sector y de la muestra tomada en consideración... los citados estudios están reflejando distintos aspectos del proceso de innovación, así unos hacen referencia al "input" del proceso de innovación mientras que otros se concentran en la medición de los outputs".

Entonces surge la pregunta, ¿es determinante el tamaño de la empresa en el comportamiento innovador? ¿Realizan las pequeñas empresas diferentes tipos de innovación? Dado que el concepto de innovación que se aplica en esta investigación es más amplio que el concepto tecnológico, sino también, organizacional, comercial, no se considera que el tamaño sea una variable discriminante pero si determinante para ejecutar ciertos tipos de innovación, sobretodo en pequeñas empresa ubicadas en zonas menos desarrolladas.

Usualmente los estudios observados se han centrado en las diferencias de comportamiento entre las grandes y pequeñas empresas concluyendo que la estrategia 
innovadora implantada por ambos tipos es distinta, a priori definidas por el tipo de tamaño al que pertenecen y no por la naturaleza de las innovaciones introducidas y del mecanismo empleado para acceder a las mismas. Sin embargo, las empresas más pequeñas en localizaciones discriminadas, suelen tener menos incentivos para implantar la innovación. Aunque el enfoque empírico sobre la relación entre el tamaño de la empresa y la innovación no es concluyente, se plantea la siguiente hipótesis;

P3: ¿actúa el tamaño de la empresa como condicionante en la innovación empresarial?

H3: el tamaño de la empresa tiene un efecto positivo en la innovación empresarial, es decir, cuanto mayor es el tamaño, mayor es la innovación empresarial.

H3a: el tamaño está relacionado positivamente con la innovación incremental.

H3b: el tamaño está relacionado positivamente con la innovación radical. 
Tabla 15

Tipo de relación entre el tamaño de la empresa y la innovación

\begin{tabular}{|c|c|c|}
\hline Autor & Tipo de relación & Argumentación \\
\hline Freeman (1975) & $\begin{array}{l}\text { Depende del sector } \\
\text { Depende del sector }\end{array}$ & $\begin{array}{l}\text { Afirman en sus conclusiones que existen diferencias significativas en la contribución de las pequeñas y de las grandes } \\
\text { empresas a las innovaciones dependiendo del sector industrial en el que se circunscriben. Freeman (1975) concluye } \\
\text { que existen diferencias en el comportamiento innovador en las dos dimensiones consideradas, revelándose las unas o } \\
\text { las otras como más innovadoras según el sector objeto de estudio. Acs y Audretsch (1988) concluyen que las } \\
\text { empresas de gran tamaño presentan ventajas en aquellos sectores intensivos en capital, con un alto grado de } \\
\text { concentración y en los que se producen bienes diferenciados, mientras que las pequeñas empresas gozan de esta } \\
\text { ventaja en sectores altamente innovadores, con empleo importante de mano de obra cualificada. }\end{array}$ \\
\hline $\begin{array}{l}\text { Mansfield (1963) } \\
\text { González et al. (1997) } \\
\text { Ying-Chieh y Cipolla (2007) }\end{array}$ & $\begin{array}{l}\text { Depende del tipo de innovación } \\
\text { Depende del tipo de innovación } \\
\text { Depende del tipo de innovación }\end{array}$ & $\begin{array}{l}\text { Muestran que las organizaciones de gran dimensión tienden a realizar las innovaciones cuando su aplicación resulta } \\
\text { costosa y cuando se requiere una comercialización a gran escala para que la misma resulte económica. Las } \\
\text { pequeñas empresas presentan una mayor capacidad para introducir cambios significativos en productos y dominar } \\
\text { nichos del mercado que no resultan atractivos ni interesantes para las grandes empresas. }\end{array}$ \\
\hline Soete (1979) & Lineal & Al tratar la industria norteamericana, llega a la conclusión de que la relación entre tamaño e innovación es lineal. \\
\hline $\begin{array}{l}\text { Scherer (1965) } \\
\text { Yin y Zuscovitch (1998) }\end{array}$ & $\begin{array}{l}\text { En forma de } U \text { invertida } \\
\text { En forma de } U \text { invertida }\end{array}$ & $\begin{array}{l}\text { En este sentido, hacen una propuesta teórica argumentando que existe una relación, entre innovación y tamaño, de U } \\
\text { invertida; es decir, la innovación crece proporcionalmente a la dimensión hasta alcanzar un cierto nivel, a partir del } \\
\text { cual estas actividades disminuyen, tesis que corroboraron con sus posteriores trabajos empíricos. }\end{array}$ \\
\hline Freeman (1982) & En forma de U & $\begin{array}{l}\text { Al analizar la industria británica proponen una relación contraria a la contrastada por Scherer, esto es, la asociación } \\
\text { entre dimensión de la empresa e innovación se representa con una gráfica en forma de U (sin invertir). Pavitt et } \\
\text { al. (1987) los resultados también sugieren que la proporción de esfuerzo innovador dedicado a la innovación de } \\
\text { procesos es mayor entre las empresas más grandes. También en consonancia con estos }\end{array}$ \\
\hline Pavitt et al. (1987) & En forma de U & $\begin{array}{l}\text { hallazgos, Freeman (1982) encuentra que las empresas más grandes tienden a ser las principales responsables de la } \\
\text { innovación de procesos en las industrias químicas de finales del siglo } 19 \text { y 20. (Tomado de Cohen y Klepper, 1996b) }\end{array}$ \\
\hline $\begin{array}{l}\text { Abemathy y Utterback (1976) } \\
\text { Quinn (1986) } \\
\text { Fernández y Fernández (1988) } \\
\text { Czarnitzki y Kraft (2004) }\end{array}$ & $\begin{array}{l}\text { Inversa } \\
\text { Inversa } \\
\text { Inversa } \\
\text { Inversa }\end{array}$ & $\begin{array}{l}\text { Los autores concluyen que la relación entre la innovación y el tamaño es inversa porque consideran en sus resultados } \\
\text { que las pequeñas empresas son más adecuadas para implantar procesos de innovación. } \\
\text { "Las pequeñas empresas parecen tener ciertas ventajas respecto a las grandes ...; ya que tienen organizaciones más } \\
\text { flexibles, con líneas de comunicación cortas y directas entre los distintos niveles, los empleados suelen estar más } \\
\text { motivados y menos alienados, y desarrollan una mayor capacidad de asimilación de respuesta al cambio" (Fernández } \\
\text { y Fernández, 1988:137). }\end{array}$ \\
\hline
\end{tabular}




\begin{tabular}{|c|c|c|}
\hline Salavou et al. (2004) & Inversa & \\
\hline Schumpeter (1944) & Directa & \multirow{10}{*}{$\begin{array}{l}\text { Los autores otorgan una mayor importancia, en cuanto al desarrollo de actividades innovadoras, a las empresas de } \\
\text { gran tamaño, ya que consideran que éstas poseen una mayor disponibilidad de recursos. Por contra, distintos autores } \\
\text { critican estas teorías destacando el protagonismo de las pequeñas empresas en los procesos innovadores, poniendo } \\
\text { de relieve el distinto comportamiento entre los dos tamaños empresariales. } \\
\text { Yagüe (1992) realiza un estudio descriptivo del comportamiento innovador de las pequeñas empresas industriales } \\
\text { españolas, concluyendo que el comportamiento innovador es distinto según la categoría de tamaño. Además, afirma } \\
\text { que existe una relación directa entre tamaño e innovación ya que son las medianas y las grandes empresas las que } \\
\text { realizan mayores esfuerzos en I+D. Además, otorgan una mayor importancia al desarrollo innovador a las grandes al } \\
\text { poseer una mayor disponibilidad de recursos. } \\
\text { Han desarrollado un modelo para la relación entre actividades de innovación y tamaño de la empresa. Un elemento } \\
\text { importante de su enfoque es la hipótesis de que el retorno de una innovación se relaciona positivamente con el } \\
\text { tamaño de la unidad de negocio correspondiente y que esta relación es más fuerte para la innovación de } \\
\text { procesos que para la innovación de productos. Como consecuencia de ello, las grandes empresas dedican una mayor } \\
\text { proporción de su gasto hacia la innovación de producto y procesos que las empresas más pequeñas (Tomado de Acs } \\
\text { y Audretsch, 1988). }\end{array}$} \\
\hline Galbraith (1956) & Directa & \\
\hline Ettlie (1984) & Directa & \\
\hline Yagüe (1992) & Directa & \\
\hline Rothwell y Dodgson (1994) & Directa & \\
\hline Arias-Aranda et al. (2001) & Directa & \\
\hline Shaffer (2002) & Directa & \\
\hline Rogers (2004) & Directa & \\
\hline Zhou et al. (2005) & Directa & \\
\hline Evangelista y Mastrostefano (2006) & Directa & \\
\hline Bean (1995) & No directa & \multirow{4}{*}{$\begin{array}{l}\text { La esta posible asociación para los autores no parece ser directa en el sentido de que variables como el tamaño } \\
\text { empresarial pueden afectar al efecto real de la innovación sobre los resultados empresariales futuros; o sea, que el } \\
\text { retorno de una innovación no se relaciona positivamente con el tamaño de la unidad de negocio correspondiente. }\end{array}$} \\
\hline Cohen y Klepper (1996b) & No directa & \\
\hline Tsai y Wang (2005) & No directa & \\
\hline Kafouros (2008) & No directa & \\
\hline Hamberg (1966) & No existe relación & $\begin{array}{l}\text { Sostienen que no existe asociación alguna entre el tamaño y la innovación, y si en algún caso se pudiera llegar a } \\
\text { establecer, ésta sería una relación inversa, es decir, la actividad innovadora decrece conforme aumenta el tamaño de }\end{array}$ \\
\hline Avermaete et al. (2003) & No existe relación & la empresa \\
\hline
\end{tabular}

Fuente: elaboración propia; ampliación del cuadro 1 de González et al. (1997: 94) 


\subsubsection{Papel del tamaño en la cultura organizativa}

Independientemente del tamaño empresarial, las empresas utilizan la cultura organizativa para promover acciones de innovación. Entonces si la cultura organizativa puede estar relacionada con la innovación y la innovación con el tamaño, será que también el tamaño está relacionado con la cultura organizativa ¿son las grandes o son las pequeñas empresas más orientadas al mercado o más emprendedoras? Como parte del marco conceptual y tomando como base la literatura de marketing y management se describe la orientación al mercado y la orientación emprendedora y su relación con las pequeñas empresas.

La importancia de la cultura organizativa había estado enfocada, principalmente al estudio de las grandes empresas (Narver y Slater, 1990; Jaworski y Kohli, 1993; Slater y Narver, 1994; Deshpandé y Farley, 2000). No obstante, otros autores se fueron interesando en el estudio de la influencia de la cultura organizativa dirigida a las pequeñas empresas (Pelham y Wilson, 1996; Pelham 1997a, 1997b, 1999, 2000; Hult y Ketchen 2001; Hult et al. 2003; Verhess y Meulenberg 2004; Kara et al. 2005).

Los resultados de los estudios de Liu (1995); Liu et al. (2002) y Hsueh y Tu (2004) indican que las empresas grandes implementan mejor la cultura organizativa que las pequeñas porque las grandes tienen una visión más competitiva. Diversos autores no han encontrado una relación significativa entre la cultura organizativa y el tamaño y, han explicado que en el caso de las grandes empresas, esto se debe a varios factores: el conformismo y la inercia, la resistencia al cambio, la aversión al riesgo y la compleja estructura organizativa. Todos estos factores les impiden procesar adecuada y rápidamente la información.

Este comportamiento marca una ventaja competitiva a las pequeñas empresas porque, según Hult et al. (2003), cuentan con mejor desempeño para enfocarse hacia la orientación al mercado por su flexibilidad y por no poseer estructuras organizacionales de múltiples capas que dificultan la toma de decisión y canales formales de aprobación, de esta manera, pueden adaptarse rápidamente a los cambios del entorno; ofreciendo una fuente de ventaja competitiva y viabilidad en el desempeño (Narver y Slater, 1990; Day y Nedungadi, 1994; Pelham y Wilson, 1996; Pelham, 2000; McAdam and Reid, 2004). 
Por parte de la orientación emprendedora, muchos autores también han llegado a la misma conclusión, aludiendo que las características de las pequeñas empresas; o sea, variables endógenas simples centradas en el mercado local, con estrategias implícitas y planes/controles limitados (Messenghen, 2003), y su habilidad para subsistir (Deeks, 1973; Julien, 1998); les permiten actuar con mayor facilidad frente a la dinamicidad de los retos endógenos, respondiendo a las futuras y potenciales necesidades del mercado (Mintzberg, 1989; Naman y Slevin, 1993; Lumpkin y Dess, 1996; Entrialgo et al., 2001; Hult y Ketchen; 2001; Messenghen, 2003).

Dada la controversia entre los argumentos sobre el tipo de relación -directa o inversaEn este estudio partimos de que si existe una relación causal entre el tamaño empresarial y la cultura organizativa, de ahí las siguientes hipótesis;

P4: ¿actúa el tamaño de la empresa como condicionante en la cultura organizativa?

H4: el tamaño de la empresa tiene un efecto positivo en la cultura organizativa.

H4a: el tamaño está relacionado positivamente con la orientación al mercado.

H4b: el tamaño está relacionado positivamente con la orientación emprendedora.

\subsubsection{Papel del tamaño: relación entre cultura organizativa e innovación}

Tal como se estudiado anteriormente, que el tamaño empresarial puede influir simultáneamente en la orientación al mercado, la orientación emprendedora y las acciones de innovación, cabe preguntarse si la relación entre estas está determinada por el tamaño empresarial.

Investigaciones anteriores han incluido diversos factores para observar el efecto moderador en la relación entre la cultura organizativa y la innovación. Algunas contribuciones han medido características moderadoras tales como la antigüedad (Hult et al., 2003), el sector o tipo de industria (Narver y Slater, 1990) o el entorno competitivo (Kohli y Jaworski, 
1990). Pero pocas investigaciones han incluido la variable tamaño como una variable moderadora de la relación (Knight, 1986; Melin, 1986; Sandberg y Hofer, 1986; Roberts et al, 1990). Este estudio se concentrará en la variable del tamaño para medir el efecto moderador en la relación. Roberts et al. (1990) concluyó que la variable tamaño actúa como controladora en la relación, pero el efecto moderador no fue significativo.

Basándonos en el estudio de Greene y Brown (1997) donde establecieron la relación entre la teoría de recursos y capacidades y la innovación, y concluyeron que las empresas con mayores recursos y capacidades emprendían mayor cantidad de nuevas actividades que aquellas que poseían menos que las primeras, entretanto, que las empresas más innovadoras entrevén un grado de crecimiento mayor y más rápido. Por lo tanto, el tamaño puede moderar la relación al tener un efecto directo, esto sería que a mayor tamaño, mayor relación entre orientación cultural e innovación (McAdam and Reid, 2004). La literatura al respecto indica que las empresas más grandes cuentan con más posibilidades de emprender iniciativas emprendedoras, por lo que el tamaño puede reforzar el potencial de la orientación al mercado y/o la orientación emprendedora para fomentar nuevas acciones de innovación en distintas áreas.

Algunos estudios proponen un efecto moderador positivo del tamaño en la relación (Melin, 1986; Roberts et al, 1990). Esto es razonable al considerar todos los argumentos a favor sobre la importancia del tamaño en la cultura organizativa y en las iniciativas innovadoras. Sin embargo pocos estudios han estudiado empíricamente esta cuestión y mucho menos, se ha estudiado la intensidad del efecto.

En el caso inverso, Zhou et al. (2005) concluyeron que el tamaño no determina la relación entre la cultura organizativa y la innovación, ya que esta no es explicada, de manera definitiva, por el tamaño, porque aunque se incorpore la variable, la relación se mantiene. De la misma manera, Yin y Zuscovitch (1998) afirman en su estudio que el tamaño no determina la relación entre la orientación al mercado y la innovación empresarial pero sí los esfuerzos emprendedores hacia la innovación. 
Existe literatura y evidencia empírica que provee argumentos en ambas direcciones sobre el papel de tamaño. En base a algunas aportaciones previas, este estudio mantiene la postura de que el tamaño actúa como modificador de la relación, entonces;

P5: ¿actúa el tamaño como moderadora de la relación entre la cultura organizativa y la innovación?

H5: el tamaño modera la relación entre la cultura organizativa y la innovación empresarial, de manera que, cuanto más grande es una empresa, mayor es la contribución de la cultura organizativa a la innovación empresarial.

H5a: el tamaño modera la relación entre la orientación al mercado y la innovación incremental.

H5b: el tamaño modera la relación entre la orientación al mercado y la innovación radical.

H5c: El tamaño modera la relación entre la orientación emprendedora y la innovación incremental.

H5d: el tamaño modera la relación entre la orientación emprendedora y la innovación radical.

La Figura 17 representa gráficamente el modelo de análisis I. Este consiste principalmente en la exploración de la orientación al mercado y el emprendedorismo como precursoras de la innovación multidimensional tomando en cuenta el papel del tamaño empresarial. A través de las flechas se pueden observar las cinco distintas relaciones que se pretenden contrastar. 
Figura 16

Modelo de análisis I: el emprendedorismo y la orientación al mercado como precursoras de la innovación: papel del tamaño empresarial

\section{Tamaño de la empresa}

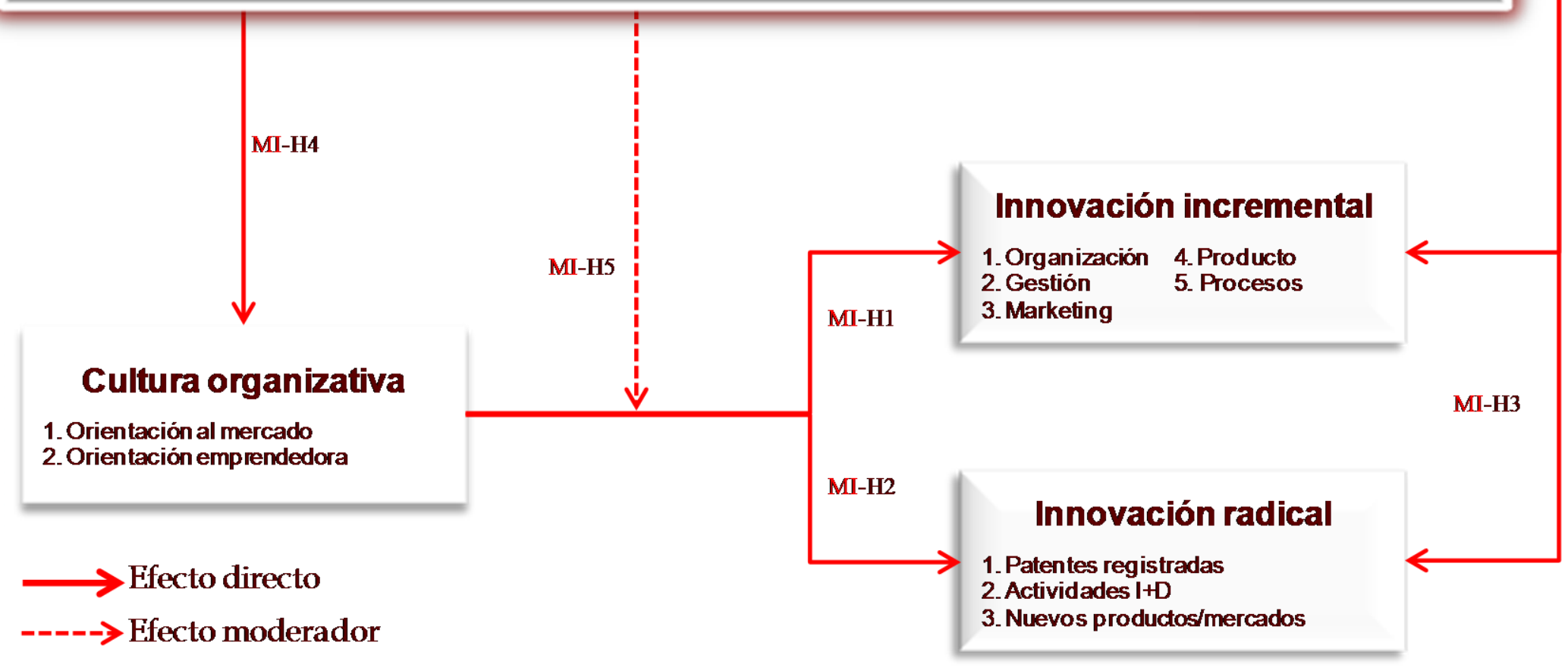




\subsection{Efecto de la innovación en el desempeño empresarial y sus moderadores}

\subsubsection{Innovación: aportación al desempeño empresarial}

Innovar conduce al cambio. Las empresas innovadoras requieren ajustar las funciones intrínsecas y extrínsecas. Estas las utilizan para responder a las exigencias del entorno y así mantener y mejorar el desempeño empresarial. Las empresas que luchan por mantener una ventaja innovadora perciben y atraen nuevas oportunidades aportándoles eficiencia y eficacia en el desempeño empresarial. Aunque hay que tener en cuenta que la innovación implica una alta propensión al riesgo, lo que significa que el éxito no siempre está asegurado.

La relación causal positiva y significativa ha sido ampliamente comprobada y cuenta con un marco literario robusto, desde Schumpeter y su teoría de economías dinámicas pasando por Zaltman et al. (1973) hasta los últimos estudios de Han et al. (1998); Mavondo et al. (2005); Bhaskaran (2006); Lin y Chen (2007) y Damanpour et al. (2009). Por ejemplo, Chudnovsky et al. (2004) encuentran que las firmas con mayor capacidad innovadora, o sea, que han implementado algún tipo de innovación en el último año, han obtenido un mejor desempeño que las menos innovadoras.

Otros estudios revelan evidencias negativas (Capon et al., 1990; Li y Atuahene-Gima, 2001); o simplemente los resultados estadísticos no son concluyentes o no muestran ninguna relación (Mole y Worrel, 2001), esto se debe, según Kemp et al. (2003) a que las empresas, muchas veces, no son eficientes en lograr que la innovación alcance el éxito en el mercado. Según Damanpour (1990), esto último puede ocurrir por la forma como se miden las variables de desempeño, de innovación, y de las características organizacionales y del entorno.

No obstante, nuestro estudio parte de que, la innovación, incremental y radical, está relacionada positivamente con el desempeño empresarial, es decir, que las empresas que realizan actividades de innovación logran forjar una posición competitiva sustentable en el marco de un mejor desempeño relativo; es decir que la innovación representa la búsqueda de nuevas soluciones, el desarrollo de productos y servicios, y la utilización de recursos tecnológicos para alcanzar el éxito de la organización en todas sus áreas (Davis et al., 1991, citado por Liu et al., 2002). 
Basándose en las conclusiones de Lin y Chen (2007) que confirman que un incremento en la innovación produce óptimos resultados, por ejemplo: (1) la innovación tecnológica genera competitividad y valor en el mercado, (2) la innovación de marketing y producto abre nuevas vías de mercado y el consumo de los productos (cuota de mercado y crecimiento en las ventas) y (3) la innovación de procesos mejora, a corto plazo, la rentabilidad.

Por otra parte, este estudio recoge también efectos positivos de la innovación radical, compuesta por el número de patentes registradas, los procesos de actividades de investigación y desarrollo (I+D) y la desarrollo de nuevos productos y mercados. Pakes y Griliches (1980) encontraron en su estudio que el impacto del crecimiento del número de patente es significativo respecto al desempeño empresarial; caso contrario al estudio de Tsai y Wang (2005) que no encontraron relaciones significativas con las medidas de éxito empresarial. También se espera que el impacto de la $\mathrm{I}+\mathrm{D}$ repercuta positivamente en los resultados de la empresa, al menos en variables como el beneficio que pueda proceder del crecimiento de las ventas, o reducción de costes, Valor en el mercado o en la mejora de la productividad (Griliches, 1981; Stoneman, 1983; Griliches y Mairesse, 1984; Hall y Mairesse, 1995; Chiesa, 2001; Guanzhou, 2005). No obstante, Morbey (1989) encontró que no existe una relación directa entre la I + D y crecimiento de los beneficios. El desarrollo de productos y mercados puede incidir directamente en su poder en el mercado; o mejora o eficiencia en los costes soportados en los procesos productivos.

La evidencia empírica sugiere que las acciones de innovación tienen un impacto positivo y significativo sobre el éxito empresarial .En vista de los argumentos anteriores se formulan las siguientes hipótesis;

P6: ¿actúa la innovación incremental como condicionante en el desempeño empresarial?

H6: la innovación incremental tiene un efecto positivo en el desempeño empresarial, es decir, cuanto mayor es la innovación incremental, mayor es el éxito empresarial. 
H6a: la innovación de organización está relacionada positivamente con el desempeño empresarial.

H6b: la innovación de marketing está relacionada positivamente con el desempeño empresarial.

H6c: la innovación de producto está relacionada positivamente con el desempeño empresarial.

H6d: la innovación de procesos está relacionada positivamente con el desempeño empresarial.

P7: ¿actúa la innovación radical como condicionante en el desempeño empresarial?

H7: la innovación radical tiene un efecto positivo en el desempeño empresarial, es decir, cuanto mayor es la innovación radical, mayor es el éxito empresarial.

H7a: las patentes están relacionadas positivamente con el desempeño empresarial.

H7b: las actividades de $\mathrm{I}+\mathrm{D}$ está relacionada positivamente con el desempeño empresarial.

H7c: el desarrollo de nuevos productos y mercados está relacionado positivamente con el desempeño empresarial.

\subsubsection{Factores empresariales claves del éxito innovador}

El éxito de la de innovación está sujeto al ajuste de diferentes variables endógenas de la empresa (Birley y Westead, 1994) y si se adapta a las condiciones externas que imperan en el entorno en el que se desenvuelve (Miller y Fiesen, 1982; Covin y Slevin, 1989). Si la capacidad innovadora de la empresa esta integrada a la estrategia corporativa, es decir, que agrega valor al resto de unidades de la empresa, es posible que este comportamiento alcance 
una ventaja competitiva. Ello implica que las repercusiones de las acciones innovadores en las actividades de la cadena de valor desenlace un efecto directo en la ventaja competitiva, por medio de bajos costes o en diferenciación. Por esto, es necesario que la dirección ejecutiva se percate sobre el gran valor de la innovación y procure fusionarla adecuadamente a los objetivos internos, así como para la sociedad en general (Porter, 1985).

El modelo teórico acoge como pilar la teoría de recursos y capacidades -resourcebase theory (Barney, 1991; Grant, 1991; Mahoney y Pyian, 1992; Peteraf, 1993; Collis y Montgomery, 1995) En primer lugar, los resultados de las empresas pueden darse por los efectos coyunturales, ya sea por el sector o la localización en la que opera, y estos podrían influir directamente sobre los resultados e indirectamente a través de la estrategia, esto es consistente con la teoría de economía industrial que sugiere que el ambiente externo o del mercado limita la estrategia de las empresas (Porter, 1979). No obstante, a pesar de las situaciones coyunturales, los resultados están más bien sustentados en recursos y capacidades que requieren una aproximación diversa de factores que muchas veces mantienen una importante relación entre sí, y dependiendo de esta relación de recursos y capacidades dentro de la empresa, se pueden lograr mejores resultados y comportamientos competitivos (Barney, 1991; Grant, 1991).

La relación entre la innovación y el desempeño empresarial ha sido estudiada considerando el papel condicionante y/o moderador de múltiples factores. Estos factores pueden ser tanto caracterizadores de las empresas como del contexto en el que operan. La innovación requiere un proceso de integración de conocimiento que tiene una faceta interna y otra externa. La integración interna hace referencia a la relación complementaria que existe entre las capacidades organizativas. La ausencia de un núcleo básico de capacidades explica muy frecuentemente el fracaso de la innovación que en su primer diseño podrían ser de gran valor. La faceta externa proviene del entorno de la empresa y es considerado un importantísimo complemento para la innovación.

En lo que respecta a las características internas de las empresas, algunos estudios se han centrado en rasgos estructurales como el tamaño (Acs y Audretsch, 1990; Damanpour, 1996; Afuah, 1998), la antigüedad (Hurley y Hult, 1998; Sorensen y Stuart, 2000) o la estructura de propiedad (Acha et al., 2005). Otros han abordado el papel de factores más 
complejos relacionados al comportamiento estratégico (Wang, 2008) y a las características culturales como la orientación emprendedora (Atuahene-Gima y Ko 2001) o la orientación al mercado (Matear et al. 2002; Mols, 2002). Se trata de comportamientos internos que, combinados con la innovación pueden generar tanto efectos sinérgicos como efecto inhibidores en la relación.

Respecto a las características del entorno en el que operan las empresas, algunas investigaciones han tratado de capturar los distintos escenarios basándose en dimensiones fácilmente observables, como el tipo sector de actividad o el país/región (Evangelista y Mastrostefano, 2006). La diferenciación según el tipo de sector permite capturar las circunstancias concretas que caracterizan cada sector de la actividad. De la misma manera, el país o región están relacionados con el contexto sociocultural económico, político legal y tecnológico.

Otra línea de investigación que ha abordado el efecto moderador de distintos aspectos directamente relacionados al grado de complejidad del entorno del mercado y del entorno competitivo son las planteadas por Kohli y Jaworski (1990): turbulencia del mercado, turbulencia tecnológica, crecimiento del mercado e intensidad competitiva. Estos efectos moderadores los han estudiado respecto a las relación entre orientación al mercado y desempeño empresarial.

En cuanto a este tema, este trabajo estudiará los efectos condicionantes y /o moderadores del tamaño de la empresa y la orientación al mercado como factores organizacionales; el dinamismo del entorno y la intensidad competitiva y la colaboración como factores del entorno. A continuación se detallen los argumentos teóricos.

\subsubsection{Factores organizacionales: cultura organizativa y tamaño empresarial}

Los factores organizacionales (internos) están centrados en dos elementos característicos: el tamaño de la empresa como un factor de estructura y la orientación al mercado como un factor cultural. Por un lado, en diversos estudios en el campo de la gestión empresarial, el tamaño se ha considerado como un factor organizacional que actúa como 
antecedente del desempeño de la organización (Aiken y Hage, 1971; Cummings y Paramita, 1977; Smith et al., 1986; Kalleberg y Leicht, 1991; Delaney y Huselid, 1996) y de la innovación (Acs y Audretsch, 1988; Arias-Aranda et al, 2001; Rogers, 2004; Evangelista y Mastrostefano, 2006).

Por otro lado, la orientación al mercado es un aspecto cultural que puede influenciar en otras actividades dentro de la organización (Slater y Narver, 1995). Una empresa orientada al mercado tendrá más posibilidades de un buen desempeño basada en la innovación porque constantemente están monitoreando las preferencias de los consumidores, las actuaciones de los competidores; y difundiendo esa información al resto de la organización (Kohli y Jaworski, 1990). Como bien sintetiza, Santos et al. (2002:15);

"La orientación al mercado es un recurso (activos o capacidades, Day, 1994) organizativo cualificado plenamente para guiar el establecimiento de la orientación estratégica de la empresa (innovación) y por tanto el sostenimiento de su ventaja competitiva".

\subsubsection{Papel de la cultura organizativa en el desempeño empresarial}

Desde hace varios años, los investigadores han abordado el interés sobre el efecto de la cultura organizativa en el desempeño empresarial, en este caso, Ruekert (1992) y Atuahene-Gima (1996) afirman que la orientación al mercado es un medio para aplicar la estrategia y alcanzar los resultados. La orientación al mercado, es esencial para el seguimiento de las oportunidades del mercado y reforzar las iniciativas de innovación orientadas hacia el cliente y el producto. Es potenciadora de otros factores que permiten optimizar el rendimiento empresarial (Deshpandé et al., 1993; Slater y Narver, 1995). La orientación al mercado conduce a la viabilidad empresarial por medio del seguimiento de las oportunidades del mercado y el desarrollo de estrategias adaptadas para mejorar el rendimiento empresarial. Esta optimización se traduce en un incremento de las ventas, un mejor posicionamiento en el mercado, mejor capacidad de adaptación y anticipo a los cambios del consumidor y, a obtener mayores márgenes de ganancia (Markides, 1997). 
Existe un numeroso listado de estudios que corroboran esta relación e inducen a una generalización empírica de la relación (Covin y Slevin, 1989; Barret y Weinstein, 1998; Pelham, 2000; Kemelgor, 2002; Matsuno et al., 2002; Langerak, 2003a, 2003b; RodríguezCano et al., 2004; González-Benito y González-Benito, 2005; Kara et al., 2005; Kirca et al., 2005; Gómez-Villanueva, 2010). Sin embargo, otros autores plantean interrogantes debido a la gran variedad de aproximaciones para formalizar la relación. No obstante, existe evidencia de que la orientación al mercado contribuye a mejorar el desempeño empresarial. Esta relación positiva entre la cultura organizativa y desempeño se puede dar en la gran empresa como en las pequeñas (Narver y Slater, 1990; Jaworski y Kohli, 1993; Pelham, 2000).

Las contribuciones que corroboran una relación positiva difieren en cuanto a las dimensiones de orientación al mercado y el desempeño implicadas y en cuanto a la intensidad de dicha relación. La intensidad de la relación depende, en ciertas ocasiones, del contexto coyuntural en que operen; por ejemplo, Covin y Slevin (1989) concluyeron que la relación entre orientación emprendedora y desempeño empresarial es mayor cuanto mayor es la hostilidad del entorno competitivo.

Sin embargo, existen excepciones que no han detectado dicha relación o que incluso han observado una relación inversa (Jaworski y Kohli, 1993); por ejemplo, en el estudio de Han et al. (1998) no se encontró una relación directa de la orientación al mercado con los resultados pero sí fue positiva con la innovación. Esto se ha probado en distintos tamaños de empresas, sectores y países (Pitt et al., 1996; Caruana et al., 1998; Kumar et al., 1998, 2002; Tung-Zong y Su-Jane, 1998; van Egeren y O’Connor, 1998), pero de la misma manera, otros no han encontrado soporte suficiente para afirmar la relación (Atuahene-Gima, 1996; Han et al., 1998; Aldas-Manzano et al., 2005; Keskin, 2006) o encontrar resultados significativos (Sargeant y Mohamad, 1999). Esta evidencia empírica conlleva una nueva hipótesis de trabajo;

P8: ¿actúa la orientación al mercado como condicionante en el desempeño empresarial?

H8: la orientación al mercado tiene un efecto positivo en el desempeño empresarial, es decir, cuanto mayor es la orientación al mercado, mayor es el éxito empresarial. 


\subsubsection{Papel de la cultura organizativa: relación entre innovación y desempeño empresarial}

Tal como se observó anteriormente, la relación entre orientación al mercado y desempeño empresarial ha sido abordada en muy distintos escenarios socioeconómicos y geográficos (Jaworski y Kohli, 1993; Deshpandé et al. 1993; Pelham y Wilson, 1996; Avlonitis y Gounaris, 1997; Appiah-Adu, 1998; Lado et al., 1998; Langerak, 2001; Singh, 2003).

Igualmente la relación entre orientación al mercado e innovación ha sido advertida teórica y empíricamente desde hace varias décadas (Morris y Paul, 1987; Miles y Arnold, 1991; Hurley y Hult, 1998; Singh, 2003; Mavondo et al., 2005; Keskin, 2006). También ha sido confirmada en el contexto de las economías emergentes (Liu et al., 2003). El argumento subyacente es que son complementarias hacia el entorno de la empresa. La innovación necesita de la orientación al mercado para canalizar con éxito las acciones dirigidas al mercado. Análogamente, la orientación al mercado necesita de la innovación para responder con rotundidad y rapidez a las oportunidades del entorno; por ejemplo, tal como lo plantea de-Luca et al. (2010) con las actividades de I + D dice que la $\mathrm{I}+\mathrm{D}$ media los efectos de la orientación al cliente y la coordinación interfuncional en el desempeño organizacional.

La discusión anterior deja claro que la cultura organizativa se relaciona tanto con la innovación como con el desempeño empresarial. Pero a pesar de la múltiple evidencia empírica sobre estas relaciones, los efectos moderadores son más escasos, especialmente, son limitados los estudios realizados en el ámbito de la Unión Europea que se han centrado exclusivamente en las zonas más desfavorecidas (González-Benito y González-Benito, 2005). Así que lo que se pretender abarcar en este apartado es si la orientación al mercado contribuye significativamente a la relación entre innovación y desempeño; o sea, si existe un efecto moderador positivo en la relación. Tal como lo propuso Matear et al. (2002) que un incremento en los niveles de orientación al mercado incrementará el aporte de la innovación al desempeño empresarial.

La argumentación de este estudio, propone que la orientación al mercado modera la relación entre innovación y desempeño, porque muchas de las acciones derivadas de la innovación, como la disposición a asumir riegos calculados y la proactividad, necesitan finalmente alcanzar la satisfacción de los consumidores y obtener un mayor rendimiento en el 
mercado, a base de un control continuo de las preferencias de los consumidores, las acciones de la competencia y difundiendo esa información al resto de la organización (Kohli y Jaworski, 1990), es posible comprender el mercado y activar adecuadamente la canalización de las iniciativas innovadoras.

Por otro lado, la innovación se ve fortalecida cuando la orientación al mercado introduce la idea del "cliente" en la empresa con el fin de conocerlos mejor, generar una cultura hacia el cliente, y ajustar los productos que se adapten a sus necesidades. Este esfuerzo conlleva al crecimiento en las ventas, mejorar el posicionamiento y la imagen, y aumentar la cuota de mercado. Por ello, la orientación al mercado puede actuar como una cualidad catalizadora en la relación entre innovación y desempeño. En resumen, cuanto más orientada al mercado sea una empresa más conocerá su mercado y los consumidores y, por tanto, acertará más con las acciones de innovación, y por ende, mejores resultados. Entonces, dado los argumentos anteriores, surgen el siguiente bloque de hipótesis;

P9: ¿actúa la orientación al mercado como moderadora de la relación entre la innovación y el desempeño empresarial?

H9: la orientación al mercado modera la relación entre la innovación y el desempeño empresarial, de manera que, cuanto más orientada al mercado es una empresa, mayor es la contribución de la innovación al desempeño empresarial.

H9a: la orientación al mercado modera la relación entre la innovación incremental y el desempeño empresarial.

H9b: la orientación al mercado modera la relación entre la innovación radical y el desempeño empresarial.

\subsubsection{Papel del tamaño en el desempeño empresarial}

De la misma manera, como vimos anteriormente, el tamaño de la empresa está relacionado con la innovación pero también ha sido relacionado con el desempeño empresarial sean estos financieros u operativos (Sengupta y Bushman, 1998; Hsueh y Tu, 2004; Ying-Chieh 
y Cipolla, 2007). Diversos estudios en el campo de la gestión empresarial, han considerado al tamaño de la empresa como un factor organizacional que actúa como antecedente del desempeño de la organización (Aiken y Hage, 1971; Cummings y Paramita, 1977; Smith et al., 1986).

Las medidas del éxito empresarial, frecuentemente han sido relacionadas con el tamaño de la empresa, las ventajas que están asociadas con el tamaño varía para las grandes y pequeñas empresas; las grandes son más rentables debido a la generación de economías de escala, mientras que las pequeñas incide en su flexibilidad y adaptabilidad. Por lo tanto, el tamaño de la empresa puede condicionar los resultados empresariales. La capacidad financiera de la empresa y su estructura financiera cambian con el tamaño; en las pyme industriales españolas el endeudamiento a corto plazo es mayor que en las de mayor tamaño (García-Teruel y Martínez-Solano, 2004) debido a un peor acceso (mayor riesgo debido a la mayor probabilidad de desaparición de las empresas pequeñas en relación a las grandes y su menor capacidad de negociación frente a las entidades financieras) a productos financieros de mayor plazo o al hecho de que deben financiar tasas de crecimiento más elevadas y en condiciones de variabilidad de ventas mayor que las empresas de mayor tamaño. Algunas investigaciones señalan que las mayores tasas de crecimiento (y variabilidad de las ventas) se dan en empresas más recientes y de menor tamaño (Dunne y Hughes, 1994; Fariñas y Moreno, 2000). La búsqueda de una mayor eficiencia (y competitividad) ligada al tamaño de la empresa puede justificar este comportamiento.

La relación positiva que postulan las teorías de economía industrial y la teoría de la estrategia han sido verificadas por distintos autores durante las últimas décadas (Hall y Weiss, 1967; Begley y Boyd, 1986; Majumdar, 1997; Hellman y Stiglitz, 2000) y apuntan que este tipo de relación positiva viene determinada fundamentalmente por la dificultad de acceso a la financiación externa por parte de las pequeñas empresas.

La relación inversa entre el tamaño y el desempeño empresarial es apoyada, más bien, por las ventajas de flexibilidad en términos de costos de control, menores costos operativos, más rapidez para adaptarse a los cambios, cercanía a la demanda, entornos menos burocráticos (Das et al. 1998; Camisón, 2001; Hsueh y Tu, 2004). Es posible que también se halle una 
ausencia de relación, especialmente debido a la elevada heterogeneidad de la medida del tamaño (Peng y Luo, 2001).

A partir de estos argumentos formulamos la hipótesis;

P10: ¿actúa el tamaño de la empresa como condicionante del desempeño empresarial?

H10: el tamaño de la empresa tiene un efecto positivo en el desempeño empresarial, es decir, cuanto mayor es el tamaño, mayor es el éxito empresarial.

\subsubsection{Papel del tamaño: relación entre innovación y desempeño empresarial}

La discusión previa deja patente las relaciones existentes entre (1) el tamaño de la empresa y la innovación y, (2) el tamaño de la empresa y el desempeño empresarial. Pero una cuestión de interés en este trabajo es conocer si existe una complementariedad entre el tamaño y la innovación que contribuya significativamente al desempeño empresarial, o sea, probar si existe un efecto de interacción positivo. La mayoría de los estudios que integran la variable tamaño dentro del modelo teórico suelen utilizarla como una variable controladora (Sengupta, y Bushman, 1998; Ying-Chieh y Cipolla, 2007), pero no es frecuente que se emplee como variable moderadora, que será el caso de esta investigación.

Se argumenta lo siguiente: aunque no hay una conclusión categórica en la literatura acerca de la relación, si positiva o inversa, del tamaño con el éxito empresarial, esta investigación parte de que la innovación es más acertada cuanto mayor tamaño tiene una empresa y ello se refleja en los resultados empresariales, esto se debe principalmente, a que las empresas ubicadas en zonas desfavorecidas, son aún menos innovadoras que las empresas ubicadas en regiones más desarrolladas.

Además, hay que tomar en cuenta que la innovación es costosa y requiere tiempo para contabilizar el retorno de la inversión. Por lo tanto, las empresas más grandes, cuentan con más recursos para desarrollar la innovación con respecto a las pequeñas. Cuánto más grande es una empresa mayores son sus capacidades de investigación, habilidades de marketing, autonomía 
financiera y equipos experimentados para desarrollar e implantar nuevas ideas. Estas capacidades ayudan a afrontar adecuadamente la implantación y tiempo de espera que demandan las iniciativas de innovación. Además, pueden sobrellevar más fácilmente el potencial fracaso financiero $\mathrm{u}$ operativo, que implica un comportamiento innovador. Consecuentemente, la hipótesis;

P11: ¿actúa el tamaño como moderador de la relación entre la innovación y el desempeño empresarial?

H11: el tamaño modera la relación entre la innovación y el desempeño empresarial, de manera que, cuanto más grande es una empresa, mayor es la contribución de la innovación al éxito empresarial.

H11a: el tamaño modera la relación entre la innovación incremental y el desempeño empresarial.

H11b: el tamaño modera la relación entre la innovación radical y el desempeño empresarial.

\subsubsection{Factores del entorno: dinamismo del entorno}

Las características del entorno o factores externos pueden actuar como cualidades impulsoras en la relación entre la innovación y el desempeño empresarial. El comportamiento innovador está inmerso en un ambiente de incertidumbre por factores ajenos a la empresa que son incontrolables (Littunen, 2000) y condicionan las operaciones externas que influyen en el éxito (Porter, 1979).

En primer lugar, el papel del entorno se aborda primeramente considerando un factor global de dinamismo del entorno, que trata de capturar el grado de volatilidad en la demanda, la rivalidad competitiva, la innovación, los cambios en los procesos y las tecnologías, etc. En segundo lugar, se considera un factor más específico centrado exclusivamente en la intensidad competitiva del entorno en que operan las empresas. 
En segundo lugar, en lo que respecta a las características del contexto o entorno en el que operan las empresas, algunos trabajos han tratado de capturar los distintos escenarios basándose en dimensiones como el sector de actividad (Narver y Slater, 1990; Avlonitis y Gounaris, 1997; Yau et al., 2000; Kaynak y Kara, 2004). La diferenciación del tipo de actividad permite capturar las circunstancias concretas que caracterizan cada sector.

En tercer lugar, dentro de los factores del entorno o externos que afectan el éxito de la innovación también podemos citar los instrumentos de apoyo externo, que pueden llegar a ser muy acertados porque fomentan la capacidad innovadora. Los agentes externos, tales como, las administraciones y entidades intermedias (gobiernos locales, fundaciones, cámaras, asociaciones, universidades), entidades de I+D (laboratorios, centros tecnológicos y de investigación), consultores, licenciadores y socios empresariales (partners, proveedores, clientes, competidores); pueden ayudar como guía para la implantación de la innovación a través de exploración de oportunidades, a la búsqueda de nuevas tecnologías y desarrollar ideas y proyectos en conjunto.

\subsubsection{Papel del dinamismo del entorno en la innovación}

Las características del dinamismo del entorno también reciben una especial atención con respecto a la innovación. El trabajo pionero de Kohli y Jaworski (1990) ya contemplaba explícitamente el papel moderador de factores como la turbulencia del mercado, la turbulencia tecnológica y la intensidad competitiva. Desde entonces, varios estudios han abordado empíricamente la influencia de este tipo de factores del entorno en la relación entre la innovación y el desempeño (González-Benito et al. 2009).

En estos entornos dinámicos es frecuente el cambio en las barreras de entrada y salida de nuevos competidores, la aparición de nuevas estrategias competitivas, la llegada de nuevas tecnologías que sustituyen/cambian procesos productivos, así como las cambiantes preferencias y gustos de los consumidores (McKee y Varadarajan, 1995). No obstante, un comportamiento flexible, proactivo, innovador y arriesgado pueden mitigar esos efectos cuando las condiciones del ambiente son difíciles. Por lo tanto, es prioritario adaptarse a los cambios, aprovechar las oportunidades y anticiparse a las amenazas (Covin y Slevin, 1989; Atuahene-Gima, 1995) para que la influencia del entorno sea positiva en el éxito empresarial (Pelham y Wilson, 1996). 
Este principio lo refuerza Meuss y Oerlemans (2000) concluyendo en su estudio que en medio de un entorno turbulento lo mejor es adoptar un enfoque de innovación continua (adaptación); pues las acciones emprendedoras promueven una cultura organizacional que capacita a la empresa a crecer en medio de dichos entornos (Liu et al., 2000).

Existen diversas perspectivas respecto a la influencia del entorno en el éxito innovador. Por ejemplo, Russell y Russell (1992) afirman que los ambientes dinámicos y hostiles favorecen la innovación llevando a la empresa a altos niveles de competitividad y desempeño empresarial. No obstante, los estudios de Entrialgo et al. (2001) y Meyer y Utterback (1995) no llegan a una conclusión contundente de que en un ambiente dinámico, hostil y heterogéneo, se produzca una mayor actitud emprendedora generadora de mejores resultados, o sea, que esos factores del entorno no necesariamente conducen al éxito. Varios autores refuerzan sobre el efecto del dinamismo del entorno en la relación entre innovación y desempeño empresarial al concluir que la percepción de la incertidumbre del entorno afecta a los cambios en la estrategia competitiva (Zahra y Covin, 1995; Pelham y Wilson, 1996; Hult et al., 2003).

Enfocándonos a la unidad de estudio de esta investigación, en el caso de las pequeñas empresas que actúan inmersas en un entorno dinámico, este las obliga a realizar cambios en distintos niveles según su actividad (van Gelderen et al., 2000), muchas de ellas están destinadas a expandirse o contraerse en su tamaño, otras sobreviven o se movilizan, mientras que otras están destinadas a morir, pero sea cual sea la dirección indicada, el entorno marca la magnitud de los cambios que toman lugar entre las empresas, por lo tanto, de ellas dependerá su capacidad para responder y actuar antes determinadas amenazas u oportunidades que el entorno les proporcione (Liedholm, 2002). Consecuentemente, las pequeñas empresas con una orientación estratégica hacia la innovación pueden adaptarse a un entorno dinámico, con ayuda de sus capacidades y características organizativas permitiéndoles explotar su flexibilidad al cambio (Messenghen, 2003). Por otro lado, las grandes empresas, cuentan con recursos humanos y financieros que les permiten estar monitoreando el entorno y así ajustarse a los cambios y desafíos, no obstante, igual que las pequeñas empresas muchas veces se ven obligadas a reestructurarse por las exigencias del entorno. 
Primeramente, antes de entrar a las hipótesis de moderación, debemos observar si las variables del dinamismo del entorno están relacionadas con la innovación empresarial. El bloque de hipótesis es la siguiente;

P12: ¿actúa el dinamismo del entorno como condicionante en la innovación empresarial?

H12: el dinamismo del entorno tiene un efecto positivo en la innovación empresarial, es decir, cuanto mayor es el dinamismo del entorno, mayor es la innovación empresarial.

H12a: la turbulencia del entorno está relacionada positivamente con la innovación incremental.

H12b: la turbulencia del entorno está relacionada positivamente con la innovación radical.

H12c: la intensidad competitiva está relacionada positivamente con la innovación incremental.

H12d: la intensidad competitiva está relacionada positivamente con la innovación radical.

\subsection{Papel de la turbulencia del entorno: relación entre innovación y desempeño empresarial}

En la turbulencia del entorno están incluidas la turbulencia del mercado, la turbulencia tecnológica y el crecimiento del mercado según las dimensiones moderadoras propuestas originalmente por Kohli y Jaworski (1990). Se estudiará el efecto moderador de la turbulencia del entorno de forma global para las tres áreas: 
(1) la turbulencia tecnológica es interpretada como el grado de inestabilidad y evolución de la tecnología que envuelve los procesos de producción y distribución de las empresas (Kohli y Jaworski, 1990).

(2) la turbulencia del mercado está relacionada con los cambios continuos en la composición y preferencias de mercado objetivo (Kohli y Jaworski, 1990).

(3) el crecimiento del mercado concierne a la fortaleza de la demanda y el crecimiento económico (Kohli y Jaworski, 1990; Boyd et al., 1993).

Para muchos autores, la turbulencia del entorno, ha supuesto un factor moderador que puede reforzar las acciones estratégicas de innovación para alcanzar un mejor desempeño empresarial (Myers y Marquis, 1969; Miles y Snow, 1978; Covin y Slater, 1989; Özsomer et al., 1997; Souza et al., 2004). Sin embargo, este argumento pierde credibilidad cuando las empresas tienen dificultad para desarrollar las iniciativas innovadoras, en medio de un entorno hostil, debido a los elevados costes y riesgos que esto conlleva, repercutiendo negativamente en el desempeño empresarial (Vázquez et al., 2001; Carbonell y Rodríguez, 2005; Freel, 2005; Chaveerug y Ussahawanitchakit, 2008; Jadesadalug y Usshawanitchakit, 2008; Phromket y Ussahawanitchakit, 2009).

La turbulencia del entorno se considera una variable moderadora que puede afectar (positiva o negativamente) la relación entre la orientación estratégica de innovación y los resultados empresariales. Por ejemplo, la turbulencia del entorno puede afectar positivamente si las empresas con una orientación estratégica hacia la innovación aprovechan los cambios para (Meuss y Oerlemans, 2000; Messenghen, 2003);

(1) explotar sus capacidades y características organizativas,

(2) ajustar su oferta y ampliar sus esfuerzos comerciales según las necesidades de su mercado,

(3) potenciar el protagonismo de I+D y adoptar un enfoque de innovación continua. 
Pero también puede afectar negativamente la relación entre la innovación y el desempeño empresarial, cuando (Carbonell y Rodríguez, 2005);

(1) las empresas no reaccionan rápida y eficientemente ante las presiones del mercado,

(2) la hostilidad del entorno entorpece la implantación de iniciativas innovadoras perjudicando el retorno de la inversión y los márgenes de ganancia.

Antes de probar el efecto moderador de la turbulencia del entorno en la relación primero se comprobarán la hipótesis anterior sobre la relación directa.

P13: ¿actúa la turbulencia del entorno como condicionante en el desempeño empresarial?

H13: la turbulencia del entorno tiene un efecto positivo en el desempeño empresarial, es decir, cuanto mayor es la turbulencia del entorno, mayor es el éxito empresarial.

Ante los argumentos a favor y en contra sobre si el efecto moderador potencia o inhibe la relación, nuestras hipótesis de partida no establece el sentido del efecto;

P14: ¿actúa la turbulencia del entorno como moderadora de la relación entre la innovación y el desempeño empresarial?

H14: la turbulencia del entorno modera la relación entre la innovación y el desempeño empresarial, de manera que, cuanto más turbulento es el entorno, mayor es la contribución de la innovación al éxito empresarial.

H14a: la turbulencia del entorno modera la relación entre la innovación incremental y el desempeño empresarial.

H14b: la turbulencia del entorno modera la relación entre la innovación radical y el desempeño empresarial. 


\subsection{Papel de la intensidad competitiva: relación entre innovación y desempeño empresarial}

La intensidad competitiva se refiere a la hostilidad o dinamismo reflejado en el grado de rivalidad competitiva en el mercado. Está presente en el entorno y se manifiesta en acciones agresivas por parte de la competencia. La literatura en dirección estratégica apunta que la intensidad competitiva impacta positivamente en la innovación, generando ventajas competitivas y mejor desempeño empresarial (Fethke y Birch, 1982; Porter, 1985; Jermias, 2006). No obstante, algunos otros no advierten ningún efecto moderador en la relación (Jadesadalug y Usshawanitchakit, 2008; Phromket y Ussahawanitchakit, 2009), mientras que otros observan un efecto moderador negativo que obstaculiza la relación (Entrialgo et al., 2001; Carbonell y Rodríguez, 2005).

La revisión previa ha apuntado argumentos y evidencias empíricas tanto a favor como en contra Esto depende del tipo de innovación a implementar. Una alta intensidad competitiva puede potenciar u obstaculizar la implantación de una estrategia innovadora disipando los efectos favorables sobre el desempeño. Específicamente, la entrada de productos sustitutos, precios agresivos o competidores más grandes, pueden incrementar o decrecer los resultados esperados (Fiol, 2001; Freel, 2005). La justificación reside en que el dinamismo del entorno puede dificultar el desarrollo de una acción innovadora eficaz, y requerir un esfuerzo no compensado por los efectos favorables en la respuesta del mercado.

Antes de probar el efecto moderador de la intensidad competitiva en la relación primero se comprobarán la hipótesis el papel condicionante de la relación;

P15: ¿actúa la intensidad competitiva como condicionante en el desempeño empresarial?

H15: la intensidad competitiva tiene un efecto positivo en el desempeño empresarial, es decir, cuanto mayor es la intensidad competitiva, mayor es el éxito empresarial. 
Dado los argumentos a favor y en contra en la literatura, nuestra hipótesis de partida no establece el sentido del efecto;

P16: ¿actúa la intensidad competitiva como moderadora de la relación entre la innovación y el desempeño empresarial?

H16: la intensidad competitiva modera la relación entre la innovación y el desempeño empresarial, de manera que, cuanto más intensa sea la competencia, mayor es la contribución de la innovación al éxito empresarial.

H16a: la intensidad competitiva modera la relación entre la innovación incremental y el desempeño empresarial.

H16b: la intensidad competitiva modera la relación entre la innovación radical y el desempeño empresarial.

La Figura 18 representa gráficamente el modelo de análisis II. Este modelo incorpora en el análisis los factores organizacionales y del entorno como moderadores de la relación entre innovación y el desempeño empresarial A través de las flechas se pueden observar las trece distintas relaciones que se pretenden contrastar. 
Figura 17

Modelo de análisis II: los factores organizacionales y del entorno como moderadores de la relación entre innovación multidimensional y desempeño empresarial

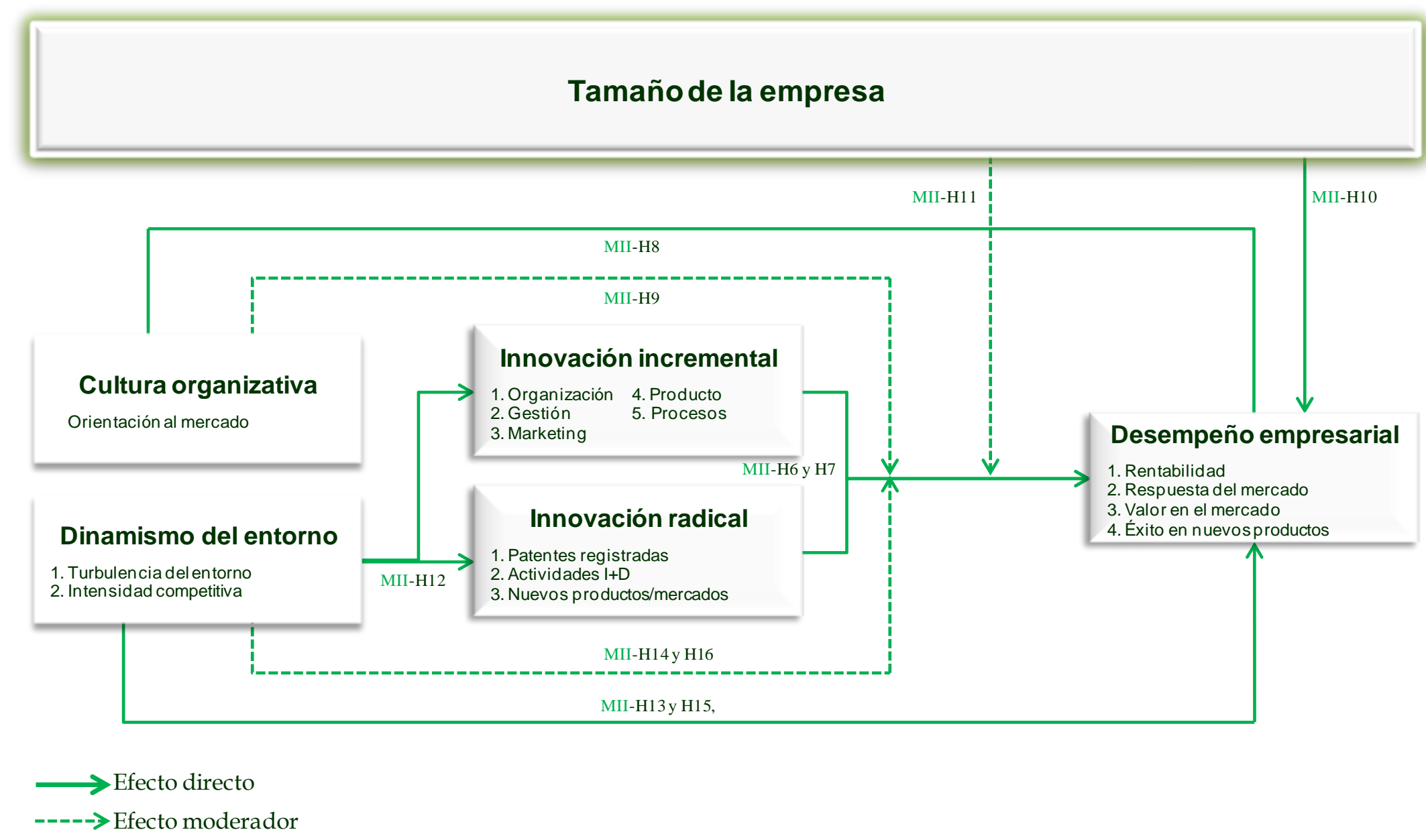




\title{
2.3.4. Factores de interacción con el entorno: colaboración organizacional
}

Para efectos de este estudio se entenderá el concepto de colaboración organizacional como un vínculo de cooperación externo que bajo un acuerdo voluntario permitan compartir $\mathrm{y}$ combinar conocimientos y recursos, y que buscan un beneficio para crear ventajas competitivas en la creación de valor para el cliente final (Kanter, 1994; Preiss et al., 1996; Wilkinson y Young, 2002). La OECD define la colaboración organizacional como;

\begin{abstract}
"Alianzas estratégicas como arreglos entre empresas independientes basadas en contratos de negocios que les permiten intercambiar recursos que mutuamente los benefician, como las tecnologías y habilidades (OECD, 2002:89).
\end{abstract}

La aportación literaria afirma que la colaboración organizacional aporta recursos complementarios o "recursos en red" (Gulati, 1998: 295). "Una de las razones del éxito de la colaboración es la disponibilidad de recursos complementarios entre los socios" (Mowery et al., 1998: 508). La complementariedad ofrece beneficio mutuo y genera un mayor y más rápido crecimiento del desempeño empresarial (Kogut y Zander, 1992; Eisenhardt y Shoonhoven, 1996; Greene y Brown, 1997).

En el marco de la teoría de redes sociales, dentro de la rama de la microeconomía, las relaciones de colaboración organizacional trabajan bajo una estructura de intercambio de conocimiento y flujos de información. Promueven soluciones en conjunto que propician una reducción de los costes de desarrollo de la innovación (capacidades de fabricación y regulación del know-how) y maximizar las oportunidades de comercialización (conocimiento del mercado y el acceso) (Chesbrough, 2003; Rothaermel y Deeds, 2004; Lundvall y Nielsen, 2005; Dhanaraj y Parkhe, 2006; Cetindamar y Ulusoy, 2008). Aprovechar esta disponibilidad aporta herramientas tecnológicas y de aprendizaje que acelerarían el desarrollo innovador (Rothwell, 1994; Saxenian, 1994). Aunque si bien es cierto, la OECD sigue insistiendo en que la capacidad existente en las redes de colaboración hace falta mecanismos para que el conocimiento y la información puedan ser dirigidos hacia procesos de innovación y apunta; 
"La visión de la innovación como sistema está estrechamente relacionada con el enfoque evolucionista. Los planteamientos de la innovación como sistema (Lundvall, 1992; Nelson, 1993) estudian la influencia de las instituciones externas, definidas en sentido amplio, sobre las actividades innovadoras de las empresas y de los otros agentes. Acentúa la importancia de la transferencia y de la difusión de las ideas, de la experiencia, del conocimiento, de la información y de otros muchos elementos. Esta información circula a través de canales y redes que se imbrican en un marco social, político y cultural que guía y delimita las actividades y la capacidad de innovación. La innovación es vista como un proceso dinámico en el que el conocimiento se acumula mediante el aprendizaje y las interacciones" (OECD 2005: 96).

Existen una serie de teorías que justifican la relación entre colaboración e innovación y el desempeño empresarial. Sin embargo, el razonamiento teórico que ampara este estudio se concentra en dos propuestas teóricas sobre las colaboraciones orientadas a la innovación y al éxito empresarial: la teoría basada en los recursos y capacidades y la teoría de redes sociales.

La idea de partida es que los recursos son escasos y limitados. Los recursos por sí solos no conducen a una ventaja competitiva. Los recursos requieren de cierta gestión y/o combinación que les de valor, porque lo esencial no radica en la propiedad del recurso en sí, sino en el valor creado a partir de cómo se combine con otros recursos dentro de la red de negocios (Harrison y Håkansson, 2006). Para ello, la introducción de las redes de colaboración refuerza esta ineficacia a través del intercambio y transferencia de recursos y capacidades entre las empresas vinculadas para fortalecer al éxito empresarial (Osborn y Hagedoorn, 1997). Estas estructuras de intercambio y colaboración tienen como objetivo potenciar el valor de los recursos de las empresas que, en línea con la teoría basada en los recursos, pueden generar una ventaja competitiva si se combinan y gestionan acertadamente (Barney, 1991; Grant, 1991; Mahoney y Pyian, 1992; Peteraf, 1993; Collis y Montgomery, 1995). 


\subsubsection{Teoría de redes sociales en el ámbito empresarial}

Para refrescar sobre la materia de la teoría de redes sociales, base del concepto de colaboración organizacional, se expondrá una serie de elementos que las caracteriza. Algunos términos relacionados a la teoría de redes tienen que ver con joint ventures, networks, alianzas estratégicas, relación entre socios, colaboración inter-organizacional, redes estratégicas y conglomerados (clusters).

¿Qué es una red? Según Håkansson y Ford (2002: 133) "un complejo mercado de negocios donde los nodos son las unidades de negocios y la relación entre las compañías son el hilo conductor". Pero no todo en las redes son beneficios también existen riesgos porque el control sobre la misma red es limitado y un cambio siempre involucra a todas las partes de la relación (Dubois, 1998). Aún así, las empresas simultáneamente cooperan por medio de mecanismos para alcanzar objetivos mutuos que conllevan a una ventaja competitiva a través de la innovación. Estos mecanismos incluyen "interacciones sociales, interacciones informales cara a cara, participación y movilidad en mercados laborales regionales, así como la participación en actividades de las instituciones regionales específicas para la acumulación y difusión del conocimiento" (Drejer y Vinding, 2007: 04).

De la literatura se pueden extraer tres grupos principales de objetivos que buscan las empresas en colaboración, que son:

(1) Aumentar los beneficios; en primer lugar, Wilkinson y Young (2002:124) dejan patente que varios tipos de costos de transacción (búsqueda de nuevos clientes o proveedores) se pueden reducir porque conocen y confían unos de otros y la coordinación se hace más habitual; y Nonaka (1994), respalda el argumento arguyendo que la colaboración ayuda a reducir el comportamiento oportunista como resultado de la inversión mutua.

(2) Obtener acceso y disponibilidad de recursos; las colaboraciones organizacionales promueven una comunicación más abierta, un mayor intercambio de información y la co-creación de conocimiento. Este conocimiento redunda en el desarrollo e implementación de estrategias de marketing (Wilkinson y Young, 2002), un incremento en la dependencia tecnológica, una amplificación de las conexiones de 
la red (Johanson y Mattson, 1992), y un refinamiento y extensión de competencias, tecnologías y paradigmas (Håkansson y Snehota, 1995; Kalwani y Narayandas, 1995).

(3) Desarrollar el conocimiento; Ingram y Simons (2002) afirma que las relaciones inter-empresariales son un mecanismo y un medio para buscar y transferir el conocimiento. Por otra parte, Hamel (1991) confirma que el objetivo de las alianzas inter-organizacionales es la posibilidad de acceder al conocimiento considerándose un medio efectivo de transferencia de aprendizaje e integración. Así que el conocimiento es valorado como un recurso clave (Day, 1994) para crear una ventaja competitiva sostenible (Mahoney y Pyian, 1992; Peteraf, 1993), además contribuye en el corto y largo plazo a aumentar los resultados del negocio (Fiol y Lyles, 1985) y al desarrollo de las competencias del personal (van Gelderen et al., 2005).

Aunque este estudio no pretende ser exhaustivo en el tema de la teoría de redes sociales, se mencionan cuatro elementos básicos de su caracterización.

(1) Tipo de estructuras de redes que poseen implicaciones según su forma -cerrada o abierta: las estructuras cerradas, son redes de alta densidad que integran una multitud de conexiones y facilitan la relación entre los actores (Walker et al., 1997). Las redes abiertas proporcionan más bien distintas oportunidades de retribución (Burt, 1992). En cuanto a esto, algunos autores opinan que la red óptima es la que está construida por una densa red conectada entre sí (Portes, 1998; Coleman, 1999; Ahuja, 2000; Dyer and Nobeoka, 2000; Chesbrough, 2006; Schilling y Phelps, 2007), mientras que para otros, la red perfecta es la que provee varios grupos desconectados y utiliza esas colaboraciones para entrar en la dinámica de aprendizaje y ventajas de control sobre los otros (Burt, 1992, 2001; Hargadon y Sutton, 1997; McEvily y Zaheer, 1999) porque proveen a los participantes acceso oportuno a la variada información (Phelps, 2010).

(2) Tipo de vínculo - directo o indirecto: tienen la finalidad de examinar su contribución eficiente y eficaz en los flujos de conocimiento (Powell et al., 1996). Los primeros 
permiten a los actores disfrutar de los beneficios del tamaño de la red sin tener que asumir los costos de mantenimiento de una red directa (Burt, 1992).

(3) Tipo de conocimiento que se proponga adquirir -tecnológico o comercial: los acuerdos de colaboración pueden implicar un componente tecnológico (horizontal) con el propósito de explorar nuevas oportunidades; por ejemplo, el desarrollo de una nueva tecnología o compartir un proceso de fabricación; o un componente comercial (vertical) para explotar una capacidad existente; por ejemplo, el intercambio de los activos de marketing o comercialización (Singh y Mitchell, 1996; Gulati y Lawrence 1999; Grant y Baden-Fuller, 2004; Rothaermel et al., 2006; Lavie y Rosenkopf, 2006; Chesbrough y Appleyard, 2007).

(4) Tipo de proximidad con lo socios para la colaboración en la innovación: la proximidad más estudiada en la literatura es la geográfica, pero Boschma (2005) argumenta que existen otras formas de proximidad, como la cognitiva, la organizacional, la social y la institucional. Las dos más sobresalientes en la literatura son la geográfica y la cognitiva. Según Morgan (2004) la proximidad geográfica ayuda a las empresas a encontrar adecuadamente a sus socios de colaboración. No obstante, la proximidad cognitiva está en función de la similitud de la base de comportamiento de las organizaciones, o sea, que las empresas están cognitivamente más próximas en la medida que compartan competencias tecnológicas y mercados similares (Boschma, 2005) con los agentes externos a la organización.

Autores como Torre y Rallet (2005) y Boschma (2004, 2005) afirman que las proximidades cognitivas facilitan el intercambio colaborativo mediante leguajes comunes de creencias, mapas cognitivos, base de conocimiento y habilidades para potenciar la relación y tener el mayor efecto en el aprendizaje tecnológico (Kim y Inkpen, 2005). Dentro de los agentes externos de proximidad cercana se encuentran los proveedores, los clientes, los competidores y otras empresas del grupo, y posiblemente una proximidad más lejana con universidades, centros tecnológicos, consultores, asociaciones y licenciadores (Nooteboom, 1999; Chesbrough, 2003; Chesbrough y Appleyard, 2007). 
Si bien es cierto, la difusión de conocimientos deseados e intencionados suelen ser limitados, son más frecuentes en la colaboración cognitiva cercana (Jong y Freel, 2010). Asimismo, Bathelt (2003) argumenta que las relaciones cercanas frecuentemente son más fructíferas para promover mejoras o nuevas ideas cuando están apoyados por las relaciones lejanas. Esta naturaleza de relación cognitiva promueve las interacciones cara a cara como una vía de superar los problemas que surgen en las relaciones, como la descoordinación y la desmotivación. La proximidad de los socios cercanos facilita este proceso. Aunque está claro que ningún tipo de proximidad es suficiente para la interacción ideal.

Para efectos de este estudio se tratara el concepto de red social con el término de colaboración organizacional. La colaboración organizacional se entenderá como un vínculo de cooperación entre organizaciones que bajo un acuerdo voluntario permiten compartir conocimientos y recursos, y que buscan un beneficio para crear ventajas competitivas en la creación de valor para el cliente final (Kanter, 1995; Preiss et al., 1996; Wilkinson y Young, 2002; Chesbrough y Appleyard, 2007). En esta investigación no se delimitará el concepto de colaboración organizacional por ninguna estructura en concreto (abierta o cerrada), ni por su tipo de contribución (directa e indirecta), ni por la dirección del componente de intercambio que posea (horizontal o vertical), pero si se diferenciará por su tipo proximidad cognitiva de colaboración (cercano o lejano).

\subsubsection{Teoría basada en los recursos y su influencia en la teoría de redes sociales}

De acuerdo a los postulados de la teoría basada en los recursos, estos son escasos y limitados (Barney, 1991; Grant, 1991; Mahoney y Pandian, 1992; Peteraf, 1993; Collis y Montgomery, 1995) y no se consideran factores determinantes para generar una ventaja competitiva respecto a su competencia (Grant, 1991). Esta teoría complementa la teoría tradicional de Porter (1985) sobre las ventajas competitivas. La utilización de estos recursos debe estar en línea con la estrategia de la empresa, procurando que estos sean únicos y no fácilmente sustituibles para sus rivales, aunque conlleven complejos procesos de coordinación dinámica y de cooperación (Grant, 1991; Schulze, 1994). Esto lleva a las 
empresas a mejorar sus condiciones para enfrentar las amenazas y fortalecer las debilidades para ser más competitivas en su propio entorno (Pelham y Wilson, 1996; Hult et al., 2003). Algunos de los estudios relacionados con la teoría de recursos y capacidades y el análisis estratégico han estado orientados generalmente al estudio de grandes empresas (Prahalad y Hamel, 1990; Hall, 1993; Collis y Montogomery, 1995), no obstante, Rangone (1999) у Aragón y Sánchez (2005) hacen una aproximación para la pequeña y mediana empresa.

Las empresas pueden alcanzar una ventaja competitiva de acuerdo al modo en que se empleen esos recursos. Es necesario que el conjunto de los recursos se combinen y manejen coordinadamente para lograr rendimientos superiores (Collis y Montgomery, 1995), y establezcan un punto de referencia competitiva (Barney, 1991). Este postulado lo resume Håkansson (1987:15) afirmando que "los recursos son combinados, desarrollados, intercambiados o creados para ser usados con otros recursos", pero lo esencial no radica en la propiedad del recursos en sí, sino en el valor creado a partir de cómo se combine con otros recursos dentro de la red de negocios (Harrison y Håkansson, 2006)

Al parecer una de las maneras en que las empresas pueden superar las limitaciones de recursos financieros y de capital humano para desarrollar proyectos de innovación es la participación conjunta para colaborar agentes externos, ya sean entes públicos o privados, cercanos al canal o mediante asesoría.

Alejándose de la centralidad de la 'potencialización' de los recursos por medio de la participación en redes de colaboración, ahora se desarrolla la idea de ¿cómo el recurso de la innovación puede potenciarse a través de las redes de colaboración empresarial? Como apunta Christensen (1995), la innovación es un recurso intangible que debe ser sostenible. Una manera de utilizar adecuadamente el recurso de la innovación para generar ventaja competitiva es introducirlo dentro del nuevo sistema de "innovación abierta -open innovation" y su derivada "modelos abiertos de negocio - open business models", liderada desde hace unos años por el profesor de la Universidad de Berkeley, Henry Chesbrough; y apunta que “... innovación abierta presenta un modelo donde los nuevos productos provienen tanto de fuentes internas como externas, y donde éstas pueden entrar a formar parte del proceso de innovación en todos los puntos de la cadena hasta llegar al producto final. Pero la 
innovación abierta no contempla las innovaciones sólo como "input” en el proceso, sino también como output" (Chesbrough, 2006). Tal como lo sintenteza Vega-Vidal (2010):

"la innovación abierta supone un cambio cultural de gran impacto donde deben aprovecharse las capacidades externas al tiempo que se superan las resistencias internas al cambio".

En la Figura 16, se puede observar como el característico proceso "endogámico" conexo a los temas de la capacidad innovadora, hoy día se releva por otro más "exogámico" que contempla una clase de vínculos más heterogéneos donde prima la absorbencia del conocimiento y su puesta en valor, entre las empresas y su entorno.

Figura 18

\section{Innovación abierta}

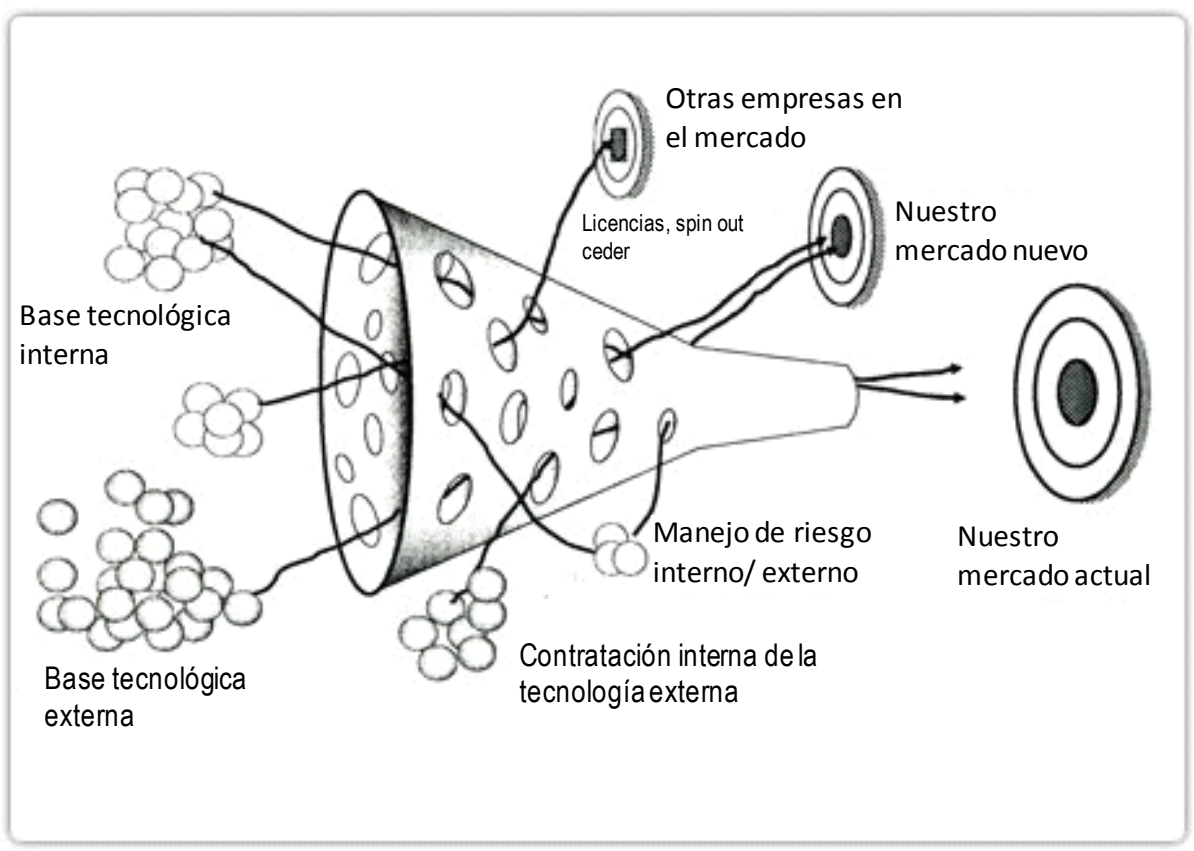

Fuente: Prof Henry Chesbrough UC Berkeley. Open innovation. Renewing growth from industrial R\&D, 10th Annual Innovation Convergence, Minneapolis Set 27, 2004.

Este sistema de colaboración genera un conjunto de oportunidades, entre ellas la contribución de recursos complementarios o mejor llamado por Gulati (1998) "recursos en red", ya que según Mowery et al. (1998) una de las razones del éxito de la colaboración es la disponibilidad de recursos complementarios y el aprendizaje entre los socios. Por un lado, las redes y los recursos deben desarrollarse y combinarse de muy distintas maneras para crear 
más oportunidades de innovación para el beneficio mutuo, un mayor crecimiento y más rápido (Greene y Brown, 1997). Por otro lado, las empresas deben desarrollar el conocimiento a través del aprendizaje mutuo, que según los propulsores de la teoría de recursos y capacidades, el aprendizaje organizacional, puede ser uno de esos recursos productivos claves para crear una ventaja competitiva sostenible (Day, 1994), además de contribuir en el corto plazo al desarrollo de las competencias del personal y a los resultados del negocio (Fiol y Lyles, 1985; van Gelderen et al., 2005).

Entonces, la dificultad de generar ventaja competitiva por medio de recursos escasos y limitados podría influir en la toma de decisiones para la formación de colaboraciones externas con el fin de multiplicar el valor (capacidades y recursos) en cada fase del proceso de innovación (Eisenhardt y Shoonhoven, 1996) y la generación de resultados empresariales (Barney, 1991; Grant, 1991). Por último, Chyler y Hanks (1994) trataron de establecer una relación entre la teoría de basada en los recursos y la innovación; concluyeron que las empresas con mayores recursos y capacidades emprendían una mayor cantidad de mejoras o nuevas actividades que conducían a mejores resultados y un comportamiento más competitivo que aquellas que poseían menos recursos.

\subsubsection{Papel de la colaboración organizacional en la innovación: diferencias entre grandes y pequeñas empresas}

La manera en que las empresas pueden satisfacer sus obligaciones de innovación tecnológica es parte de los objetivos primordiales en la agenda estratégica. Una opción es establecer alianzas de colaboración tecnológica que constituye una vía intermedia entre el mercado y el desarrollo interno, lo que provoca un ahorro de costes en los proyectos de innovación (Zysman, 1993). Por medio de las alianzas de colaboración, la innovación se implica en una constante labor multidisciplinar y de equipo, y conlleva a una reorganización endógena y a estrechar asociaciones exógenas con proveedores, clientes, competidores, sistema público etc., que les permitirán complementar los recursos y capacidades empresariales.

La lógica subyacente a la contribución de la colaboración a la innovación es la aportación de recursos y capacidades necesarios para un desempeño favorable. De esa 
manera, las empresas no dependen exclusivamente de desarrollar recursos y conocimiento internamente (Swaminathan y Moorman, 2009). La capacidad limitada para predecir el resultado de las acciones estratégicas, sumado a la escasez de los recursos y al elevado costo de adquirir el conocimiento, hacen cada vez más difícil alcanzar el éxito empresarial (Wilkinson y Young, 2002).

En el contexto de emprendedorismo, Cassandra (2004) apunta que uno de los principales problemas de las empresas emprendedoras es lograr acumular y acceder a recursos y capacidades. A este respecto, la interacción inter-organizacional refuerza las habilidades, aminora la limitación de los recursos, favorece la combinación del conocimiento, propicia la creatividad y promueve la exploración y explotación de nuevas vías de negocio. Esto aporta una mejora del crecimiento económico y un aumento de la competitividad (Dyer and Singh, 1998; Gulati, 1999; Soh, 2003; Soh y Roberts, 2005; Hewitt-Dundas, 2006; Daugherty et al., 2006). "La colaboración organizacional se afianza como un mecanismo firme para que las empresas puedan aprovechar el acceso al entorno de recursos y conocimiento externo, y por ende, a la mejora de los resultados" (Rothaermel y Deeds, 2004: 216). En definitiva, las alianzas proactivas derivan en un incremento de la competitividad.

En particular, las empresas se unen para aprovechar las fuentes externas de conocimiento y recursos para potenciar y orientar certeramente sus procesos de innovación. En este sentido, la innovación puede ser fuente de competitividad al beneficiarse de las herramientas que proporcionan los entornos de colaboración. Todo ello dependerá, principalmente, de la capacidad de absorber, promover, y aplicar el nuevo conocimiento adquirido para hacer más acertada la innovación (Cohen y Levinthal, 1990; Inkpen, 1998; Lane y Lubatkin, 1998; Kenney, 2001; Lane et al., 2001; Nieto y Quevedo, 2005).

Por otra parte, el papel de la colaboración puede diferir según el tamaño de las empresas. La limitación de las pequeñas empresas al acceso de recursos y capacidades las hace menos asertivas a la hora de encaminar proyectos de innovación (Yasuda, 2005). Por esa razón, las pequeñas empresas refuerzan sus limitaciones aprovechando de las redes de colaboración. Buscan beneficiarse de la complementariedad que estos entornos facilitan para emprender el éxito innovador (Sen y Haq, 2011). 


\subsection{Innovación y colaboración organizacional}

La línea más tradicional ha expuesto a que gracias a la influencia de las alianzas establecidas es más frecuente el aprendizaje empresarial, nuevas capacidades y la adopción e implementación de la innovación (Hamel, 1991; Shan et al 1994; Leonard-Barton, 1995; Walker et al., 1997; Smith- Doerr et al., 1999; Ahuja, 2000; Soh, 2003; Soh y Roberts, 2005). Desde casi dos décadas se ha utilizado un enfoque de red de colaboración para analizar el estudio de la generación de innovación, algunos trabajos pioneros han ido por esta dirección (Poldony y Stuart, 1995; Powell et al. 1996; Jassawalla y Sashittal, 1998; Stuart, 1998; Fukugawa, 2005; Story et al., 2011).

Por otra parte, también se observa en la literatura de management distintos enfoques que estudian la relación de la colaboración organizacional y la innovación. Algunos han distinguido entre los vínculos horizontales y verticales (Gulati y Lawrence, 1999) o sólo se han restringido a los efectos técnicos entre empresas del mismo sector (Ahuja, 2000; Hess y Rothaermel, 2011). Otro estudio que ha explorado el nexo de la colaboración y la innovación, es el de Lefebvre (2003) donde ha involucrado el elemento electrónico que estudia los sistemas de colaboración basados en Internet. Hay quienes han utilizado el elemento más específico de la innovación radical aportando una fuerte evidencia de como la cooperación está relacionada con el desarrollo de nuevos productos (Eisenhardt y Tabrizi, 1995; Griffin y Hauser, 1996; Jassawalla y Sashittal, 1998), mientras que otros más dedicados al elemento incremental de la innovación, concluyen que la colaboración de recursos tecnológicos mejoran la innovación empresarial (Baum et al., 2000; Stuart, 2000).

Cuando hay colaboración, la innovación empresarial es un vehículo que encamina hacia el éxito, proveyendo un entorno de coyunturas que por si solas las empresas no serían capaces de alcanzar (Czarnitzki y Spielkamp, 2000; Kogut, 2000). La colaboración se convierte, por tanto, en una clave para el éxito del proceso innovador. La investigación de Sanders y Premus (2005) predijeron y dedujeron que la colaboración externa tiene un impacto directo y positivo en la innovación. En la Tabla 16, se puede apreciar las diferentes relaciones que se han contrastado a nivel teórico y/o empírico en la literatura de organización industrial y management. En primer lugar se observan las relaciones de la colaboración organizacional, como un todo, con la innovación, sea unidimensional o multidimensional. 
El estudio de Tether (2002b), que trabaja, con una muestra de empresas innovadoras inglesas, confirma que la colaboración está en manos de empresas que buscan innovaciones radicales antes que incrementales, lo que confirma también el estudio de Story et al. (2011). Por otro lado, Kim y Park (2010), examinaron el impacto de la innovación radical e incremental de una empresa mediante el análisis de su posición en una red de I+D y su orientación hacia el uso de los conocimientos científicos; y concluyeron que la colaboración organizacional se relaciona positivamente con la innovación porque permiten a las empresas lograr objetivos económicos.

Más concretamente y en línea con los objetivos de este estudio, se cita la investigación de Sen y Haq (2011) que analizan el papel de la colaboración para obtener innovación de productos. Las dos principales conclusiones del trabajo, respecto a la relación, sugieren que las empresas están involucradas en la colaboración externa para apoyar el desarrollo de nuevos productos y concuerdan que las empresas colaboran con las redes externas para sus actividades básicas y no básicas.

Otros varios autores también concluyeron que la relación entre colaboración e innovación permiten mejorar y crear nuevos productos y nuevos mercados, mejorar procesos productivos, de gestión y comercialización, optimizar la I+D, e introducir patentes (Griffith, 1999; Vanhaverbeke et al., 2002; Harris y Robinson, 2003; Belderbos et al., 2004; Fukugawa, 2005; Kim y Inkpen, 2005; Kim y Park, 2010; Lehtoranta, 2010; Sen y Haq, 2011). Hay quienes han utilizado el elemento más específico de la innovación radical aportando una fuerte evidencia de la relación entre la cooperación y el desarrollo de nuevos productos (Eisenhardt y Tabrizi, 1995; Griffin y Hauser, 1996; Jassawalla y Sashittal, 1998). No obstante, Klomp y van Leeuwen (2001) consideran que una correlación positiva entre la cooperación y los "outputs" de la innovación, tales como patentes y nuevos productos y mercados, puede ser falsa y no causal.

Las empresas establecen colaboraciones para gestionar con éxito la cooperación que aporta mayores fuentes externas de recursos y mecanismos de aprendizaje para absorber las técnicas de innovación. Reconocer la importancia de las redes de colaboración es de suma importancia para la gestión innovadora pues de una manera flexible se logran coordinar una serie de proyectos de gran valor dinámico (aprendizaje) y creativo. 


\subsubsection{2. Colaboración con los proveedores, clientes, y competidores}

La literatura confirma que la colaboración con los proveedores, clientes y competidores pueden estar enfocados a las innovaciones radicales e incrementales. Para Klomp y van Leeuwen (2001) y Belderbos et al. (2004), la colaboración de los proveedores y competidores está más enfocada a la innovación incremental, mientras que la colaboración con los clientes es más fuerte para lograr innovaciones radicales. Respecto a este punto, Lööf y Heshmati (2002), llegan a conclusiones distintas a Belderbos et al. (2004), estos dicen que las empresas innovadoras que están sumergidas en colaboraciones con los competidores obtienen mejores "outputs" de la innovación, o sea, que incentivan mejor las patentes y la creación de nuevos negocios.

Los investigadores Fritsch y Lukas (2001) hallan que es más probable que la mejora en la innovación de procesos sea más factible a través de las colaboraciones con los proveedores, mientras que las innovaciones de producto están más relacionadas con la colaboración con los clientes, esta última conclusión, sobre los clientes, también alcanzaron Griffith (1999) y Harris y Robinson (2003), sin embargo para Belderbos et al. (2004) persiste una relación negativa con las acciones de producto cuando la colaboración se hace mediante los clientes de la empresa.

\subsection{Colaboración con consultores y universidades}

Según el estudio Fukugawa (2005) las empresas suelen colaborar más con las consultoras para solucionar problemas en la producción o desarrollo de procesos. Lööf y Heshmati (2002) y Belderbos et al. (2004), concuerdan que la colaboración con la universodad aporta al esfuerzo empresarial, sobre todo, en empresas con actividades de desarrollo tecnológico y de producto, innovaciones radicales. Al parecer, la colaboración con la universidad juegan un papel decisivo en la creación y llevar al mercado las innovaciones radicales, la generación de las ventas de productos que son novedosos en el mercado y, por lo tanto, mejorar el desempeño del crecimiento de las empresas (Klomp y van Leeuwen, 2001). No obstante, para Motohashi (2005) la base científica de la universidad intenta alcanzar un mayor éxito en innovaciones técnicas y comerciales. 
Dados los argumentos anteriores que respaldan o rechazan la significatividad de la relación entre la colaboración y la innovación, se parten la siguiente hipótesis de trabajo;

P17: ¿actúa la colaboración organizacional como condicionante en la innovación empresarial?

H17: La colaboración organizacional tiene un efecto positivo en la innovación empresarial, es decir, cuanto mayor es la colaboración organizacional, mayor es la innovación empresarial.

H17a: la colaboración del canal está relacionada positivamente con la innovación incremental.

H17b: la colaboración de asesoría está relacionada positivamente con la innovación incremental.

H17c: la colaboración canal está relacionada positivamente con la innovación radical.

H19d: la colaboración asesoría está relacionada positivamente con la innovación radical.

\subsection{Innovación y colaboración: diferencias entre grandes y pequeñas empresas}

Las pequeñas empresas han tenido una creciente interacción con la colaboración organizacional para implantar acciones innovadoras; por ejemplo, las empresas pequeñas han decidido dedicarse a la investigación compartida con la base científica de la universidad para implantar más innovaciones técnicas y comerciales (Harris y Trainor, 1995; Motohashi, 2007, 2008). En la misma línea, tanto las grandes empresas (Powell et al., 1996; Baum et al., 2000; Sampson, 2007) como las pequeñas (Rothwell, 1991; Sen y Haq, 2011) aprovechan las colaboraciones con los socios externos para implantar innovaciones radicales enfocadas a los "outputs", desarrollo de productos y patentes. 
Tabla 16

Tipo de contribución de la colaboración a la innovación e interacción con el tamaño

\begin{tabular}{|c|c|c|c|c|c|c|c|c|c|}
\hline & Innovación radical & $\begin{array}{l}\text { Patentes } \\
\text { registradas }\end{array}$ & Actividades I+D & $\begin{array}{l}\text { Desarrollo de nuevos } \\
\text { productos y mercados }\end{array}$ & $\begin{array}{l}\text { Innovación } \\
\text { incremental }\end{array}$ & $\begin{array}{l}\text { Innovación de } \\
\text { organización }\end{array}$ & $\begin{array}{l}\text { Innovación de } \\
\text { marketing }\end{array}$ & $\begin{array}{c}\text { Innovación de } \\
\text { producto }\end{array}$ & $\begin{array}{c}\text { Innovación de } \\
\text { procesos }\end{array}$ \\
\hline $\begin{array}{l}\text { Colaboración } \\
\text { organizacional }\end{array}$ & $\begin{array}{l}\text { Tether }(2002 b) ; \\
\text { Kim y Park (2010) }\end{array}$ & $\begin{array}{l}\text { Klomp y van } \\
\text { Leeuwen (2001); } \\
\text { Vanhaverbeke et } \\
\text { al. (2002); } \\
\text { Fukugawa (2005); } \\
\text { Kim y Park (2010) }\end{array}$ & $\begin{array}{l}\text { Belderbos et al. } \\
(2004) ; \\
\text { Kim y Inkpen } \\
(2005) ; \\
\text { Kim y Park (2010) }\end{array}$ & $\begin{array}{l}\text { Eisenhardt y Tabrizi } \\
\text { (1995); Griffin y Hauser } \\
\text { (1996); Jassawalla y } \\
\text { Sashittal (1998); Griffith } \\
\text { (1999); Klomp y van } \\
\text { Leeuwen (2001); Harris y } \\
\text { Robinson (2003); Kim y } \\
\text { Inkpen (2005); Kim y Park } \\
\text { (2010); Sen y Haq (2011) }\end{array}$ & $\begin{array}{l}\text { Kim y Park } \\
(2010)\end{array}$ & $\begin{array}{l}\text { Kim y Inkpen } \\
(2005) ; \\
\text { Kim y Park } \\
(2010)\end{array}$ & $\begin{array}{l}\text { Lehtoranta } \\
(2010)\end{array}$ & $\begin{array}{l}\text { Sen y Haq } \\
(2011)\end{array}$ & $\begin{array}{l}\text { Kim y Inkpen } \\
(2005) ; \\
\text { Kim y Park } \\
(2010)\end{array}$ \\
\hline $\begin{array}{l}\text { Colaboración } \\
\text { proveedores }\end{array}$ & & & & & $\begin{array}{l}\text { Belderbos et al. } \\
(2004)\end{array}$ & & & & $\begin{array}{l}\text { Fritsch y Lukas } \\
(2001)\end{array}$ \\
\hline $\begin{array}{l}\text { Colaboración } \\
\text { clientes }\end{array}$ & $\begin{array}{l}\text { Belderbos et al. } \\
(2004)\end{array}$ & $\begin{array}{l}\text { Lööf y Heshmati } \\
(2002)\end{array}$ & & $\begin{array}{l}\text { Griffith (1999); } \\
\text { Lööf y Heshmati (2002); } \\
\text { Harris y Robinson (2003) }\end{array}$ & & & & $\begin{array}{l}\text { Fritsch y Lukas } \\
(2001)\end{array}$ & \\
\hline $\begin{array}{l}\text { Colaboración } \\
\text { competidores }\end{array}$ & & $\begin{array}{l}\text { Lööf y Heshmati } \\
(2002)\end{array}$ & & Lööf y Heshmati (2002) & $\begin{array}{l}\text { Belderbos et al. } \\
(2004)\end{array}$ & & & & \\
\hline $\begin{array}{l}\text { Colaboración } \\
\text { consultores }\end{array}$ & & & & & & & & & $\begin{array}{l}\text { Fukugawa } \\
(2005)\end{array}$ \\
\hline $\begin{array}{l}\text { Colaboración } \\
\text { universidad }\end{array}$ & $\begin{array}{l}\text { Belderbos et al. } \\
(2004)\end{array}$ & & Lehtoranta (2010) & Motohashi (2005) & & & $\begin{array}{l}\text { Motohashi } \\
(2005)\end{array}$ & $\begin{array}{l}\text { Motohashi } \\
(2005)\end{array}$ & $\begin{array}{l}\text { Motohashi } \\
(2005)\end{array}$ \\
\hline $\begin{array}{l}\text { Colaboración x } \\
\text { tamaño }\end{array}$ & $\begin{array}{l}\text { Powell etal.(1996); } \\
\text { Baum etal.(2000); } \\
\text { Sampson (2007); } \\
\text { Harris yTrainor(1995) }\end{array}$ & $\begin{array}{l}\text { Powell etal.(1996); } \\
\text { Baum etal.(2000); } \\
\text { Sampson (2007); } \\
\text { Sen y Haq (2011) }\end{array}$ & $\begin{array}{l}\text { Powell etal.(1996); } \\
\text { Sampson (2007) }\end{array}$ & $\begin{array}{l}\text { Powell et al. (1996); } \\
\text { Motohashi (2007); } \\
\text { Sampson (2007); } \\
\text { Sen y Haq (2011) }\end{array}$ & & & $\begin{array}{l}\text { Motohashi } \\
(2008)\end{array}$ & $\begin{array}{l}\text { Motohashi } \\
(2008)\end{array}$ & $\begin{array}{l}\text { Motohashi } \\
(2008)\end{array}$ \\
\hline
\end{tabular}

Fuente: elaboración propia 


\subsubsection{Papel de colaboración organizacional en la relación entre innovación y desempeño empresarial: diferencias entre grandes y pequeñas empresas}

\subsection{Colaboración y desempeño empresarial}

Todo lo anterior se refiere a la relación de la colaboración con la innovación pero ¿qué sucede con la relación vinculada al desempeño empresarial? Diversas posiciones teóricas y empíricas han constatado que la colaboración entre organizaciones facilita y promueve el comportamiento innovador y el éxito de los resultados empresariales (Gulati, 1998). Principalmente, el papel facilitador de las colaboraciones se resume en la dinámica de aprendizaje y los recursos en red. Existe un amplio consenso en la literatura especializada sobre los beneficios de las redes en el desempeño empresarial reflejándose en la acumulación de conocimiento útil que ayudará a los administradores en la gestión de la innovación tecnológica para obtener resultados exitosos, no obstante, los efectos específicos sobre los resultados siguen teniendo un interés particular.

Parece que no solamente es importante observar como las empresas entran en asociaciones de innovación sino también explorar el desempeño que producen al formarse este tipo de colaboraciones. Los datos resultantes de la investigación relacionados al desempeño empresarial ayudarán a divisar los elementos y mecanismos críticos de la colaboración organizacional. Por esta razón, proponemos investigar la relación entre colaboración y las dimensiones propuestas de desempeño empresarial.

La colaboración organizacional en conjunto con la innovación promueven la intensidad del conocimiento, contribuyendo, en gran medida, al crecimiento y al desempeño económico (Drejer y Vinding, 2005), por lo tanto, puede derivar beneficios potenciales operacionales, estratégicos y financieros, tangibles e intangibles como la mejora del servicio al cliente, mejores tiempos de respuesta, etc. que se traducen en:

(1) aumento de la rentabilidad (Lummus et al. 1998; Tether, 2002b; Belderbos et al., 2004; Drejer y Vinding, 2005; Sanders y Premus, 2005), 
(2) crecimiento de las ventas (Cincera et al., 2004),

(3) mejora la productividad laboral (Griffith, 1999; Harris y Robinson, 2003),

(4) intensifica el posicionamiento e imagen empresarial (Lummus et al. 1998; Mentzer et al. 2000; Lefebvre, 2003),

(5) alcanza el éxito de los nuevo productos (Klomp y van Leeuwen, 2001; Lööf y Heshmati, 2002; van Leeuwen, 2002; Criscuolo y Haskel 2003; Janz et al 2003; Janz et al 2004).

\subsection{Colaboración con los proveedores, clientes, y competidores}

En el estudio de Belderbos et al. (2004), la colaboración con los competidores puede alcanzar múltiples objetivos en el éxito empresarial, por un lado, intensifica la productividad del trabajo, por otro lado, aumenta el crecimiento de las ventas y el éxito de nuevos productos; probablemente se debe que al colaborar juntos se comparte el riesgo en los proyectos de innovación y a la vez, las ventas permiten iniciar nuevos ciclos de innovación conjunta. También concluyen que la colaboración con los proveedores impacta significativamente con la productividad laboral, mientras que las colaboraciones externas con la universidad afecta positivamente el crecimiento de las ventas y el éxito de los nuevos productos incursionados en el mercado. Los resultados de Lehtoranta (2010) sugieren que la colaboración con los clientes, y competidores puede contribuir directamente al crecimiento de las ventas.

\subsection{Colaboración con consultores y universidades}

Las colaboraciones con los consultores y las universidades pueden originar el éxito de nuevos producto y el crecimiento de las ventas, ya que es frecuente que se realicen este tipo de alianzas para lograr una reducción de costes y optimizar los procesos enfocados a incrementar la rentabilidad de las innovaciones radicales (Belderbos et al., 2004; Fukugawa, 2005). 
Entonces a partir de los argumentos sobre la relación entre la colaboración y el desempeño empresarial, se formula la siguiente hipótesis;

P18: ¿actúa la colaboración organizacional como condicionante en el desempeño empresarial?

H18: la colaboración organizacional tiene un efecto positivo en el desempeño empresarial, es decir, cuanto mayor es la colaboración organizacional, mayor es el éxito empresarial.

H18a: la colaboración del canal tiene un efecto positivo en el desempeño empresarial.

H18b: la colaboración de asesoría tiene un efecto positivo en el desempeño empresarial.

\subsection{Colaboración y desempeño empresarial: diferencias entre grandes y pequeñas empresas}

Como se ha puesto de manifiesto, los entornos de colaboración promueven el intercambio y transferencia de recursos y conocimiento proveyendo a las empresas de ventaja competitiva (Mowery et al., 1996). Sin embargo, la diferencia del tamaño de la empresa induce a pensar que algunas empresas aprovechen más de unas colaboraciones u otras para alcanzar la competitividad.

Algunos autores han encontrado evidencia de que las pequeñas empresas aprovechan más la colaboración para obtener resultados más óptimos; por ejemplo, Link y Rees (1990) y Sen y Haq (2011) encontraron una interacción inversa del efecto del tamaño en la relación, aluden que las pequeñas empresas aprovechan mejor las colaboraciones con el canal externo para generar un crecimiento potencial basado en la relación (desarrollo de productos y patentes) y obtener un mayor aumento en el retorno (Sakakibara, 1997). Contrario a la evidencia anterior, Baum et al. (2000) y Motohashi (2007, 2008) confirman que son las 
grandes empresas las que aprovechan más la innovación conjunta para alcanzar mayor desempeño empresarial.

\subsection{Papel de la colaboración en la relación entre innovación y desempeño}

Según la argumentación teórica anterior, la colaboración (del canal o de asesoría) promovida simultáneamente con la innovación origina una sinergia que hace mayor el beneficio que la suma de ambos. Cuando actúan en conjunto, la colaboración genera acciones de innovación más acertadas. Por lo tanto, la sinergia de la colaboración y la innovación pueden derivar a mayor desempeño operacional, estratégico y financiero. Belderbos et al. (2004) y Lehtoranta (2010) confirman esta deducción al afirmar que las empresas con colaboraciones con los clientes y la universidad enfocadas a las innovaciones radicales conducen a un mayor crecimiento de las ventas, sin embargo, Klomp y van Leeuwen (2001) encontraron evidencia negativa en relación a esta postura. Por otro lado, en consecuencia con los estudios de Belderbos et al. (2004) y Lehtoranta (2010), las colaboraciones entre los competidores y con los proveedores hacia innovaciones radicales generan una rentabilidad empresarial mayor que con otros tipos de colaboración.

También encontramos resultados de éxito empresarial cuando la colaboración se relaciona con los "outputs" de la innovación (patentes y desarrollo de nuevos productos); por ejemplo, Vanhaverbeke et al. (2002) encontró que la relación de la colaboración con la innovación radical de patentes está positivamente relacionado con la rentabilidad de la empresa. Respecto al desarrollo de nuevos productos y servicios en nuevos mercado, Belderbos et al. (2004) concluye que la colaboración ente competidores y con las universidades promueve el incremento de las ventas.

Concerniente a las actividades de $\mathrm{I}+\mathrm{D}$, numerosos estudios han medido el impacto de la colaboración organizacional en las inversiones I+D (gastos-personal) y han llegando a la conclusión de que este tipo de relación genera un mayor rendimiento, mayores ventas de productos innovadores, y crecimiento de las ventas, que si se actuara en solitario (Klomp y van Leeuwen, 2001; Lööf y Heshmati, 2002; van Leeuwen, 2002; Criscuolo y Haskel 2003; 
Janz et al 2003; Cincera et al. 2004; Janz et al 2004). Es posible que la colaboración en general (Kim y Inkpen, 2005; Kim y Park, 2010) o, específicamente, con los clientes, relacionada, sobretodo, para la innovación de organización, comercialización, producto y procesos, contribuya a la mejora del crecimiento de las ventas (Griffith, 1999; Harris y Robinson 2003; Lehtoranta, 2010), la rentabilidad, la expansión de la cuota de mercado, la satisfacción de los clientes, la repercusión positiva en la imagen de la empresa y en el éxito de los nuevos productos (Kim y Inkpen, 2005; Kim y Park, 2010). Este análisis invita a pensar que la colaboración ejerce una sinergia con la innovación para asegura el éxito empresarial, por lo tanto, se plante el siguiente bloque de hipótesis;

P19: ¿actúa la colaboración organizacional como moderador de la relación entre la innovación y el desempeño empresarial?

H19: la colaboración organizacional modera la relación entre innovación y desempeño empresarial, de manera que, cuanto mayor es la colaboración, mayor es la contribución de la innovación al éxito empresarial.

H19a: colaboración del canal modera positivamente la relación entre innovación incremental y el desempeño empresarial.

H19b: la colaboración del canal modera positivamente la relación entre la innovación radical y el desempeño empresarial.

H19c: la colaboración de asesoría modera positivamente la relación entre la innovación incremental y el desempeño empresarial.

H19d: la colaboración de asesoría modera positivamente la relación entre la innovación radical y el desempeño empresarial. 


\subsection{Papel de la colaboración en la relación entre innovación y desempeño empresarial: diferencias entre grandes y pequeñas empresas}

Igual que venimos repitiendo en los argumentos anteriores, que las limitaciones de autonomía financiera, capacidad tecnológica y capital humano de las pequeñas empresas van en detrimento del éxito innovador ya que la puesta en marcha de proyectos innovadores es costosa y compleja; y que las redes de colaboración complementan esas limitaciones a través del intercambio de recursos y la transferencia de conocimiento. Surge una cuestión relevante a este respecto y es, si el papel de la colaboración en el éxito de la innovación difiere con el tamaño de las empresas.

Como se estudio anteriormente, algunos autores han encontrado evidencia de que las pequeñas empresas aprovechan más la colaboración para obtener resultados más óptimos pero ¿qué sucede con el éxito de la innovación a través del éxito empresarial?

La Tabla 17 presenta en forma sistematiza algunos estudios que demuestran distintos argumentos sobre este principio. Baum et al. (2000) y Motohashi (2007) confirman que son las grandes empresas las que aprovechan más la innovación conjunta para alcanzar mayor desempeño empresarial (rentabilidad y éxito de nuevos productos). Contrario a la evidencia anterior, al igual que las pequeñas empresas se aprovechan más de las colaboraciones en el canal para optimizar su desempeño, de la misma forma actúan para alcanzar el éxito innovador; por ejemplo, Link y Rees (1990); Sakakibara (1997) y Sen y Haq (2011) encontraron una interacción inversa del efecto del tamaño en la relación, aluden que las pequeñas empresas aprovechan mejor las colaboraciones con el canal externo para generar un crecimiento potencial basado en la relación (desarrollo de productos y patentes) y obtener un mayor aumento en el retorno de la inversión y el éxito de nuevos productos.

Las empresas grandes se aprovechan mejor de las colaboraciones de asesoría para alcanzar el éxito innovador porque este tipo de colaboración les brindan contribuciones más complejas. Ofrecen diversidad de capacidades y recursos diferentes (diversas perspectivas y la diversidad tecnológica) que fomentan más la co-creatividad, el aprendizaje especializado (investigación) y las soluciones novedosas a los problemas (Powell et al. 1996; Sampson, 
2007). Por ejemplo, según Baum et al. (2000), las grandes empresas biotecnológicas aprovechan mejor la colaboración con diferentes tipos de socios (fuera de su canal), como por ejemplo, asociaciones del sector farmacéutico, universidades, consultores y asesores de laboratorios del gobierno, y que tuvieron más éxito a la hora de innovar. Se añade a que las empresas grandes no solamente buscan efectos o beneficios directos (acceso a recursos y capacidades) de las redes de colaboración, sino que también está interesadas en beneficios indirectos (aprendizaje especializado o el desarrollo nuevas competencias) que servirán como base para futuros proyectos (Ahuja y Katila, 2001; Sampson, 2005).

Por el contrario, las colaboraciones en el canal refuerzan las habilidades comerciales de las pequeñas empresas para comprender el entorno y reaccionar adecuadamente aprovechando los aciertos del mercado y anticipándose a sus amenazas. Esta transferencia de habilidades comerciales, con los socios del canal, se asimila mejor porque el "conocimiento externo" está más estrechamente relacionado con el "conocimiento previo" (Cohen y Levinthal, 1990; Lane et al., 2001), brindando información oportuna para el proceso innovador. Las empresas grandes son menos dependientes de la colaboración del canal puesto que su tamaño les aporta recursos suficientes para alcanzar el éxito incluso sin estas relaciones. De los argumentos anteriores se plantean las siguientes hipótesis;

P20: ¿difiere el papel de la colaboración en el éxito de la innovación según el tamaño de la empresa?

H20: la influencia de la colaboración organizacional en el éxito innovador difiere según el tamaño de la empresa.

H20a: las pequeñas empresas aprovechan mejor que las grandes empresas la sinergia entre colaboración del canal e innovación incremental para alcanzar el éxito empresarial.

H20b: las pequeñas empresas aprovechan mejor que las grandes empresas la sinergia entre colaboración del canal e innovación radical para alcanzar el éxito empresarial. 
H20c: las grandes empresas aprovechan mejor que las pequeñas empresas la sinergia entre colaboración de asesoría y la innovación incremental para alcanzar el éxito empresarial.

H20d: las grandes empresas aprovechan mejor que las pequeñas empresas la sinergia entre colaboración de asesoría y la innovación radical para alcanzar el éxito empresarial.

La Figura 19 representa gráficamente el modelo de análisis III. Este modelo examina fundamentalmente el papel de la colaboración en el éxito de la innovación haciendo la diferencia entre grandes y pequeñas empresas. A través de las flechas se pueden observar las cinco distintas relaciones que se pretenden contrastar. 
Tabla 17

Tipo de contribución de la colaboración al desempeño empresarial: interacción colaboración y tamaño

\begin{tabular}{|c|c|c|c|c|c|c|c|}
\hline & Rentabilidad & $\begin{array}{l}\text { Crecimiento de } \\
\text { ventas }\end{array}$ & $\begin{array}{l}\text { Cuota } \\
\text { mercado }\end{array}$ & $\begin{array}{l}\text { Satisfacción / } \\
\text { imagen }\end{array}$ & $\begin{array}{l}\text { Éxito en nuevos } \\
\text { producto }\end{array}$ & $\begin{array}{l}\text { Reducción } \\
\text { costes }\end{array}$ & Productividad \\
\hline Colaboración organizacional & $\begin{array}{l}\text { Gulati, 1998; Das y } \\
\text { Teng (2000); Tether } \\
\text { (2002b); Belderbos et } \\
\text { al. (2004); Drejer y } \\
\text { Vinding (2005) } \\
\text { Sanders y Premus } \\
\text { (2005) }\end{array}$ & Cincera et al. (2004) & $\begin{array}{l}\text { Lummus et al. } \\
(1998) ; \\
\text { Mentzer et al. } \\
(2000) ; \\
\text { Lefebvre ( 2003) }\end{array}$ & $\begin{array}{l}\text { Lummus et al. (1998); } \\
\text { Mentzer et al. (2000); } \\
\text { Lefebvre ( 2003) }\end{array}$ & $\begin{array}{l}\text { Klomp y van Leeuwen } \\
\text { (2001); Lööf y } \\
\text { Heshmati (2002); van } \\
\text { Leeuwen (2002); } \\
\text { Criscuolo y Haskel } \\
\text { (2003); Janz et al. } \\
\text { (2003); Janz et al. } \\
\text { (2004) }\end{array}$ & & $\begin{array}{l}\text { Griffith (1999); } \\
\text { Harris y Robinson (2003) }\end{array}$ \\
\hline Colaboración proveedores & & & & & & Lehtoranta (2010) & Belderbos et al. (2004) \\
\hline Colaboración clientes & & Lehtoranta (2010) & Lehtoranta (2010) & Lehtoranta (2010) & & & \\
\hline Colaboración competidores & & Belderbos et al. (2004) & & & $\begin{array}{l}\text { Belderbos et al. } \\
(2004)\end{array}$ & & Belderbos et al. (2004) \\
\hline Colaboración consultores & & & & & Fukugawa (2005) & Fukugawa (2005) & \\
\hline Colaboración universidad & Fukugawa (2005) & Belderbos et al. (2004) & & & $\begin{array}{l}\text { Belderbos etal. } \\
\text { (2004); } \\
\text { Fukugawa(2005) }\end{array}$ & & \\
\hline Colaboración $\mathrm{x}$ tamaño & $\begin{array}{l}\text { Link y Rees (1990); } \\
\text { Powell et al. (1996); } \\
\text { Sakakibara (1997); } \\
\text { Baum et al. (2000); } \\
\text { Motohashi (2007); } \\
\text { Sampson (2007); Sen } \\
\text { y Haq (2011) }\end{array}$ & & & & & & \\
\hline
\end{tabular}




\begin{tabular}{|c|c|c|c|c|c|c|c|}
\hline $\begin{array}{l}\text { Colaboración } \mathrm{x} \\
\text { innovaciones radicales }\end{array}$ & & $\begin{array}{l}\text { Klomp y van Leeuwen } \\
\text { (2001); Belderbos et } \\
\text { al. (2004); } \\
\text { Lehtoranta (2010) }\end{array}$ & & & & & \\
\hline $\begin{array}{l}\text { Colaboración } \mathrm{x} \\
\text { patentes registradas }\end{array}$ & $\begin{array}{l}\text { Vanhaverbeke et al. } \\
(2002)\end{array}$ & & & & & & \\
\hline $\begin{array}{l}\text { Colaboración } x \\
\text { actividades I+D } \\
\text { (gasto-personal) }\end{array}$ & $\begin{array}{l}\text { Klomp y van Leeuwen } \\
\text { (2001); Lööfy } \\
\text { Heshmati (2002); van } \\
\text { Leeuwen (2002); } \\
\text { Monjon y Waelbroeck } \\
\text { (2003); Criscuolo y } \\
\text { Haskel (2003); Janz } \\
\text { et al. (2003); Janz et } \\
\text { al. (2004); van } \\
\text { Leeuwen y Klomp } \\
\text { (2006); }\end{array}$ & Cincera et al. (2004) & & & & $\begin{array}{l}\text { Griffith (1999); } \\
\text { Harris y Robinson } \\
(2003)\end{array}$ & \\
\hline $\begin{array}{l}\text { Colaboración x nuevos } \\
\text { productos y mercados }\end{array}$ & & Belderbos et al. (2004) & & & $\begin{array}{l}\text { Belderbos et al. } \\
(2004)\end{array}$ & & \\
\hline $\begin{array}{l}\text { Colaboración x } \\
\text { innovaciones incrementales }\end{array}$ & $\begin{array}{l}\text { Belderbos etal. (2004); } \\
\text { Lehtoranta (2010) }\end{array}$ & & & & & & $\begin{array}{l}\text { Griffith (1999); } \\
\text { Harris y Robinson (2003) }\end{array}$ \\
\hline $\begin{array}{l}\text { Colaboración x innovación } \\
\text { de organización }\end{array}$ & $\begin{array}{l}\text { Kim y Inkpen (2005); } \\
\text { Kim y Park (2010) }\end{array}$ & & & & & & \\
\hline $\begin{array}{l}\text { Colaboración } \mathrm{x} \\
\text { innovación de marketing }\end{array}$ & & Lehtoranta (2010) & $\begin{array}{l}\text { Kim y Inkpen (2005) } \\
\text { Kim y Park (2010) }\end{array}$ & $\begin{array}{l}\text { Kim y Inkpen (2005); } \\
\text { Kim y Park (2010) }\end{array}$ & & & \\
\hline $\begin{array}{l}\text { Colaboración x } \\
\text { Innovación de producto }\end{array}$ & & $\begin{array}{l}\text { Griffith (1999); Harris y } \\
\text { Robinson (2003); } \\
\text { Lehtoranta (2010) }\end{array}$ & & & $\begin{array}{l}\text { Kim y Inkpen (2005); } \\
\text { Kim y Park (2010) }\end{array}$ & & \\
\hline $\begin{array}{l}\text { Colaboración x } \\
\text { innovación de procesos }\end{array}$ & & & & & $\begin{array}{l}\text { Kim y Inkpen (2005); } \\
\text { Kim y Park (2010) }\end{array}$ & & \\
\hline
\end{tabular}


Figura 19

Modelo de análisis III: el papel de la colaboración en el éxito

de la innovación: diferencias entre grandes y pequeñas empresas

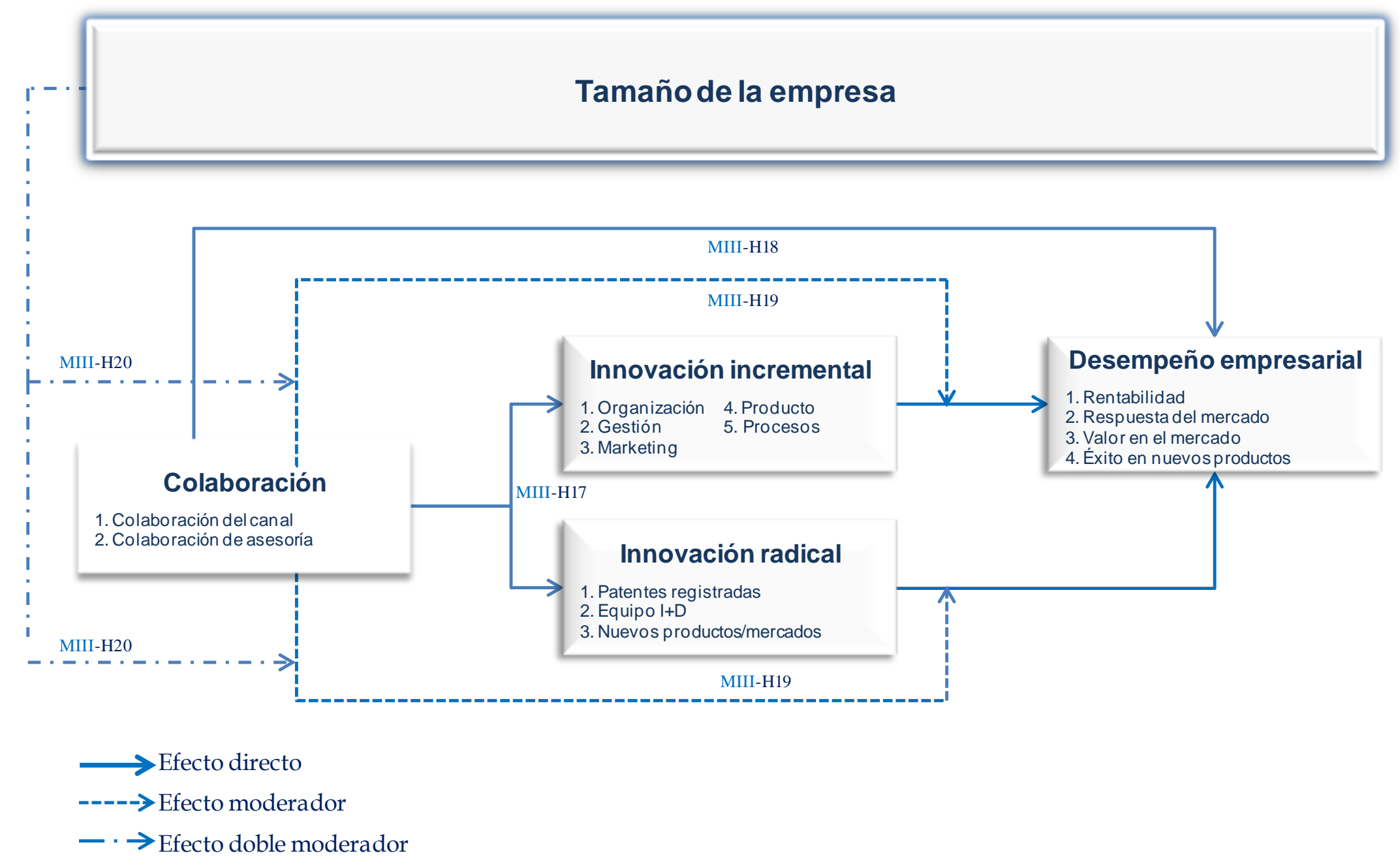


Siguiendo el eje teórico que se marcan en los objetivos específicos se presenta el modelo explicativo integrado (Figura 20), este modelo solo presenta las principales hipótesis de los tres modelos. El modelo integrado se desglosa en tres submodelos que dan paso a cada uno de los tres pilares explicativos que conforman el objetivo general de la investigación. Por medio de cada modelo se pretender dilucidar los objetivos empíricos propuestos.

Aunque el modelo se subdivida en tres partes, siguen perteneciendo a una única totalidad porque todos los modelos están estrechamente conectados, complementados y relacionados entre si. El propósito de subdividir el modelo en tres partes complementarias radica, básicamente, en proveer un el análisis empírico estructurado y facilitar la discusión de los resultados según cada patrón seguido. En la Tabla 18 se observan las hipótesis que desarrolla cada modelo; por ejemplo;

Tabla 18

Hipótesis planteadas por el modelo teórico

\begin{tabular}{|c|c|c|c|}
\hline Modelo teórico & & Hipótesis & Sección \\
\hline M I & $\mathrm{H} 1$ & $\begin{array}{l}\text { La orientación al mercado tiene un efecto positivo en la } \\
\text { innovación, es decir, cuanto mayor es la orientación al } \\
\text { mercado, mayor es la innovación empresarial. }\end{array}$ & 2.2.1.1.1. \\
\hline M I & $\mathrm{H} 2$ & $\begin{array}{l}\text { La orientación emprendedora tiene un efecto positivo en la } \\
\text { innovación, es decir, cuanto mayor es la orientación } \\
\text { emprendedora, mayor es la innovación empresarial. }\end{array}$ & 2.2.1.1.2. \\
\hline M I y MII & $\mathrm{H} 3$ & $\begin{array}{l}\text { El tamaño de la empresa tiene un efecto positivo en la } \\
\text { innovación empresarial, es decir, cuanto mayor es el } \\
\text { tamaño, mayor es la innovación empresarial. }\end{array}$ & 2.2.2. \\
\hline M I y MII & $\mathrm{H} 4$ & $\begin{array}{l}\text { El tamaño de la empresa tiene un efecto positivo en la } \\
\text { cultura organizativa. }\end{array}$ & 2.2.3. \\
\hline M I & H5 & $\begin{array}{l}\text { El tamaño modera la relación entre la cultura organizativa } \\
\text { y la innovación empresarial, de manera que, cuanto más } \\
\text { grande es una empresa, mayor es la contribución de la } \\
\text { cultura organizativa a la innovación empresarial. }\end{array}$ & 2.2.4. \\
\hline M II & $\mathrm{H} 6$ & $\begin{array}{l}\text { La innovación incremental tiene un efecto positivo en el } \\
\text { desempeño empresarial, es decir, cuanto mayor es la } \\
\text { innovación incremental, mayor es el éxito empresarial. }\end{array}$ & 2.3.1. \\
\hline M II & $\mathrm{H} 7$ & $\begin{array}{l}\text { La innovación radical tiene un efecto positivo en el } \\
\text { desempeño empresarial, es decir, cuanto mayor es la } \\
\text { innovación radical, mayor es el éxito empresarial. }\end{array}$ & 2.3.2. \\
\hline
\end{tabular}




\begin{tabular}{|c|c|c|c|}
\hline M II & H8 & $\begin{array}{l}\text { La orientación al mercado tiene un efecto positivo en el } \\
\text { desempeño empresarial, es decir, cuanto mayor es la } \\
\text { orientación al mercado, mayor es el éxito empresarial. }\end{array}$ & 2.3.2.2. \\
\hline M II & $\mathrm{H} 9$ & $\begin{array}{l}\text { La orientación al mercado modera la relación entre la } \\
\text { innovación y el desempeño empresarial, de manera que, } \\
\text { cuanto más orientada al mercado es una empresa, mayor } \\
\text { es la contribución de la innovación al desempeño } \\
\text { empresarial. }\end{array}$ & 2.3.2.3. \\
\hline M II & $\mathrm{H} 10$ & $\begin{array}{l}\text { El tamaño de la empresa tiene un efecto positivo en el } \\
\text { desempeño empresarial, es decir, cuanto mayor es el } \\
\text { tamaño, mayor es el éxito empresarial. }\end{array}$ & 2.3.2.4. \\
\hline M II & $\mathrm{H} 11$ & $\begin{array}{l}\text { El tamaño modera la relación entre la innovación y el } \\
\text { desempeño empresarial, de manera que, cuanto más } \\
\text { grande es una empresa, mayor es la contribución de la } \\
\text { innovación al éxito empresarial. }\end{array}$ & 2.3.2.5. \\
\hline MI y M II & $\mathrm{H} 12$ & $\begin{array}{l}\text { El dinamismo del entorno tiene un efecto positivo en la } \\
\text { innovación empresarial, es decir, cuanto mayor es el } \\
\text { dinamismo del entorno, mayor es la innovación } \\
\text { empresarial. }\end{array}$ & 2.3.3.1. \\
\hline M II & $\mathrm{H} 13$ & $\begin{array}{l}\text { La turbulencia del entorno tiene un efecto positivo en el } \\
\text { desempeño empresarial, es decir, cuanto mayor es la } \\
\text { turbulencia del entorno, mayor es el éxito empresarial. }\end{array}$ & 2.3.3.1.1. \\
\hline M II & H14 & $\begin{array}{l}\text { La turbulencia del entorno modera la relación entre la } \\
\text { innovación y el desempeño empresarial, de manera que, } \\
\text { cuanto más turbulento es el entorno, mayor es la } \\
\text { contribución de la innovación al éxito empresarial. }\end{array}$ & 2.3.3.1.1. \\
\hline M II & H15 & $\begin{array}{l}\text { La intensidad competitiva tiene un efecto positivo en el } \\
\text { desempeño empresarial, es decir, cuanto mayor es la } \\
\text { intensidad competitiva, mayor es el éxito empresarial. }\end{array}$ & 2.3.3.1.2. \\
\hline M II & H16 & $\begin{array}{l}\text { La intensidad competitiva modera la relación entre la } \\
\text { innovación y el desempeño empresarial, de manera que, } \\
\text { cuanto más intensa sea la competencia, mayor es la } \\
\text { contribución de la innovación al éxito empresarial. }\end{array}$ & 2.3 .3 .1 .2 \\
\hline M III & $\mathrm{H} 17$ & $\begin{array}{l}\text { La colaboración organizacional tiene un efecto positivo en } \\
\text { la innovación empresarial, es decir, cuanto mayor es la } \\
\text { colaboración organizacional, mayor es la innovación } \\
\text { empresarial. }\end{array}$ & 2.3.3.3.3.3. \\
\hline M III & $\mathrm{H} 18$ & $\begin{array}{l}\text { La colaboración organizacional tiene un efecto positivo en } \\
\text { el desempeño empresarial, es decir, cuanto mayor es la } \\
\text { colaboración organizacional, mayor es el éxito } \\
\text { empresarial. }\end{array}$ & 2.3.3.3.4.3. \\
\hline M III & H19 & $\begin{array}{l}\text { La colaboración organizacional modera la relación entre } \\
\text { innovación y desempeño empresarial, de manera que, } \\
\text { cuanto mayor es la colaboración, mayor es la contribución } \\
\text { de la innovación al éxito empresarial. }\end{array}$ & 2.3 .3 .3 .4 .5 \\
\hline M III & $\mathrm{H} 2 \mathrm{O}$ & $\begin{array}{l}\text { La influencia de la colaboración organizacional en el éxito } \\
\text { innovador difiere según el tamaño de la empresa. }\end{array}$ & 2.3.3.3.4.6. \\
\hline
\end{tabular}


Figura 20

Modelo explicativo integrado

Tamaño de la empresa

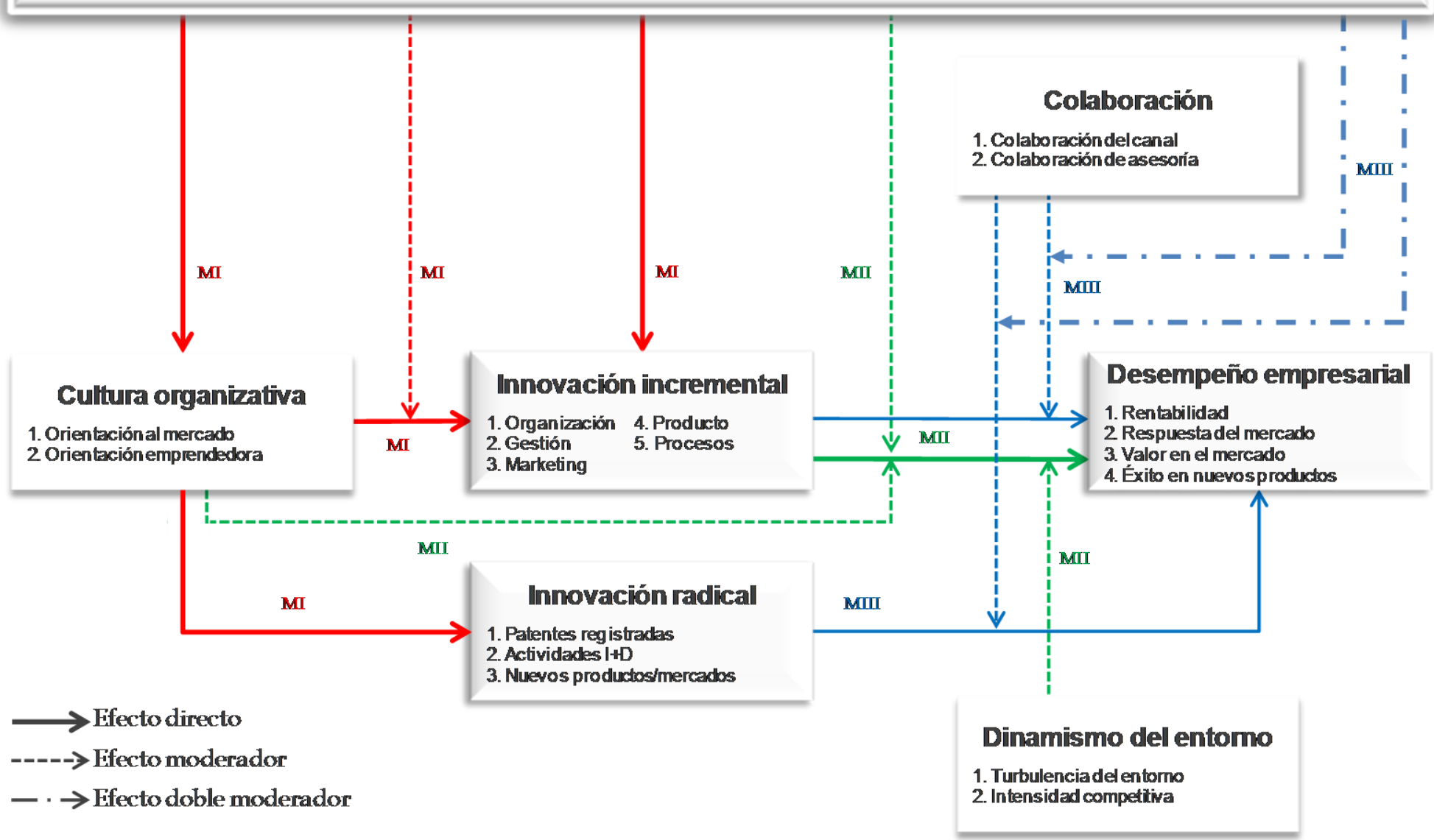





\section{Tercer capítulo}

\section{Metodología general}

de la investigación 



\section{Metodología general}

Del conjunto de los objetivos que parte esta investigación y el marco teórico expuesto que desarrolla el modelo hipotético, pasamos al estudio metodológico que da cuerpo al análisis empírico. Esta etapa permite detallar sobre el escenario de estudio, la descripción de los datos, el perfil de la muestra y comentar la metodología utilizada para descifrar las medidas del conjunto de variables dependientes e independientes que conforman el modelo empírico.

\subsection{Población objeto de estudio}

\subsubsection{Escenario de estudio y datos}

El marco muestral de la población se basó en la base de datos Dun y Bradstreet 2004. El trabajo de campo, que se inicio en el año 2004, consistió de un pretest a un grupo cinco empresas de pequeño y mediano tamaño con el fin de depurar las variables consideradas; y del cuestionario que está compuesto por 36 preguntas (muchas de ellas subdivididas por otras) con una métrica de siete puntos de escala Likert.

Inicialmente se limitó el estudio de las pequeñas empresas a las comunidades autónomas españolas de Castilla \& León y Extremadura. Al pretender hacer un comparativo con las empresas grandes de estas dos zonas, convergió con el inconveniente de que la población de grandes empresas era escasa, principalmente porque estas zonas son periféricas y marginales. Por lo tanto, se extendió la muestra de grandes empresas a toda la población nacional. Las grandes y pequeñas empresas fueron seleccionadas de acuerdo al número de empleados y las ventas obtenidas en el último año fiscal.

Los parámetros de medida de selección de las pequeñas empresas fueron: $>20$ y $<99$ empleados y $<50$ millones de euros de facturación de ventas del último año fiscal. El rango "cantidad de empleados" se limitó hasta noventa y nueve, porque las pequeñas empresas en cuestión se localizan en dos de las comunidades autónomas menos desarrolladas de España. 
Las grandes empresas se clasificaron bajo los parámetros: > 100 empleados y > 50 millones de euros una facturación de ventas anual. Subyace en este planteamiento que las empresas localizadas en regiones "periféricas" y/o de pequeña dimensión pueden diferir en su comportamiento innovador de aquellas otras de mayores tamaños y localizados en regiones empresarialmente más desarrolladas. Estas medidas no se basan en los estándares de la European Commission, DG Research porque son desproporcionadas para las empresas localizadas en zonas desfavorecidas, las llamadas regiones "objetivo uno" de la Unión Europa bajo el marco de Interreg IIIA. Una empresa pequeña, localizada en la comunidad castellana-leonesa o extremeña, es difícil que alcance un número de empleados de esas magnitudes (20 a 250 empleados), en la práctica a esas empresas se reconocen como 'grandes'. Hay que considerar que según el Instituto Nacional de Estadística de España, casi el 99\% de las empresas españolas dispone de menos de 100 trabajadores.

La población total de empresas que cumplieron los parámetros de selección fueron 2602 empresas españolas (1569 grandes empresas españolas y 1033 pequeñas empresas de Castilla \& León y Extremadura). Se realizó un contacto inicial por vía postal para presentar el proyecto y el posible interés de participar. El seguimiento del primer contacto se realizó vía telefónica. Del contacto postal inicial y del seguimiento telefónico, 1580 empresas aceptaron participar, de las cuales 793 eran grandes empresas de todas las regiones españolas y 787 pequeñas empresas de de las dos comunidades autónomas en cuestión. Se envío el cuestionario a las empresas interesadas vía Internet o vía postal. Una vez enviado el cuestionario, se realizó un seguimiento telefónico y vía e-mail. El formato del cuestionario fue electrónico y automatizado. Esto facilitó el envío de recordatorios a los contactos y la bitácora del seguimiento.

Finalmente de las 1580 empresas que accedieron participar respondieron 498 empresas. La tasa promedio de respuesta fue del 31,5\%. Del total de respuestas, 222 grandes empresas y 276 pequeñas empresas. Una vez obtenida la base de datos, se aplicaron los métodos de depuración. Se examinaron los gráficos de las observaciones de la base de datos para detectar los casos atípicos y se realizó un diagnóstico de casos del análisis de regresión lineal. Se procedió a convertir, algunos casos, en logaritmos neperariano con el fin de mejorar los resultados de los coeficientes en la regresión. Para identificar la linealidad de las variables se observaron los gráficos de dispersión (residuos) para detectar cualquier pauta no lineal de 
los datos. También se recurrió al análisis de regresión múltiple y se examinaron los estadísticos de los residuos y se observaron que la media de los residuos eran igual a cero o muy cercanas a cero y con distribución normal.

Como resultado de la depuración, se eliminaron las empresas que presentaban exceso de datos ausentes en las variables a utilizar. Por lo tanto, la muestra final es de 440 empresas (190 grandes empresas y 250 pequeñas empresas). Este número de muestra es suficiente para abordar este tipo de estudio. Muestras semejantes han sido utilizadas para estudios con nexos afines (Petrakis, 1995; Freel, 2000; Lechler, 2001; McCann et al., 2001; Entrialgo et al., 2001; Santos et al. 2002).

\subsubsection{Perfil de la población y la muestra}

La encuesta fue enviada a las empresas indistintamente del sector al que pertenecían. En la población general, los sectores dominantes son industria y comercio-servicios siendo los sectores más representativos en ambas muestras (industria y del comercio-servicios), aunque para fines de este estudio no se discrimina el resto de sectores.

La Tabla 19 muestra las características de la población y de la muestra del estudio. Los sectores industria y del comercio-servicios son más representativos en la muestra de las grandes empresas (49\% y 35\%, respectivamente) que en la muestra de las pequeñas empresas. El sector más fuerte en la muestra de pequeñas empresas es comercio-servicios con el $42 \%$, seguido por el de industria con el $30 \%$, probablemente esto se deba a la importancia del sector de la construcción, pero además, esas pequeñas empresas están ubicadas en zonas menos favorecidas, son regiones periféricas y con economías marginales respecto a otras regiones españolas, usualmente están más encaminadas a este sector dadas las bajas barreras de entrada. El sector de la construcción representa el $20 \%$ de la población de las pequeñas empresas, este sector venía tomando cierta relevancia en estas comunidades debido al auge económico suscitado en el país durante los últimos años mediado por la burbuja inmobiliaria. Estos porcentajes representan paralelamente a los obtenidos en el perfil de la población total siendo la distribución sectorial de las muestras muy similar a la de las poblaciones, lo que implica la validez de las muestras en este sentido. 
Respecto al tamaño según el número de empleados de las grandes empresas de la población, el 30\% corresponde a empresas con 100-249 empleados y el 70\% con más de 250 empleados. Estos porcentajes se asemejan a los obtenidos en la muestra final donde el $37 \%$ son empresas con 100 a 249 empleados, y el 63\% emplea más de 250 personas. De la misma manera, hay una correspondencia entre los porcentajes del tamaño por número de empleados tanto en la población como en la muestra en las pequeñas empresas. Como se observa en la Tabla 19, una relación similar define la población total de las pequeñas empresas con la muestra seleccionada donde se alcanza un $67 \%$ de la población total versus un $66 \%$ de la muestra y paralelamente un $33 \%$ versus un $34 \%$ y la muestra. Esta distribución paralela entre la población y las muestras corroboran su validez.

Tabla 19

Características de la población y de la muestra

\begin{tabular}{|c|c|c|c|c|c|c|c|c|}
\hline \multirow{3}{*}{$\begin{array}{ll} & \text { Ítem } \\
\text { Sectores }\end{array}$} & \multicolumn{4}{|c|}{ Población (DUN) } & \multicolumn{4}{|c|}{ Muestra (Cuestionario) } \\
\hline & \multicolumn{2}{|c|}{$\begin{array}{c}\text { Grandes } \\
(\text { Total=1569) }\end{array}$} & \multicolumn{2}{|c|}{$\begin{array}{l}\text { Pequeñas } \\
\text { (Total=1033) }\end{array}$} & \multicolumn{2}{|c|}{$\begin{array}{c}\text { Grandes } \\
(\text { Total }=190)\end{array}$} & \multicolumn{2}{|c|}{$\begin{array}{l}\text { Pequeñas } \\
\text { (Total=250) }\end{array}$} \\
\hline & & & & & & & & \\
\hline Industria & 744 & $47 \%$ & 393 & $38 \%$ & 93 & $49 \%$ & 75 & $30 \%$ \\
\hline Construcción & 107 & $7 \%$ & 204 & $20 \%$ & 26 & $14 \%$ & 49 & $20 \%$ \\
\hline Agricultura & 23 & $1 \%$ & 37 & $4 \%$ & 5 & $3 \%$ & 22 & $9 \%$ \\
\hline Comercio-Servicios & 695 & $44 \%$ & 400 & $39 \%$ & 66 & $35 \%$ & 104 & $42 \%$ \\
\hline \multicolumn{9}{|l|}{ Empleados } \\
\hline$<$ que 50 & & & 690 & $67 \%$ & & & 166 & $66 \%$ \\
\hline entre 51 y 99 & & & 343 & $33 \%$ & & & 84 & $34 \%$ \\
\hline entre 100 y 249 & 478 & $30 \%$ & & & 71 & $37 \%$ & & \\
\hline$>$ que 250 & 1091 & $70 \%$ & & & 119 & $63 \%$ & & \\
\hline
\end{tabular}

Fuente: Base de datos Dun y Bradstreet 2004 y datos procedentes de la recolección de datos

\subsection{Análisis previo de los datos}

La metodología empleada para contrastar las hipótesis planteadas fue mediante estadística descriptiva y diversas técnicas de análisis multivariante, con el fin de evaluar los efectos de las variaciones paramétricas ocurridas de forma natural en el contexto en que normalmente ocurren y, posibilitar que la investigación sea teóricamente significativas. Para estimar las distintas técnicas multivariantes se ha utilizado el programa estadístico SPSS v14.0 para Windows. 
En primer lugar se realizó un análisis de frecuencias de todas las variables estructurales y de innovación según el tamaño de la empresa. Este análisis permitirá observar las diferencias entre las dos muestras tanto en sus particularidades internas como en su comportamiento innovador. Los resultados se recogen en las tablas 31 y 32 [4.1.].

Una vez realizado el examen de los datos para la preparación del análisis multivariante, se confeccionaron las matrices de correlaciones de cada modelo explicativo con el propósito de observar las intercorrelaciones entre todas las variables implicadas en el modelo [4.2.]. Al estudiar la matriz de correlaciones bivariadas se detectaron que varios de los grupos de variables eran significativamente elevadas entre sí, por lo que se procedió a realizar distintos análisis factoriales para los grupos de las variables implicadas.

Se han realizado análisis factoriales para estudiar la manera en que las variables que conforman un constructo se agrupan, y así depurar las que menos se ajusta al modelo teórico. Para comprobar la fiabilidad de los constructos se corroboraron por medio del alpha de Cronbach. El test de los constructos se ha realizado mediante el método estadístico multivariante del análisis factorial exploratorio tipo $R$. Una vez que se seleccionó el tipo de análisis se optó por el método de factores por varianza común por contener supuestos más restrictivos y el método de rotación varimax para alcanzar la máxima simplificación posible. Las tablas que recogen la información de los análisis factoriales no se exponen en la sección [4.] sino en la sección [3.4.], para poder justificar la selección de los constructos. Además, se aprovechó la tabla para indicar la fuente de medida de las variables, exponer algunos estadísticos descriptivos y los datos relevantes del análisis factorial (carga factorial, varianza explicada) y el alfa de Cronbach; que justificaran como un todo el por qué se decidió considerar cierto grupos de variables como un único constructo.

Por otra parte, se efectuaron análisis de comparación de medias para verificar si la variable categórica tamaño de la empresa, que es el centro de esta investigación, está asociada con el resto de variables cuantitativas del modelo. Se estimaron con un $\mathrm{IC}_{95 \%}$. Las pruebas de contraste de normalidad se asumirán si estas son $p>0,05$. Si lo que procede es una estimación de la $\mathrm{t}$ de Student se asumirán que las medias son iguales $\mathrm{p}<0,05$. Si procede una prueba no paramétrica, dependiendo del cumplimiento de los requisitos de normalidad y homocedasticidad, se contrastará con U de Mann-Whitney al p<0,05. El test de Levene bajo 
el supuesto de varianzas distintas se asumirá si $\mathrm{p}<0,05$. Una vez que se ha constatado que las variables moderadoras tienen una influencia sobre algunas variables se prosiguió a la evaluación de las relaciones propuestas en el modelo [4.3]. Para realizar el análisis se centraron las variables en la media según el procedimiento seguido por Aiken y West (1991).

Para examinar las relaciones de las variables dependientes y las variables independientes seleccionadas en cada modelo explicativo teórico, se estimaron análisis de regresión múltiple paso a paso (stepwise), con el objetivo de explicar el problema de la investigación [4.4.]. Se indican solamente los coeficientes beta significativos hasta el 90\%. Todos los valores del estadístico Durbin-Watson son significativos al 0,05\%, para esta muestra y número de variables independientes.

En distintas regresiones se incorporan variables moderadoras. Hay que observar que cuando se mezclan dos situaciones (interacciones); por ejemplo, la variable tamaño de la empresa y la orientación al mercado; el efecto es mucho mayor del esperado como suma de los dos. El termino moderador es una variable compuesta por la multiplicación de la variable independiente por el moderador que entra en la ecuación de regresión. De hecho, el término no lineal puede ser considerado como una forma de interacción, donde la variable independiente se "modera" a sí misma, elevándose al cuadrado $\left(\mathrm{X}_{\mathrm{i}} \mathrm{X}_{\mathrm{i}}\right)$ (Hair et al., 2002:164)

En todas las regresiones lineales el ANOVA F, sobre el resultado del análisis de la varianza de los modelos, resultan significativos al $\mathrm{p}<0,001$. Por tanto se rechaza la hipótesis nula de que la variabilidad observada en la variable dependiente sea explicable por el azar, y admitimos que se halla algún tipo de asociación entre la variable dependiente y las independientes.

El estadístico $\mathrm{R}^{2}$ indica la predicción del modelo al incluir las variables independientes en la ecuación de la regresión. Muchas veces, cuando existen varios modelos en una misma regresión se valora la capacidad explicativa, en este caso, solamente se valora el efecto del incremento, no las variables individuales (Hair et al., 2002: 165).

La mayoría de las regresiones de la sección [4.4.] se cumple que el $\mathrm{R}^{2}$ es estadísticamente significativo para el tamaño muestral especificado, con una potencia $80 \%$; 
para este caso: tamaño muestral $<500$, dos variables independientes, $\alpha=0,01$, valores $R^{2}$ del $3 \%-5 \%$ y superior (Hair et al. 2002: 159). La Tabla 20, muestra el mínimo $\mathrm{R}^{2}$ que se puede encontrar estadísticamente significativo con una potencia del $80 \%$ para diferentes variables independientes y tamaños muestrales.

Tabla 20

Mínimo $\mathbf{R}^{2}$ según el tamaño de la muestra y las variables utilizadas

\begin{tabular}{l|c|c|c|c|c|c|c|c}
\multirow{2}{*}{ Tamaño muestral } & \multicolumn{4}{|c|}{ Nivel de significación $(\boldsymbol{\alpha}) \mathbf{0 , 0 1}$} & \multicolumn{4}{c}{ Nivel de significación $(\boldsymbol{\alpha}) \mathbf{0} \mathbf{0 , 0 5}$} \\
\cline { 2 - 8 } & \multicolumn{2}{|c|}{ Número de variables independientes } & \multicolumn{3}{c}{ Número de variables independientes } \\
\cline { 2 - 8 } & $\mathbf{2}$ & $\mathbf{5}$ & $\mathbf{1 0}$ & $\mathbf{2 0}$ & $\mathbf{2}$ & $\mathbf{5}$ & $\mathbf{1 0}$ & $\mathbf{2 0}$ \\
\hline 100 & 13 & 16 & 20 & 26 & 10 & 12 & 15 & 22 \\
250 & 5 & 7 & 8 & 11 & 4 & 5 & 6 & 8 \\
500 & 3 & 3 & 4 & 6 & 3 & 4 & 5 & 9
\end{tabular}

Fuente: Hair et al. (202):159

\subsection{Medida de las variables $y$ análisis factorial exploratorio}

En el anexo 01., se detalla el instrumento que se utilizó para medir las variables. Por otro lado, antes de iniciar la explicación sobre la medición de las variables es importarte hacer una acotación sobre los análisis factoriales exploratorios antes de proseguir con la exposición de las medidas de las variables.

Los constructos de la innovación radical e incremental, orientación al mercado, emprendedora, turbulencia del entorno, intensidad competitiva, colaboración del canal y colaboración de asesoría, se estudian cada uno por separado. La mayoría de estos constructos han sido repetidamente testados por muchos autores, entre otros; Pelham y Wilson (1996); Liu et al. (2000); Hult y Ketchen (2001); Hult et al. (2003) y Li et al. (2006). Los análisis factoriales exploratorios se ejecutaron para:

(1) determinar si realmente existía una estructura común entre los ítems que forman las variables, tengan estas un papel dependiente o independiente, 
(2) definir la distribución subyacente de los constructos a testar y analizar la estructura de las correlaciones entre las variables de estos posibles constructos y lograr la definición de los factores.

Antes de ejecutar los análisis factoriales, se observaron las correlaciones entre las variables de cada posible constructo y se notaron altas correlaciones entre las variables casi todas al 99\% de significación. Por otro lado, se ejecutó el contraste de Barlett y este mostró que las correlaciones no nulas existen a un nivel de significación del $\mathrm{p}<0,001$ para todos los casos, o sea, que la matriz de correlación entera es conveniente para los distintos análisis.

Por otro lado, se extrajeron las medidas de suficiencia de muestreo (MSA) que cuantifica el grado de intercorrelaciones entre las variables y la conveniencia del análisis factorial. Para el constructo orientación al mercado, innovación incremental, colaboración del canal y colaboración de asesoría, el MSA es sobresaliente $(>0,80)$, para los constructos de orientación emprendedora, turbulencia del entorno, intensidad competitiva e innovación radical el MSA es apropiado (>0,70), pero ninguno de los constructos cae en el índice de inapropiado $(<0,60)$, por lo tanto, no es necesario excluir ninguna variable. Este panorama es apto para aplicar el método factorial.

En todos los análisis factoriales desarrollados, se encontraron cargas significativas y las comunalidades fueron suficientes. Hay que recordar que la muestra utilizada en este estudio es $<500$ casos, por ende la carga factorial que se considera significativa para este tamaño de muestra debe ser mayor a +0,30 -0,3, según las directrices para la identificación de cargas factoriales significativas al 0,05 $(\alpha)$ en el tamaño muestra, y un nivel de potencia del $80 \%$ y los errores estándar supuestamente dos veces mayores que los coeficientes convencionales de correlación (Hair et al., 2002:100). Para este caso, la matriz de factores demostró que todas las cargas son significativas para un solo factor. Al examinar la comunalidad de cada variable de los constructos se constató que todas las variables alcanzan los niveles apropiados de explicación con una comunalidad $>0,50$.

Para verificar si era necesaria la eliminación de alguna de las variables se analizó la matriz anti-imagen y el alpha de Cronbach, el resultado de esta observación determinó que se mantuvieran las variables dentro del constructo. Por último, se identificaron las dimensiones 
(factores) separadas de la estructura y se determinó el grado que justifica cada variable por cada dimensión. El resumen, la reducción de los datos se sometieron a una sola dimensión subyacente para cada análisis. Cada factorial contiene una tabla que expone los datos para cada constructo. Se muestran los datos descriptivos, las cargas factoriales, la varianza explicada y el alpha de Cronbach. Estas tablas están ubicadas dentro de la explicación de la medida de cada variable [3.3.].

\subsubsection{Innovación empresarial}

Para medir la innovación, este estudio utiliza diversas magnitudes desde la perspectiva incremental/radical, pasando por los posibles indicadores operativos, y por último, la dimensionalidad del concepto de innovación, tanto unidimensional como multidimensional, según el modelo explicativo al que se refiera el contraste de hipótesis. De esta manera, se observaran distintas acciones de innovación que ejecutan las empresas según los factores internos o externos que intervengan; por ejemplo, la cultura organizativa o el dinamismo del entrono (Cooper, 1998).

Concerniente a los indicadores de innovación, en consonancia con el concepto expuesto, se ha preferido medir la innovación empresarial a partir de la información obtenida, de lo "inputs" y de los "outputs" del proceso innovador, en concreto, las innovaciones adaptadas y/o generadas por la empresa.

Los dos primeros modelos explicativos de la investigación [3.1] incluyen la variable de innovación incremental de forma multidimensional, en cambio el tercer modelo contendrá el formato unidimensional con el fin de poder comparar con la innovación radical que también se transforma en un solo constructo.

\subsubsection{Innovación incremental}

Dado que algunos estudios plantean las acciones de innovación incremental de forma agrupada, se realizaron análisis factoriales exploratorios y confirmatorios para comprobar si 
el modelo agrupado o separado tenía mayor capacidad explicativa. Se testaron cuatro tipos de agrupaciones para la innovación incremental:

(1) producto y procesos (Zahra et al. 2000; Kickul y Gundry 2002),

(2) organización y marketing (Zahra et al. 2000; Kickul y Gundry, 2002; Salavou et al., 2004),

(3) todas las acciones de innovación incremental por separado (González et al, 1997; Johannessen et al., 2001; Lee y Tsai, 2005),

(4) todas las acciones de innovación incremental en conjunto (Christensen y Bower, 1996; Baker y Sinkula, 2002).

Después de testar las cuatro maneras de agrupación y examinado a través del $\mathrm{R}^{2}$ ajustado, las dos primeras agrupaciones se ajustan menos que la tercera y la cuarta, por lo tanto, se han desestimado. En cambio, es más claro el resultado, por la alta correlación entre las variables, si se tratan una a una las acciones de innovación (modelos I y II) o en su conjunto total (modelo III) según el objetivo que se desee alcanzar en la investigación.

Cabe aclarar que no existe un solapamiento conceptual entre el concepto general de innovación incremental y el constructo orientación emprendedora porque esta última se trata desde una perspectiva cultural mientras que la innovación es más bien operativa. Además, la orientación emprendedora sigue una propia escala comprobada y utilizada por la mayoría de autores del área de management.

Las variables dependientes que miden la innovación incremental son de escala de ítem único para cada dimensión y poseen una escala de Likert de 7 puntos $(1=$ ninguna innovación/ 7= muchas innovaciones). Las variables dependientes son: innovación de organización, innovación de marketing, innovación de producto e innovación de procesos.

En la Tabla 21, se observan los datos descriptivos y las correlaciones de las variables. Las cuatro medidas de innovación están altamente correlacionadas. Al ejecutar la técnica 
estadística del análisis factorial se extrajeron las cargas factoriales, todas son $>0,70$. El porcentaje de la varianza explicada supera el $80 \%$ y el alfa de Cronbach es sobresaliente al 90\% para la muestra. Los resultados obtenidos sugieren considerar que la innovación incremental también puede utilizarse como un único constructo.

\subsubsection{Innovación radical}

Las medidas de la innovación radical se basó en una evaluación de la empresa respecto a tres ítems (escala tipo Likert de 7 puntos): patentes registradas, equipo en actividades $\mathrm{I}+\mathrm{D}$, desarrollo de nuevos productos y mercados, tal como se han utilizado en algunos estudios de innovación (Kemp et al., 2003; Kim y Park, 2010; Hess y Rothaermel, 2011; Sen y Haq, 2011).

La Tabla 22 muestra los resultados estadísticos descriptivos, correlaciones y análisis factorial de la innovación radical. Al ejecutar la técnica estadística del análisis factorial y extraer las cargas factoriales se observa que todas son $>0,70$, el porcentaje de la varianza explicada ronda el 70\% y el alfa de Cronbach es aceptable al 70\% para la muestra. Los resultados obtenidos sugieren considerar a la innovación radical como un único constructo. 
Tabla 21

Escala de medida de la innovación incremental

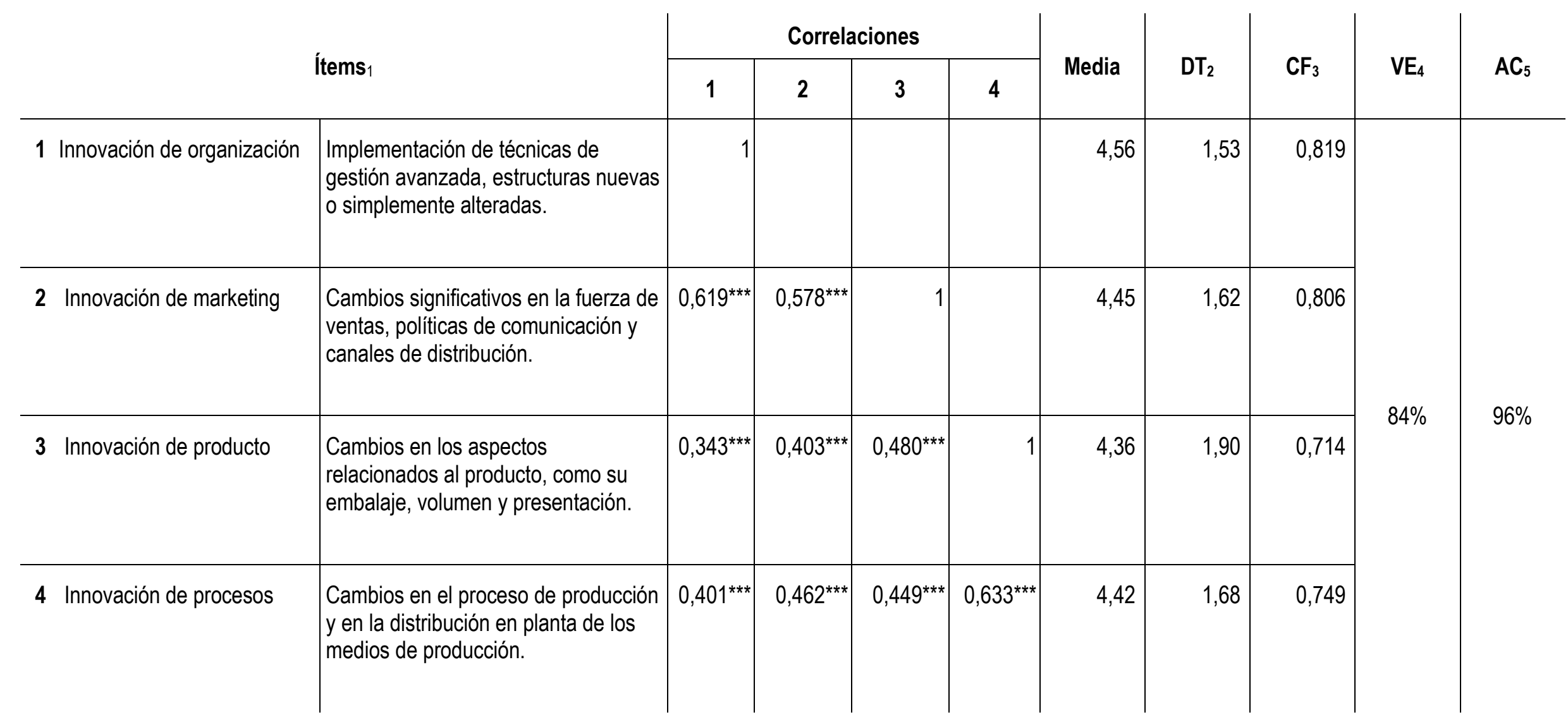

1 Fuente: OECD, 2005 / 2 Desviación Típica / 3 Carga Factorial / 4 Varianza Explicada / 5 Alfa de Cronbach ${ }^{* * *} p<0,001$ 
Tabla 22

Escala de medida de la innovación radical

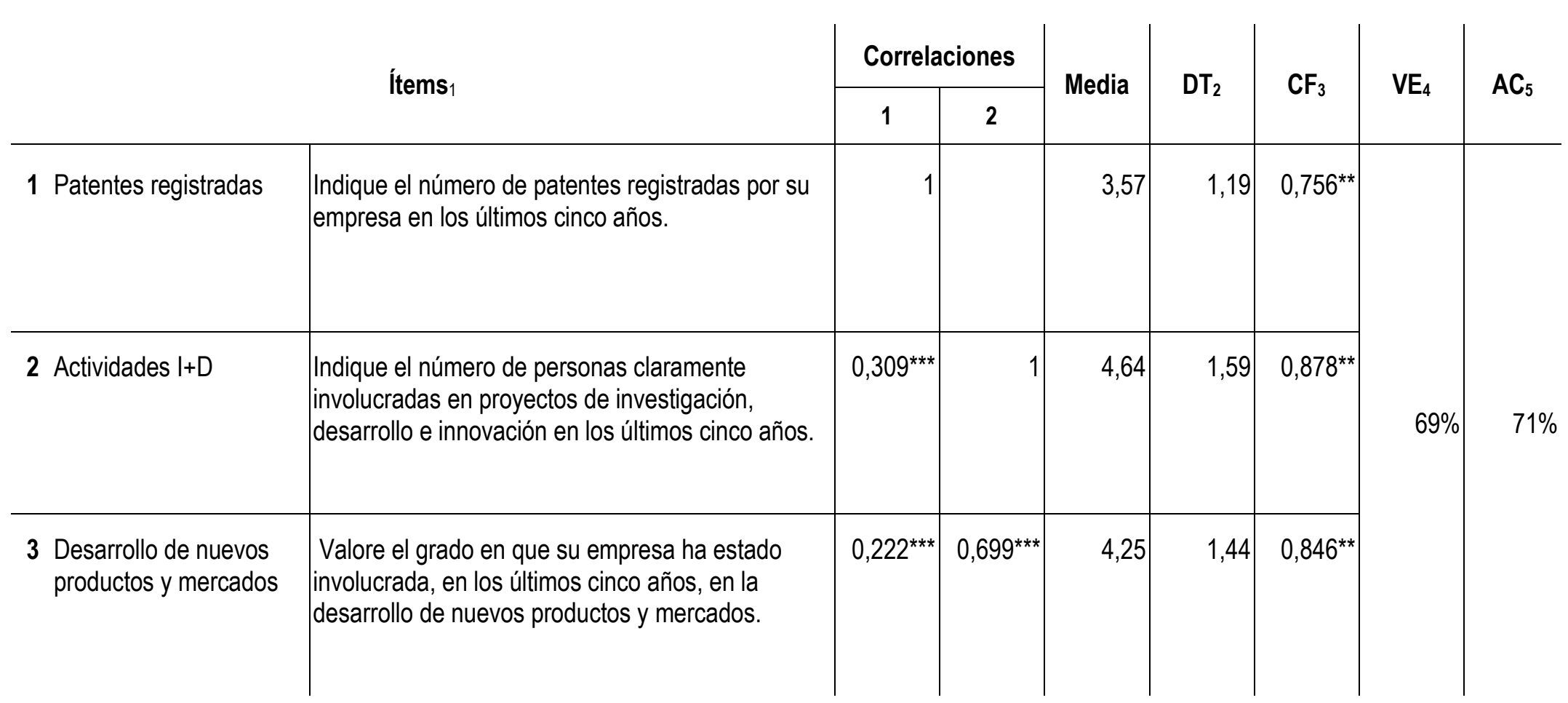

1 Fuente: OECD, 2002; Kemp et al. (2003) / 2 Desviación Típica / 3 Carga Factorial / 4 Varianza Explicada / 5 Alfa de Cronbach ${ }^{* * *} p<0,001$ 


\subsubsection{Desempeño empresarial}

Para los propósitos de esta investigación, se sigue el planteamiento sobre el desempeño empresarial de González-Benito et al. (2009). Se proponen cuatro tipos de variables:

(1) rentabilidad, traducido en beneficio, margen de ganancia, ROI, etc., medido con un único ítem haciendo referencia al rendimiento económico alcanzado. El uso de la rentabilidad para medir los resultados de la empresa ha sido ampliamente utilizado como medida de los resultados (Jaworski y Kohli, 1993; Morris y Sexton, 1996; Pelham y Wilson, 1996; Liu et al., 2002; Santos et al, 2002; Barth, 2003; Hult et al., 2003; Kara et al., 2005).

(2) respuesta de mercado, o sea, la reacción de la demanda ante la oferta de productos y servicios de las empresas, medido mediante dos ítems relativos al crecimiento de ventas y crecimiento de la cuota de mercado. También el crecimiento de las ventas y de la cuota de mercado han sido usados como indicadores de resultados, principalmente porque pueden explicar de varias maneras los cambios en la demanda, lo que no significa necesariamente, un incremento en la plantilla del personal (Morris y Sexton, 1996; Pelham y Wilson, 1996; Liu et al., 2002; Santos et al, 2002; Barth, 2003; Hult et al., 2003; Kara et al., 2005).

(3) valor en el mercado, siguiendo las medidas de desempeño utilizadas por GonzálezBenito et al. (2009) la variable valor en el mercado equivale a la consecución del posicionamiento favorable en la mente de los consumidores, lo cual permite que éste identifique claramente el producto, se sienta conforme con él y lo adopte para sí. Las estrategias exitosas de posicionamiento dan lugar a la percepción mental del consumidor hacia la marca, traduciéndose en lealtad y notoriedad a la empresa (Kotler y Armstrong, 1997). Este indicador está compuesto por dos ítems, satisfacción de los clientes e imagen/reputación de la empresa.

(4) éxito en nuevo producto, medido con una sola variable. Suele utilizarse la variable éxito en nuevos productos como otro indicador de los resultados de la empresa (Slater y Narver, 1994; Atuahene-Gima, 1995-1996; Pelham y Wilson, 1996; Reid 
y Smith, 2000; Santos et al, 2002; Kara et al., 2005). Para Slater y Narver (1994), es usual que la operacionalización de la variable nuevos productos sea determinada por el promedio de dos variables: desarrollo de nuevos productos y servicios, y desarrollo de nuevos mercados. No obstante, en el presente estudio no se realizaron preguntas distintas para cada variable como en el estudio de Slater y Narver (1994) sino como una sola variable.

Es generalmente aceptado que los resultados empresariales estén conformados por un constructo multidimensional o que correspondan a otras tipificaciones; por ejemplo las seguidas por Venkatraman y Ramanujam (1986 y 1987); Walker y Ruekert (1987); Varadarajan y Jayachandran (1999). No obstante, hay dos clasificaciones habituales.

Por un lado, Walker y Ruekert (1987) distan entre medidas de eficacia, eficiencia y adaptabilidad. Las medidas de eficacia tratan de cuantificar el éxito de la actividad comercial de las empresas (ventas, cuota de mercado, satisfacción del cliente, calidad percibida, etc.). Las medidas de eficiencia comparan la eficacia de la actividad comercial con los recursos empleados en su consecución (margen de beneficio, ROI, etc.). Finalmente, las medidas de adaptabilidad tratan de capturar la capacidad de la empresa para responder a los cambios y oportunidades del entorno (éxito de nuevos productos, peso de los nuevos productos en la facturación global, etc.).

Por otro lado, Venkatraman y Ramanujam (1986) diferencian entre medidas de desempeño financiero y medidas de desempeño operativo. Las primeras consisten en indicadores observables de tipo contable centrados en el resultado económico, como ventas, beneficio, ROI, etc. Las segundas hacen referencia a resultados intermedios de la actividad realizada y que deberían conducir al éxito económico, como satisfacción, calidad percibida, desarrollo de nuevos productos, etc.

Nuestro planteamiento del desempeño se esquematiza de la siguiente manera; 
Tabla 23

Clasificación de las dimensiones de desempeño

\begin{tabular}{l|c|c|c} 
& Eficiencia & Eficacia & Adaptabilidad \\
\hline $\begin{array}{l}\text { Desempeño } \\
\text { financiero }\end{array}$ & Rentabilidad & Respuesta de mercado & \\
Corto plazo & & Valor en el mercado & $\begin{array}{c}\text { Éxito de nuevos } \\
\text { productos }\end{array}$ \\
\hline $\begin{array}{l}\text { Desempeño } \\
\text { operativo } \\
\text { Mediano y largo plazo }\end{array}$ & &
\end{tabular}

Fuente: elaboración propia según clasificación seguida por Venkatraman y Ramanujam (1986); Walker y Ruekert (1987)

Las variables rentabilidad, crecimiento en las ventas, crecimiento de la cuota de mercado, satisfacción de los clientes, imagen/reputación de la empresa y éxito de nuevos productos se formularon en el cuestionario de manera relativa o en comparación a los competidores tal como previamente lo han elaborado Jaworski y Kohli (1993); Pelham (2000); Hult et al. (2003). La valoración se realizó mediante una serie de indicadores de desempeño. Las respuestas se registraron conforme a una escala de tipo Likert de 7 puntos (1= mucho peor que la competencia; $7=$ mucho mejor que la competencia).

Los datos de la Tabla 24 incluyen los datos de correlación, descriptivos y análisis de fiabilidad, y permiten asumir la unidimensionalidad, según su media, en las escalas multiítem de la respuesta de mercado y el valor en el mercado., las cuatro medidas están fuertemente correlacionadas pero la varianza no compartida permite pequeñas diferencias entre los indicadores de desempeño, los cuales no sería posible capturarlas si se midieran de forma global. Al ejecutar la técnica estadística del análisis factorial se extrajeron las cargas factoriales, ambas son superiores al $80 \%$. El porcentaje de la varianza explicada ronda casi el $80 \%$ y el alfa de Cronbach es sobresaliente al $90 \%$ para la muestra. Los resultados obtenidos sugieren considerar a las variables respuesta de mercado y Valor en el mercado como constructos únicos. 
Tabla 24

Escala de medida de las variables de desempeño

\begin{tabular}{|c|c|c|c|c|c|c|c|c|c|c|}
\hline \multirow{2}{*}{\multicolumn{2}{|c|}{ Ítems $s_{1}$}} & \multicolumn{4}{|c|}{ Correlaciones } & \multirow{3}{*}{$\begin{array}{r}\text { Media } \\
4,46\end{array}$} & \multirow{3}{*}{$\begin{array}{r}\mathrm{DT}_{2} \\
1,21\end{array}$} & \multirow{3}{*}{$\mathrm{CF}_{3}$} & \multirow{3}{*}{$\mathrm{VE}_{4}$} & \multirow{3}{*}{$\mathrm{AC}_{5}$} \\
\hline & & 1 & 2 & 3 & 4 & & & & & \\
\hline 1 Rentabilidad & Rentabilidad & $0,583^{* * *}$ & 1 & & & & & & & \\
\hline \multirow[t]{2}{*}{2 Respuesta de mercado } & Crecimiento en las ventas & $0,598^{* * *}$ & $0,683^{* \star *}$ & 1 & & 4,67 & 1,21 & \multirow{2}{*}{$0,851^{* *}$} & \multirow{2}{*}{$81 \%$} & \multirow{2}{*}{$91 \%$} \\
\hline & $\begin{array}{l}\text { Crecimiento de la cuota de } \\
\text { mercado }\end{array}$ & & & & & 4,65 & 1,24 & & & \\
\hline \multirow[t]{2}{*}{3 Valor en el mercado } & Satisfacción del cliente & $0,492^{\star * *}$ & $0,530^{* * *}$ & $0,560^{* * *}$ & 1 & 5,37 & 1,21 & \multirow{2}{*}{$0,812^{* *}$} & \multirow{2}{*}{$79 \%$} & \multirow{2}{*}{$90 \%$} \\
\hline & $\begin{array}{l}\text { Imagen/reputación de la } \\
\text { empresa }\end{array}$ & & & & & 5,44 & 1,21 & & & \\
\hline 4 Éxito de nuevos productos & $\begin{array}{l}\text { Porcentaje de sus ventas } \\
\text { que corresponde a nuevos } \\
\text { productos/ servicios } \\
\text { lanzados en los últimos } \\
\text { cinco años }\end{array}$ & $0,518^{* * *}$ & $0,429 * * *$ & $0,455^{* * *}$ & $0,573^{* * *}$ & 4,77 & 1,45 & & & \\
\hline
\end{tabular}

1 Fuente: Jaworski y Kohli (1993); Slater y Narver (1994); Pelham y Wilson (1996); Kotler y Armstrong (1997) / 2 Desviación Típica / 3 Carga Factorial / 4 Varianza Explicada / 5 Alfa de Cronbach ${ }^{* * *} p<0,001$ 


\subsubsection{Factores organizacionales}

Algunos factores organizacionales, como el tamaño, y la orientación al mercado, se han integrado a la relación entre innovación y desempeño empresarial con el propósito de proporcionar mayor rigor al análisis de la función La selección de los ítems se basó en la literatura al respecto, aunque adaptada al escenario concreto en el que se desarrolla el estudio. Con estas medidas organizacionales se pretende captar el efecto estructural, cultural y del entorno de la relación principal de esta investigación.

\subsubsection{Tamaño empresarial}

El tamaño empresarial marca la diferencia entre empresas pequeñas y grandes. En el análisis posterior se considera una variable binaria que toma valor $=0$ para las pequeñas empresas y valor $=1$ para las grandes empresas. La medida del tamaño se basó en el número de empleados (Covin y Slevin, 1989) y la facturación de ventas del último año fiscal.

Concretamente al número de empleados se diferenciaron cuatro categorías: (1) menos de 50 empleados, (2) entre 50 y 100 empleados, (3) entre 100 y 250 empleados, y (4) más de 250 empleados. Distintamente del número de empleados, la facturación de ventas del último año fiscal se diferenció en cinco categorías, en miles de euros: (1). < que 2.000, (2) entre 2.000 y 10.000 , (3) entre 2.000 y 50.000 , (4) entre 50.000 y 250.000 , y (5) > que 250.000 .

Al final la selección para las pequeñas empresas (valor $=0$ ) se clasificaron bajo los parámetros $>20$ y $<99$ empleados y $<50$ millones de euros de facturación de ventas del último año fiscal. Las grandes empresas $($ valor $=1$ ) se clasificaron bajo los parámetros: $>100$ empleados y > 50 millones de euros una facturación de ventas anual.

\subsubsection{Orientación al mercado}

Los constructos orientación al mercado y orientación emprendedora, se estudian por separado porque tienen diferentes aspectos y no están fundamentadas en la misma filosofía de negocio (Miles y Arnold, 1991). De esta misma manera lo han utilizado otros autores (Liu et al., 2000; Hult y Ketchen, 2001; Hult et al., 2003; Hsueh y Tu, 2004). 
Cabe destacar que se ha utilizado la escala de González-Benito y González-Benito (2005) para medir el constructo de orientación al mercado. Esta escala parte de una combinación de las escalas de Kohli y Jaworski (1990) y Narver y Slater (1990). La elección se basó en que es una escala más apropiada para nuestra investigación porque no sólo mide la orientación al mercado desde un énfasis cultural sino también operativo que va más ligado a los resultados y es más cercana con el tema del comportamiento innovador en la empresa.

La orientación al mercado es una variable multi-ítem. Estas variables fueron valoradas por los encuestados según el grado de acuerdo y desacuerdo relativo a las prácticas ejercidas por la empresa $(1=$ totalmente en desacuerdo/ $7=$ totalmente de acuerdo $)$ siguiendo una escala Likert de 7 puntos. Las correlaciones entre las variables son significativas.

La Tabla 25 muestra el detalle de cada ítem, sus descriptivos estadísticos, cargas factoriales, varianza explicada y la fiabilidad del constructo. Dado el resultado del análisis factorial, se ha optado por utilizar el constructo de forma unidimensional. Se encontraron cargas significativas y las comunalidades fueron suficientes. El porcentaje de la varianza explicada del constructo es del 70\%. El alfa de Cronbach es sobresaliente al 90\%. Las cargas factoriales son superiores al $65 \%$. Los resultados obtenidos sugieren considerar a la orientación al mercado como un único constructo. 
Tabla 25

Escala de medida de la orientación al mercado

\begin{tabular}{|c|c|c|c|c|c|c|c|c|c|c|c|c|c|}
\hline \multirow{2}{*}{ Ítems 1} & \multicolumn{8}{|c|}{ Correlaciones } & \multirow{2}{*}{ Media } & \multirow{2}{*}{$\mathrm{DT}_{2}$} & \multirow{2}{*}{$\mathrm{CF}_{3}$} & \multirow{2}{*}{$\mathrm{VE}_{4}$} & \multirow{2}{*}{$\mathrm{AC}_{5}$} \\
\hline & 1 & 2 & 3 & 4 & 5 & 6 & 7 & 8 & & & & & \\
\hline $\begin{array}{l}1 \text { Continuamente estamos reuniendo información a } \\
\text { cerca de nuestro mercado objetivo. }\end{array}$ & 1 & & & & & & & & 4,93 & 1,75 & $0,863^{* * *}$ & & \\
\hline $\begin{array}{l}2 \text { Recogemos regularmente información sobre las } \\
\text { estrategias de nuestros competidores. }\end{array}$ & $0,806^{* * *}$ & 1 & & & & & & & 4,72 & 1,72 & $0,849^{* * *}$ & & \\
\hline $\begin{array}{l}3 \text { Recogemos información sobre la satisfacción de } \\
\text { nuestros clientes. }\end{array}$ & $0,678^{* * *}$ & $0,583^{* * *}$ & 1 & & & & & & 5,58 & 1,59 & $0,801^{* * *}$ & & \\
\hline $\begin{array}{l}4 \text { Utilizamos informes internos sobre la estructura y } \\
\text { tendencias del mercado. }\end{array}$ & $0,680^{* * *}$ & $0,680^{* * *}$ & $0,662^{\star \star *}$ & 1 & & & & & 4,62 & 1,78 & $0,855^{\star * *}$ & & \\
\hline $\begin{array}{l}5 \text { Regularmente nos reunimos con los responsables } \\
\text { de marketing/ ventas para discutir las tendencias } \\
\text { del mercado. }\end{array}$ & $0,675^{\star * *}$ & $0,698^{* *}$ & $0,599^{* * *}$ & $0,786^{* * *}$ & 1 & & & & 4,66 & 1,93 & $0,89^{* * *} 5$ & & \\
\hline $\begin{array}{l}6 \text { Se nos informa regularmente de reclamaciones y } \\
\text { sugerencias de nuestros clientes. }\end{array}$ & $0,624^{* * *}$ & $0,575^{\star * *}$ & $0,763^{* * *}$ & $0,562^{* * *}$ & $0,620^{* * *}$ & 1 & & & 5,57 & 1,58 & $0,804^{* * *}$ & & $\%$ \\
\hline $\begin{array}{l}7 \text { Los responsables de las distintas unidades } \\
\text { funcionales se reúnen regularmente para } \\
\text { anticiparse a los cambios del entorno. }\end{array}$ & $0,679 * * *$ & $0,694^{* * *}$ & $0,590^{* * *}$ & $0,721^{* * *}$ & $0,733^{* * *}$ & $0,646^{* * *}$ & 1 & & 4,66 & 1,80 & $0,853^{* * *}$ & & \\
\hline $\begin{array}{l}8 \text { Nuestra estrategia está más basada en el } \\
\text { conocimiento del mercado que en las capacidades } \\
\text { productivas. }\end{array}$ & $0,476^{\star * *}$ & $0,521^{* * *}$ & $0,397^{\star * *}$ & $0,492^{* * *}$ & $0,521^{* * *}$ & $0,417^{* * *}$ & $0,531^{* * *}$ & 1 & 4,52 & 1,66 & $0,669^{* * *}$ & & \\
\hline $\begin{array}{l}9 \text { Nuestra prioridad en el desarrollo de nuevos } \\
\text { productos se basa más en la satisfacción del } \\
\text { consumidor que en la obtención de ventajas de la } \\
\text { capacidad productiva. }\end{array}$ & $0,526^{\star * *}$ & $0,474^{\star * *}$ & $0,516^{\star * *}$ &, $470^{\star \star *}$ & $0,522^{\star \star *}$ & $0,563^{* \star *}$ & $0,491^{* * *}$ & $0,580^{* * *}$ & 4,82 & 1,65 & $0,707^{\star * *}$ & & \\
\hline
\end{tabular}

1 Fuente: Narver y Slater (1990); Kohli y Jaworski (1990) / 2 Desviación Típica / 3 Carga Factorial / 4 Varianza Explicada / 5 Alfa de Cronbach ${ }^{* * *} p<0,001$ 


\subsubsection{Orientación emprendedora}

La orientación emprendedora está compuesta por seis ítems relacionados al comportamiento emprendedor. De la misma manera, se ha utilizado la escala de GonzálezBenito y González-Benito (2005), basada en Naman y Slevin (1993); Covin y Miles (1999); Slater y Narver (2000), para medir el constructo de orientación emprendedora porque miden la orientación emprendedora desde un énfasis operativo que conexa mejor con el desempeño empresarial y es cercano a las estrategias innovadoras de la empresa

Igualmente, éstas variables fueron valoradas por los encuestados según el grado de acuerdo y desacuerdo relativo a las prácticas ejercidas por la empresa $(1=$ totalmente en desacuerdo; 7= totalmente de acuerdo) siguiendo una escala Likert de 7 puntos. Las correlaciones entre las variables son significativas.

La Tabla 26 muestra el detalle de cada ítem. Dado el resultado del análisis factorial, se optó por utilizar la forma unidimensional. Al ejecutar la técnica estadística del análisis factorial se extrajeron las cargas factoriales que son superiores al $75 \%$. El porcentaje de la varianza explicada es de $70 \%$ y el alfa de Cronbach es sobresaliente al $90 \%$ para la muestra. Los resultados obtenidos sugieren considerar a la orientación emprendedora como constructo único.

\subsubsection{Factores del entorno}

Con el fin de proporcionar mayor rigor al análisis de la relación entre la innovación y el desempeño empresarial, se han integrado a la función algunas variables adicionales, relativas a los factores externos de la empresa como el dinamismo del entorno y la colaboración organizacional. La selección de los ítems se basó en la literatura al respecto, aunque adaptada al escenario concreto en el que se desarrolla el estudio. Con las medidas del entorno se pretende captar el efecto del entorno competitivo y colaborativo. 
Tabla 26

Escala de medida de la orientación emprendedora

\begin{tabular}{|c|c|c|c|c|c|c|c|c|c|c|c|}
\hline \multirow{2}{*}{\multicolumn{2}{|c|}{ Ítems 1}} & \multicolumn{5}{|c|}{ Correlaciones } & \multirow{2}{*}{ Media } & \multirow{2}{*}{$\mathrm{DT}_{2}$} & \multirow{2}{*}{$\mathrm{CF}_{3}$} & \multirow{2}{*}{$\mathrm{VE}_{4}$} & \multirow{2}{*}{$\mathrm{AC}_{5}$} \\
\hline & & 1 & 2 & 3 & 4 & 5 & & & & & \\
\hline 1 & $\begin{array}{l}\text { En los últimos cinco años hemos lanzado al mercado } \\
\text { muchas nuevas líneas de productos/ servicios. }\end{array}$ & 1 & & & & & 4,00 & 2,05 & $0,808^{* * *}$ & & \\
\hline 2 & $\begin{array}{l}\text { Los cambios en nuestras líneas de productos/ servicios } \\
\text { generalmente son considerables. }\end{array}$ & $0,797^{\star * \star}$ & 1 & & & & 3,89 & 1,85 & $0,834^{* * *}$ & & \\
\hline 3 & $\begin{array}{l}\text { Nos anticipamos a las acciones de nuestros } \\
\text { competidores al introducir nuevos productos/ servicios } \\
\text { para desarrollar técnicas administrativas e incorporar } \\
\text { tecnologías operativas. }\end{array}$ & $0,643^{\star * *}$ & $0,705^{\star \star *}$ & 1 & & & 4,16 & 1,79 & $0,851^{* * *}$ & & \\
\hline 4 & $\begin{array}{l}\text { Generalmente adoptamos una postura competitiva } \\
\text { deshaciéndonos de nuestros competidores. }\end{array}$ & $0,515^{* \star *}$ & $0,552^{* * *}$ & $0,656^{* * *}$ & 1 & & 3,46 & 1,68 & $0,800^{* * *}$ & $70 \%$ & $90 \%$ \\
\hline 5 & $\begin{array}{l}\text { Generalmente la dirección de mi empresa es propensa } \\
\text { a desarrollar proyectos de alto riesgo con } \\
\text { oportunidades de altos beneficios. }\end{array}$ & $0,452^{* \star \star}$ & $0,466^{\star \star *}$ & $0,528^{* \star *}$ & $0,593^{\star * \star}$ & 1 & 3,08 & 1,68 & $0,773^{\star * *}$ & & \\
\hline 6 & $\begin{array}{l}\text { En situaciones de tomas de decisión con } \\
\text { incertidumbre, Generalmente la dirección de mi } \\
\text { empresa adopta una postura valiente y agresiva con el } \\
\text { objetivo de maximizar la probabilidad de explotar las } \\
\text { posibles oportunidades. }\end{array}$ & $0,444^{* * *}$ & $0,465^{\star \star *}$ & $0,528^{\star \star \star}$ & $0,534^{* * *}$ & $0,709^{* * *}$ & 3,62 & 1,63 & $0,775^{\star * *}$ & & \\
\hline
\end{tabular}

1 Fuente: Naman y Slevin (1993); Covin y Miles (1999); Slater y Narver (2000) / 2 Desviación Típica / 3 Carga Factorial / 4 Varianza Explicada / 5 Alfa de Cronbach ${ }^{* * *} p<0,001$ 


\subsubsection{Turbulencia del entorno}

Para medir la turbulencia del entorno se solicitó a los encuestados valorar el grado de acuerdo de la situación del negocio principal de la empresa respecto al sector y a la competencia. Respecto al sector, se valoró siguiendo cuatro ítems básicos relacionados con los cambios en los procesos y técnicas de producción, cambios en la demanda de los consumidores, incorporación de nuevos productos y estrategias y actuaciones de los competidores. Estas variables fueron valoradas según el grado de estabilidad siguiendo una escala Likert de 7 puntos (1= muy estable; $7=$ cambios frecuentes y muy importantes).

En la Tabla 27, se observan los datos descriptivos y las correlaciones de las variables que miden la turbulencia del entorno. Existe una alta correlación entre las cuatro variables. Al ejecutar la técnica estadística del análisis factorial se extrajeron las cargas factoriales la cuales son superiores al $80 \%$. El porcentaje de la varianza explicada es superior al $70 \%$ y el alfa de Cronbach es sobresaliente al 86\%. Los resultados obtenidos sugieren considerar a la turbulencia del entorno como una construcción unidimensional.

\subsubsection{Intensidad competitiva}

En relación a la intensidad competitiva los encuestados debían de valorar el grado de acuerdo sobre las características del comportamiento de sus competidores: precios agresivos, nuevos/mejorados productos, oferta sustitutiva y mayor tamaño. De la misma forma se siguió una escala Likert de 7 puntos (1= nada de acuerdo; $7=$ muy de acuerdo).

En la Tabla 28, se observan los datos descriptivos y las correlaciones de las variables que miden la intensidad competitiva. Existe una alta correlación entre las cuatro variables. Al ejecutar la técnica estadística del análisis factorial se extrajeron las cargas factoriales la cuales rondan el 70\%. El porcentaje de la varianza explicada es del 70\% y el alfa de Cronbach es aceptable al 65\%. Los resultados obtenidos sugieren considerar a la intensidad competitiva como una construcción unidimensional. 
Tabla 27

Escala de medida del turbulencia del entorno

\begin{tabular}{|c|c|c|c|c|c|c|c|c|c|}
\hline \multirow{2}{*}{\multicolumn{2}{|c|}{ Ítems 1}} & \multicolumn{3}{|c|}{ Correlaciones } & \multirow{2}{*}{ Media } & \multirow{2}{*}{$\mathrm{DT}_{2}$} & \multirow{2}{*}{$\mathrm{CF}_{3}$} & \multirow{2}{*}{$\mathrm{VE}_{4}$} & \multirow{2}{*}{$\mathrm{AC}_{5}$} \\
\hline & & 1 & 2 & 3 & & & & & \\
\hline & $\begin{array}{l}\text { Cambios experimentados en los procesos de } \\
\text { producción y en las técnicas de producción }\end{array}$ & 1 & & & 4,27 & 1,67 & $0,824^{\star \star *}$ & \multirow{4}{*}{$71 \%$} & \multirow{4}{*}{$86 \%$} \\
\hline 2 & $\begin{array}{l}\text { Cambios experimentados en la demanda } \\
\text { de los consumidores }\end{array}$ & $0,660^{* * *}$ & 1 & & 4,56 & 1,54 & $0,868^{* \star *}$ & & \\
\hline & $\begin{array}{l}\text { Incorporación de nuevos productos y } / 0 \\
\text { nuevos servicios }\end{array}$ & $0,601^{* * *}$ & $0,640^{* * *}$ & 1 & 4,67 & 1,60 & $0,856^{\star \star \star}$ & & \\
\hline & $\begin{array}{l}\text { Estrategias organizacionales implantadas } \\
\text { y actuaciones de los competidores }\end{array}$ & $0,519^{* \star *}$ & $0,611^{* * *}$ & $0,636^{\star \star *}$ & 4,49 & 1,51 & $0,819^{\star \star \star}$ & & \\
\hline
\end{tabular}

${ }_{1}^{1}$ Fuente: Kohli y Jaworski (1990); Pelham y Wilson (1996); Hult et al. (2003) / 2 Desviación Típica / 3 Carga Factorial / 4 Varianza Explicada / 5 Alfa de Cronbach ${ }^{* * *} p<0,001$ 
Tabla 28

Escala de medida de la intensidad competitiva

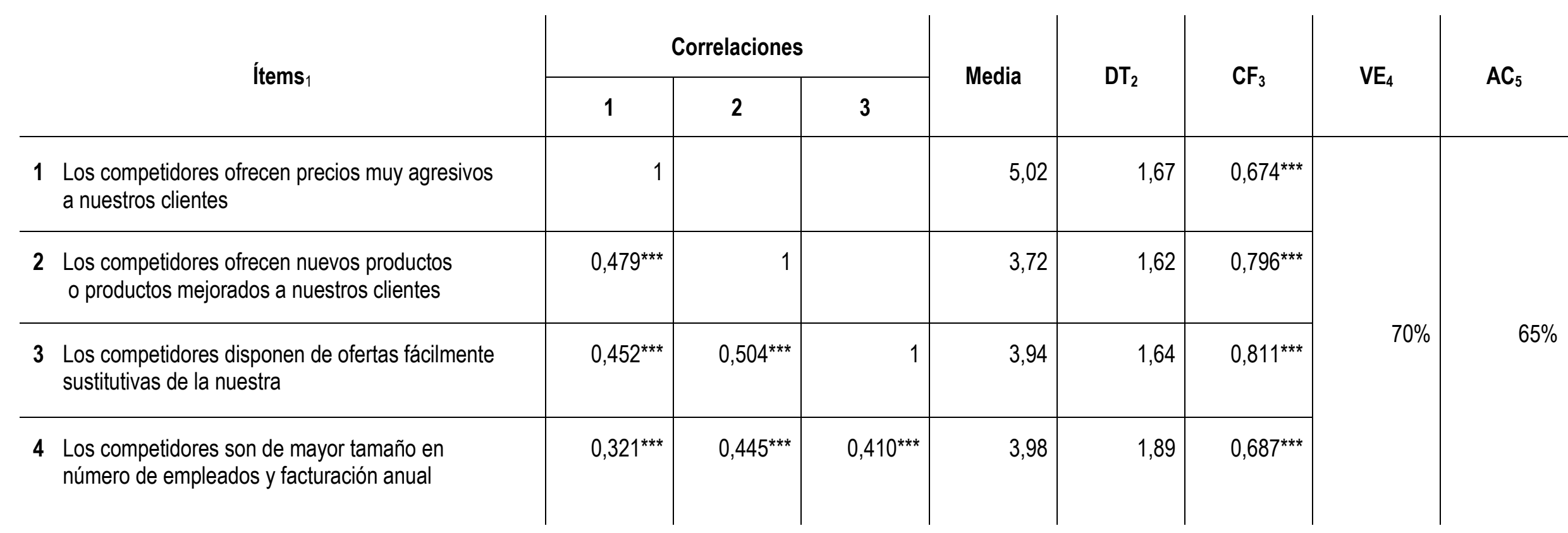

1 Fuente: Kohli y Jaworski (1990); Pelham y Wilson (1996); Hult et al. (2003) / 2 Desviación Típica / 3 Carga Factorial / 4 Varianza Explicada / 5 Alfa de Cronbach ${ }^{* * \star} p<0,001$ 


\subsubsection{Colaboración organizacional}

La colaboración organizacional fue medida por separado tanto para la innovación radical como para la innovación incremental. En la primera, se solicitó a los entrevistados valorar el grado de importancia de la colaboración de un conjunto de entidades para el registro de patentes, las actividades I+D y al desarrollo de nuevos productos y mercados. Para la innovación incremental se solicitó valorar el grado de importancia de la colaboración, del mismo conjunto de entidades, en la introducción de mejoras de innovaciones en la empresa en los últimos 5 años.

El conjunto de entidades que se consideraron para medir las variables de colaboración se basó en lo que en el Manual de Oslo, OECD (2005) consideró como agentes del sistema de innovación que aportan vínculos importantes a la actividad emprendedora de la empresa;

"Cada vínculo relaciona a la empresa innovadora con los otros agentes del sistema de innovación: laboratorios públicos, universidades, ministerios, autoridades reguladoras, competidores, proveedores y clientes. Las encuestas sobre innovación permiten obtener información sobre el predominio y la importancia de los distintos tipos de vínculos y sobre los factores que influyen en la utilización de vínculos específicos. La identificación de los vínculos en la actividad innovadora facilita evidencias sobre la complejidad de esta actividad, pero no permite obtener la información necesaria para formular un modelo dinámico que incluya la retroalimentación de los efectos positivos y negativos del intercambio de información y los resultados no lineales debidos al cambio" (OECD, 2005: 253)

Las respuestas se registraron conforme a una escala de tipo Likert de siete puntos $(1=$ nada importante; 7 = muy importante). El conjunto de entidades cuya colaboración se pidió valorar había sido definido teniendo en cuenta la colaboración del canal (otras empresas, proveedores, clientes, competencia) y la colaboración de asesoría (licenciadores, consultores, asociaciones empresariales, universidades). 
Las Tablas 29 y 30 muestran los resultados estadísticos descriptivos, correlaciones y del factorial para cada tipo de colaboración y cada tipo de innovación. Los datos obtenidos permiten asumir unidimensionalidad de dos constructos creados para cada tipo de colaboración: colaboración del canal y colaboración de asesoría. Existe una escasa correlación entre estos dos factores.

Al ejecutar la técnica estadística del análisis factorial se extrajeron las cargas factoriales la cuales son superiores al 70\% para ambos tipos de colaboración. El porcentaje de la varianza explicada es superior en los cuatros casos al $75 \%$ y el alfa de Cronbach es sobresaliente para todos los casos al 0,80. Los resultados obtenidos sugieren considerar a los cuatros tipos de colaboración como constructos únicos. 
Tabla 29

Escala de medida de la colaboración para la innovación radical

\begin{tabular}{|c|c|c|c|c|c|c|c|c|c|c|c|c|c|}
\hline \multirow{2}{*}{ Variables } & \multirow{2}{*}{ Ítems 1} & \multicolumn{7}{|c|}{ Correlaciones } & \multirow{2}{*}{ Media } & \multirow{2}{*}{$\mathrm{DT}_{2}$} & \multirow{2}{*}{$\mathrm{CF}_{3}$} & \multirow{2}{*}{$\mathrm{VE}_{4}$} & \multirow{2}{*}{$\mathrm{AC}_{5}$} \\
\hline & & 1 & 2 & 3 & 4 & 5 & 6 & 7 & & & & & \\
\hline $\begin{array}{l}\text { Colaboración } \\
\text { Canal }\end{array}$ & $\begin{array}{ll}1 & \text { Otras empresas del grupo } \\
2 & \text { Proveedores } \\
3 & \text { Clientes } \\
4 & \text { Competencia }\end{array}$ & $\begin{array}{r}1 \\
0,301^{* * *} \\
0,329^{* * *} \\
0,300^{* * *}\end{array}$ & $\begin{array}{c}1 \\
0,454^{* * *} \\
0,428^{* \star *}\end{array}$ & $\begin{array}{r}1 \\
0,666^{* * *}\end{array}$ & 1 & & & & $\begin{array}{l}3,82 \\
3,50 \\
4,00 \\
3,65\end{array}$ & $\begin{array}{l}2,25 \\
1,95 \\
1,87 \\
1,81\end{array}$ & $\begin{array}{l}0,776^{* \star \star} \\
0,783^{* \star *} \\
0,831^{* \star *} \\
0,841^{* \star *}\end{array}$ & $75 \%$ & $82 \%$ \\
\hline $\begin{array}{l}\text { Colaboración } \\
\text { Asesoría }\end{array}$ & $\begin{array}{ll}5 & \text { Licenciadores } \\
6 & \text { Consultores } \\
7 & \text { Universidad } \\
8 & \text { Asociaciones empresariales }\end{array}$ & $\begin{array}{l}0,179^{* \star *} \\
0,222^{* \star *} \\
0,442^{* * *} \\
0,170^{* * *}\end{array}$ & $\begin{array}{l}0,513^{\star \star \star} \\
0,495^{\star \star \star} \\
0,587^{\star * \star} \\
0,511^{* \star *}\end{array}$ & $\begin{array}{l}0,347^{\star * \star} \\
0,432^{\star * *} \\
0,491^{* * *} \\
0,429^{* * *}\end{array}$ & $\begin{array}{l}0,340^{* * *} \\
0,456^{* * *} \\
0,463^{* * *} \\
0,440^{* * *}\end{array}$ & $\begin{array}{r}1 \\
0,517^{* * *} \\
0,528^{* * *} \\
0,476^{* * *}\end{array}$ & $\begin{array}{c}0,531^{\star * \star} \\
0,546^{\star * \star}\end{array}$ & $0,587^{\star \star \star}$ & $\begin{array}{l}2,34 \\
2,60 \\
2,71 \\
2,56\end{array}$ & $\begin{array}{l}1,57 \\
1,61 \\
1,65 \\
1,63\end{array}$ & $\begin{array}{l}0,783^{* \star \star} \\
0,818^{\star \star \star} \\
0,822^{\star * \star} \\
0,834^{* \star *}\end{array}$ & $78 \%$ & $87 \%$ \\
\hline
\end{tabular}

1 Fuente: OECD (2005) / 2 Desviación Típica / 3 Carga Factorial / 4 Varianza Explicada / 5 Alfa de Cronbach ${ }^{* * *} p<0,001$ 
Tabla 30

Escala de medida de la colaboración para la innovación incremental

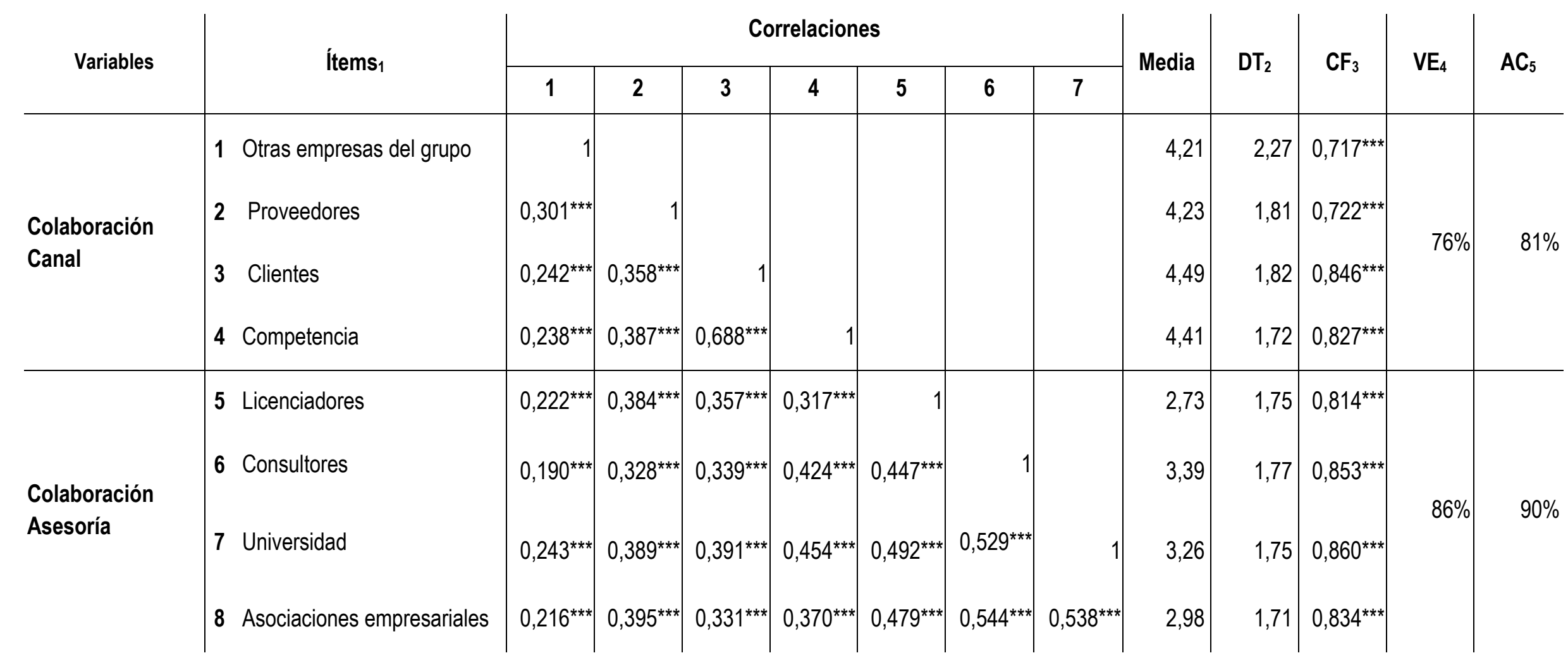

1 Fuente: OECD (2005) / 2 Desviación Típica / 3 Carga Factorial / 4 Varianza Explicada / 5 Alfa de Cronbach ${ }^{* *} p<0,001$ 



\title{
Cuarto capítulo
}

\author{
Análisis empírico \\ y presentación de los resultados
}





\section{Análisis empírico}

\subsection{Análisis de frecuencias}

El análisis de frecuencias permite conocer en primer plano dos cuestiones: (1) ¿cuáles son las características estructurales básicas de las empresas?, y (2) ¿qué tipo de innovación aplican más las empresas?

Las características estructurales analizadas en este trabajo son: sector de actividad, antigüedad, ámbito geográfico de actividad, tamaño (número de empleados) y cifra de negocios (facturación anual). En la siguiente explicación no se contempla las características del sector y tamaño porque ya se han tratado en la sección anterior correspondiente [3.2.2.]. A primera impresión puede parecer redundante los datos, no obstante, en la sección anterior se pretendía delimitar las diferencias con respecto a la población, en este caso, solamente se ofrecen más datos estructurales que acercan más al prototipo de empresas en cuestión. La distribución de frecuencias relativas a las características estructurales de la Tabla 31 se explica a continuación;

(1) antigüedad: es de esperar que en cuanto a la antigüedad en actividad industrial, las grandes empresas (86\%) sean más maduras que la pequeñas empresas $(75 \%)$.

(2) ámbito geográfico de actividad de las empresas: se reparte a lo largo de las cuatro esferas de acción industrial, sea provincial, autonómico, nacional e internacional, pero son las grandes empresas (89\%) las que abarcan un espacio nacional e internacional mayor que las pequeñas empresas (33\%).

(3) cifra de negocios: se observa como la mayor parte de las grandes empresas de la muestra se encuentran en el intervalo superior (61\%) obteniendo más de 50.000 (miles) en ventas. 
Tabla 31

Características estructurales de la muestra según tamaño de la empresa

\begin{tabular}{|c|c|c|c|}
\hline \multirow{2}{*}{ Perfil } & \multirow{2}{*}{ Descripción } & \multicolumn{2}{|c|}{ Frecuencia } \\
\hline & & Pequeñas & Grandes \\
\hline Sector & \begin{tabular}{|l|} 
Industria \\
Construcción \\
Agricultura \\
Comercio-Servicios \\
\end{tabular} & $\begin{array}{c}30 \% \\
20 \% \\
9 \% \\
42 \% \\
\end{array}$ & $\begin{array}{c}38 \% \\
20 \% \\
4 \% \\
39 \%\end{array}$ \\
\hline Antigüedad & $\begin{array}{l}\text { entre } 2 \text { y } 5 \text { años } \\
\text { entre } 6 \text { y } 10 \text { años } \\
\text { entre } 11 \text { y } 15 \text { años } \\
>\text { que } 15 \text { años }\end{array}$ & $\begin{array}{c}5 \% \\
10 \% \\
10 \% \\
75 \%\end{array}$ & $\begin{array}{c}1 \% \\
1 \% \\
13 \% \\
86 \%\end{array}$ \\
\hline Ámbito de actividad & $\begin{array}{l}\text { Provincial } \\
\text { Autónoma } \\
\text { Nacional } \\
\text { Internacional }\end{array}$ & $\begin{array}{l}50 \% \\
19 \% \\
20 \% \\
11 \% \\
\end{array}$ & $\begin{array}{c}3 \% \\
8 \% \\
56 \% \\
33 \% \\
\end{array}$ \\
\hline Tamaño plantilla & $\begin{array}{l}\text { entre } 21 \text { y } 50 \\
\text { entre } 51 \text { y } 100 \\
\text { entre } 101 \text { y } 250 \\
>\text { que } 250\end{array}$ & $\begin{array}{c}66 \% \\
34 \% \\
- \\
- \\
\end{array}$ & $\begin{array}{c}- \\
- \\
37 \% \\
63 \% \\
\end{array}$ \\
\hline $\begin{array}{l}\text { Facturación anual } \\
\text { (miles de euros) }\end{array}$ & $\begin{array}{l}\text { < que } 2.000 \\
\text { entre } 2.000 \text { y } 10.000 \\
\text { entre } 2.000 \text { y } 50.000 \\
\text { entre } 50.000 \text { y } 250.000 \\
>\text { que } 250.000\end{array}$ & $\begin{array}{c}16 \% \\
50 \% \\
35 \% \\
- \\
-\end{array}$ & $\begin{array}{c}- \\
- \\
- \\
61 \% \\
39 \%\end{array}$ \\
\hline
\end{tabular}

Fuente: elaboración propia.

Una vez estudiadas las características básicas de las empresas de la muestra se procede a describir qué tipos de innovaciones realizan según la naturaleza de dicha actividad. La distribución de frecuencias del tipo de innovaciones aparece en la Tabla 32.

En general existe un predominio de la innovación incremental tanto para las pequeñas (67\%) como para las grandes empresas (83\%) frente al $31 \%$ de innovaciones radicales por parte de las pequeñas empresas y un $63 \%$ en las grandes.

Las pequeñas empresas manifiestan su preferencia por el desarrollo para las innovaciones de organización, mientras que para las grandes empresas es el tipo de 
innovación que menos implantan (79\%) en comparación con el resto de innovaciones, aunque los porcentajes referente a la innovación incremental son muy regulares.

Tabla 32

Tipo de innovación realizada según tamaño de la empresa

\begin{tabular}{l|cc|cc}
\multirow{2}{*}{\multicolumn{1}{c|}{ Tipo de innovación }} & \multicolumn{2}{|c|}{ Pequeñas } & \multicolumn{2}{c}{ Grandes } \\
\cline { 2 - 5 } & $\begin{array}{c}\text { Pocas } \\
\text { innovaciones }\end{array}$ & $\begin{array}{c}\text { Muchas } \\
\text { innovaciones }\end{array}$ & $\begin{array}{c}\text { Pocas } \\
\text { innovaciones }\end{array}$ & $\begin{array}{c}\text { Muchas } \\
\text { innovaciones }\end{array}$ \\
\hline Innovación incremental & $33 \%$ & $67 \%$ & $17 \%$ & $83 \%$ \\
Innovación de organización & $25 \%$ & $75 \%$ & $21 \%$ & $79 \%$ \\
Innovación de marketing & $32 \%$ & $68 \%$ & $16 \%$ & $84 \%$ \\
Innovación de producto & $41 \%$ & $59 \%$ & $17 \%$ & $83 \%$ \\
Innovación de procesos & $33 \%$ & $67 \%$ & $15 \%$ & $85 \%$ \\
\hline Innovación radical & $69 \%$ & $31 \%$ & $37 \%$ & $63 \%$ \\
Patentes registradas & $82 \%$ & $18 \%$ & $53 \%$ & $47 \%$ \\
Actibidades I+D & $83 \%$ & $17 \%$ & $43 \%$ & $57 \%$ \\
Desarrollo de nuevos & $43 \%$ & $57 \%$ & $20 \%$ & $80 \%$ \\
productos y mercados & & & &
\end{tabular}

Fuente: elaboración propia.

Una diferencia abismal se vislumbra a la hora de implantar innovaciones radicales, el $31 \%$ frente al $63 \%$ de implantaciones. De las tres medidas, el registro de patentes y personal implicado en I+D son las variables menos utilizadas por las pequeñas empresas; es más frecuente encontrar innovaciones que propicien nuevos productos y mercados (57\%). Aunque en el caso de las grandes empresas el juego de las tres medidas es parecido al de las pequeñas, se diferencia en cuanto a estas que están más implicadas en el desarrollo y registro de patentes y en la creación de un departamento de I+D con su propio personal y estructura; a la vez, el porcentaje más alto se centra en la desarrollo de nuevos productos y mercados (80\%). 


\subsection{Análisis de la matriz de correlaciones}

El análisis de matriz de correlación permite conocer de entrada dos asuntos: (1) ¿cuál es el comportamiento entre las variables?, y (2) ¿qué tipo de relación mantienen (lineal (+) o cuadrática u otro grado (-)?

Es elemental estudiar la relación o comportamiento que puede existir entre dos variables, por este motivo se utilizará la matriz de correlación. Como es claro, la matriz de correlación esta conformada por $n$ filas y $n$ columnas, es simétrica, es decir, que los valores de los elementos $a_{\mathrm{ij}}$ de la matriz son el mismo valor de los elementos $a_{\mathrm{ji}}$.

La matriz de correlación explica como está relacionada cada una de las variables con otra variable, o sea, mide y muestra la interdependencia en relaciones asociadas o entre cada pareja de variables y todas al mismo tiempo. Su diagonal siempre contendrá el valor de 1 . Si el coeficiente de correlación $(r)^{1}$ tiene un valor 0 , indicará que no tiene ninguna relación con esa variable, por lo menos no lineal, es decir, puede que la relación sea cuadrática o de otro grado.

Cuando el coeficiente lineal de la correlación es positivo, indica que su proyección de la regresión lineal va a tender a crecer conjuntamente con la contra variable. Cuando la correlación es negativa, esto nos indica que su proyección de la regresión lineal va a tender a decrecer conjuntamente con la contra variable.

\subsubsection{Matriz de correlaciones: modelo explicativo I}

De la matriz de correlaciones de la Tabla 33 se observa que la variable tamaño está correlacionada con las cuatro vertientes de innovación incremental, destacándose los coeficientes más elevados para las innovaciones incrementales tecnológicas (producto y procesos) y de organización que para las innovaciones incrementales comerciales (marketing). Indicando que la correlación es lineal, cuando aumenta el tamaño de la empresa

\footnotetext{
${ }^{1} r$ es igual a la suma de los productos de cada pareja de datos y dividido por el producto del número de datos por la desviación estándar de cada variable o serie de datos.
} 
incrementa el comportamiento innovador. Por otra parte, no se observa ninguna correlación con la innovación radical medida por las patentes, pero si con las actividades de I+D y desarrollo de nuevos productos y mercados.

Los coeficientes positivos y significativos de la variable tamaño de la empresa y la cultura organizativa pueden indicar que existe una correlación lineal con la orientación al mercado y orientación emprendedora. De modo que cuando aumenta el tamaño también crece la tendencia a mejorar el entorno hacia el cliente y el comportamiento emprendedor.

Dentro del entorno dinámico los coeficientes parecen indicar que el tamaño de la empresa está correlacionado con la turbulencia del entorno pero su correlación con la intensidad competitiva no es significativa. Esto puede indicar que las empresas más grandes afrontan mejor las amenazas y oportunidades que se puede dar en un ambiente hostil y de incertidumbre, pero no, cuando la intensidad competitiva apremia.

Al parecer la orientación al mercado y la orientación emprendedora desencadenan los perfiles innovadores incrementales y radicales. Sin embargo, explican en mayor parte lo que ocurre con las innovaciones incrementales de organización, marketing, producto y procesos, que con las acciones radicales. En todo caso, la orientación al mercado como la orientación emprendedora tiene que ver con vías de buscar acciones innovadoras estratégicas y operativas para la organización.

Por otro lado, se encuentran coeficientes lineales positivos y significativos entre los cuatros niveles de innovación y el dinamismo del entorno. A primera vista, estos coeficientes de correlación son más elevados para el elemento turbulencia del entorno que para la intensidad competitiva. Igualmente las cifras de correlación son más significativas para la innovación incremental que para la radical. Pero al parecer, en términos generales, la correlación indica que en medio de la creciente hostilidad del entorno las empresas pueden encontrar modos significativos para hacer implantaciones innovadoras.

Por último, interesa atender a la correlación existente entre la cultura organizativa y el dinamismo del entorno. A grandes rasgos se puede decir que la orientación emprendedora está mejor correlacionada con el entorno dinámico que la orientación al mercado. De manera 
que en la medida que la empresa emprenda una cultura emprendedora estará más preparada para asumir los riesgos y beneficios del entorno.

\subsubsection{Matriz de correlaciones: modelo explicativo II}

En la Tabla 33 se adveren las mismas correlaciones del modelo explicativo I pero con el añadido de las variables de desempeño empresarial, que son las que se analizarán a continuación. Las variables de resultados están positivamente correlacionadas con las variables de innovación incremental, solamente se muestra una baja correlación entre las tres primeras variables de resultados con las variables de innovación tecnológica (producto y procesos) y en cambio la variable éxito de nuevos productos está altamente correlacionada con las cuatro vertientes innovadoras. Al parecer las relaciones más fuertes se establecen con las innovaciones incrementales de organización y marketing. Las cuatro medidas de desempeño muestran correlaciones significativas con las actividades I+D y con el desarrollo de nuevos producto y mercados, sin embargo, la correlación con la variable patentes es baja o nula.

La correlación lineal de las variables de desempeño empresarial con los factores empresariales varía según su tipificación. Respecto a los factores organizacionales o internos alcanzan coeficientes de correlación más significativos que los factores del entorno o externos. Respecto al factor estructural tamaño de la empresa el comportamiento de la correlación es más elevada para los elementos de desempeño que tienen ver con indicadores observables de tipo contable; lo que indica que en la medida que aumenta el tamaño de la empresa los beneficios centrados en los resultados económicos y a corto plazo también aumentan. Mientras que cuando el tamaño es más pequeño, las ganancias están más orientadas a resultados operativos intermedios de la actividad realizada y que deberían conducir al éxito económico a mediano/largo plazo.

Por el lado del factor interno, que está más centrado en la cultura organizacional, o sea, la orientación al mercado, se percibe una positiva y alta significatividad de los coeficientes de correlación con los indicadores del desempeño empresarial. Principalmente se observa que en la medida que aumenta la orientación al mercado también aumentan con mayor facilidad los resultados de eficiencia y operativos; y menos en la eficiencia financiera (rentabilidad). 
Igualmente, los factores del entorno o externos también juegan un papel importante en las correlaciones lineales con los indicadores de desempeño. Por el lado de la turbulencia del entorno, se deduce que la correlación es más alta con los resultados de eficiencia y adaptabilidad, mientras que cuando la turbulencia del entorno aumenta se denota una leve disminución de los resultados operativos, por supuesto, tomando en cuenta el conjunto de los cuatro elementos de resultados empresariales. Relativo al factor externo de la intensidad competitiva, se observa claramente que los resultados financieros y eficaces sufren una considerable disminución (hasta no alcanzar la significatividad), o sea, no hay una correlación aparente, que contrariamente si se advierte en la variable éxito de nuevos productos. 
Tabla 33

Correlaciones entre las variables del modelo explicativo I y II

\begin{tabular}{|c|c|c|c|c|c|c|c|c|c|c|c|c|c|c|c|c|}
\hline Variables & 1 & 2 & 3 & 4 & 5 & 6 & 7 & 8 & 9 & 10 & 11 & 12 & 13 & 14 & 15 & 16 \\
\hline 1 Tamaño de la empresa & 1 & & & & & & & & & & & & & & & \\
\hline 2 Sector & -0.067 & 1 & & & & & & & & & & & & & & \\
\hline 3 Innovación de organización & $0,214^{* * *}$ & 0,089 & 1 & & & & & & & & & & & & & \\
\hline 4 Innovación de marketing & $0,147^{\star \star *}$ & 0,084 & $0,706^{* * *}$ & 1 & & & & & & & & & & & & \\
\hline 5 Innovación de producto & $0,206^{* * *}$ & $-0,138^{* *}$ & $0,467^{* \star *}$ & $0,480^{* * *}$ & 1 & & & & & & & & & & & \\
\hline 6 Innovación de procesos & $0,215^{\star \star *}$ & $-0,133^{*}$ & $0,516^{* * *}$ & $0,449^{* * *}$ & $0,633^{* * *}$ & 1 & & & & & & & & & & \\
\hline 7 Patentes registradas & 0,088 & $-0,107^{\star *}$ & 0,069 & $0,146^{* * *}$ & $0,250^{* * *}$ & $0,110^{\star *}$ & 1 & & & & & & & & & \\
\hline 8 Actividades I+D & $0,477^{* * *}$ & $-0,067$ & $0,378^{* * *}$ & $0,294^{* * *}$ & $0,320^{* * *}$ & $0,314^{* * *}$ & $0,259^{* * *}$ & 1 & & & & & & & & \\
\hline $\begin{array}{l}9 \text { Desarrollo de nuevos productos } \\
\text { y mercados }\end{array}$ & $0,259^{* * *}$ & 0,039 & $0,459^{* * *}$ & $0,410^{* * *}$ & $0,284^{* * *}$ & $0,374^{* * *}$ & $0,148^{* * *}$ & $0,374^{* * *}$ & 1 & & & & & & & \\
\hline 10 Rentabilidad & $0,215^{\star * *}$ & $-0,017$ & $0,253^{* * *}$ & $0,270^{* * *}$ & $0,184^{* * *}$ & $0,155^{\star \star *}$ & 0,043 & $0,240^{* * *}$ & $0,204^{* * *}$ & 1 & & & & & & \\
\hline 11 Respuesta de mercado & $0,165^{\star * *}$ & 0,032 & $0,277^{* * *}$ & $0,287^{* * *}$ & $0,161^{* * *}$ & $0,178^{* * *}$ & $0,110^{* *}$ & $0,228^{* * *}$ & $0,285^{\star * *}$ & $0,683^{* * *}$ & 1 & & & & & \\
\hline 12 Valor en el mercado & 0,067 & $-0,018$ & $0,317^{* * *}$ & $0,288^{* * *}$ & $0,172^{\star * *}$ & $0,197^{* * *}$ & 0,037 & $0,135^{\star * *}$ & $0,214^{* * *}$ & $0,530^{* * *}$ & $0,560^{* * *}$ & 1 & & & & \\
\hline 13 Éxito nuevos productos & $0,114^{* *}$ & $-0,068$ & $0,356^{\star * *}$ & $0,384^{* * *}$ & $0,429^{* * *}$ & $0,308^{* * *}$ & $0,114^{* *}$ & $0,223^{* * *}$ & $0,263^{* * *}$ & $0,429^{* * *}$ & $0,455^{\star * *}$ & $0,573^{* * *}$ & 1 & & & \\
\hline 14 Orientación al mercado & $0,256^{* * *}$ & 0,067 & $0,611^{* * *}$ & $0,618^{* * *}$ & $0,511^{* * *}$ & $0,445^{* * *}$ & $0,190^{* * *}$ & $0,360^{* * *}$ & $0,411^{* * *}$ & $0,275^{\star * *}$ & $0,326^{* * *}$ & $0,411^{* * *}$ & $0,489^{* * *}$ & 1 & & \\
\hline 15 Orientación emprendedora & $0,211^{* * *}$ & $0,103^{* *}$ & $0,514^{* * *}$ & $0,574^{\star * *}$ & $0,547^{\star \star *}$ & $0,457^{* * *}$ & $0,270^{\star * *}$ & $0,401^{* * *}$ & $0,489^{* * *}$ & $0,259^{* * *}$ & $0,264^{* * *}$ & $0,230^{* * *}$ & $0,444^{* * *}$ & $0,600^{* * *}$ & 1 & \\
\hline 16 Turbulencia del entorno & $0,165^{* \star *}$ & $-0,002$ & $0,434^{\star * *}$ & $0,476^{\star * *}$ & $0,475^{\star * *}$ & $0,365^{\star * *}$ & $0,181^{* * *}$ & $0,320^{* * *}$ & $0,337^{* * *}$ & $0,346^{* * *}$ & $0,280^{* * *}$ & $0,298^{* * *}$ & $0,435^{\star * *}$ & $0,582^{\star * \star}$ & $0,623^{* * *}$ & 1 \\
\hline 17 Intensidad competitiva & 0,077 & 0,001 & $0,296^{* * *}$ & $0,315^{* * *}$ & $0,288^{* * *}$ & $0,214^{* * *}$ & $0,110^{* *}$ & $0,108^{* *}$ & $0,163^{* * *}$ & 0,05 & 0,019 & 0,046 & $0,140^{* * *}$ & $0,323^{* * *}$ & $0,374^{* * *}$ & $0,537^{* * *}$ \\
\hline
\end{tabular}

*** La correlación es significativa al nivel 0,01 (bilateral)

** La correlación es significante al nivel 0,05 (bilateral) 


\subsubsection{Matriz de correlaciones: modelo explicativo III}

La Tabla 34 resume las correlaciones pertinentes para el modelo III. En primer lugar, se explican las correlaciones de los dos constructos de innovación (incremental y radical) con los indicadores de desempeño empresarial. Ambos tipos de innovación están positiva y significativamente correlacionadas con los cuatro elementos de resultados, sin embargo la correlación más alta, por partida doble, se halla en la variable éxito de nuevos productos. De manera que, en la medida que aumenta la innovación de la empresa, paralelamente se hace más patente que acrecienten los beneficios operativos adaptables a mediano y largo plazo. Estos resultados siguen el patrón del modelo explicativo II sobre la correlación entre innovación (multidimensional) y desempeño.

Respecto al tamaño de la empresa y la innovación, los coeficientes siguen la misma línea de las matrices de los modelos anteriores. A pesar de que en este modelo ya no jugamos con el factor multidimensional de la innovación sino más bien con dos factores distintos de innovación, la correlación sigue siendo positiva y significativa con el tamaño, pero con una diferencia sustancial, el tamaño está mucho más correlacionado con la innovación radical que con la innovación incremental. Por tanto, las empresas de mayor tamaño experimentan mayores innovaciones radicales que progresivas.

Relativo a los factores externos se observan algunas discrepancias esenciales. Tanto la innovación incremental como la innovación radical están más altamente correlacionadas con la turbulencia del entorno que con la intensidad competitiva. Aunque hay que advertir que el coeficiente de correlación de la turbulencia del entorno y la intensidad competitiva son bastante mayores para la innovación incremental que para la radical. Se podría decir, que en la medida que crece el dinamismo del entorno es posible que se adopten más innovaciones progresivas que radicales.

Referente al factor externo de la colaboración organizacional podemos deducir que existe una fuerte correlación con la innovación incremental e radical. Esto puede indicar que en la medida que aumenta la colaboración organización, igualmente aumenta la implantación de la innovación. 
Por último, las medidas de colaboración organizacional presentan positivas y significativas correlaciones lineales con los cuatro elementos que miden el desempeño empresarial. Concerniente a las correlaciones con la colaboración organizacional (II) se puede deducir que tanto la colaboración del canal (II) como la colaboración de asesoría (II) están fuertemente correlacionadas con las cuatro medidas de desempeño empresarial, excepto en la rentabilidad para la colaboración del canal (II) que es más bajo que las demás. No obstante, la colaboración de asesoría (II) es la única variable que presenta una alta correlación con la variable rentabilidad, aportando un mayor efecto financiero y eficaz al corto plazo. Por lo tanto, se deriva que un incremento de la colaboración organizacional (II) incentiva una mejora en los resultados económicos financieros y operativos.

Conexo a la colaboración del canal (IR), se muestran fuertes correlaciones con las medidas de eficacia y operativas, pero es más débil, en comparación, con la variable de la rentabilidad. La colaboración de asesoría (IR) muestra el mismo patrón anterior. Estas correlaciones podrían indicar que un aumento en la dinámica colaboradora, sea por medio del canal o de la asesoría, podría aumentar, equivalentemente, la mejora del éxito empresarial. 
Tabla 34

Correlaciones entre las variables del modelo explicativo III

\begin{tabular}{|c|c|c|c|c|c|c|c|c|c|c|c|c|}
\hline Variables & 1 & 2 & 3 & 4 & 5 & 6 & 7 & 8 & 9 & 10 & 11 & 12 \\
\hline 1 Tamaño de la empresa & 1 & & & & & & & & & & & \\
\hline 3 Innovación incremental & $0,253^{* * *}$ & 1 & & & & & & & & & & \\
\hline 2 Innovación radical & $0,429^{* * *}$ & $0,512^{* * *}$ & 1 & & & & & & & & & \\
\hline 4 Rentabilidad & $0,315^{\star * \star}$ & $0,364^{* * *}$ & $0,361^{* * *}$ & 1 & & & & & & & & \\
\hline 5 Respuesta de mercado & $0,265^{\star \star *}$ & $0,383^{* * *}$ & $0,401^{* * *}$ & $0,683^{\star \star \star}$ & 1 & & & & & & & \\
\hline 6 Valor en el mercado & 0,067 & $0,398^{* * *}$ & $0,307^{* * *}$ & $0,530^{\star \star *}$ & $0,560^{* * *}$ & 1 & & & & & & \\
\hline 7 Éxito de nuevos productos & $0,214^{\star * *}$ & $0,442^{* \star *}$ & $0,592^{\star \star \star}$ & $0,429^{* \star *}$ & $0,455^{\star \star *}$ & $0,573^{\star \star *}$ & 1 & & & & & \\
\hline 8 Turbulencia del entorno & $0,265^{\star \star *}$ & $0,515^{*}+^{*}$ & $0,384^{\star * \star}$ & $0,346^{* \star *}$ & $0,280^{* * *}$ & $0,298^{* * *}$ & $0,435^{\star * *}$ & 1 & & & & \\
\hline 9 Intensidad competitiva & 0,077 & $0,325^{\star \star *}$ & $0,148^{\star * *}$ & 0,05 & 0,019 & 0,046 & $0,140^{* * *}$ & $0,537^{* * *}$ & 1 & & & \\
\hline 10 Colaboración del canal (IR) & 0,081 & $0,359^{* \star *}$ & $0,469^{\star \star \star}$ & $0,259^{\star \star \star}$ & $0,416^{* * *}$ & $0,412^{\star \star \star}$ & $0,458^{* * *}$ & $0,412^{\star \star *}$ & $0,248^{* * *}$ & 1 & & \\
\hline 11 Colaboración de asesoría (IR) & $0,332^{\star \star *}$ & $0,307^{\star \star *}$ & $0,482^{\star \star *}$ & $0,297^{\star \star \star}$ & $0,440^{* \star *}$ & $0,390^{\star \star *}$ & $0,392^{\star * *}$ & $0,326^{* \star *}$ & $0,239^{\star \star *}$ & $0,683^{* \star *}$ & 1 & \\
\hline 12 Colaboración del canal (II) & 0,053 & $0,543^{* * *}$ & $0,269^{* * *}$ & $0,254^{* \star *}$ & $0,429^{* * *}$ & $0,475^{\star * \star}$ & $0,364^{* * *}$ & $0,399^{* * *}$ & $0,311^{* * *}$ & $0,626^{* * *}$ & $0,438^{* \star \star}$ & 1 \\
\hline 13 Colaboración de asesoría (II) & $0,351^{* * *}$ & $0,491^{\star * *}$ & $0,328^{* * *}$ & $0,459^{* * *}$ & $0,438^{* * *}$ & $0,439^{* * *}$ & $0,417^{* * *}$ & $0,362^{* * *}$ & $0,221^{* * *}$ & $0,523^{* * *}$ & $0,722^{* \star *}$ & $0,577^{* * *}$ \\
\hline
\end{tabular}

*** La correlación es significativa al nivel 0,01 (bilateral)

* La correlación es significante al nivel 0,05 (bilateral)

$(\mathrm{IR})=$ Innovación radical

(II) = Innovación incrementa 


\subsection{Comparación de medias}

En esta sección se pretende evaluar el grado de asociación o independencia entre la variable categórica tamaño de la empresa (dicotómica, pequeñas $=0$, grandes $=1$ ) con las variables cuantitativas de los tres modelos en las que se ven directamente afectadas por el tamaño.

Previamente se exigen ciertos requisitos previos como la distribución normal de las variables cuantitativas en los grupos que se comparan y la homogeneidad de varianzas en las poblaciones de las que proceden los grupos; su no cumplimiento conlleva la necesidad de recurrir a pruebas estadísticas no paramétricas. Se podría asumir que se cumplen los requisitos para muestras grandes $(\mathrm{n}>100)$ como nuestro caso, pero aún así se procede a la exploración.

El procedimiento estadístico inferencial recurre a comparar las medias de las distribuciones de la variable cuantitativa en los diferentes grupos establecidos por la variable categórica a través de la prueba estadística del test $t$ de Student o pruebas no paramétricas cuando no se cumple el requisito de normalidad en las variables cuantitativas.

Ahora se evalúa el grado de asociación del tamaño con las variables cuantitativas de innovación, de desempeño empresarial, cultura organizativa y colaboración organizacional. Se desea conocer si el tamaño está relacionada con ellas: la pregunta por ejemplo podría ser ¿hay diferencias en la innovación de las empresas según su tamaño? O de forma alternativa, ¿está relacionada la innovación con el tamaño? Y así sucesivamente con el conjunto de variables.

En la Tabla 35 se advierten los $\mathrm{IC}_{95 \%}$ para la media en cada grupo, una forma alternativa al contraste de hipótesis clásico para tomar decisiones sobre la relación entre variables. Se observa que tanto la estimación puntual de la media de las variables en ambos grupos (pequeñas=0, grandes $=1$ ) como sus intervalos de confianza, son mas elevados en las grandes que en las pequeñas, por lo tanto, no están superpuestas, por lo que hace probable que la variable tamaño y las demás variables cuantitativas estén relacionadas en la población. La diferencia puntual de estás medias varían desde 0,990 a 0,130 con una promedio de 0,510. 
Es probable que ambas medias sean estadísticamente diferentes y que podamos concluir que existe relación entre la variable tamaño con las demás variables en la población de la que proviene la muestra.

Por otro lado, la Tabla 35 muestra las pruebas de normalidad, para tomar una decisión sobre la adecuación de los test paramétricos a la comparación de medias. Ambas contrastes para las pruebas de normalidad, Kolmogorov-Smirnov y Shapiro-Wilk, muestran que en ambos grupos no se distribuye según una ley normal, ya que los valores son al $p<0,05$. Esto obliga a tomar una vía distinta en el análisis de la relación entre las variables, optando por pruebas no paramétricas.

Respecto a los estadísticos de contraste de las pruebas no paramétricas de dos muestras independientes, el programa procesa la información contenida en las variables cuantitativas en cada grupo y calcula varios estadísticos de contraste, pero se centrará el análisis al estadístico de U de Mann-Whitney. Se puede interpretar que la significatividad asintótica (bilateral) de las variables para este contraste son significativas al $p<0,05$, que en este caso vale para casi todas las variables, excepto para la variable valor en el mercado y la variable colaboración de asesoría (IR). Por lo tanto cabe concluir que la media de las variables son similares entre grupos y que por ende puede existir una relación estadísticamente significativa entre el tamaño y las variables expuestas. 
Tabla 35

Comparación de medias tomando como base de comparación el tamaño de la empresa

\begin{tabular}{|c|c|c|c|c|c|c|c|c|c|c|c|c|}
\hline \multirow[b]{2}{*}{ Variables } & \multicolumn{5}{|c|}{ Pequeñas } & \multicolumn{5}{|c|}{ Grandes } & \multirow[b]{2}{*}{ Levene } & \multirow{2}{*}{$\begin{array}{l}\text { U-Mann- } \\
\text { Whitney }\end{array}$} \\
\hline & Media & Inferior & Superior & \multicolumn{2}{|c|}{$\begin{array}{c}\text { Kolmogorov- Shapiro- } \\
\text { Smirnov Wilk }\end{array}$} & Media & Inferior & Superior & \multicolumn{2}{|c|}{\begin{tabular}{|cc} 
Kolmogorov- & Shapiro- \\
Smirnov Wilk
\end{tabular}} & & \\
\hline Innovación incremental & 4,20 & 4,04 & 4,37 & 0,001 & 0,002 & 4,89 & 4,72 & 4,37 & 0,000 & 0,000 & 0,001 & 0,000 \\
\hline Innovación de organización & 4,51 & 4,33 & 4,70 & 0,000 & 0,000 & 5,12 & 4,93 & 4,70 & 0,000 & 0,000 & 0,001 & 0,000 \\
\hline Innovación de marketing & 4,25 & 4,04 & 4,47 & 0,000 & 0,000 & 4,78 & 4,56 & 5,00 & 0,000 & 0,000 & 0,016 & 0,001 \\
\hline Innovación de producto & 4,01 & 3,75 & 4,27 & 0,000 & 0,000 & 4,79 & 4,55 & 5,04 & 0,000 & 0,000 & 0,097 & 0,000 \\
\hline Innovación de procesos & 4,15 & 3,97 & 4,37 & 0,000 & 0,000 & 4,80 & 4,58 & 5,03 & 0,000 & 0,000 & 0,001 & 0,000 \\
\hline Innovación radical & 2,13 & 1,98 & 2,28 & 0,000 & 0,000 & 3,12 & 2,93 & 3,32 & 0,000 & 0,001 & 0,038 & 0,000 \\
\hline Patentes registradas & 2,45 & 1,78 & 2,19 & 0,000 & 0,000 & 3,17 & 2,89 & 3,33 & 0,000 & 0,000 & 0,012 & 0,000 \\
\hline Actividades de I+D & 2,15 & 1,92 & 2,34 & 0,000 & 0,000 & 3,32 & 2,72 & 3,19 & 0,000 & 0,000 & 0,021 & 0,000 \\
\hline $\begin{array}{l}\text { Desarrollo nuevos productos y } \\
\text { mercados }\end{array}$ & 2,23 & 1,88 & 2,10 & 0,000 & 0,000 & 3,01 & 2,99 & 3,27 & 0,000 & 0,000 & 0,039 & 0,000 \\
\hline Rentabilidad & 4,35 & 4,19 & 4,50 & 0,000 & 0,000 & 4,83 & 4,67 & 4,99 & 0,000 & 0,000 & 0,168 & 0,000 \\
\hline Respuesta de mercado & 4,53 & 4,38 & 4,70 & 0,000 & 0,000 & 4,89 & 4,75 & 5,04 & 0,000 & 0,000 & 0,030 & 0,000 \\
\hline Valor en el mercado & 5,34 & 5,20 & 5,48 & 0,000 & 0,000 & 5,48 & 5,35 & 5,62 & 0,000 & 0,000 & 0,018 & 0,125 \\
\hline Éxito nuevos productos & 4,80 & 4,61 & 4,98 & 0,000 & 0,000 & 5,14 & 4,95 & 5,32 & 0,000 & 0,000 & 0,048 & 0,015 \\
\hline Orientación al mercado & 4,59 & 4,40 & 4,77 & 0,000 & 0,000 & 5,29 & 5,12 & 5,46 & 0,000 & 0,000 & 0,001 & 0,000 \\
\hline Orientación emprendedora & 3,44 & 3,25 & 3,63 & 0,002 & 0,000 & 4,07 & 3,89 & 4,25 & 0,000 & 0,001 & 0,001 & 0,000 \\
\hline Colaboración del canal (IR) & 3,35 & 3,16 & 3,51 & 0,000 & 0,000 & 3,79 & 3,57 & 4,00 & 0,091 & 0,000 & 0,610 & 0,003 \\
\hline Colaboración de asesoría (IR) & 2,36 & 2,21 & 2,52 & 0,000 & 0,000 & 2,49 & 2,30 & 2,68 & 0,000 & 0,002 & 0,929 & 0,118 \\
\hline Colaboración del canal (II) & 3,87 & 3,71 & 4,04 & 0,001 & 0,002 & 4,23 & 4,03 & 4,43 & 0,004 & 0,002 & 0,986 & 0,006 \\
\hline $\begin{array}{l}\text { Colaboración de asesoría (II) } \\
(\mathbb{R})=\text { Innovación radical }\end{array}$ & 2,83 & 2,66 & 2,99 & 0,000 & 0,000 & 3,14 & 2,94 & 3,34 & 0,001 & 0,001 & 0,223 & 0,012 \\
\hline
\end{tabular}

$(\mathrm{IR})=$ Innovación radical 


\subsection{Regresiones estadísticas}

Habiendo observado las matrices de correlaciones queda más claro las relaciones que se pretenden contrastar. Para examinar las relaciones observadas de las variables dependientes y las variables independientes, seleccionadas en los modelos teóricos, se estimaron mediante el análisis de regresión múltiple paso a paso (stepwise), para estimar el valor promedio de una variable sobre la base de valores fijos de otras variables, con el objetivo de explicar el problema de la investigación.

\subsubsection{Emprendedorismo y orientación al mercado como precursoras de la innovación: papel del tamaño empresarial (modelo explicativo I)}

\subsubsection{Papel de la cultura organizativa en la innovación}

La Tabla 36a y la Tabla 36b desglosan las regresiones de las cuatro variables dependientes de innovación incremental y radical con la turbulencia del entorno y la intensidad competitiva, como variables de control, y las orientaciones al mercado y emprendedoras, como variables independientes. Se regresan cuatro modelos distintos. En el primer modelo M1 solo se testaron la constante más las variables de control en conjunto: turbulencia del entorno e intensidad competitiva. El segundo modelo M2 contempla la relación básica entre las innovaciones (incrementales y radicales) con la orientación al mercado y en el siguiente modelo M3, se agrega la orientación emprendedora. El último modelo M4 ejecuta la regresión con todas las variables en conjunto.

La observación del modelo M1 de la Tabla 36a para las distintas medidas de innovación incremental permite esclarecer la P12: ¿actúa el dinamismo del entorno como condicionante en la innovación empresarial? De los coeficientes se aprecia una alta relación entre la innovación incremental y las variables de control utilizadas. La turbulencia del entorno actúa como determinante de los cuatro tipos de acciones innovadoras $(p<0,01)$. En todos los casos, la relación es positiva y significativa, no obstante, la intensidad competitiva determina solo las acciones de innovación que tienen que ver con la organización $(p<0,01)$ y 
el marketing $(\mathrm{p}<0,05)$. De esta manera se soporta la hipótesis $\mathrm{H} 12 \mathrm{a}$ para la turbulencia del entorno y se acepta parcialmente la hipótesis H12c para la intensidad competitiva.

Por otro lado, en el modelo M1 de la Tabla 36b, correspondiente a las medidas de innovación radical, se observa que la variable de control turbulencia del entorno sigue el mismo efecto positivo para las tres medidas de innovación radical $(\mathrm{p}<0,01)$, y la intensidad competitiva solamente es negativamente significativa para las actividades de $\mathrm{I}+\mathrm{D}(\mathrm{p}<0,05)$. De esta manera se soporta la hipótesis H12b para la turbulencia del entorno y se acepta parcialmente la hipótesis H12d para la intensidad competitiva.

Los datos de los modelos M2 de las Tabla 36a y Tabla 36b, sirven para esclarecer las cuestiones P1: ¿actúa la orientación al mercado como condicionante en la innovación empresarial? Se observa que el efecto de la orientación al mercado en los cuatro tipos de acciones progresivas y las tres radicales son todos positivos y significativos a $p<0,01$. Por tanto, se percibe que los indicadores de la orientación al mercado retienen una proporción significativa de la varianza explicada de todos los perfiles de las acciones innovadoras. La orientación al mercado refleja indicadores más dominantes para las innovaciones de organización y marketing y desarrollo de nuevos productos. Estos resultados soportan las hipótesis H1a para la innovación incremental y H1b para la innovación radical.

Asimismo, el modelo M3 de las Tabla 36a y Tabla 36b da pie a la siguiente cuestión P2: ¿actúa la orientación emprendedora como condicionante en la innovación empresarial? Los coeficientes de la regresión son evidentes, por cuanto todos los resultados son positivos y significativos $(\mathrm{p}<0,01)$ para la innovación incremental y radical. Aunque se distinguen mayores indicadores para las innovaciones de producto, procesos y desarrollo de nuevos productos. Con estos resultados se soporta en su totalidad las hipótesis H2a para la innovación incremental y H2b para la innovación radical.

Los modelos M2 y M3 retienen alrededor de un tercio de la varianza $\left(\mathrm{R}^{2}\right)$ en casi todas las regresiones. No obstante, la relación encontrada podría ser ficticia y venir explicada por alguna de las variables de control propuestas. Por ello se realizó el modelo M4 para advertir todas las variables en su conjunto. En ambos casos, la relación de la innovación incremental y radical con la cultura organizativa sigue siendo positiva y con un $\mathrm{R}^{2}$ creciente 
en la mayoría, aunque si se debe acotar que la significatividad de la orientación emprendedora disminuye de $\mathrm{p}<0,01$ a $\mathrm{p}<0,05$ para las innovaciones de organización y marketing cuando la variable de control intensidad competitiva se mantiene significativa en la estimación. Otro apunte importante es que en el modelo M4 de la innovación radical para la medida de patentes, la orientación al mercado no es significativa, al parecer la orientación emprendedora es la que ejercita todo el peso de la relación para incentivar las patentes cuando las variables de control entran en la acción de la función.

En general los dos predictores son estadísticamente significativos para explicar las variables criterio, o sea, que el análisis de regresión propuesto se considera suficiente para identificar no sólo relaciones estadísticamente significativas sino también relaciones que tiene relevancia práctica. Por lo anterior, se acepta las hipótesis H1 relacionada a la orientación al mercado, y la hipótesis H2, relacionada a la orientación emprendedora.

\subsubsection{Papel del tamaño: relación cultura organizativa e innovación}

La Tabla 37, muestra las estimaciones de la relación del tamaño con las distintas variables de innovación incremental y radical, sin intervenir ninguna variable de control. Se puede apreciar las relaciones positivas y significativas con todos los tipos de innovación $(\mathrm{p}<0,01)$. Cabe destacar, la altísima estimación regresada para las variables de innovación en producto y procesos, dentro de la innovación incremental; y actividades I+D y desarrollo de nuevos productos y mercados, dentro del bloque de la innovación radical.

Seguidamente, la Tabla 38 está dividida en tres partes manteniéndose las variables de control del "entorno dinámico". En la primera parte de la tabla se extraen los resultados de la regresión tamaño y acciones de innovación incremental; en la segunda parte de la tabla se observan las estimaciones del tamaño con las variables dependientes de la innovación radical. Con estas primeras regresiones se intenta dar respuesta a la cuestión P3: ¿actúa el tamaño de la empresa como condicionante en la innovación?

La tercera parte de la tabla, muestra la regresión de la relación entre la variable independiente tamaño de la empresa con las variables dependientes (orientación al mercado y 
orientación emprendedora), para dar respuesta a la cuestión P4: ¿actúa el tamaño de la empresa como condicionante de la cultura organizativa?

Respecto a la P3, se puede decir que la relación del tamaño con todas las acciones de innovación incremental y radical son al $\mathrm{p}<0,01$, excepto para las acciones de innovación en marketing donde el coeficiente no es tan significativo. La relación es positiva y significativa para todos los tipos de innovación y, están controladas, mayoritariamente, por la turbulencia del entorno. Solamente la relación entre el tamaño y la innovación de organización ( $p<0,01$ y $\mathrm{p}<0,05)$ y el tamaño y las actividades $\mathrm{I}+\mathrm{D}(\mathrm{p}<0,01$ y $\mathrm{p}<0,10)$, están controladas por ambos factores del entorno dinámico. Estos resultados soportan parcialmente la hipótesis H3a porque no existe una relación entre tamaño e innovación de marketing, y acepta en su totalidad la H3b para la innovación radical.

Al parecer si existe un efecto positivo entre el tamaño y la innovación de marketing (Tabla 37) pero cuando las variables del dinamismo del entorno entran en la regresión (Tabla 38), la variable tamaño deja de serlo, esto se debe a que el dinamismo del entorno actúa como una variable confusa o controladora de la relación.

Por otro lado, para dilucidar la cuestión P4, es necesario observar la tercera parte de la Tabla 38. Los resultados indican que sí existe una relación positiva entre el tamaño y la orientación al mercado con un coeficiente significativo a $\mathrm{p}<0,01$, de la misma manera, se comprueba que también existe una relación positiva y significativa del tamaño con la orientación emprendedora, estas relaciones están controladas por la turbulencia del entorno $(\mathrm{p}<0,01)$. Esclarecidas estas cuestiones se concluye que las hipótesis H4a para la orientación al mercado y H4b para la orientación emprendedora, son soportadas en su totalidad.

La Tabla 39a-b y la Tabla 39c presentan los resultados de la regresión de las variables dependientes (innovación incremental y radical) y de las variables independientes (orientación al mercado, orientación emprendedora), con sus respectivas interacciones y controladas por el entorno dinámico. Estas tablas están formadas por seis modelos distintos. En los modelos M1 al M3 tratan de resolver la cuestión ¿actúa el tamaño empresarial como causa de la relación entre la cultura organizativa y la innovación empresarial?, ¿persiste la relación aún considerándose el efecto del tamaño? En M1 y M2 las orientaciones entran cada 
una por separado, mientras que en M3 las orientaciones entran en conjunto en la regresión. Los modelos M4 al M6 intentan explicar P5: ¿actúa el tamaño como moderadora de la relación entre la cultura organizativa y la innovación? En los modelos M4 y M5 las orientaciones entran por separado, y en M6 entran todas las variables independientes a la vez.

Ahora bien, la evidencia de los resultados significativos de las dos relaciones anteriores tanto del tamaño con la innovación (H3) como del tamaño con la cultura organizativa (H4), permiten la explicación de la cuestión P5.

En la Tabla 39a se observan algunos cambios en la relación entre la cultura organizativa y la innovación de organización. En primer lugar, la relación entre la orientación al mercado y la innovación organizacional se mantiene en M1 pero el tamaño no es significativo. Respecto a la orientación emprendedora, la relación con la acción innovadora también se mantiene $(\mathrm{p}<0,01)$ pero en este caso, la variable tamaño sí es positiva y significativa $(\mathrm{p}<0,05)$ y, los efectos controladores del entorno se conservan (M2). En cambio, cuando entran las dos orientaciones a la vez el tamaño vuelve a ser no significativo (M3).

En la Tabla 39a, también se observa que los resultados de la relación entre la cultura organizativa y la innovación de marketing se mantiene $(\mathrm{p}<0,01)$ a pesar de introducirse la variable tamaño de la empresa, la cual no es significativa, por lo tanto, en este caso, el tamaño no es causa de la relación. También se mantienen los mismos coeficientes de las variables de control.

En la Tabla 39b, la relación entre la cultura organizativa y la innovación de producto (M1 y M2), la relación sigue siendo significativa $(\mathrm{p}<0,01)$ y la variable tamaño también es significativa $(\mathrm{p}<0,05$ y $\mathrm{p}<0,10)$ para ambas orientaciones pero cuando los dos constructos entran juntos con el tamaño (M3), está última deja de ser significativa.

De la misma manera, en la Tabla 39b, la relación entre la cultura organizativa y la innovación de procesos sigue siendo positiva y significativa $(\mathrm{p}<0,01)$ y también el tamaño lo es para los tres modelos $(\mathrm{p}<0,05)(\mathrm{M} 1, \mathrm{M} 2$ y M3), solo que el entorno dinámico deja de controlar la relación cuando las dos orientaciones entran en conjunto en la regresión (M3). 
Concerniente a la innovación radical en la Tabla 39c se puede observar que la relación entre la cultura organizativa (M1 y M2) y las tres medidas radicales se mantiene aún cuando se incorpora la variable tamaño. Solo hay que atender que, en el caso de patentes la variable tamaño pierde su significatividad, no obstante, en las otras dos medidas, la significatividad se mantiene muy elevada. Por lo tanto, el tamaño no es la causa de la relación, en la medida en que la relación entre la cultura organizativa y la innovación incremental y radical se mantiene aún cuando el tamaño se agrega a la regresión.

Continuando con los modelos M4, M5 y M6 de la Tabla 39a-b, que tratan de explicar la cuestión P5, específicamente para la innovación incremental. Por un lado, se observan efectos de interacción solamente para la relación entre la orientación emprendedora y las acciones innovadoras en organización $((\mathrm{p}<0,05)$ y marketing $(\mathrm{p}<0,01)$ el resto de los coeficientes no son significativos. Por otro lado, en el modelo M5, el efecto moderador positivo con la innovación de organización se pierde al introducir las dos orientaciones a la vez, en cambio, se mantiene el efecto positivo para la innovación de marketing $(p<0,01)$. Proporcionados los resultados anteriores, se puede decir que se rechaza la hipótesis H5a para la orientación al mercado y se soporta parcialmente la hipótesis H5c para la orientación emprendedora, ya que solo se presentan efectos moderadores para dos de los cuatro tipos de innovación incremental y sólo con la variable independiente de la orientación emprendedora.

Por último, los resultados de los modelos M4, M5 y M6 de la Tabla 39c, coherente a la innovación radical, dilucidan que la variable tamaño actúa también como moderadora de la relación entre la cultura organizativa y la innovación radical. Se hallan moderadores positivos y significativos solamente en dos de las variables. Existe un efecto moderador de la orientación al mercado en las variables patentes $(p<0,01)$ y actividades $I+D(p<0,01)$. En el caso del efecto moderador de la orientación emprendedora se inclina solo para la variable actividades $\mathrm{I}+\mathrm{D}(\mathrm{p}<0,01)$. Sin embargo, en el modelo M5, donde todas las variables entran a la vez, se pierde la significatividad del efecto para la variable patente, pero el efecto en las actividades $\mathrm{I}+\mathrm{D}$ se mantiene solo para la interacción con la orientación al mercado $(\mathrm{p}<0,01)$. Por lo tanto, también se acepta parcialmente la hipótesis H5b para la orientación al mercado y H5d para la orientación emprendedora relativa la innovación radical. 
Tabla 36a

\section{Regresiones: la innovación incremental en relación con la cultura organizativa y el dinamismo del entorno}

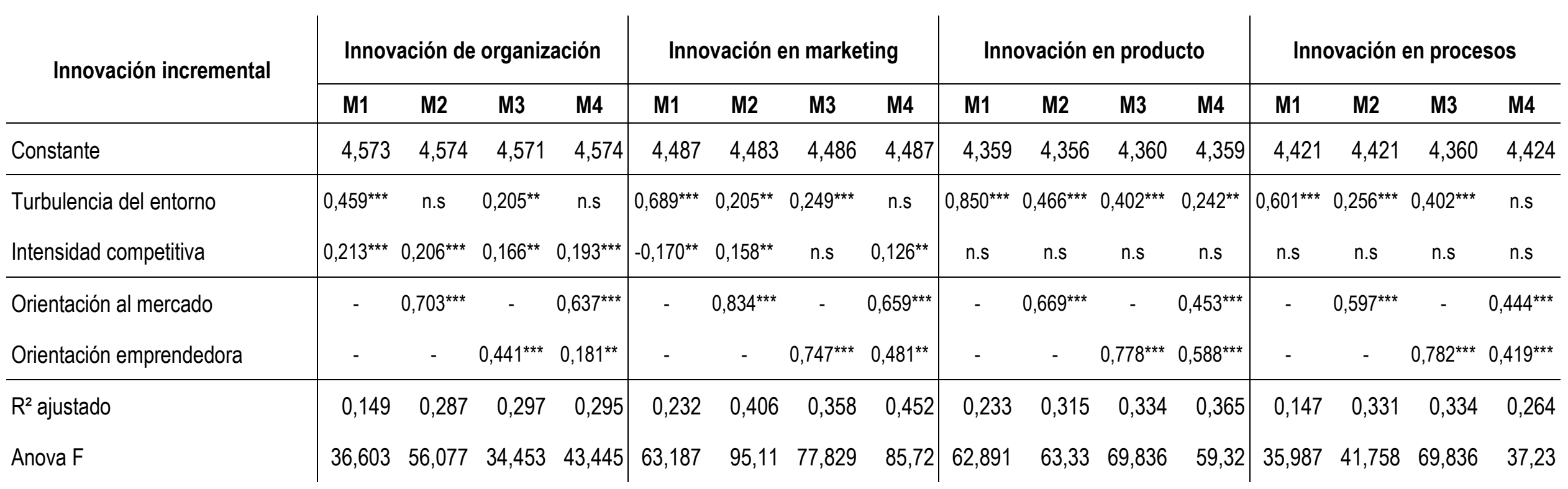

Todos los ANOVA F son $p<0,001$, Todas las constantes son $p<0,001$

${ }^{*} p<0,10 /{ }^{* *} p<0,05 /{ }^{* * *} p<0,01 /$ n.s $=$ no significativo $/$ - = no entra en la regresión 
Tabla 36b

Regresiones: la innovación radical en relación con la cultura organizativa y el dinamismo del entorno

\begin{tabular}{|c|c|c|c|c|c|c|c|c|c|c|c|c|}
\hline \multirow{2}{*}{ Innovación radical } & \multicolumn{4}{|c|}{ Patentes registradas } & \multicolumn{4}{|c|}{ Actividades I+D } & \multicolumn{4}{|c|}{$\begin{array}{l}\text { Desesarrollo de nuevos productos } \\
\text { y mercados }\end{array}$} \\
\hline & M1 & M2 & M3 & M4 & M1 & M2 & M3 & M4 & M1 & M2 & M3 & M4 \\
\hline Constante & 3,133 & 3,663 & 3,162 & 3,163 & 3,386 & 3,383 & 3,386 & 3,386 & 3,319 & 3,316 & 3,360 & 3,319 \\
\hline Turbulencia del entorno & $0,466^{\star * *}$ & $0,295^{\star * *}$ & n.s & n.s & $0,813^{\star \star \star}$ & $0,532^{* *}$ & $0,434^{* * *}$ & $0,332^{\star \star \star}$ & $0,770^{\star \star \star}$ & $0,393^{\star \star *}$ & n.s & n.s \\
\hline Intensidad competitiva & n.s & n.s & n.s & n.s & $-0,174^{\star *}$ & $-0,177^{\star *}$ & $-0,212^{* *}$ & $-0,206^{\star *}$ & n.s & n.s & n.s & n.s \\
\hline Orientación al mercado & - & $0,254^{* \star *}$ & - & n.s & - & $0,435^{\star \star *}$ & - & $0,307^{* \star *}$ & - & $0,570^{* \star *}$ & - & $0,370^{* * *}$ \\
\hline Orientación emprendedora & - & - & $0,418^{\star * *}$ & $0,403^{\star \star \star}$ & - & - & $0,560^{* * *}$ & $0,480^{\star \star \star}$ & - & - & $0,720^{\star \star *}$ & $0,617^{* * *}$ \\
\hline $\mathrm{R}^{2}$ ajustado & 0,193 & 0,219 & 0,290 & 0,291 & 0,329 & 0,387 & 0,423 & 0,437 & 0,337 & 0,433 & 0,493 & 0,513 \\
\hline Anova $\mathrm{F}$ & 26,003 & 26,100 & 31,983 & 33,444 & 33,703 & 41,181 & 47,244 & 55,792 & 62,891 & 63,33 & 69,836 & 59,32 \\
\hline
\end{tabular}

Todos los ANOVA F son $p<0,001$, Todas las constantes son $p<0,001$

${ }^{*} \mathrm{p}<0,10 /{ }^{* *} p<0,05 /{ }^{* * *} \mathrm{p}<0,01 / \mathrm{n} . \mathrm{s}=$ no significativo $/$ - = no entra en la regresión 
Tabla 37

Regresiones: la innovación incremental y radical en relación con el tamaño de la empresa

\begin{tabular}{|c|c|c|c|c|c|c|c|}
\hline Variables & $\begin{array}{l}\text { Innovación de } \\
\text { organización }\end{array}$ & $\begin{array}{l}\text { Innovación de } \\
\text { marketing }\end{array}$ & $\begin{array}{l}\text { Innovación de } \\
\text { producto }\end{array}$ & $\begin{array}{c}\text { Innovación de } \\
\text { procesos }\end{array}$ & $\begin{array}{l}\text { Patentes } \\
\text { registradas }\end{array}$ & Actividades I+D & $\begin{array}{l}\text { Des. nuevos } \\
\text { productos y } \\
\text { mercados }\end{array}$ \\
\hline Constante & 4,329 & 4,242 & 4,012 & 4,102 & 2,628 & 1,881 & 3,722 \\
\hline Tamaño & $0,672^{* * *}$ & $0,583^{* * *}$ & $0,891^{* * *}$ & $0,820^{* * *}$ & $0,387^{* * *}$ & $1,864^{* * *}$ & $1,026^{* * *}$ \\
\hline Anova $\mathrm{F}$ & 20,875 & 29,650 & 28,919 & 30,913 & 18,440 & 126,915 & 41,391 \\
\hline
\end{tabular}

Todos los ANOVA F son $p<0,001$, Todas las constantes son $p<0,001$

${ }^{*} p<0,10 /{ }^{* *} p<0,05 /{ }^{* * *} p<0,01 /$ n.s $=$ no significativo 
Tabla 38

Regresiones: la innovación (incremental y radical) y la cultura organizativa en relación con el dinamismo del entorno y el tamaño de la empresa

\begin{tabular}{|c|c|c|c|c|c|c|c|c|c|}
\hline \multirow{2}{*}{ Variables } & \multicolumn{4}{|c|}{ Innovación incremental } & \multicolumn{3}{|c|}{ Innovación radical } & \multicolumn{2}{|c|}{ Cultura organizativa } \\
\hline & $\begin{array}{l}\text { Innovación de } \\
\text { organización }\end{array}$ & $\begin{array}{l}\text { Innovación } \\
\text { de marketing }\end{array}$ & $\begin{array}{l}\text { Innovación } \\
\text { de producto }\end{array}$ & $\begin{array}{l}\text { Innovación } \\
\text { de procesos }\end{array}$ & $\begin{array}{l}\text { Patentes } \\
\text { registradas }\end{array}$ & $\begin{array}{l}\text { Actividade } \\
\text { s I+D }\end{array}$ & $\begin{array}{l}\text { Des. nuevos } \\
\text { productos y } \\
\text { mercados }\end{array}$ & $\begin{array}{l}\text { Orientación } \\
\text { al mercado }\end{array}$ & $\begin{array}{l}\text { Orientación } \\
\text { emprendedora }\end{array}$ \\
\hline Constante & 4,421 & 4,388 & 4,156 & 4,216 & $3,863^{* *}$ & 3,850 & 3,555 & $-0,140$ & $-0,107$ \\
\hline Turbulencia del entorno & $0,426^{\star \star \star}$ & $0,678^{\star \star \star}$ & $0,806^{\star \star \star}$ & $0,537^{\star \star *}$ & $0,401^{\star \star \star}$ & $0,670^{\star \star \star}$ & $0,702^{\star \star \star}$ & $0,549^{* \star *}$ & $0,575^{\star \star \star}$ \\
\hline Intensidad competitiva & $0,191^{* *}$ & $0,153^{*}$ & n.s & n.s & n.s & $-0,161^{*}$ & n.s & n.s & n.s \\
\hline Tamaño & $0,363^{* * *}$ & n.s & $0,460^{* * *}$ & $0,509^{* * *}$ & $0,360^{* \star *}$ & n.s & $0,892^{* \star *}$ & $0,324^{* * *}$ & $0,225^{\star \star *}$ \\
\hline $\mathrm{R}^{2}$ ajustado & 0,152 & 0,237 & 0,242 & 0,156 & 0,208 & 1,691 & 0,392 & 0,365 & 0,404 \\
\hline
\end{tabular}

Todos los ANOVA F son $p<0,001$, Todas las constantes son $p<0,001$

${ }^{*} \mathrm{p}<0,10 /^{* *} \mathrm{p}<0,05 /{ }^{* \star *} \mathrm{p}<0,01 / \mathrm{n} . \mathrm{s}=$ no significativo 
Tabla 39a

Regresiones: efecto moderador del tamaño en la relación entre la cultura organizativa y la innovación incremental

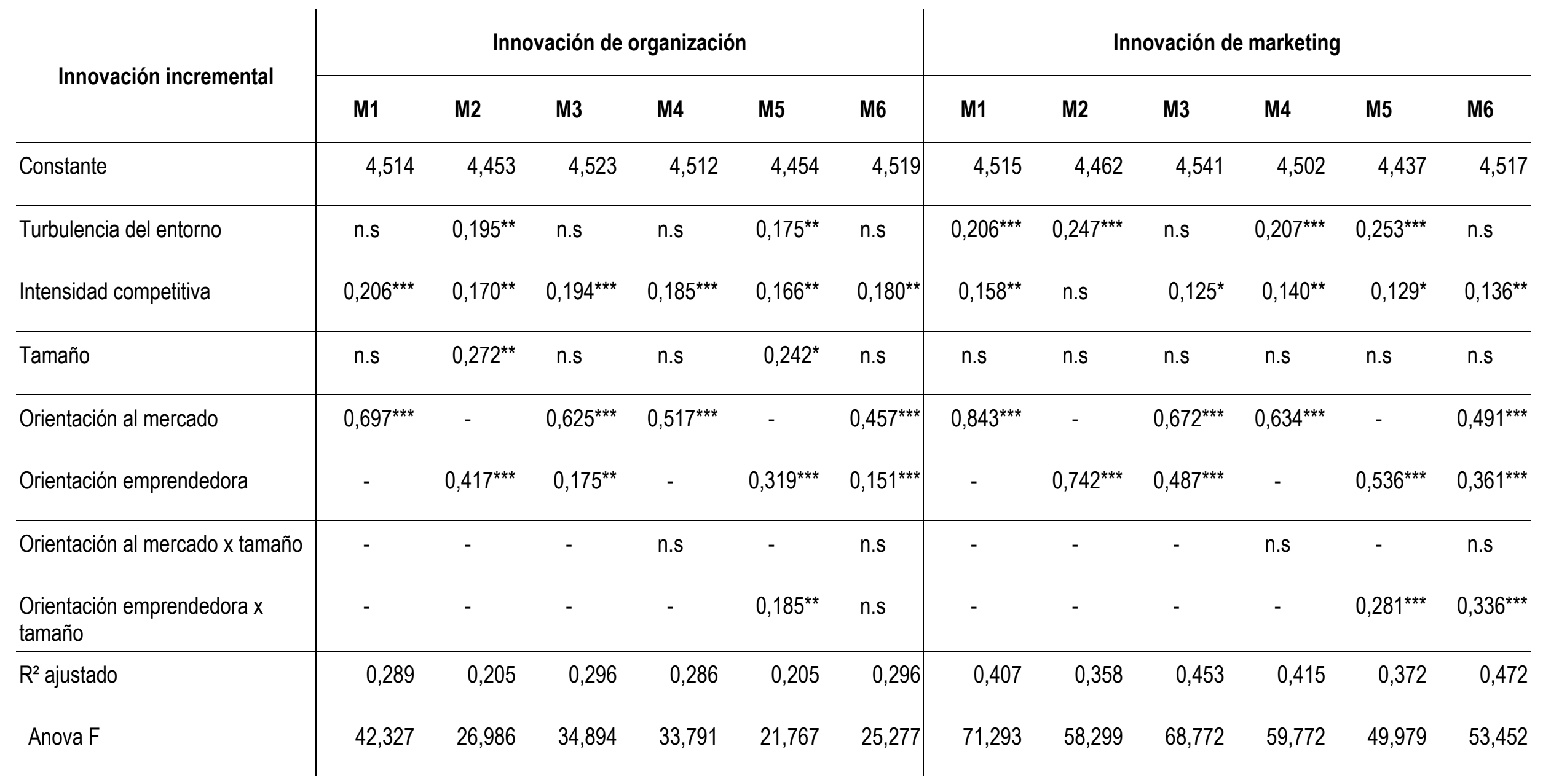


Tabla 39b

Regresiones: efecto moderador del tamaño en la relación entre la cultura organizativa y la innovación incremental

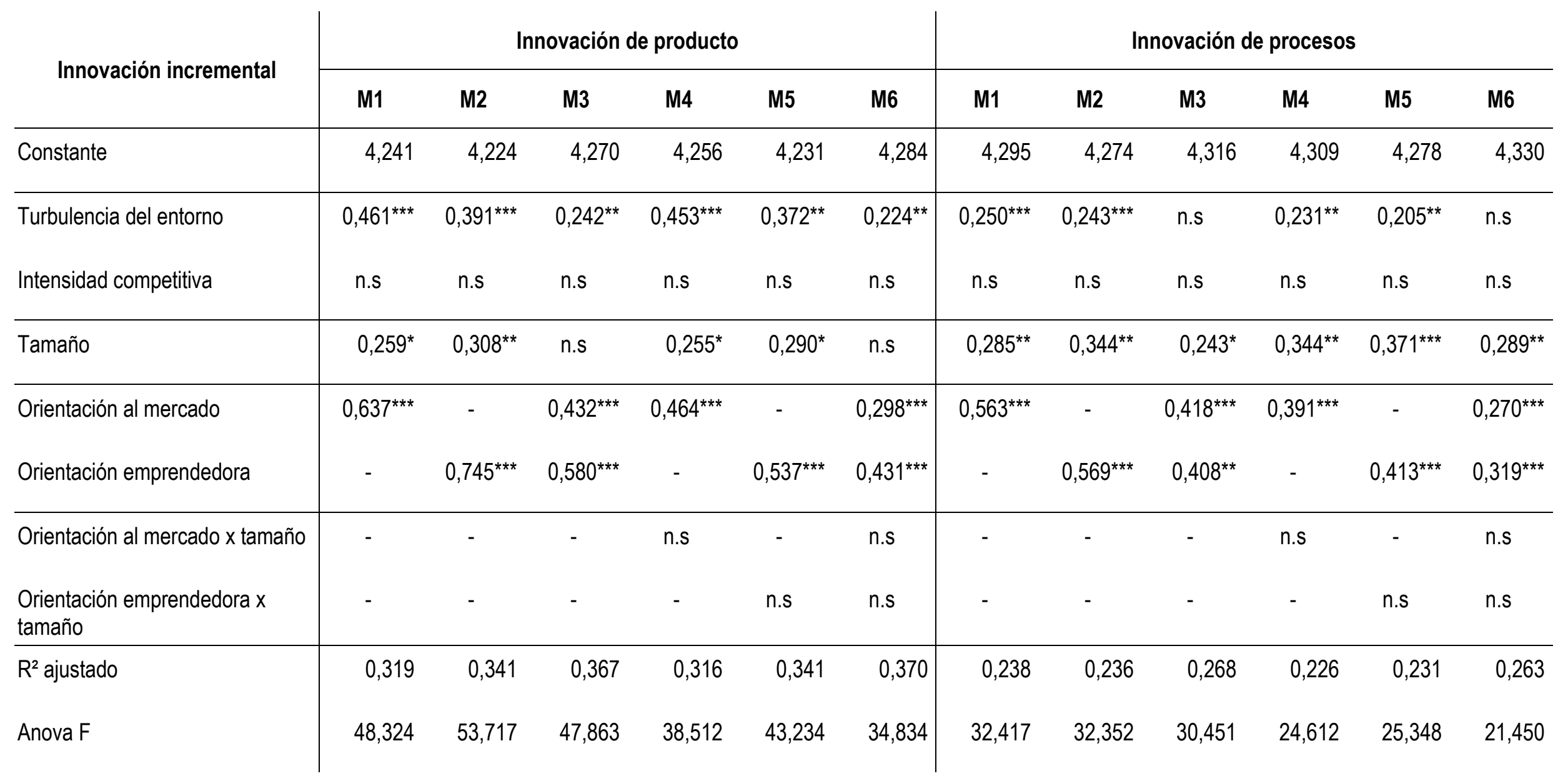

Todos los ANOVA F son $p<0,001$, Todas las constantes son $p<0,001$

${ }^{*} p<0,10 /{ }^{* *} p<0,05 /{ }^{* * \star} p<0,01 /$ n.s = no significativo / - = no entra en la regresión 
Tabla 39c

Regresiones: efecto moderador del tamaño en la relación entre la cultura organizativa y la innovación radical

\begin{tabular}{|c|c|c|c|c|c|c|c|c|c|c|c|c|c|c|c|c|c|c|}
\hline \multirow{2}{*}{$\begin{array}{c}\text { Innovación } \\
\text { radical }\end{array}$} & \multicolumn{6}{|c|}{ Patentes registradas } & \multicolumn{6}{|c|}{ Actividades I+D } & \multicolumn{6}{|c|}{ Desarrollo de nuevos productos y mercados } \\
\hline & M1 & M2 & M3 & M4 & M5 & M6 & M1 & M2 & M3 & M4 & M5 & M6 & M1 & M2 & M3 & M4 & M5 & M6 \\
\hline Constante & 4,834 & 4,703 & 4,883 & 4,772 & 4,498 & 4,628 & 4,229 & 4,361 & 4,439 & 4,533 & 4,677 & 4,520 & 4,554 & 4,623 & 4,734 & 4,622 & 4,834 & 4,643 \\
\hline $\begin{array}{l}\text { Turbulencia del } \\
\text { entorno }\end{array}$ & $0,298^{* * *}$ & n.s & n.s & $0,299^{* * *}$ & n.s & n.s & $0,409^{\star * *}$ & $0,370^{\star * *}$ & $0,325^{\star \star *}$ & $0,505^{\star * *}$ & $0,365^{\star * *}$ & $0,333^{* * *}$ & $0,287^{\star * *}$ & $0,252^{* * *}$ & n.s & $0,283^{* * *}$ & n.s & n.s \\
\hline $\begin{array}{l}\text { Intensidad } \\
\text { competitiva }\end{array}$ & n.s & n.s & n.s & n.s & n.s & n.s & $-0,179^{* *}$ & $-0,189^{* *}$ & $-0,187^{* *}$ & $-0,181^{* *}$ & $-0,178^{* *}$ & $-0,209^{* *}$ & n.s & n.s & n.s & n.s & n.s & n.s \\
\hline Tamaño & n.s & n.s & n.s & n.s & n.s & n.s & $1,578^{* * *}$ & $1,597^{\star * *}$ & $1,565^{\star * *}$ & $1,530 * * *$ & $1,531^{* * *}$ & $1,148^{* * *}$ & $0,604^{* * *}$ & $0,570^{* * *}$ & $0,590^{* * *}$ & $0,692^{* * *}$ & $0,585^{\star * *}$ & $0,607^{* * *}$ \\
\hline $\begin{array}{l}\text { Orientación al } \\
\text { mercado }\end{array}$ & $0,294^{* * *}$ & - & n.s & $0,271^{* * *}$ & - & $0,331^{* * *}$ & $0,315^{\star * *}$ & - & $0,467^{* * *}$ & $0,268^{* *}$ & - & $0,243^{\star *}$ & 586 & - & $0,344^{* * *}$ & $0,530^{\star * *}$ & - & $0,339^{* * *}$ \\
\hline $\begin{array}{l}\text { Orientación } \\
\text { emprendedora }\end{array}$ & - & $0,455^{\star \star *}$ & $0,540^{* *}$ & - & $0,422^{* * *}$ & $0,330^{\star * *}$ & - & $0,518^{* * *}$ & n.s & - & $0,487^{* * *}$ & $0,426^{* * *}$ & - & $0,823^{* * *}$ & $0,696^{* * *}$ & - & $0,542^{* * *}$ & $0,606^{* * *}$ \\
\hline $\begin{array}{l}\text { Orientación al } \\
\text { mercado x } \\
\text { tamaño }\end{array}$ & - & - & - & $0,372^{\star * *}$ & - & n.s & - & - & - & $0,465^{* * *}$ & - & $0,496^{\star * *}$ & - & - & - & n.s & - & n.s \\
\hline $\begin{array}{l}\text { Orientación } \\
\text { emprendedora } \\
\text { x tamaño }\end{array}$ & - & - & - & - & n.s & n.s & - & - & - & - & $0,308^{* * *}$ & n.s & - & - & - & - & n.s & n.s \\
\hline $\mathrm{R}^{2}$ ajustado & 0,231 & 0,296 & 0,397 & 0,230 & 0,297 & 0,315 & 0,553 & 0,578 & 0,560 & 0,571 & 0,585 & 0,546 & 0,460 & 0,513 & 0,529 & 0,459 & 0,516 & 0,531 \\
\hline Anova F & 41,657 & 26,299 & 38,337 & 32,634 & 27,002 & 29,270 & 61,253 & 67,555 & 61,869 & 52,023 & 53,900 & 59,752 & 41,463 & 57,698 & 65,519 & 42,034 & 53,962 & 54,644 \\
\hline
\end{tabular}

Todos los ANOVA F son $p<0,001$, Todas las constantes son $p<0,001$

${ }^{*} p<0,10 /{ }^{* *} p<0,05 /{ }^{* * *} p<0,01 /$ n.s = no significativo / - = no entra en la regresión 


\subsubsection{Factores organizacionales y del entorno como moderadores de la relación entre innovación multidimensional y desempeño empresarial (modelo explicativo II)}

\subsubsection{Innovación: aportación al desempeño empresarial}

Primeramente, se atenderá a la exploración de la relación entre la innovación (incremental y radical) y el desempeño empresarial, el análisis se basó en la regresión múltiple. El bloque de Tablas 40 (a, b, c, d) para la innovación incremental y el bloque de Tablas 41 (a, b, c, d) para la innovación radical, presentan los resultados estimados de la función. Para cada una de las cuatro dimensiones de desempeño empresarial se estimó una secuencia de diez modelos. Se aclara que los modelos M2, M4 y M6, se repiten en ambas tablas con el fin de facilitar al lector la comparación de los resultados entre los modelos de cada tipo de innovación: incremental y radical.

El modelo M1 examina la relación básica entre las medidas de innovación (incremental y radical) y el desempeño empresarial, dando respuesta a la P6 y P7. El modelo M2 contempla exclusivamente el papel de la variable de control, tamaño de la empresa. El modelo M3 valora el conjunto de las variables de innovación (incremental y radical) y el tamaño. El modelo M4 analiza solamente el papel de la orientación al mercado, y en el modelo M5, se agregan las medidas de innovación (incremental y radical). Los modelos M6 y M8 prueban la relación de los factores del entorno, turbulencia del entorno e intensidad competitiva, con el desempeño y, seguidamente, los modelos M7 y M9 incorporan los todos tipos de innovación. Finalmente, el modelo M10 ejecuta la regresión de todas las variables a la vez.

Las estimaciones del modelo M1 de la Tabla 40 (a, b, c, d) proporcionan respuesta a la cuestión P6: ¿actúa la innovación incremental como condicionante en el desempeño empresarial? Las estimaciones de la regresión permiten observar que la contribución de la innovación incremental es altamente significativa para todas las medidas de desempeño. La rentabilidad y la respuesta del mercado están explicadas de forma positiva y significativa por las acciones de innovación de organización $(\mathrm{p}<0,05)$ y marketing $(\mathrm{p}<0,01)$. La variable de 
desempeño valor en el mercado, está altamente relacionada por tres innovaciones diferentes: innovación de organización $(\mathrm{p}<0,01)$, marketing $(\mathrm{p}<0,01)$ y producto $(\mathrm{p}<0,05)$. La variable éxito de nuevos productos está determinada por las innovaciones en marketing $(\mathrm{p}<0,01)$ y producto $(\mathrm{p}<0,01)$.

Según estos resultados, la variable que mejor explica la relación entre la innovación incremental y el desempeño son las acciones de marketing porque está altamente relacionada con las cuatro medidas del éxito empresarial. Esto puede significar que los cambios implantados en la fuerza de ventas, políticas de comunicación y canales de distribución repercuten positivamente en el aumento de los resultados financieros y operativos de la empresa.

En segundo lugar, la innovación de organización tiene una importante influencia en tres medidas de desempeño. La inversión de recursos para las mejoras en la gestión; por ejemplo, en los diseños de trabajo, en el fortalecimiento de las habilidades, en la administración de sistemas, en los programas de incentivos, en la gerencia de la calidad total y en el just-in-time; logran aumentar la eficacia y la eficiencia de las empresas convirtiéndose en ventajas competitivas. Su baja significatividad $(\mathrm{p}<0,05)$ puede deberse a que algunos cambios organizativos dirigidos a la mejora de las estructuras organizativas, al diseño de reglas y procedimientos, a los sistemas de información y estructuras de comunicación, no estén dirigidas a incentivar la actividad comercial.

Los cambios realizados en los aspectos relacionados al producto, como el embalaje, el volumen y la presentación, inciden en la mejora del desempeño operativo (valor en el mercado y éxito de nuevos productos). Estos resultados parecen indicar que las empresas de la muestra se esfuerzan por adaptar las características de sus productos a las necesidades de sus clientes para responder a las oportunidades del mercado. De esta manera, las empresas ganan fidelidad del consumidor, diferenciación de producto y un posicionamiento ventajoso.

Es interesante que la innovación de procesos no influya en ninguna medida de desempeño empresarial. Ni siquiera cuando se introducen las variables de control. Esto parece indicar que los cambios relacionados en los procesos; por ejemplo, el manejo de la materia prima hasta el producto final, el incremento en la rotación de inventarios o el acortamiento de los tiempos de entrega, etc.; no mejora la posición competitiva de las 
empresas de la muestra. Este resultado podría ser explicado dado que nuestra medida está más ligada al recorte de costes que a generar ingresos. Los resultados soporta parcialmente el bloque de hipótesis H6 (a, b, c; excepto d), por lo tanto, la innovación incremental (en tres de sus medidas) están relacionadas con el desempeño empresarial (en sus cuatro medidas).

Referente al modelo M1 de la Tabla 41 (a, b, c, d), que da respuesta a la pregunta P7: ¿actúa la innovación radical como condicionante en el desempeño empresarial?, apunta los siguientes resultados: la variable que menos explica la relación con los resultados es patentes porque sólo está relacionada con la variable rentabilidad $(\mathrm{p}<0,01)$, es posible que este resultado se debe a que muchas de las innovaciones patentadas no son viables comercialmente y, por lo tanto, no generan beneficios provenientes del mercado.

En segundo lugar la variable actividades de $\mathrm{I}+\mathrm{D}$ es positiva y significativamente relacionada con los resultados financieros $(p<0,01)$ y de adaptabilidad $(p<0,01)$. En tercer lugar, la variable desarrollo de nuevos productos y mercados es la que mejor explica el modelo, para todos los casos a $\mathrm{p}<0,01$. La importancia de las innovaciones radicales (excepto patentes) en la explicación de los resultados, es claro, ya que la investigación y desarrollo está ligada al desarrollo de nuevos productos $\mathrm{y}$, consecuentemente, una vez que entran en el mercado se obtienen los resultados esperados. Las derivaciones estadísticas soportan el bloque de hipótesis de $\mathrm{H} 7$ (a, b, c), por lo tanto la innovación radical (en sus tres medidas) están relacionadas con el desempeño empresarial (en sus cuatro medidas).

La observación del modelo M2 de la Tabla 40, que se basa en la pregunta P10: ¿actúa el tamaño de la empresa como condicionante del desempeño empresarial? permite apreciar una contundente relación entre el tamaño y el desempeño empresarial. El tamaño esta relacionado positivamente con los cuatro indicadores de éxito. La relación más significativa del tamaño se establece con la rentabilidad $(\mathrm{p}<0,01)$, la respuesta de mercado $(\mathrm{p}<0,01)$ y el éxito de nuevos producto $(\mathrm{p}<0,01)$ y menos con el valor en el mercado $(\mathrm{p}<0,05)$. A partir de estos datos, se puede deducir que las empresas de mayor tamaño se caracterizan por ser más eficaces, eficientes y adaptadas a los cambios del entorno. Mientras que las pequeñas empresas encuentran más dificultades en obtener mejores desempeños financieros y operativos en comparación con las grandes empresas. De esta manera, se soporta la H10 para las cuatro medidas de resultados. 
El modelo M3 de la Tabla 40, demuestra si el actúa el tamaño empresarial como causa de la relación entre la innovación incremental y el desempeño empresarial; o sea, si persiste la relación aún considerándose el efecto del tamaño. Cuando se introduce la variable tamaño en la función de la relación entre innovación incremental y rentabilidad, la innovación de producto se torna significativa, en cambio en el valor en el mercado, esta misma innovación pierde la significatividad. En ambos casos la capacidad de explicación del modelo se mantiene muy parecida. Entonces se puede concluir que la variable tamaño actúa como causa de la relación entre la innovación incremental y las variables de desempeño rentabilidad y valor en el mercado. Las otras dos medidas de éxito se mantiene igual, o sea, que el tamaño no es la causa de la relación.

Por parte de la innovación radical, el modelo M3 de la Tabla 41, el tamaño de la empresa ejerce un efecto de causa en las cuatro medidas de desempeño, puesto que la relación de la innovación radical se altera considerablemente al entrar en la regresión el tamaño de la empresa; por ejemplo, la relación de patentes con la rentabilidad deja de ser significativa, también la relación de las actividades de I+D con respuesta de mercado pierde su significatividad, y la relación con patentes y el éxito de nuevos productos gana una significatividad positiva en la regresión; solamente la relación con la variable valor en el mercado la relación persiste, es decir, se mantiene igual para las tres medidas de innovación radical. Por tanto, se puede concluir que el tamaño actúa como causa de la relación para tres medidas de financieras y de adaptabilidad.

El modelo M4 de Tabla 40 analiza el papel de la orientación al mercado junto a las medidas de desempeño, para dar respuesta a la incógnita P8: ¿actúa la orientación al mercado como condicionante en la innovación empresarial? Todos los coeficientes juegan un papel significativo en el modelo $(\mathrm{p}<0,01)$. La relación es más acentuada con las medidas de desempeño operativo (valor en el mercado y éxito de nuevos producto). Se soporta la hipótesis H8, porque la orientación al mercado está relacionada positivamente con el desempeño empresarial.

En el modelo M5 de la Tabla 40, la orientación al mercado afecta directamente la relación entre la innovación incremental y el desempeño. Cuando la variable de la cultura organizativa, orientación al mercado, entra en la función, la relación pierde significatividad, 
sobre todo para las acciones de innovación incremental de marketing; solamente se mantiene la relación con la rentabilidad. Por lo tanto, se concluye (innovación incremental) que la orientación al mercado actúa como causa de la relación entre la innovación y el desempeño empresarial; la relación persiste cuando se incluye la variable orientación al mercado pero solo para la rentabilidad.

Comparativamente, en el M5 de la Tabla 41, la orientación al mercado es la causa de la relación entre la innovación radical y el desempeño empresarial. En su mayoría las estimaciones de las innovaciones dejan de ser significativas a la hora de entrar en juego la orientación al mercado, sobre todo para las actividades de I+D cuando se relacionan con los resultados financieros, y desarrollo de nuevos productos cuando se relaciona con las medidas operativas. Posiblemente este efecto de causa se deba a que las innovaciones radicales que realizan las empresas de la muestra no tengan su fuente en el mercado y en el canal.

El modelo M6 de la regresión en la Tabla 40, aclara la pregunta P13: ¿actúa la turbulencia del entorno como condicionante en el desempeño empresarial? Los coeficientes permiten concluir que este factor del dinamismo del entorno actúa positiva y significativamente $(\mathrm{p}<0,01)$ en todas las medidas de desempeño. Es interesante conocer que las empresas que se encuentran en entornos turbulentos, caracterizados por una mayor incertidumbre y hostilidad, resulten más exitosas. Este éxito puede ser fruto de las diversas oportunidades que se presentan en este tipo de entornos. Se vislumbra que las empresas que se enfrentan a entornos más turbulentos están más capacitadas para adaptarse a los cambios y fortalecer su posicionamiento asegurándose de esta forma su viabilidad en el tiempo. Se soporta la hipótesis H13, donde la turbulencia del entorno está relacionada positivamente con el desempeño empresarial.

En el modelo M7 de la Tabla 40, introduce la cuestión sobre la causa de la turbulencia del entorno en la relación entre la innovación y el desempeño empresarial. Cuando la variable tamaño de la empresa entra en la regresión de la relación se observa que la variable de innovación de marketing baja su explicación en todas las medidas de desempeño; de p $<0,01$ a $\mathrm{p}<0,1$ para las medidas financieras, $\mathrm{y}$ de $\mathrm{p}<0,01$ a $\mathrm{p}<0,05$ para las operativas. Sin embargo, no se podría catalogar enfáticamente que la causa de la relación sea el tamaño, pero para efectos de esta investigación sí se tomará en cuenta como una causa real. 
En el modelo M7 de la Tabla 41 la turbulencia del entorno interviene directamente en la relación entre innovación radical y desempeño. En el caso de la innovación radical, el efecto de la causa del tamaño en la relación es más contundente, puesto que la variable $\mathrm{I}+\mathrm{D}$ deja de ser significativa para todas las medidas de desempeño excepto para valor en el mercado, y la variable patentes deja de ser significativa en la relación con la rentabilidad. Se conclue que en la innovación radical, la turbulencia actúa como causa de la relación entre la innovación radical y el desempeño empresarial.

En el modelo M8 de la Tabla 40 permite explicar la interrogación P15: ¿actúa la intensidad competitiva como condicionante en el desempeño empresarial? La intensidad competitiva es significativa y positiva para el desempeño operativo (valor en el mercado, $\mathrm{p}<0,10$ y éxito de nuevos productos, $\mathrm{p}<0,01)$. Por lo tanto, un ambiente altamente competitivo posibilita la satisfacción/imagen y la adaptación al entorno. Sin embargo no tiene relación alguna para las medidas de desempeño financiero, al parecer una mayor intensidad competitiva no entorpece la atracción de la demanda ni fuerza a las empresas a trabajar con márgenes más ajustados. Se soporta parcialmente la hipótesis H15, donde la intensidad competitiva está relacionada positivamente con el desempeño empresarial.

Los resultados del modelo M9 de la Tabla 40 dilucida la pregunta teórica acerca de la causa de intensidad competitiva en la relación entre la innovación y el desempeño empresarial. En el caso de la innovación incremental, solamente se observa un cambio aparente de significatividad en la variable innovación de producto, la cual deja de ser significativa cuando se relaciona con valor en el mercado, además, en esta misma relación, las innovaciones de marketing pierden significatividad de de $p<0,01$ a $p<0,05$. El resto de las relaciones se mantienen igual porque la intensidad competitiva no es la causa de la relación.

Las estimaciones del modelo M9 de la Tabla 41, dejan entrever que la intensidad competitiva es la causa de la relación entre innovación radical y desempeño empresarial. Respecto a la relación entre innovación radical y rentabilidad, la variable patente deja de ser significativa y el desarrollo de nuevos producto pasa de una significatividad de $\mathrm{p}<0,01$ a $\mathrm{p}<0,05$. En cuanto a la relación con la respuesta de mercado, la variable I+D también pierde significatividad de $\mathrm{p}<0,01$ a $\mathrm{p}<0,05$. Por parte de la relación con el éxito de nuevos productos, la variable patentes que no era significativa se convierte en altamente significativa 
para explicar la relación. Todas las relaciones cambian excepto para la variable valor en el mercado, porque al entrar la variable, la relación se mantiene igual, probablemente, porque que en medio de altas intensidades competitivas no aumenta el éxito de la actividad comercial encaminada a la satisfacción/lealtad e imagen corporativa. Estos resultados permiten concluir que tanto para la innovación incremental como para la innovación radical, la intensidad competitiva actúa como causa de la relación entre la innovación y el desempeño empresarial, excepto para valor en el mercado (innovación radical).

El modelo M10 de la Tabla 40 introduce todas las variables en conjunto. Es importante destacar que el efecto de la orientación al mercado sobre la rentabilidad no es significativo, según González-Benito et al. (2005), porque la orientación al mercado está completamente explicada por su relación con el dinamismo del entorno. Por otra parte, la variable tamaño sigue sin explicar el modelo cuando el efecto se centra en el desempeño operativo. Por último, se destaca que la intensidad competitiva es negativa y significativa en la eficiencia, eficacia y adaptabilidad de la empresa. En este último, aún cuando no lo era en el modelo M9.

En el M10 de la Tabla 41, se puede observar que el desarrollo de nuevos productos, es la variable que mejor explica el desempeño empresarial, seguida por las actividades de $\mathrm{I}+\mathrm{D}$, en algunos casos, la relación es explicada por la intensidad competitiva que lleva a la empresa a ser más agresiva en el mercado para mantener su competitividad investigando y desarrollando nuevos productos y abriéndose a nuevos mercados.

Como resumen, consecuentemente con los resultados se confirman parcialmente las hipótesis para todas las medidas de desempeño; H6: la innovación incremental influye positivamente en el desempeño empresarial, excepto la variable innovación de procesos. Igualmente se soporta parcialmente la hipótesis $\mathrm{H7}$ : la innovación radical influye positivamente en el desempeño empresarial, aunque la variable patente no explica directamente ninguna de las medidas, solamente cuando la causa de su relación está explicada por el tamaño de la empresa. 


\subsubsection{Efectos moderadores de los factores organizacionales y del entorno}

La relación entre la innovación (incremental y radical) - el desempeño empresarial, y los efectos moderadores de los factores organizacionales (tamaño y orientación al mercado) y del entorno (dinamismo del entorno e intensidad competitiva), también, se han probado mediante el análisis de regresión múltiple. La Tabla 42a para la innovación incremental y la Tabla 42b para la innovación radical, muestran, separadamente, el papel de cada factor en la regresión. Para cada medida de desempeño como variable dependiente se han estimado cuatro modelos. Cada modelo captura un efecto moderador distinto incluyendo la interacción con las acciones de innovación.

El modelo M1 responde a la pregunta P11: ¿actúa el tamaño como moderador de la relación entre la innovación y el desempeño empresarial? El modelo M2 mide la moderación de la orientación al mercado, para explicar la cuestión P9: ¿actúa la orientación al mercado como moderadora de la relación entre la innovación y el desempeño empresarial? El modelo M3 dilucida la interrogante P14: ¿actúa la turbulencia del entorno como moderadora de la relación entre la innovación y el desempeño empresarial? Por último, el modelo M4 contrasta el efecto de la intensidad competitiva en la relación explicando P16: ¿actúa la intensidad competitiva como moderadora de la relación entre la innovación y el desempeño empresarial?

El modelo M1 de la Tabla 42a muestra que el tamaño actúa como un moderador de la relación entre innovación y los resultados empresariales tanto para las medidas de desempeño financiero como operativo. La relación entre la innovación y el desempeño es más fuerte para las grandes empresas. El tamaño de la empresa ejerce un efecto moderador en la relación de la innovación respecto al desempeño financiero y operativo. Se entiende, entonces, que las acciones de innovación de organización $(\mathrm{p}<0,1 ; \mathrm{p}<0,5 ; \mathrm{p}<0,1)$, marketing $(\mathrm{p}<0,05 ; \mathrm{p}<0,5$; $\mathrm{p}<0,5 ; \mathrm{p}<0,1)$ y producto $(\mathrm{p}<0,05 ; \mathrm{p}<0,1)$ mejoran considerablemente la viabilidad económica a corto y largo plazo de las grandes empresas. Estos resultados confirman, parcialmente, la H11a: el tamaño modera la relación entre la innovación incremental y el desempeño empresarial, de manera que cuanto más grande es una empresa mayor es la contribución de la innovación en el desempeño empresarial. 
El modelo M1 de la Tabla 42b, el tamaño modera la relación entre patentes y las variables de desempeño financiero $(\mathrm{p}<0,05$ y $\mathrm{p}<0,01)$. También se encuentra un efecto moderador con la variable desarrollo de nuevos productos y lograr el éxito de nuevos productos. Estos resultados confirman, parcialmente, la H11b: el tamaño modera la relación entre la innovación radical y el desempeño empresarial, de manera que cuanto más grande es una empresa mayor es la contribución de la innovación en el desempeño empresarial.

El efecto moderador de la orientación al mercado en la relación arroja contribuciones interesantes en el modelo M2 de la Tabla 42a. El efecto moderador está presente en los cuatro tipos de innovación parra todas las medidas de desempeño empresarial y aportan indicadores positivos y significativos. Además, concurre una interacción positiva y significativa de la orientación al mercado y la innovación de marketing $(\mathrm{p}<0,05)$ en las cuatro medidas de desempeño. Esto puede indicar que la orientación al mercado induce a consecuencias positivas respecto a resultados contables a corto plazo, pero cobran mayor protagonismo en la consolidación de la posición en el mercado y en la capacidad de adaptación a las nuevas tendencias. Posiblemente esto se deba a que la orientación al mercado potencia las habilidades comerciales y capacidades de marketing para percibir y responder rápidamente a las oportunidades de producto-mercado. Dados los resultados anteriores, se acepta la hipótesis H9a: la orientación al mercado modera la relación entre innovación incremental y desempeño de manera que cuanto más orientada al mercado es una empresa mayor es la contribución de la innovación al desempeño empresarial.

El modelo M2 de la Tabla 42b, igual que la moderación anterior, la orientación al mercado modera la innovación radical. Ejerce un efecto moderador en el desarrollo de nuevos productos $(\mathrm{p}<0,05)$, potenciando los resultados financieros, mientras que modera las patentes $(\mathrm{p}<0,05)$ para generar mejores resultados financieros. La orientación al mercado al estar más asociada a la orientación al consumidor puede evaluar sus preferencias cuando estas pueden ser inestables facilitando su seguimiento y el consecuente ajuste de la oferta y esfuerzos comerciales para lograr la satisfacción y obtener mejores beneficios financieros. Sin embargo, la orientación al mercado no parece afectar de forma significativa la I + D igual que los resultados de De Luca et al. (2010). Entonces, la relación entre innovación y desempeño, es más fructífera cuando se incorpora la orientación al mercado dentro de la cultura organizativa de las empresas. La sinergia entre la orientación al mercado y la innovación potencian el éxito 
empresarial comprobándose, parcialmente, la hipótesis H9b: la orientación al mercado modera la relación entre innovación radical y desempeño de manera que cuanto más orientada al mercado es una empresa mayor es la contribución de la innovación al desempeño empresarial.

El modelo M3 de la Tabla 42a permite aceptar un efecto moderador de la turbulencia del entorno en la relación. Se encuentra evidencia a favor de que cuando se innova en entornos turbulentos, el desempeño operativo y financiero es más fructífero. La interacción de la turbulencia del entorno ejerce un aumento de la rentabilidad cuando la empresa innova en marketing $(p<0,01)$ y producto $(p<0,05)$. Sin embargo, impide ese aumento cuando la innovación se enfoca en los procesos, probablemente, se deba a la inestabilidad tecnológica implicada en los procesos de producción. De la misma manera, la hostilidad e incertidumbre del ambiente promueve las innovaciones en marketing para mejorar la eficacia de la actividad comercial - respuesta de mercado $(\mathrm{p}<0,05)$ y valor en el mercado $(\mathrm{p}<0,01)$. También se destaca un efecto moderador positivo y significativo de la turbulencia del entorno en la relación entre innovación de productos $(\mathrm{p}<0,05)$ y procesos $(\mathrm{p}<0,05)$ con el éxito de nuevos productos. Posiblemente, este efecto moderador positivo se deba a que la turbulencia tecnológica demanda un mayor esfuerzo para adaptar la capacidad innovadora a las necesidades del mercado objetivo (Han et al., 1998). Pero no todos los resultados son ideales, puesto que una mayor turbulencia del entorno inhibe las consecuencias positivas de las acciones de innovación de organización sobre la eficacia (respuesta de mercado, $\mathrm{p}<0,01$ y valor en el mercado, $\mathrm{p}<0,01$ ) y la adaptabilidad de la empresa $(\mathrm{p}<0,10)$. Los resultados mostrados soportan parcialmente la hipótesis la H14a: la turbulencia del entorno modera la relación entre la innovación incremental y el desempeño empresarial.

El modelo M3 de la Tabla 42b comprueba que modera la relación entre innovación radical y el desempeño empresarial, específicamente para las variables de desarrollo de nuevos productos y patentes. Por otro lado, el desarrollo de nuevos producto $(\mathrm{p}<0,05)$ en medio de alta turbulencia del entorno hace que aumente el crecimiento de las ventas y la cuota de mercado, por lo tanto, genera mayores ventajas financieras a la empresa. Por otro lado, una alta turbulencia del entorno favorece que las patentes registradas $(\mathrm{p}<0,01$ y $\mathrm{p}<0,05)$ generen resultados operativos oportunos. Los resultados arrogan evidencia que soportan parcialmente la 
hipótesis H14b: la turbulencia del entorno modera la relación entre la innovación radical y el desempeño empresarial.

El modelo M4 de la Tabla 42a, demuestra que la intensidad competitiva desempeña un efecto moderador en la relación entre innovación y desempeño. Cuando la moderación está centrada en la eficacia (respuesta de mercado y valor en el mercado), la intensidad competitiva potencia las acciones de innovación de marketing $(\mathrm{p}<0,05)$ para atraer la demanda, aumentar las ventas y favorecer el posicionamiento en el mercado. Por otro lado, observando las interacciones, cuando la intensidad competitiva ejerce un efecto moderador centrado en la relación entre innovación - rentabilidad y éxito de nuevos productos, las acciones de innovación de producto contribuyen positiva y significativamente $(p<0,05)$. En cambio, los efectos moderadores negativos de la intensidad competitiva, en las innovaciones de organización $(\mathrm{p}<0,05)$ y procesos $(\mathrm{p}<0,01 ; \mathrm{p}<0,05 ; \mathrm{p}<0,05, \mathrm{p}<0,10$ respectivamente $)$ van en detrimento del éxito financiero y operativo. De esta manera, se acepta parcialmente la hipótesis H16a: la intensidad competitiva modera la relación entre la innovación incremental y el desempeño empresarial.

El modelo M4 de la Tabla 42b para la innovación radical, marca tres efectos moderadores. Al parecer, la evidencia indica que las patentes registradas $(\mathrm{p}<0,05$, para todos los casos), en medio de un entorno de intensidad competitiva, potencia los resultados empresariales eficaces y operativos. Las patentes, que no lograban explicar las variables de desempeño financiero y operativo, por medio de la intensidad competitiva logran contribuir al éxito empresarial. Dados los resultados se soporta parcialmente la hipótesis H16b: la intensidad competitiva modera la relación entre la innovación radical y el desempeño empresarial. 
Tabla 40a

Regresiones: la innovación incremental en relación con la rentabilidad

\begin{tabular}{|c|c|c|c|c|c|c|c|c|c|c|}
\hline \multirow{2}{*}{ Innovación incremental } & \multicolumn{10}{|c|}{ Rentabilidad } \\
\hline & M1 & M2 & M3 & M4 & M5 & M6 & M7 & M8 & M9 & M10 \\
\hline Constante & 3,436 & 4,318 & 3,385 & 4,545 & 3,816 & 4,543 & 3,930 & 2,538 & 3,333 & 3,805 \\
\hline Innovación de organización & $0,104^{* *}$ & - & $0,203^{* * *}$ & - & $0,174^{\star \star *}$ & - & $0,176^{* \star *}$ & - & $0,218^{* * *}$ & $0,159^{* * *}$ \\
\hline Innovación de marketing & $0,289^{* * *}$ & - & $0,138^{* \star *}$ & - & $0,098^{* *}$ & - & $0,095^{\star *}$ & - & $0,146^{* \star *}$ & $0,187^{\star \star *}$ \\
\hline Innovación de producto & n.s & - & $0,105^{\star *}$ & - & n.s & - & n.s & - & n.s & n.s \\
\hline Innovación de procesos & n.s & - & n.s & - & n.s & - & n.s & - & n.s & n.s \\
\hline Tamaño & - & $0,505^{\star \star \star}$ & $0,391^{* \star *}$ & - & - & - & - & - & - & $0,322^{\star \star \star}$ \\
\hline Orientación al mercado & - & - & - & $0,321^{* * *}$ & $0,191^{* \star *}$ & - & - & - & - & n.s \\
\hline Turbulencia del entorno & - & - & - & - & - & $0,404^{\star \star \star}$ & $0,328^{\star \star \star}$ & - & - & $0,409^{* * *}$ \\
\hline Intensidad competitiva & - & - & - & - & - & - & - & n.s & n.s & $-0,202^{\star \star *}$ \\
\hline $\mathrm{R}^{2}$ ajustado & 0,112 & 0,148 & 0,128 & 0,176 & 0,119 & 0,120 & 0,159 & 0,044 & 0,105 & 0,448 \\
\hline Anova $F$ & 12,173 & 20,594 & 17,217 & 24,684 & 19,236 & 37,839 & 23,046 & 17,050 & 18,073 & 57,119 \\
\hline
\end{tabular}

Todos los ANOVA F son $p<0,001$, Todas las constantes son $p<0,001$

${ }^{*} p<0,10 /{ }^{* *} p<0,05 /{ }^{* \star *} p<0,01 /$ n.s = no significativo / - = no entra en la regresión 
Tabla 40b

Regresiones: la innovación incremental en relación con la respuesta del mercado

\begin{tabular}{|c|c|c|c|c|c|c|c|c|c|c|}
\hline \multirow{2}{*}{ Innovación incremental } & \multicolumn{10}{|c|}{ Respuesta del mercado } \\
\hline & M1 & M2 & M3 & M4 & M5 & M6 & M7 & M8 & M9 & M10 \\
\hline Constante & 4,066 & 4,145 & 4,085 & 4,010 & 4,507 & 4,007 & 4,760 & 2,132 & 3,183 & 4,496 \\
\hline Innovación de organización & $0,139^{* * *}$ & - & $0,136^{* * *}$ & - & $0,126^{* * *}$ & - & $0,132^{* * *}$ & - & $0,135^{\star * *}$ & $0,107^{* *}$ \\
\hline Innovación de marketing & $0,117^{* * *}$ & - & $0,116^{* \star *}$ & - & $0,064^{*}$ & - & $0,085^{* *}$ & - & $0,128^{* \star *}$ & $0,124^{* * *}$ \\
\hline Innovación de producto & n.s & - & n.s & - & n.s & - & n.s & - & n.s & n.s \\
\hline Innovación de procesos & n.s & - & n.s & - & n.s & - & n.s & - & n.s & n.s \\
\hline Tamaño & - & $0,332^{* * *}$ & $0,217^{* \star \star}$ & - & - & - & - & - & - & $0,140^{* *}$ \\
\hline Orientación al mercado & - & - & - & $0,325^{\star \star *}$ & $0,238^{* * *}$ & - & - & - & - & $0,198^{* * *}$ \\
\hline Turbulencia del entorno & - & - & - & - & - & $0,280^{\star \star *}$ & $0,189^{\star \star *}$ & - & - & $0,227^{\star * \star}$ \\
\hline Intensidad competitiva & - & - & - & - & - & - & - & n.s & $-0,096^{* *}$ & $-0,177^{\star * *}$ \\
\hline $\mathrm{R}^{2}$ ajustado & 0,112 & 0,127 & 0,113 & 0,106 & 0,131 & 0,108 & 0,126 & 0,132 & 0,110 & 0,397 \\
\hline Anova $\mathrm{F}$ & 23,170 & 22,031 & 18,818 & 30,432 & 20,380 & 36,127 & 29,935 & 17,621 & 18,515 & 49,308 \\
\hline
\end{tabular}

Todos los ANOVA F son $p<0,001$, Todas las constantes son $p<0,001$

${ }^{*} p<0,10 /{ }^{* *} p<0,05 /{ }^{* *} p<0,01 /$ n. $s=$ no significativo $/$ - = no entra en la regresión 
Tabla 40c

Regresiones: la innovación incremental en relación con el valor en el mercado

\begin{tabular}{|c|c|c|c|c|c|c|c|c|c|c|}
\hline Innovación incremental & M1 & M2 & M3 & M4 & M5 & M6 & M7 & M8 & M9 & M10 \\
\hline Innovación de organización & $0,215^{\star \star \star}$ & - & $0,158^{* * *}$ & - & $0,143^{\star \star *}$ & - & $0,153^{\star * *}$ & - & $0,217^{\star \star \star}$ & $0,134^{* * *}$ \\
\hline Innovación de marketing & $0,197^{\star \star *}$ & - & $0,088^{* *}$ & - & $0,083^{*}$ & - & $0,092^{* *}$ & - & $0,095^{\star \star *}$ & $0,096^{* \star}$ \\
\hline Innovación de procesos & n.s & - & n.s & - & n.s & - & n.s & - & n.s & n.s \\
\hline Tamaño & - & $0,136^{* *}$ & n.s & - & - & - & - & - & - & n.s \\
\hline Orientación al mercado & - & - & - & $0,410^{* \star *}$ & $0,401^{\star \star *}$ & - & - & - & - & $0,334^{* * \star}$ \\
\hline Turbulencia del entorno & - & - & - & - & - & $0,599^{\star * \star}$ & $0,318^{\star \star \star}$ & - & & $0,194^{\star \star \star}$ \\
\hline Anova F & 25,241 & 17,939 & 18,554 & 15,354 & 16,509 & 21,015 & 18,314 & 15,883 & 18,762 & 22,582 \\
\hline
\end{tabular}

Todos los ANOVA F son $p<0,001$, Todas las constantes son $p<0,001$

${ }^{*} p<0,10 /{ }^{* *} p<0,05 /{ }^{* * *} p<0,01 /$ n.s = no significativo / - = no entra en la regresión 
Tabla 40d

Regresiones: la innovación incremental en relación con el éxito de nuevos productos

\begin{tabular}{|c|c|c|c|c|c|c|c|c|c|c|}
\hline \multirow{2}{*}{ Innovación incremental } & \multicolumn{10}{|c|}{ Éxito de nuevos productos } \\
\hline & M1 & M2 & M3 & M4 & M5 & M6 & M7 & M8 & M9 & M10 \\
\hline Constante & 3,075 & 4,780 & 4,892 & 4,924 & 3,926 & 3,119 & 3,463 & 3,920 & 3,821 & 4,254 \\
\hline Innovación de organización & n.s & - & n.s & - & n.s & - & n.s & - & n.s & n.s \\
\hline Innovación de marketing & $0,185^{\star \star *}$ & - & $0,143^{* * *}$ & - & $0,096^{*}$ & - & $0,108^{* *}$ & - & $0,151^{* * *}$ & $0,087^{* *}$ \\
\hline Innovación de producto & $0,237^{* * *}$ & - & $0,217^{* \star *}$ & - & $0,167^{* \star *}$ & - & $0,168^{* * *}$ & - & $0,224^{* * *}$ & $0,156^{* * *}$ \\
\hline Innovación de procesos & n.s & - & n.s & - & n.s & - & n.s & - & n.s & n.s \\
\hline Tamaño & - & $0,316^{\star \star *}$ & n.s & - & - & - & - & - & - & n.s \\
\hline Orientación al mercado & - & - & - & $0,676^{\star \star \star}$ & $0,441^{* \star *}$ & - & - & - & - & $0,379^{\star * *}$ \\
\hline Turbulencia del entorno & - & - & - & - & - & $0,601^{\star \star *}$ & $0,331^{* \star *}$ & - & - & $0,336^{* \star *}$ \\
\hline Intensidad competitiva & - & - & - & - & - & - & - & $0,193^{* * *}$ & n.s & $-0,192^{* * *}$ \\
\hline$R^{2}$ ajustado & 0,221 & 0,113 & 0,226 & 0,239 & 0,280 & 0,189 & 0,266 & 0,140 & 0,228 & 0,310 \\
\hline Anova $\mathrm{F}$ & 49,090 & 25,592 & 20,124 & 21,306 & 26,603 & 23,366 & 24,943 & 18,474 & 24,255 & 46,249 \\
\hline
\end{tabular}

Todos los ANOVA F son $p<0,001$, Todas las constantes son $p<0,001$

${ }^{*} \mathrm{p}<0,10 /{ }^{* *} \mathrm{p}<0,05 /{ }^{* * *} \mathrm{p}<0,01 / \mathrm{n} . \mathrm{s}=$ no significativo $/$ - = no entra en la regresión 
Tabla 41a

Regresiones: la innovación radical en relación con la rentabilidad

\begin{tabular}{|c|c|c|c|c|c|c|c|c|c|c|}
\hline \multirow{2}{*}{ Innovación radical } & \multicolumn{10}{|c|}{ Rentabilidad } \\
\hline & M1 & M2 & M3 & M4 & M5 & M6 & M7 & M8 & M9 & M10 \\
\hline Constante & 3,376 & 4,318 & 3,785 & 4,545 & 3,376 & 4,543 & 3,468 & 2,538 & 3,834 & 3,298 \\
\hline Patentes registras & $0,320^{\star \star *}$ & - & n.s & - & n.s & - & n.s & - & n.s & n.s \\
\hline Actividades I+D & $0,272^{* * *}$ & - & $0,287^{* * *}$ & - & $0,289^{* *}$ & - & $0,281^{* *}$ & - & $0,311^{* * *}$ & $0,271^{* *}$ \\
\hline $\begin{array}{l}\text { Desarrollo de nuevos } \\
\text { productos y mercados }\end{array}$ & $0,366^{\star \star *}$ & - & $0,256^{* * *}$ & - & n.s & - & n.s & - & $0,260^{* *}$ & n.s \\
\hline Tamaño & - & $0,505^{\star * *}$ & $0,424^{* * *}$ & - & - & - & - & - & - & $0,361^{* * *}$ \\
\hline Orientación al mercado & - & - & - & $0,321^{* * *}$ & $0,374^{* * *}$ & - & - & - & - & n.s \\
\hline Turbulencia del entorno & - & - & - & - & - & $0,404^{* \star *}$ & $0,533^{\star \star *}$ & - & - & $0,522^{\star \star \star}$ \\
\hline Intensidad competitiva & - & - & - & - & - & - & - & n.s & n.s & $-0,205^{\star *}$ \\
\hline$R^{2}$ ajustado & 0,266 & 0,148 & 0,245 & 0,176 & 0,297 & 0,120 & 0,354 & 0,044 & 0,229 & 0,397 \\
\hline Anova F & 21,173 & 20,594 & 17,217 & 24,684 & 29,290 & 37,839 & 33,630 & 17,050 & 28,876 & 39,549 \\
\hline
\end{tabular}

Todos los ANOVA F son $p<0,001$, Todas las constantes son $p<0,001$

${ }^{*} p<0,10 /{ }^{* *} p<0,05 /{ }^{* *} p<0,01 /$ n.s $=$ no significativo $/$ - = no entra en la regresión 
Tabla 41b

Regresiones: la innovación radical en relación con la respuesta del mercado

\begin{tabular}{|c|c|c|c|c|c|c|c|c|c|c|}
\hline \multirow{2}{*}{ Innovación radical } & \multicolumn{10}{|c|}{ Respuesta del mercado } \\
\hline & M1 & M2 & M3 & M4 & M5 & M6 & M7 & M8 & M9 & M10 \\
\hline Constante & 4,221 & 4,145 & 4,176 & 4,010 & 4,248 & 4,007 & 4,231 & 2,132 & 3,264 & 4,292 \\
\hline Patentes registras & n.s & - & n.s & - & n.s & - & n.s & - & n.s & n.s \\
\hline Actividades I+D & $0,378^{\star * *}$ & - & n.s & - & n.s & - & n.s & - & $0,256^{* *}$ & n.s \\
\hline $\begin{array}{l}\text { Desarrollo de nuevos } \\
\text { productos y mercados }\end{array}$ & $0,326^{\star * *}$ & - & $0,310^{* * *}$ & - & $0,272^{* * *}$ & - & $0,291^{* * *}$ & - & $0,314^{* * *}$ & $0,311^{* * *}$ \\
\hline Tamaño & - & $0,332^{\star * \star}$ & n.s & - & - & - & - & - & - & $0,279^{* *}$ \\
\hline Orientación al mercado & - & - & - & $0,325^{\star \star *}$ & $0,377^{\star \star *}$ & - & - & - & - & $0,405^{\star \star *}$ \\
\hline Turbulencia del entorno & - & - & - & - & - & $0,280^{* * *}$ & $0,378^{* * *}$ & - & - & $0,397^{* * *}$ \\
\hline Intensidad competitiva & - & - & - & - & - & - & - & n.s & n.s & $-0,278^{* * *}$ \\
\hline $\mathrm{R}^{2}$ ajustado & 0,305 & 0,127 & 0,192 & 0,106 & 0,362 & 0,108 & 0,331 & 0,132 & 0,289 & 0,390 \\
\hline Anova $\mathrm{F}$ & 20,192 & 22,031 & 19,956 & 30,432 & 31,621 & 36,127 & 33,692 & 70,621 & 27,565 & 38,399 \\
\hline
\end{tabular}

Todos los ANOVA F son $p<0,001$, Todas las constantes son $p<0,001$

${ }^{*} p<0,10 /{ }^{* *} p<0,05 /{ }^{* * *} p<0,01 / n . s=$ no significativo $/$ - = no entra en la regresión 
Tabla 41c

Regresiones: la innovación radical en relación con el valor en el mercado

\begin{tabular}{|c|c|c|c|c|c|c|c|c|c|c|}
\hline \multirow{2}{*}{ Innovación radical } & \multicolumn{10}{|c|}{ Valor en el mercado } \\
\hline & M1 & M2 & M3 & M4 & M5 & M6 & M7 & M8 & M9 & M10 \\
\hline Patentes registras & n.s & - & n.s & - & n.s & - & n.s & - & n.s & n.s \\
\hline Actividades I+D & n.s & - & n.s & - & n.s & - & n.s & - & n.s & n.s \\
\hline Tamaño & - & $0,136^{\star *}$ & n.s & - & - & - & - & - & - & $-0,210^{* *}$ \\
\hline Orientación al mercado & - & & - & $0,410^{* * *}$ & $0,386^{* * *}$ & - & - & - & - & $0,466^{\star * *}$ \\
\hline Turbulencia del entorno & - & - & - & - & - & $0,599^{* * *}$ & $0,467^{* * *}$ & - & - & $0,389^{\star * *}$ \\
\hline Intensidad competitiva & - & - & - & - & - & - & - & $0,096^{*}$ & n.s & $-0,270^{* *}$ \\
\hline
\end{tabular}

Todos los ANOVA F son $p<0,001$, Todas las constantes son $p<0,001$

${ }^{*} p<0,10 /{ }^{* *} p<0,05 /{ }^{* * *} p<0,01 /$ n.s $=$ no significativo $/$ - = no entra en la regresión 
Tabla 41d

Regresiones: la innovación radical en relación con el éxito de nuevos productos

\begin{tabular}{|c|c|c|c|c|c|c|c|c|c|c|}
\hline \multirow{2}{*}{ Innovación radical } & \multicolumn{10}{|c|}{ Éxito de nuevos productos } \\
\hline & M1 & M2 & M3 & M4 & M5 & M6 & M7 & M8 & M9 & M10 \\
\hline Constante & 3,372 & 4,780 & 4,123 & 4,924 & 3,659 & 3,119 & 3,533 & 3,920 & 3,734 & 4,122 \\
\hline Patentes registras & n.s & - & $0,256^{* *}$ & - & n.s & - & n.s & - & $0,252^{* *}$ & n.s \\
\hline Actividades I+D & $0,297^{* * *}$ & - & $0,278^{* *}$ & - & n.s & - & n.s & - & $0,261^{* *}$ & n.s \\
\hline $\begin{array}{l}\text { Desarrollo de nuevos } \\
\text { productos y mercados }\end{array}$ & $0,346^{* \star *}$ & - & $0,340^{* * *}$ & - & n.s & - & $0,277^{\star * *}$ & - & $0,328^{* * *}$ & n.s \\
\hline Tamaño & - & $0,316^{* * *}$ & n.s & - & - & - & - & - & - & $-0,234^{* * *}$ \\
\hline Orientación al mercado & - & - & - & $0,676^{* * *}$ & $0,645^{* * *}$ & - & - & - & - & $0,675^{\star * *}$ \\
\hline Turbulencia del entorno & - & - & - & - & - & $0,601^{* * *}$ & $0,705^{\star * \star}$ & - & - & $0,541^{\star \star *}$ \\
\hline Intensidad competitiva & - & - & - & - & - & - & - & $0,193^{* * *}$ & $0,323^{* \star *}$ & $-0,286^{* \star *}$ \\
\hline$R^{2}$ ajustado & 0,298 & 0,113 & 0,265 & 0,239 & 0,480 & 0,189 & 0,432 & 0,140 & 0,276 & 0,522 \\
\hline Anova F & 28,890 & 25,592 & 22,760 & 21,306 & 48,912 & 23,366 & 45,394 & 18,474 & 23,290 & 52,385 \\
\hline
\end{tabular}

Todos los ANOVA F son $p<0,001$, Todas las constantes son $p<0,001$

${ }^{*} p<0,10 /{ }^{* *} p<0,05 /{ }^{* * *} p<0,01 /$ n.s = no significativo / - = no entra en la regresión 
Tabla 42a

Regresiones: efectos moderadores de los factores organizacionales y del entorno en la relación entre innovación incremental y desempeño empresarial

\begin{tabular}{|c|c|c|c|c|c|c|c|c|c|c|c|c|c|c|c|c|}
\hline $\begin{array}{l}\text { Innovación } \\
\text { incremental }\end{array}$ & M1 & M2 & M3 & M4 & M1 & M2 & M3 & M4 & M1 & M2 & M3 & M4 & M1 & M2 & M3 & M4 \\
\hline Constante & 4,530 & 4,506 & 4,539 & 4,589 & 4,032 & 4,033 & 4,017 & 4,038 & 4,066 & 4,055 & 4,014 & 4,039 & 4,905 & 4,971 & 4,935 & 4,947 \\
\hline $\begin{array}{l}\text { Innovación de } \\
\text { organización }\end{array}$ & $0,170^{\star \star \star}$ & $0,167^{* \star *}$ & $0,158^{\star \star *}$ & $0,170^{* \star *}$ & $0,120^{\star \star *}$ & $0,125^{\star \star \star}$ & $0,138^{\star * *}$ & $0,124^{* * *}$ & $0,174^{\star * *}$ & $0,131^{* * *}$ & $0,130^{\star * *}$ & $0,127^{\star \star \star}$ & 0,012 & 0,014 & 0,014 & 0,007 \\
\hline $\begin{array}{l}\text { Innovación de } \\
\text { marketing }\end{array}$ & $0,143^{* * *}$ & $0,090^{* *}$ & $0,097^{* *}$ & $0,151^{* * *}$ & $0,114^{* * *}$ & $0,092^{*}$ & $0,102^{* * *}$ & $0,130^{* * *}$ & $0,085^{\star *}$ & $0,108^{\star *}$ & $0,074^{* *}$ & $0,099^{* \star *}$ & $0,134^{* * *}$ & $0,047^{*}$ & $0,087^{* *}$ & $0,148^{\star * \star}$ \\
\hline $\begin{array}{l}\text { Innovación de } \\
\text { procesos }\end{array}$ & n.s & n.s & n.s & n.s & n.s & n.s & n.s & n.s & 0,038 & 0,035 & 0,006 & $0,039 *$ & 0,025 & 0,012 & 0,009 & 0,018 \\
\hline $\begin{array}{l}\text { Tamaño de la } \\
\text { empresa }\end{array}$ & $0,374^{* * *}$ & - & - & - & $0,188^{* *}$ & - & - & - & 0,040 & - & - & - & 0,030 & - & - & - \\
\hline $\begin{array}{l}\text { Tamaño x } \\
\text { innovación de } \\
\text { organización }\end{array}$ & n.s & - & - & - & $0,110^{*}$ & - & - & - & $0,158^{* *}$ & - & - & - & $0,083^{*}$ & - & - & - \\
\hline $\begin{array}{l}\text { Tamaño x } \\
\text { innovación de } \\
\text { producto }\end{array}$ & n.s & - & - & - & $0,122^{\star *}$ & - & - & - & $-0,017$ & - & - & - & $0,075^{\star}$ & - & - & - \\
\hline $\begin{array}{l}\text { Tamaño x } \\
\text { innovación de } \\
\text { procesos }\end{array}$ & n.s & - & - & - & n.s & - & - & - & 0,029 & - & - & - & 0,041 & - & - & - \\
\hline
\end{tabular}




\begin{tabular}{|c|c|c|c|c|c|c|c|c|c|c|c|c|c|c|c|c|}
\hline $\begin{array}{l}\text { Orientación al } \\
\text { mercado }\end{array}$ & - & $0,175^{\star * *}$ & - & - & - & 0,190 *** & - & - & - & $0,264^{* * *}$ & - & - & - & $0,307^{* * *}$ & - & - \\
\hline $\begin{array}{l}\text { Orientación al } \\
\text { mercado x } \\
\text { innovación de } \\
\text { organización }\end{array}$ & - & n.s & - & - & - & $0,076^{*}$ & - & - & - & $0,069^{* *}$ & - & - & - & $-0,016$ & - & - \\
\hline $\begin{array}{l}\text { Orientación al } \\
\text { mercado x } \\
\text { innovación de } \\
\text { marketing }\end{array}$ & - & $0,152^{\star *}$ & - & - & - & $0,117^{* *}$ & - & - & - & $0,081^{* *}$ & - & - & - & $0,093^{* *}$ & - & - \\
\hline $\begin{array}{l}\text { Orientación al } \\
\text { mercado x } \\
\text { innovación de } \\
\text { producto }\end{array}$ & - & n.s & - & - & - & n.s & - & - & - & 0,008 & - & - & - & $0,085^{\star *}$ & - & - \\
\hline $\begin{array}{l}\text { Orientación al } \\
\text { mercado x } \\
\text { innovación de } \\
\text { procesos }\end{array}$ & - & n.s & - & - & - & n.s & - & - & - & $-0,047$ & - & - & - & $0,060^{* *}$ & - & - \\
\hline $\begin{array}{l}\text { Turbulencia del } \\
\text { entorno }\end{array}$ & - & - & $0,267^{* * *}$ & - & - & - & $0,198^{* * *}$ & - & - & - & $0,194^{* * *}$ & - & - & - & $0,250^{* * *}$ & - \\
\hline $\begin{array}{l}\text { Turbulencia del } \\
\text { entorno x } \\
\text { innovación de } \\
\text { organización }\end{array}$ & - & - & n.s & - & - & - & $-0,189^{\star \star *}$ & - & - & - & $-0,155^{\star \star \star}$ & - & - & - & $-0,068^{*}$ & - \\
\hline $\begin{array}{l}\text { Turbulencia del } \\
\text { entorno x } \\
\text { innovación de } \\
\text { marketing }\end{array}$ & - & - & $0,123^{* * *}$ & - & - & - & $0,167^{* * *}$ & - & - & - & $0,150^{* *}$ & - & - & - & $-0,022$ & - \\
\hline $\begin{array}{l}\text { Turbulencia del } \\
\text { entorno x } \\
\text { innovación de } \\
\text { producto }\end{array}$ & - & - & $0,087^{* *}$ & - & - & - & n.s & - & - & - & 0,013 & - & - & - & $0,101^{* *}$ & - \\
\hline
\end{tabular}




\begin{tabular}{|c|c|c|c|c|c|c|c|c|c|c|c|c|c|c|c|c|}
\hline $\begin{array}{l}\text { Turbulencia del } \\
\text { entorno x } \\
\text { innovación de } \\
\text { procesos }\end{array}$ & - & - & $-0,069^{* *}$ & - & - & - & n.s & - & - & - & $-0,005$ & - & - & - & $0,091^{* *}$ & - \\
\hline $\begin{array}{l}\text { Intensidad } \\
\text { competitiva }\end{array}$ & - & - & - & n.s & - & - & - & $-0,066^{*}$ & - & - & - & $-0,084^{* *}$ & - & - & - & $-0,039$ \\
\hline $\begin{array}{l}\text { Intensidad } \\
\text { competitiva x } \\
\text { innovación de } \\
\text { organización }\end{array}$ & - & - & - & $-0,087^{* *}$ & - & - & - & $0,083^{* *}$ & - & - & - & $0,056^{* *}$ & - & - & - & $-0,001$ \\
\hline $\begin{array}{l}\text { Intensidad } \\
\text { competitiva x } \\
\text { innovación de } \\
\text { marketing }\end{array}$ & - & - & - & n.s & - & - & - & $0,074^{* *}$ & - & - & - & $0,072^{* *}$ & - & - & - & $-0,037$ \\
\hline $\begin{array}{l}\text { Intensidad } \\
\text { competitiva x } \\
\text { innovación de } \\
\text { producto }\end{array}$ & - & - & - & $0,081^{* *}$ & - & - & - & n.s & - & - & - & 0,008 & - & - & - & $0,091^{* *}$ \\
\hline $\begin{array}{l}\text { Intensidad } \\
\text { competitiva x } \\
\text { innovación de } \\
\text { procesos } \\
\end{array}$ & - & - & - & $-0,085^{\star \star \star}$ & - & - & - & $-0,071^{* *}$ & - & - & - & $-0,068 * *$ & - & - & - & $-0,053^{*}$ \\
\hline $\mathrm{R}^{2}$ ajustado & 0,149 & 0,131 & 0,179 & 0,130 & 0,131 & 0,140 & 0,158 & 0,137 & 0,116 & 0,205 & 0,176 & 0,158 & 0,233 & 0,288 & 0,280 & 0,233 \\
\hline Anova F & 12,848 & 10,635 & 15,140 & 10,454 & 14,638 & 11,080 & 12,995 & 10,904 & 14,528 & 19,497 & 16,862 & 13,924 & 21,281 & 24,972 & 24,398 & 11,232 \\
\hline
\end{tabular}

${ }^{*} p<0,10 /{ }^{* *} p<0,05 /{ }^{* *} p<0,01 / n$. $s=$ no significativo $/$ - = no entra en la regresión 


\section{Tabla 42b}

Regresiones: efectos moderadores de los factores organizacionales y del entorno en la relación entre innovación radical y desempeño empresarial

\begin{tabular}{|c|c|c|c|c|c|c|c|c|c|c|c|c|c|c|c|c|}
\hline \multirow{2}{*}{ Innovación radical } & \multicolumn{4}{|c|}{ Rentabilidad } & \multicolumn{4}{|c|}{ Respuesta de mercado } & \multicolumn{4}{|c|}{ Valor en el mercado } & \multicolumn{4}{|c|}{ Éxito de nuevos productos } \\
\hline & M1 & M2 & M3 & M4 & M1 & M2 & M3 & M4 & M1 & M2 & M3 & M4 & M1 & M2 & M3 & M4 \\
\hline Constante & 4,839 & 4,367 & 4,237 & 4,312 & 4,654 & 4,287 & 4,395 & 4,266 & 4,388 & 4,332 & 4,477 & 4,223 & 4,884 & 4,294 & 4,666 & 4,365 \\
\hline Patentes registras & n.s & n.s & n.s & n.s & n.s & n.s & n.s & n.s & n.s & n.s & n.s & n.s & n.s & n.s & n.s & $0,242^{* *}$ \\
\hline Actividades I+D & $0,281^{* *}$ & $0,291^{* *}$ & * $0,287^{* *}$ & ${ }^{*} 0,317^{* \star *}$ & $0,254^{* *}$ & $0,233^{* *}$ & $0,250^{* *}$ & $0,265^{\star *}$ & n.s & n.s & n.s & $0,234^{* *}$ & $0,285^{\star *}$ & n.s & n.s & $0,287^{\star *}$ \\
\hline $\begin{array}{l}\text { Desarrollo de nuevos } \\
\text { productos y mercados }\end{array}$ & $0,255^{\star *}$ & n.s & n.s & $0,261^{* *}$ & $0,307^{* * *}$ & $0,272^{* *}$ & $0,286^{\star *}$ & $0,314^{* * *}$ & $0,286^{\star \star *}$ & n.s & $0,251^{* * *}$ & $0,282^{* * *}$ & $0,340^{\star * *}$ & n.s & $0,276^{\star * *}$ & $0,330^{* * *}$ \\
\hline Tamaño de empresa & $0,407^{\star * *}$ & - & - & - & $0,316^{\star * *}$ & - & - & - & n.s & - & - & - & n.s & - & - & - \\
\hline Tamaño x patentes & $0,287^{* *}$ & - & - & - & $0,309 * * *$ & - & - & - & n.s & - & - & - & n.s & - & - & - \\
\hline Tamaño $x$ activ. I+D & n.s & - & - & - & n.s & - & - & - & n.s & - & - & - & n.s & - & - & - \\
\hline $\begin{array}{l}\text { Tamaño x nuevos } \\
\text { productos/mercados }\end{array}$ & n.s & - & - & - & n.s & - & - & - & n.s & - & - & - & $0,271^{* *}$ & - & - & - \\
\hline $\begin{array}{l}\text { Orientación al } \\
\text { mercado }\end{array}$ & - & $0,418^{* * *}$ & - & - & - & $0,435^{\star * *}$ & - & - & - & $0,483^{* * *}$ & - & - & - & $0,792^{* * *}$ & - & - \\
\hline $\begin{array}{l}\text { Orientación al } \\
\text { mercado x patentes }\end{array}$ & - & n.s & - & - & - & n.s & - & - & - & $0,229^{* *}$ & - & - & - & $0,221^{* *}$ & - & - \\
\hline $\begin{array}{l}\text { Orientación al } \\
\text { mercado } x \text { activ. I+D }\end{array}$ & - & n.s & - & - & - & n.s & - & - & - & n.s & - & - & - & n.s & - & - \\
\hline $\begin{array}{l}\text { Orientación al } \\
\text { mercado x nuevos } \\
\text { productos/mercados }\end{array}$ & - & $0,227^{* *}$ & - & - & - & $0,236^{* *}$ & - & - & - & n.s & - & - & - & n.s & - & - \\
\hline $\begin{array}{l}\text { Turbulencia del } \\
\text { entorno }\end{array}$ & - & - & $0,529^{* * *}$ & - & - & - & $0,381^{* * *}$ & - & - & - & $0,445^{\star * *}$ & - & - & - & $0,657^{* * *}$ & - \\
\hline
\end{tabular}




\begin{tabular}{|c|c|c|c|c|c|c|c|c|c|c|c|c|c|c|c|c|}
\hline $\begin{array}{l}\text { Turbulencia del } \\
\text { entorno } x \text { patentes }\end{array}$ & - & - & n.s & - & - & - & n.s & - & - & - & $0,262^{\star \star \star}$ & - & - & - & $0,251^{* *}$ & - \\
\hline $\begin{array}{l}\text { Turbulencia del } \\
\text { entorno } x \text { activ. I+D }\end{array}$ & - & - & n.s & - & - & - & n.s & - & - & - & n.s & - & - & - & n.s & - \\
\hline Intensidad competitiva & - & - & - & n.s & - & - & - & $-0,259^{* *}$ & - & - & - & n.s & - & - & - & $0,277^{* *}$ \\
\hline $\begin{array}{l}\text { Intensidad competitiva } \\
x \text { activ. } 1+D\end{array}$ & - & - & - & n.s & - & - & - & n.s & - & - & - & n.s & - & - & - & n.s \\
\hline $\begin{array}{l}\text { Intensidad competitiva } \\
\text { x nuevos } \\
\text { productos/mercados }\end{array}$ & - & - & - & n.s & - & - & - & n.s & - & - & - & n.s & - & - & - & n.s \\
\hline
\end{tabular}




\subsubsection{El papel de la colaboración en el éxito de la innovación: diferencias entre grandes y pequeñas empresas (modelo explicativo III)}

En la Tabla 43 se exponen los resultados de la regresión múltiple que explica, principalmente la cuestión P17: ¿actúa la colaboración organizacional como condicionante en la innovación empresarial?, en este apartado se incluyen los datos tanto para la variable de innovación incremental como la radical.

Observando la Tabla 43, se nota que la innovación tanto incremental como radical es explicada, significativamente por la colaboración, tanto del canal como de asesoría ( $\mathrm{p}<0,01$, para todos los casos). Esto quiere decir que las empresas alcanzan mayor innovación cuando participan en redes de colaboración organizacional. De esta manera se acepta el bloque de hipótesis $\mathrm{H} 17$ (a, b, c y d).

Existe una contundente evidencia teórica acerca de la modificación que sufre la relación entre la innovación y la colaboración cuando la variable del tamaño empresarial entra en el juego de la función. La Tabla 43 muestra el papel que juega el tamaño como variable confusa o de control. Es interesante que cuando la variable se integra al modelo, esté aumenta considerablemente su varianza explicada $\left(\mathrm{R}^{2}\right)$, además, las variables de colaboración siguen positivas y significativas $(\mathrm{p}<0,01)$ pero cambian en relación al modelo anterior. Esto demuestra que la variable de tamaño de la empresa actúa como causa de la relación entre la colaboración y la innovación.

La Tabla 44 pretende dar respuesta a la cuestión P18: ¿actúa la colaboración organizacional como condicionante en el desempeño empresarial? Los coeficientes de la regresión indican que la colaboración del canal, tanto para la innovación incremental como radical, son más altamente significativos para el éxito operativo de la empresa, por el contrario, la colaboración de asesoría, tanto para la innovación incremental como radical, son más altamente significativos para el éxito financiero. Consecuentemente con los resultados se reconfirma las hipótesis H18a y H18b para todos los resultados financieros y operativos.

Las Tablas 45a y 45b, y las Tablas 46a y 46b presentan los resultados del análisis del efecto de la colaboración organizacional relacionado a la innovación (incremental y radical) y 
al desempeño empresarial. Para cada una de las dimensiones de desempeño empresarial propuestas se estimó una secuencia de ocho modelos. El modelo M1, vuelve a examinar la relación básica de la investigación entre la innovación y el desempeño empresarial, aunque ya en el modelo explicativo II se contrastó esta relación, se vuelve a introducir para diferenciar el punto de vista multidimensional con el unidimensional.

El modelo M2 pretende dar respuesta a si la colaboración organizacional actúa como causa de la relación entre la innovación y el desempeño empresarial, es decir, si persiste la relación aún considerándose el efecto de la colaboración organizacional.

Los modelos M3 y M4 contemplan el moderador de la colaboración del canal y la colaboración de asesoría, respectivamente, este apartado trata de explicar la pregunta original P19: ¿actúa la colaboración organizacional como moderador de la relación entre la innovación y el desempeño empresarial?

El modelo M5 analiza solamente el papel del tamaño y su interacción con la innovación. Aunque en modelos anteriores, específicamente en la hipótesis H11, incluimos está variable de control, se vuelve a introducir con el fin de dar paso a las explicaciones de los siguientes modelos.

El modelo M6 trata de explicar si el tamaño de la empresa actúa como causa de la relación entre la colaboración organizacional y desempeño empresarial; o sea si persiste la relación aún considerándose el efecto del tamaño.

Finalmente, los modelos M7 y M8 consideran el papel moderador del tamaño sobre el efecto moderador de la colaboración organizacional (canal y asesoría) en la relación entre la innovación y el desempeño empresarial. Es decir, se considera como un efecto moderador doble. Con estos modelos se pretende dilucidar la pregunta P20: ¿difiere el papel de la colaboración en el éxito de la innovación según el tamaño de la empresa?

Atendiendo primeramente a la relación entre la innovación y el desempeño empresarial, los resultados del modelo M1 permiten observar que la contribución de la innovación (radical e incremental) es positiva y altamente significativa $(\mathrm{p}<0,01)$ para todas 
las medidas de desempeño, como se había contrastado con las hipótesis H6 y H7. Estos resultados reiteran que los cambios implantados en el área de organización, marketing, producto y procesos y la introducción patentes, I+D y desarrollo nuevos producto repercuten positivamente en el aumento de los resultados financieros y operativos de la empresa. La inversión de recursos para la innovación radical o incremental fortalece las habilidades para lograr aumentar la eficacia y la eficiencia de las empresas convirtiéndose en ventajas competitivas.

Los coeficientes de la regresión del modelo M2 indican que, para ambos tipos de colaboración (canal y asesoría) y su orientación innovadora, es decir, colaboraciones para generar innovaciones incrementales y las colaboraciones para generar innovaciones radicales, la causa de la relación entre la innovación (incremental y radical) y el desempeño empresarial no es la colaboración organizacional, puesto que la relación se mantiene aún cuando se introduce la variable colaboración.

El modelos M3, de ambas tablas, permiten observar que la contribución de la colaboración del canal modera positivamente la relación entre innovación incremental $(\mathrm{p}<0,01$ en todos los casos) y radical ( $\mathrm{p}<0,05$ en todos los casos) con los resultados empresariales. De la misma manera, los modelos M4 confirman el papel moderador que ejerce la colaboración de asesoría en el éxito innovador. Sin embargo, hay que apuntar que la colaboración del canal es en general más fructífera que la colaboración de asesoría cuando actúan en sinergia con la innovación incremental y radical. Esta conveniencia está presente en la mayoría de las medidas financieras y operativas de la empresa.

Es posible que la colaboración más cercana al canal, sea más fructífera porque promueve con más frecuencia mejoras y nuevas ideas que las colaboraciones externas de la asesoría, siendo las colaboraciones del canal más dinámicas (Bathelt, 2003; Jong y Freel, 2010) debido a que las interacciones suelen ser cara a cara como una vía de superar los problemas que surgen en las relaciones, desafíos únicos de coordinación, la desmotivación y problemas de riesgo moral (Sampson, 2007). Además se marca una similitud de comportamientos por la frecuencia de las interacciones en la medida que compartan competencias tecnológicas y mercados similares (Boschma, 2005). 
Por otra parte, los efectos moderadores de la colaboración, tanto del canal como de asesoría, son en general más ventajosos en la relación cuando la innovación es incremental. Esto puede deberse a que las colaboraciones suelen ofrecer, frecuentemente, más información y recursos de exploración que facilita la mejora de lo existente (innovaciones incrementales) sin demandar excesivos recursos económicos y operativos (Nooteboom, 1999).

Los datos del modelo M3 y M4 se complementan con los indicadores de las Tablas 47a-b y 48a-b para reforzar la evidencia empírica de la hipótesis para cada muestra independiente por tamaño. De estas tablas podemos extraer que las grandes empresas son más eficientes, eficaces y adaptables en sus resultados cuando acceden a innovar por medio de la colaboración de asesoría, posiblemente esté explicado por la cantidad de recursos y capacidades que las empresas están dispuestas a intercambiar en alianzas más complejas. Mientras tanto las pequeñas empresas se benefician más de la implantación de innovación incremental o radical cuando se centran en colaboraciones del canal. Hay que acotar que este tipo de colaboración es más frecuente en las pequeñas empresas porque su estructura flexible les permite constantemente interactuar con el canal y su reducida capacidad financiera le impide incurrir en grandes costes de I+D y desarrollo de nuevos productos. Los resultados son contundentes para confirmar empíricamente el bloque de hipótesis propuesto para H19 (a, b, c y d).

El modelo M5 plantea el papel del tamaño en el éxito de la innovación. Los coeficientes de la regresión confirman que el tamaño actúa como un moderador de la relación entre la innovación incremental y radical y el desempeño empresarial, aunque los coeficientes son más contundentes para los indicadores característicos por la eficacia hacia el mercado $(\mathrm{p}<0,01$ y $\mathrm{p}<0,05)$. Parece razonable que en el caso de la innovación incremental exista menos diferencia entre pequeñas y grandes empresas, al fin y al cabo, este tipo de innovación suele requerir menos recursos y las ventajas de las grandes pueden ser menores en estos casos. Dados los resultados se reconfirma parcialmente la hipótesis H11.

El modelo M6 trata de explicar el papel del tamaño en la relación entre la colaboración organizacional y el desempeño empresarial. Como se puede observar, el tamaño actúa como una variable confusa o controladora de la relación. Observando las Tabla 45a-b y las Tablas 46a-b, se extrae que el tamaño actúa como causa de la relación entre la 
colaboración y el desempeño empresarial, especialmente para los resultados respuesta de mercado $(\mathrm{p}<0,01)$ y éxito de nuevos productos $(\mathrm{p}<0,01)$, cuando la colaboración está más encaminada a cambios incrementales. En cambio, la causalidad en la innovación radical, se centra prioritariamente en la variable rentabilidad.

Por último, los modelos M7 y M8 examinan el papel de la colaboración en el éxito de la innovación diferenciando entre grandes y pequeñas empresas. Por un lado se percibe como las pequeñas empresas aprovechan mejor que las grandes empresas de la sinergia entre colaboración del canal y la innovación, tanto radical como incremental para aumentar los resultados financieros y operativos.

Lo anterior sugiere que las empresas más pequeñas buscan colaboraciones en el canal por la similitud entre los recursos y capacidades. Además, este tipo de colaboraciones facilita el aprendizaje por medio de mecanismos más sencillos y directos. Estas facilidades se deben prioritariamente a la estrecha relación que mantienen constantemente con sus clientes, proveedores y competidores (Sampson, 2007). Contrariamente, se aprecia que las grandes empresas sacan más provecho de la colaboración de asesoría para alcanzar el éxito de la innovación. Posiblemente debido a que estas empresas buscan colaboraciones más complejas y de naturaleza más explosiva, y le aportan una combinación de recursos y conocimiento que de algún modo las colaboraciones en el canal no le proporcionan. (Rodan y Galunic, 2004; Nooteboom et al., 2005). De este modo, se confirma el cuarto bloque de hipótesis $\mathrm{H} 20$ (a, b, c y d). 
Tabla 43

Regresiones: relación entre la colaboración organizacional y la innovación: papel del tamaño de la empresa

\begin{tabular}{|c|c|c|c|c|}
\hline Variables & \multicolumn{2}{|c|}{ Innovación incremental } & \multicolumn{2}{|c|}{ Innovación radical } \\
\hline Constante & 2,662 & 2,518 & 1,781 & 1,452 \\
\hline Colaboración canal & $0,391^{* * *}$ & $0,406^{\star \star *}$ & $0,319^{\star \star *}$ & $0,266^{* * *}$ \\
\hline Colaboración asesoría & $0,295^{\star * *}$ & $0,258^{* * *}$ & $0,418^{\star \star *}$ & $0,246^{\star * *}$ \\
\hline Tamaño & - & $0,642^{\star \star \star}$ & - & $1,263^{\star \star *}$ \\
\hline $\mathrm{R}^{2}$ ajustado & 0,473 & 0,516 & 0,410 & 0,516 \\
\hline ANOVA F & 73,326 & 72,306 & 63,671 & 86,216 \\
\hline
\end{tabular}

Todos los ANOVAF son $p<0,001$, Todas las constantes son $p<0,001$

${ }^{*} p<0,10 /{ }^{* *} p<0,05 /{ }^{* * *} p<0,01 / n . s=$ no significativo $/$ - = no entra en la regresión 
Tabla 44

Regresiones: relación entre la colaboración organizacional y el desempeño empresarial

\begin{tabular}{|c|c|c|c|c|c|c|c|c|}
\hline \multirow[t]{2}{*}{ Variables } & \multicolumn{4}{|c|}{ Colaboración para la innovación incremental } & \multicolumn{4}{|c|}{ Colaboración para la innovación radical } \\
\hline & Rentabilidad & $\begin{array}{l}\text { Respuesta del } \\
\text { mercado }\end{array}$ & $\begin{array}{l}\text { Valor en el } \\
\text { mercado }\end{array}$ & $\begin{array}{c}\text { Éxito de } \\
\text { nuevos } \\
\text { productos }\end{array}$ & Rentabilidad & $\begin{array}{l}\text { Respuesta del } \\
\text { mercado }\end{array}$ & $\begin{array}{l}\text { Valor en el } \\
\text { mercado }\end{array}$ & $\begin{array}{c}\text { Éxito de } \\
\text { nuevos } \\
\text { productos }\end{array}$ \\
\hline Constante & 3,825 & 3,802 & 3,467 & 3,744 & 3,993 & 3,997 & 3,826 & 3,946 \\
\hline Colaboración canal & n.s & $0,210^{* *}$ & $0,351^{* * *}$ & $0,373^{* * *}$ & n.s & $0,174^{* *}$ & $0,337^{* * *}$ & $0,425^{* * *}$ \\
\hline Colaboración asesoría & $0,325^{\star \star *}$ & $0,285^{\star * *}$ & $0,194^{* *}$ & $0,200^{* *}$ & $0,356^{* * *}$ & $0,357^{* * *}$ & $0,177^{\star *}$ & n.s \\
\hline $\mathrm{R}^{2}$ ajustado & 0,259 & 0,266 & 0,292 & 0,276 & 0,200 & 0,259 & 0,221 & 0,259 \\
\hline ANOVA F & 25,415 & 36,083 & 48,211 & 31,554 & 28,895 & 34,467 & 31,133 & 30,276 \\
\hline
\end{tabular}

Todos los ANOVA F son $p<0,001$. Todas las constantes son $p<0,001$ ${ }^{*} p<0,10 /{ }^{* *} p<0,05 /{ }^{* * *} p<0,01 /$ n.s $=$ no significativo 
Tabla 45a

Regresiones: efecto moderador de la colaboración organizacional en la relación entre innovación incremental y desempeñoempresarial: papel de tamaño como doble moderador

\begin{tabular}{|c|c|c|c|c|c|c|c|c|c|c|c|c|c|c|c|c|}
\hline \multirow{2}{*}{ Innovación incremental } & \multicolumn{8}{|c|}{ Rentabilidad } & \multicolumn{8}{|c|}{ Respuesta del mercado } \\
\hline & M1 & M2 & M3 & M4 & M5 & M6 & M7 & M8 & M1 & M2 & M3 & M4 & M5 & M6 & M7 & M8 \\
\hline Constante & 4,181 & 3,316 & 3,572 & 3,543 & 4,132 & 3,316 & 3,376 & 3,365 & 4,393 & 3,313 & 3,696 & 3,671 & 4,241 & 3,315 & 3,575 & 3,557 \\
\hline Innovación incremental & $0,343^{* * *}$ & $0,291^{* * *}$ & $0,307^{* * *}$ & $0,275^{* * *}$ & 0,309 & $0,258^{* * *}$ & $0,264^{* * *}$ & $0,248^{* * *}$ & $0,352^{* * *}$ & $0,284^{* * *}$ & $0,296^{* * *}$ & 0,309 & $0,332^{* * *}$ & $0,264^{* * *}$ & $0,296^{* * *}$ & $0,286^{* * *}$ \\
\hline Colaboración canal & - & n.s & n.s & - & - & n.s & $0,233^{* * *}$ & - & - & n.s & n.s & - & - & $0,166^{* *}$ & $0,228^{* * *}$ & - \\
\hline Colaboración canal x innovación & - & - & $0,219^{* * *}$ & - & - & - & n.s & - & - & - & $0,201^{* * *}$ & - & - & - & n.s & - \\
\hline Colaboración asesoría & - & $0,287^{\star * *}$ & - & $0,177^{\star \star *}$ & - & $0,270^{\star * *}$ & - & $0,204^{* * *}$ & - & $0,299^{* * *}$ & - & n.s & - & $0,190^{* *}$ & - & $0,195^{\star * *}$ \\
\hline $\begin{array}{l}\text { Colaboración asesoría x } \\
\text { innovación }\end{array}$ & - & - & - & $0,183^{* * *}$ & - & - & - & n.s & - & - & - & $0,172^{* *}$ & - & - & - & n.s \\
\hline Tamaño & - & - & - & - & $0,482^{* * *}$ & $0,442^{* * *}$ & $0,346^{* * *}$ & $0,203^{* * *}$ & - & - & - & - & $0,322^{* * *}$ & $0,295^{\star * *}$ & $0,278^{* * *}$ & n.s \\
\hline Tamaño x innovación & - & - & - & - & n.s & - & $0,192^{* * *}$ & $0,176^{* * *}$ & - & - & - & - & $0,193^{* *}$ & - & $0,186^{* *}$ & $0,191^{* * *}$ \\
\hline Colaboración canal x tamaño & - & - & - & - & - & - & $0,170^{* *}$ & - & - & - & - & - & - & - & $0,278^{\star * *}$ & - \\
\hline $\begin{array}{l}\text { Colaboración canal x tamaño x } \\
\text { innovación }\end{array}$ & - & - & - & - & - & - & $-0,257^{* * *}$ & - & - & - & - & - & - & - & $-0,226^{* * *}$ & - \\
\hline Colaboración asesoría x tamaño & - & - & - & - & - & - & - & $0,176^{\star *}$ & - & - & - & - & - & - & - & $0,262^{* * *}$ \\
\hline $\begin{array}{l}\text { Colaboración asesoría x tamaño } \\
\mathrm{x} \text { innovación }\end{array}$ & - & - & - & - & - & - & - & $0,268^{* * *}$ & - & - & - & - & - & - & - & $0,180^{* * *}$ \\
\hline $\mathrm{R}^{2}$ ajustado & 0,388 & 0,317 & 0,286 & 0,224 & 0,266 & 0,345 & 0,256 & 0,272 & 0,234 & 0,319 & 0,216 & 0,226 & 0,243 & 0,330 & 0,255 & 0,263 \\
\hline ANOVA F & 31,148 & 35,936 & 30,429 & 35,550 & 46,066 & 54,443 & 28,453 & 29,135 & 26,642 & 36,364 & 34,918 & 36,022 & 33,438 & 43,132 & 28,243 & 28,696 \\
\hline
\end{tabular}

Todos los ANOVA F son $p<0,001$, Todas las constantes son $p<0,001$

${ }^{*} p<0,10 /{ }^{* *} p<0,05 /{ }^{* * *} p<0,01 /$ n.s $=$ no significativo $/$ - = no entra en la regresión 
Tabla $45 b$

Regresiones: efecto moderador de la colaboración organizacional en la relación entre

innovación incremental y desempeñoempresarial: papel de tamaño como doble moderador

\begin{tabular}{|c|c|c|c|c|c|c|c|c|c|c|c|c|c|c|c|c|}
\hline \multirow{2}{*}{ Innovación incremental } & \multicolumn{8}{|c|}{ Valor en el mercado } & \multicolumn{8}{|c|}{ Éxito de nuevos productos } \\
\hline & M1 & M2 & M3 & M4 & M5 & M6 & M7 & M8 & M1 & M2 & M3 & M4 & M5 & M6 & M7 & M8 \\
\hline Constante & 4,012 & 4,019 & 4,466 & 4,425 & 4,726 & 3,014 & 4,442 & 4,413 & 3,022 & 2,581 & 3,102 & 3,910 & 3,181 & 2,581 & 3,005 & 3,074 \\
\hline Colaboración canal & - & $0,202^{* * *}$ & $0,237^{\star \star *}$ & - & - & $0,202^{\star \star *}$ & $0,206^{* * *}$ & - & - & $0,270^{* * *}$ & n.s & - & - & $0,274^{* * *}$ & n.s & - \\
\hline Colaboración canal x innovación & - & - & $0,203^{* \star *}$ & - & - & - & $0,176^{* * *}$ & - & - & - & $0,193^{* * *}$ & - & - & - & n.s & - \\
\hline Tamaño & - & - & - & - & $0,233^{* *}$ & n.s & n.s & n.s & - & - & - & - & $0,169^{* *}$ & $0,173^{* *}$ & $0,160^{* *}$ & n.s \\
\hline Tamaño x innovación & - & - & - & - & $0,183^{*}$ & - & $0,126^{*}$ & $0,098^{*}$ & - & - & - & - & n.s & - & $0,111^{*}$ & n.s \\
\hline Colaboración canal x tamaño & - & - & - & - & - & - & n.s & - & - & - & - & - & - & - & $0,210^{\star \star \star}$ & - \\
\hline $\mathrm{R}^{2}$ ajustado & 0,256 & 0,344 & 0,283 & 0,242 & 0,343 & 0,344 & 0,290 & 0,251 & 0,350 & 0,447 & 0,359 & 0,354 & 0,358 & 0,448 & 0,366 & 0,362 \\
\hline ANOVA F & 31,339 & 39,289 & 43,276 & 37,836 & 37,954 & 34,436 & 30,292 & 28,068 & 48,995 & 45,431 & 55,688 & 54,738 & 46,636 & 46,610 & 35,832 & 35,441 \\
\hline
\end{tabular}


Tabla 46a

Regresiones: efecto moderador de la colaboración organizacional en la relación entre innovación radical y desempeñoempresarial: papel de tamaño como doble moderador

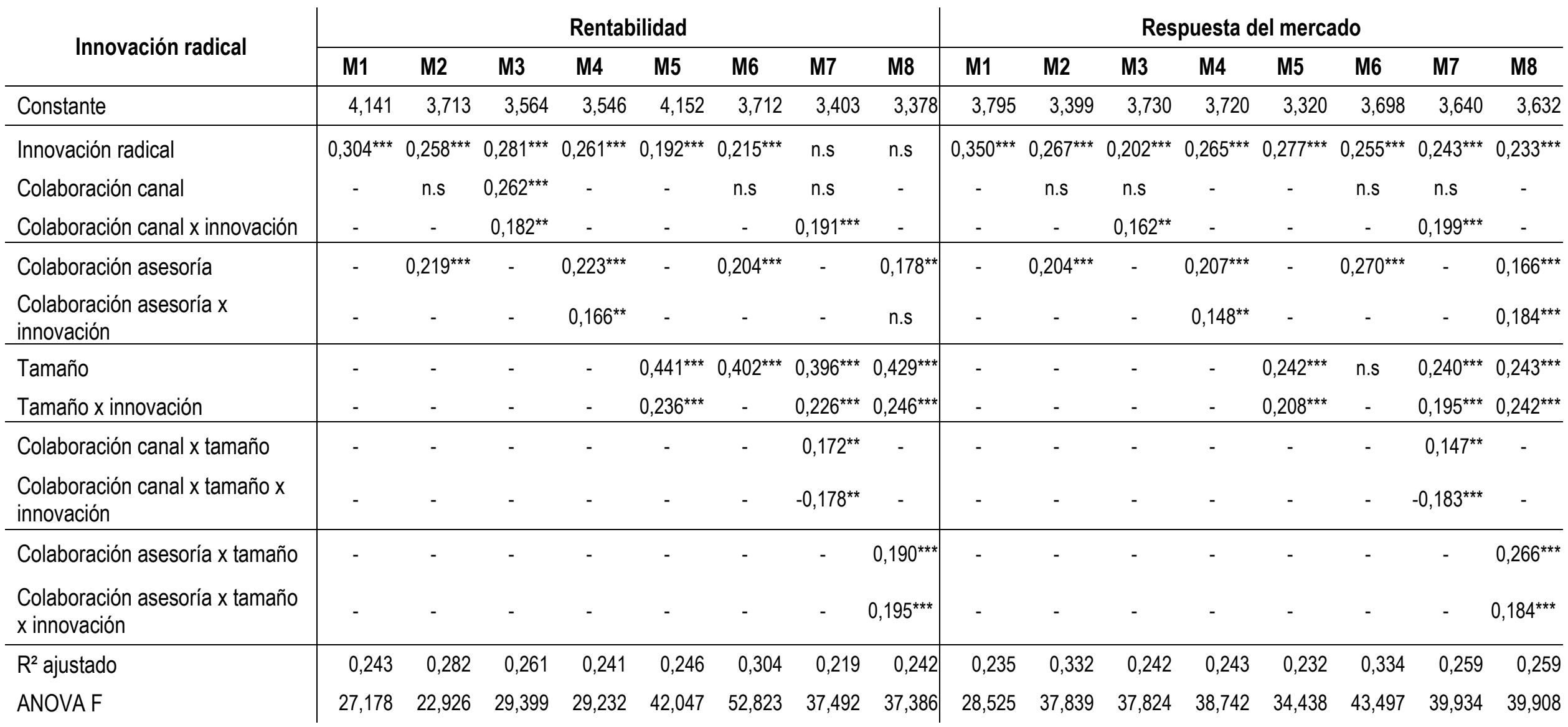

Todos los ANOVA F son $p<0,001$, Todas las constantes son $p<0,001$

${ }^{*} p<0,10 /{ }^{* *} p<0,05 /{ }^{* * *} p<0,01 /$ n.s = no significativo / - = no entra en la regresión 
Tabla 46b

Regresiones: efecto moderador de la colaboración organizacional en la relación entre innovación radical y desempeño empresarial: papel de tamaño como doble moderador

\begin{tabular}{|c|c|c|c|c|c|c|c|c|c|c|c|c|c|c|c|c|}
\hline \multirow{2}{*}{ Innovación radical } & \multicolumn{8}{|c|}{ Valor en el mercado } & \multicolumn{8}{|c|}{ Éxito de nuevos productos } \\
\hline & M1 & M2 & M3 & M4 & M5 & M6 & M7 & M8 & M1 & M2 & M3 & M4 & M5 & M6 & M7 & M8 \\
\hline Constante & 4,730 & 3,665 & 4,426 & 4,422 & 4,767 & 3,666 & 4,389 & 4,409 & 3,254 & 2,708 & 3,935 & 3,940 & 3,631 & 3,707 & 3,880 & 3,907 \\
\hline Innovación radical & $0,244^{* * *}$ & $0,290^{* * *}$ & $0,193^{* * *}$ & $0,199^{* * *}$ & $0,211^{* * *}$ & $0,294^{* * *}$ & n.s & n.s & $0,386^{* * *}$ & $0,296^{* * *}$ & $0,231^{* * *}$ & $0,320^{* * *}$ & $0,340^{* * *}$ & $0,289^{* * *}$ & $0,271^{* * *}$ & $0,309^{* * *}$ \\
\hline Colaboración canal & - & $0,187^{* \star *}$ & $0,188^{* * *}$ & - & - & $0,285^{\star * *}$ & $0,195^{* * *}$ & - & - & $0,272^{* * *}$ & $0,269^{* * *}$ & - & - & $0,272^{\star * \star}$ & $0,242^{* * *}$ & - \\
\hline Colaboración canal x innovación & - & - & $0,146^{* *}$ & - & - & - & n.s & - & - & - & $0,187^{* *}$ & - & - & - & n.s & - \\
\hline Colaboración asesoría & - & n.s & - & n.s & - & n.s & - & n.s & - & n.s & - & n.s & - & n.s & - & n.s \\
\hline $\begin{array}{l}\text { Colaboración asesoría x } \\
\text { innovación }\end{array}$ & - & - & - & $0,183^{* * *}$ & - & - & - & $0,187^{* * *}$ & - & - & - & n.s & - & - & - & $0,189^{* * *}$ \\
\hline Tamaño & - & - & - & - & n.s & n.s & n.s & n.s & - & - & - & - & n.s & n.s & $0,174^{* * *}$ & n.s \\
\hline Tamaño x innovación & - & - & - & - & $0,162^{* * *}$ & - & $0,171^{* * *}$ & $0,180^{* * *}$ & - & - & - & - & 0,211 & - & 0,211 & 0,183 \\
\hline Colaboración canal x tamaño & - & - & - & - & - & - & $0,112^{*}$ & - & - & - & - & - & - & - & $0,114^{*}$ & - \\
\hline $\begin{array}{l}\text { Colaboración canal x tamaño x } \\
\text { innovación }\end{array}$ & - & - & - & - & - & - & $-0,167^{* * *}$ & - & - & - & - & - & - & - & $-0,188^{* * *}$ & - \\
\hline Colaboración asesoría x tamaño & - & - & - & - & - & - & - & $0,150^{* * *}$ & - & - & - & - & - & - & - & $0,242^{* * *}$ \\
\hline $\begin{array}{l}\text { Colaboración asesoría x tamaño } \\
\mathrm{x} \text { innovación }\end{array}$ & - & - & - & - & - & - & - & $0,176^{* * *}$ & - & - & - & - & - & - & - & $0,192^{* * *}$ \\
\hline $\mathrm{R}^{2}$ ajustado & 0,255 & 0,256 & 0,255 & 0,244 & 0,235 & 0,256 & 0,268 & 0,266 & 0,229 & 0,331 & 0,237 & 0,210 & 0,133 & 0,331 & 0,243 & 0,217 \\
\hline ANOVAF & 33,555 & 28,183 & 29,354 & 28,405 & 38,962 & 32,561 & 25,084 & 27,598 & 26,385 & 37,431 & 36,965 & 34,043 & 23,534 & 43,037 & 28,795 & 32,555 \\
\hline
\end{tabular}

Todos los ANOVA F son $p<0,001$, Todas las constantes son $p<0,001$

${ }^{*} p<0,10 /{ }^{* *} p<0,05 /{ }^{* * *} p<0,01 /$ n.s = no significativo / - = no entra en la regresión 
Tabla 47a

Regresiones: efecto moderador de la colaboración organizacional en la relación entre innovación incremental y desempeño empresarial según tamaño de la empresa

\begin{tabular}{|c|c|c|c|c|c|c|c|c|c|c|c|c|}
\hline \multirow{3}{*}{ Innovación incremental } & \multicolumn{6}{|c|}{ Rentabilidad } & \multicolumn{6}{|c|}{ Respuesta de mercado } \\
\hline & \multicolumn{3}{|c|}{ Grandes empresas } & \multicolumn{3}{|c|}{ Pequeñas empresas } & \multicolumn{3}{|c|}{ Grandes empresas } & \multicolumn{3}{|c|}{ Pequeñas empresas } \\
\hline & M1 & M2 & M3 & M1 & M3 & M3 & M1 & M2 & M3 & M1 & M2 & M3 \\
\hline Constante & 4,132 & 4,704 & 3,874 & 3,941 & 3,900 & 3,822 & 3,726 & 4,743 & 3,991 & 3,988 & 3,654 & 4,101 \\
\hline Innovación incremental & $0,375^{* * *}$ & $0,350^{* * *}$ & $0,330^{* * *}$ & $0,273^{\star * *}$ & n.s & $0,189^{* * *}$ & $0,413^{\star * *}$ & $0,430^{* * *}$ & $0,394^{* * *}$ & n.s & $0,208^{* * *}$ & $0,188^{* * *}$ \\
\hline Colaboración canal & n.s & - & n.s & $0,211^{* * *}$ & - & $0,194^{* * *}$ & $0,222^{* *}$ & - & $0,187^{* *}$ & $0,201^{* * *}$ & - & $0,195^{* * *}$ \\
\hline Colaboración canal x innovación & $-0,214^{* * *}$ & - & $-0,231^{* * *}$ & $0,213^{* * *}$ & - & $0,188^{* * *}$ & n.s & - & $-0,148^{* *}$ & $0,200^{* * *}$ & - & $0,167^{* * *}$ \\
\hline Colaboración asesoría & - & $0,269^{* * *}$ & $0,278^{* * *}$ & - & $0,170^{* *}$ & $0,161^{* *}$ & - & $0,284^{* *}$ & $0,262^{* * *}$ & - & $0,186^{* * *}$ & $0,177^{* * *}$ \\
\hline Colaboración asesoría x innovación & - & $0,187^{* *}$ & $0,143^{* *}$ & - & n.s & n.s & - & $0,221^{* *}$ & $0,188^{* *}$ & - & n.s & n.s \\
\hline $\mathrm{R}^{2}$ ajustado & 0,216 & 0,249 & 0,224 & 0,193 & 0,197 & 0,195 & 0,268 & 0,276 & 0,245 & 0,218 & 0,217 & 0,264 \\
\hline ANOVA F & 40,077 & 39,375 & 44,210 & 34,438 & 29,229 & 32,444 & 38,994 & 49,405 & 47,666 & 23,632 & 33,432 & 34,777 \\
\hline
\end{tabular}

Todos los ANOVA F son $p<0,001$, Todas las constantes son $p<0,001$

${ }^{*} p<0,10 /{ }^{* *} p<0,05 /{ }^{* * *} p<0,01 /$ n.s = no significativo / - = no entra en la regresión 
Tabla $47 b$

Regresiones: efecto moderador de la colaboración organizacional en la relación entre innovación incremental y desempeño empresarial según tamaño de la empresa

\begin{tabular}{|c|c|c|c|c|c|c|c|c|c|c|c|c|}
\hline \multirow{3}{*}{ Innovación incremental } & \multicolumn{6}{|c|}{ Valor en el mercado } & \multicolumn{6}{|c|}{ Éxito de nuevos productos } \\
\hline & \multicolumn{3}{|c|}{ Grandes empresas } & \multicolumn{3}{|c|}{ Pequeñas empresas } & \multicolumn{3}{|c|}{ Grandes empresas } & \multicolumn{3}{|c|}{ Pequeñas empresas } \\
\hline & M1 & M2 & M3 & M1 & M3 & M3 & M1 & M2 & M3 & M1 & M2 & M3 \\
\hline Constante & 4,625 & 4,427 & 4,333 & 4,613 & 4,109 & 4,492 & 3,561 & 3,954 & 3,764 & 3,961 & 3,974 & 3,922 \\
\hline Innovación incremental & $0,287^{\star * *}$ & $0,329^{* * *}$ & $0,271^{* * *}$ & $0,211^{* * *}$ & 0,253 & $0,218^{* * *}$ & $0,630^{* * *}$ & $0,662^{* * *}$ & $0,627^{* * *}$ & $0,460^{* * *}$ & $0,500^{* * *}$ & $0,472^{* * *}$ \\
\hline Colaboración canal & $0,234^{* * *}$ & - & $0,203^{* * *}$ & $0,214^{* * *}$ & - & $0,197^{\star \star *}$ & n.s & - & $0,195^{\star *}$ & n.s & - & n.s \\
\hline Colaboración canal x innovación & $-0,209^{* * *}$ & - & $-0,125^{* *}$ & $0,179^{* *}$ & - & $0,221^{* * *}$ & n.s & - & $-0,133^{*}$ & $0,176^{* *}$ & - & $0,163^{* *}$ \\
\hline Colaboración asesoría & - & $0,288^{* * *}$ & $0,164^{* * *}$ & - & $0,206^{* * *}$ & $0,160 * *$ & - & n.s & n.s & - & n.s & n.s \\
\hline Colaboración asesoría x innovación & - & $0,191^{* *}$ & n.s & - & n.s & n.s & - & n.s & n.s & - & n.s & n.s \\
\hline $\mathrm{R}^{2}$ ajustado & 0,222 & 0,224 & 0,227 & 0,287 & 0,209 & 0,257 & 0,295 & 0,304 & 0,309 & 0,257 & 0,263 & 0,263 \\
\hline ANOVA F & 21,633 & 35,201 & 35,399 & 32,890 & 22,166 & 33,651 & 38,777 & 47,041 & 45,863 & 25,603 & 33,531 & 37,227 \\
\hline
\end{tabular}

Todos los ANOVA F son $p<0,001$, Todas las constantes son $p<0,001$

${ }^{*} p<0,10 /{ }^{* *} p<0,05 /{ }^{* \star *} p<0,01 /$ n.s $=$ no significativo $/$ - = no entra en la regresión 
Tabla 48a

Regresiones: efecto moderador de la colaboración organizacional en la relación entre innovación radical y desempeño empresarial según tamaño de la empresa

\begin{tabular}{|c|c|c|c|c|c|c|c|c|c|c|c|c|}
\hline \multirow{3}{*}{ Innovación radical } & \multicolumn{6}{|c|}{ Rentabilidad } & \multicolumn{6}{|c|}{ Respuesta de mercado } \\
\hline & \multicolumn{3}{|c|}{ Grandes Empresas } & \multicolumn{3}{|c|}{ Pymes } & \multicolumn{3}{|c|}{ Grandes Empresas } & \multicolumn{3}{|c|}{ Pymes } \\
\hline & M1 & M2 & M3 & M1 & M3 & M3 & M1 & M2 & M3 & M1 & M2 & M3 \\
\hline Constante & 4,181 & 4,132 & 4,107 & 3,393 & 4,137 & 4,400 & 4,090 & 4,059 & 4,096 & 4,091 & 4,155 & 4,154 \\
\hline Innovación radical & $0,287^{* * *}$ & $0,275^{\star * *}$ & $0,272^{\star * *}$ & n.s & n.s & n.s & $0,338^{* * *}$ & $0,327^{* * *}$ & $0,220^{* * *}$ & $0,243^{* * *}$ & $0,232^{* * *}$ & $0,234^{* * *}$ \\
\hline Colaboración canal & $0,190^{* * *}$ & - & n.s & n.s & - & n.s & $0,269^{* * *}$ & - & n.s & n.s & - & n.s \\
\hline Colaboración canal x innovación & n.s & - & n.s & $0,191^{* * *}$ & - & $0,112^{* *}$ & $-0,170^{* *}$ & - & n.s & $0,199^{* * *}$ & - & $0,189^{* * *}$ \\
\hline Colaboración asesoría & - & $0,268^{* * *}$ & $0,184^{* *}$ & - & n.s & $0,181^{* * *}$ & - & $0,332^{* * *}$ & $0,257^{* * *}$ & - & n.s & $0,169^{* *}$ \\
\hline Colaboración asesoría x innovación & - & $0,193^{* * *}$ & $0,158^{* *}$ & - & n.s & n.s & - & $0,183^{* *}$ & $0,147^{* *}$ & - & $-0,101^{* *}$ & n.s \\
\hline $\mathrm{R}^{2}$ ajustado & 0,218 & 0,215 & 0,222 & 0,223 & 0,213 & 0,237 & 0,235 & 0,223 & 2,460 & 0,160 & 0,182 & 0,192 \\
\hline ANOVA F & 23,118 & 24,158 & 29,528 & 28,624 & 25,101 & 32,912 & 33,589 & 36,264 & $, 38,153$ & 28,205 & 28,140 & 0,314 \\
\hline
\end{tabular}

Todos los ANOVA F son $p<0,001$, Todas las constantes son $p<0,001$

${ }^{*} p<0,10 /{ }^{* *} p<0,05 /{ }^{* * *} p<0,01 /$ n.s $=$ no significativo / - = no entra en la regresión 
Tabla 48b

Regresiones: efecto moderador de la colaboración organizacional en la relación entre innovación radical y desempeño empresarial según tamaño de la empresa

\begin{tabular}{|c|c|c|c|c|c|c|c|c|c|c|c|c|}
\hline \multirow{3}{*}{ Innovación radical } & \multicolumn{6}{|c|}{ Valor en el mercado } & \multicolumn{6}{|c|}{ Éxito de nuevos productos } \\
\hline & \multicolumn{3}{|c|}{ Grandes Empresas } & \multicolumn{3}{|c|}{ Pymes } & \multicolumn{3}{|c|}{ Grandes Empresas } & \multicolumn{3}{|c|}{ Pymes } \\
\hline & M1 & M2 & M3 & M1 & M3 & M3 & M1 & M2 & M3 & M1 & M2 & M3 \\
\hline Constante & 4,884 & 4,992 & 4,454 & 4,883 & 4,723 & 4,725 & 4,074 & 4,004 & 3,954 & 4,146 & 4,278 & 4,298 \\
\hline Innovación radical & $0,234^{* * *}$ & $0,217^{* * *}$ & $0,215^{\star * *}$ & n.s & n.s & n.s & $0,338^{* * *}$ & $0,391^{* * *}$ & $0,371^{* * *}$ & $0,271^{* * *}$ & $0,308^{* * *}$ & $0,275^{\star * *}$ \\
\hline Colaboración canal & n.s & - & $0,207^{* *}$ & $0,195^{* * *}$ & - & $0,195^{\star * *}$ & $0,300^{* * *}$ & - & $0,252^{* * *}$ & $0,242^{* * *}$ & - & $0,290^{* * *}$ \\
\hline Colaboración canal x innovación & $-0,165^{\star *}$ & - & $-0,211^{* *}$ & $0,195^{\star * *}$ & - & $0,167^{\star * *}$ & $-0,178^{* *}$ & - & $-0,162^{* *}$ & $0,204^{* * *}$ & - & $0,190^{* * *}$ \\
\hline Colaboración asesoría & - & $0,277^{\star * *}$ & $0,274^{* * *}$ & - & n.s & n.s & - & $0,320^{* * *}$ & $0,188^{* * *}$ & - & n.s & $0,210^{* * *}$ \\
\hline Colaboración asesoría x innovación & - & n.s & $0,181^{* * *}$ & - & $-0,189^{* *}$ & $-0,178^{* *}$ & - & $0,209^{* * *}$ & n.s & - & n.s & $-0,187^{* *}$ \\
\hline $\mathrm{R}^{2}$ ajustado & 0,206 & 0,200 & 0,198 & 0,225 & 0,219 & 0,216 & 0,206 & 0,244 & 0,232 & 0,242 & 0,201 & 0,228 \\
\hline ANOVA F & 25,378 & 21,295 & 29,528 & 28,856 & 23,902 & 33,392 & 39,361 & 44,544 & 40,555 & 35,544 & 36,067 & 42,274 \\
\hline
\end{tabular}

Todos los ANOVA F son $p<0,001$, Todas las constantes son $p<0,001$

${ }^{*} p<0,10 /{ }^{* *} p<0,05 /{ }^{* * *} p<0,01 /$ n.s $=$ no significativo / - = no entra en la regresión 


\subsection{Contraste de hipótesis}

La Tabla 49 muestra un resumen de todas las hipótesis contrastadas en la investigación. Esta forma facilita al lector los resultados obtenidos del estudio empírico y orientarse sobre la manera en que se definirán las conclusiones en el siguiente apartado.

\section{Tabla 49}

Contraste de las hipótesis planteadas del modelo teórico

\begin{tabular}{|c|c|c|c|c|}
\hline $\begin{array}{l}\text { Modelo } \\
\text { teórico }\end{array}$ & Hipótesis & Descripción & Tabla & Contraste \\
\hline \multirow[t]{3}{*}{ M I } & H1 & $\begin{array}{l}\text { La orientación al mercado tiene un efecto } \\
\text { positivo en la innovación, es decir, cuanto } \\
\text { mayor es la orientación al mercado, mayor es } \\
\text { la innovación empresarial. }\end{array}$ & $38 a$ y $38 b$ & Acepta \\
\hline & $\mathrm{H} 1 \mathrm{a}$ & $\begin{array}{l}\text { La orientación al mercado está relacionada } \\
\text { positivamente con la innovación incremental. }\end{array}$ & $38 \mathrm{a}$ & Acepta \\
\hline & $\mathrm{H} 1 \mathrm{~b}$ & $\begin{array}{l}\text { La orientación al mercado está relacionada } \\
\text { positivamente con la innovación radical. }\end{array}$ & $38 b$ & Acepta \\
\hline \multirow[t]{3}{*}{ M I } & $\mathrm{H} 2$ & $\begin{array}{l}\text { La orientación emprendedora tiene un efecto } \\
\text { positivo en la innovación, es decir, cuanto } \\
\text { mayor es la orientación emprendedora, mayor } \\
\text { es la innovación empresarial. }\end{array}$ & $38 a$ y $38 b$ & Acepta \\
\hline & $\mathrm{H} 2 \mathrm{a}$ & $\begin{array}{l}\text { La orientación emprendedora está relacionada } \\
\text { positivamente con la innovación incremental. }\end{array}$ & $38 \mathrm{a}$ & Acepta \\
\hline & $\mathrm{H} 2 \mathrm{~b}$ & $\begin{array}{l}\text { La orientación emprendedora está relaciona-da } \\
\text { positivamente con la innovación radical. }\end{array}$ & $38 b$ & Acepta \\
\hline \multirow[t]{3}{*}{ M I y M II } & H3 & $\begin{array}{l}\text { El tamaño de la empresa tiene un efecto } \\
\text { positivo en la innovación empresarial, es } \\
\text { decir, cuanto mayor es el tamaño, mayor es la } \\
\text { innovación empresarial. }\end{array}$ & 40 & Acepta parcialmente \\
\hline & $\mathrm{H} 3 \mathrm{a}$ & $\begin{array}{l}\text { El tamaño está relacionado positivamente con la } \\
\text { innovación incremental. }\end{array}$ & 40 & Acepta parcialmente \\
\hline & $\mathrm{H} 3 \mathrm{~b}$ & $\begin{array}{l}\text { El tamaño está relacionado positivamente con la } \\
\text { innovación radical. }\end{array}$ & 40 & Acepta \\
\hline \multirow[t]{3}{*}{ M I y M II } & $\mathrm{H} 4$ & $\begin{array}{l}\text { El tamaño de la empresa tiene un efecto } \\
\text { positivo en la cultura organizativa. }\end{array}$ & 40 & Acepta \\
\hline & $\mathrm{H} 4 \mathrm{a}$ & $\begin{array}{l}\text { El tamaño está relacionado positivamente con la } \\
\text { orientación al mercado. }\end{array}$ & 40 & Acepta \\
\hline & $\mathrm{H} 4 \mathrm{~b}$ & $\begin{array}{l}\text { El tamaño está relacionado positivamente con la } \\
\text { orientación emprendedora. }\end{array}$ & 40 & Acepta \\
\hline
\end{tabular}




\begin{tabular}{|c|c|c|c|c|}
\hline \multirow[t]{5}{*}{ M I } & H5 & $\begin{array}{l}\text { El tamaño modera la relación entre la cultura } \\
\text { organizativa y la innovación empresarial, de } \\
\text { manera que, cuanto más grande es una } \\
\text { empresa, mayor es la contribución de la } \\
\text { cultura organizativa a la innovación } \\
\text { empresarial. }\end{array}$ & $\begin{array}{r}41 a-b y \\
41 c\end{array}$ & Acepta parcialmente \\
\hline & $\mathrm{H} 5 \mathrm{a}$ & $\begin{array}{l}\text { El tamaño modera la relación entre la orientación } \\
\text { al mercado y la innovación incremental. }\end{array}$ & $41 a-b$ & Rechaza \\
\hline & $\mathrm{H} 5 \mathrm{~b}$ & $\begin{array}{l}\text { El tamaño modera la relación entre la orientación } \\
\text { al mercado y la innovación radical. }\end{array}$ & $41 \mathrm{c}$ & Acepta parcialmente \\
\hline & $\mathrm{H} 5 \mathrm{c}$ & $\begin{array}{l}\text { El tamaño modera la relación entre la orientación } \\
\text { emprendedora y la innovación incremental. }\end{array}$ & $41 a-b$ & Acepta parcialmente \\
\hline & H5d & $\begin{array}{l}\text { El tamaño modera la relación entre la orientación } \\
\text { emprendedora y la innovación radical. }\end{array}$ & $41 \mathrm{c}$ & Acepta parcialmente \\
\hline \multirow[t]{5}{*}{ M II } & $\mathrm{H} 6$ & $\begin{array}{l}\text { La innovación incremental tiene un efecto } \\
\text { positivo en el desempeño empresarial, es } \\
\text { decir, cuanto mayor es la innovación } \\
\text { incremental, mayor es el éxito empresarial. }\end{array}$ & 42 & Acepta \\
\hline & $\mathrm{H} 6 \mathrm{a}$ & $\begin{array}{l}\text { La innovación de organización está relacionada } \\
\text { positivamente con el desempeño empresarial. }\end{array}$ & 42 & Acepta \\
\hline & $\mathrm{H} 6 \mathrm{~b}$ & $\begin{array}{l}\text { La innovación de marketing está relacionada } \\
\text { positivamente con el desempeño empresarial. }\end{array}$ & 42 & Acepta \\
\hline & $\mathrm{H} 6 \mathrm{c}$ & $\begin{array}{l}\text { La innovación de producto está relacionada } \\
\text { positivamente con el desempeño empresarial. }\end{array}$ & 42 & Acepta \\
\hline & H6d & $\begin{array}{l}\text { La innovación de procesos está relacionada } \\
\text { positivamente con el desempeño empresarial. }\end{array}$ & 42 & Acepta \\
\hline \multirow[t]{4}{*}{ M II } & $\mathrm{H} 7$ & $\begin{array}{l}\text { La innovación radical tiene un efecto positivo } \\
\text { en el desempeño empresarial, es decir, cuanto } \\
\text { mayor es la innovación radical, mayor es el } \\
\text { éxito empresarial. }\end{array}$ & 43 & Acepta \\
\hline & $\mathrm{H} 7 \mathrm{a}$ & $\begin{array}{l}\text { Las patentes de la empresa están relacionadas } \\
\text { positivamente con el desempeño empresarial. }\end{array}$ & 43 & Acepta \\
\hline & $\mathrm{H} 7 \mathrm{~b}$ & $\begin{array}{l}\text { Las actividades de I+D están relacionadas } \\
\text { positivamente con el desempeño empresarial. }\end{array}$ & 43 & Acepta \\
\hline & $\mathrm{H} 7 \mathrm{c}$ & $\begin{array}{l}\text { El desarrollo de nuevos productos y mercados } \\
\text { está relacionado positivamente con el desempeño } \\
\text { empresarial. }\end{array}$ & 43 & Acepta \\
\hline M II & H8 & $\begin{array}{l}\text { La orientación al mercado tiene un efecto } \\
\text { positivo en el desempeño empresarial, es } \\
\text { decir, cuanto mayor es la orientación al } \\
\text { mercado, mayor es el éxito empresarial. }\end{array}$ & 42 & Acepta \\
\hline
\end{tabular}




\begin{tabular}{|c|c|c|c|c|}
\hline \multirow[t]{3}{*}{ M II } & H9 & $\begin{array}{l}\text { La orientación al mercado modera la relación } \\
\text { entre la innovación y el desempeño } \\
\text { empresarial, de manera que, cuanto más } \\
\text { orientada al mercado es una empresa, mayor } \\
\text { es la contribución de la innovación al } \\
\text { desempeño empresarial. }\end{array}$ & $44 a$ y44b & Acepta parcialmente \\
\hline & $\mathrm{H9a}$ & $\begin{array}{l}\text { La orientación al mercado modera la relación } \\
\text { entre la innovación incremental y el desempeño } \\
\text { empresarial. }\end{array}$ & $44 a$ & Acepta \\
\hline & $\mathrm{H} 9 \mathrm{~b}$ & $\begin{array}{l}\text { La orientación al mercado modera la relación } \\
\text { entre la innovación radical y el desempeño } \\
\text { empresarial. }\end{array}$ & $44 b$ & Acepta parcialmente \\
\hline M II & H10 & $\begin{array}{l}\text { El tamaño de la empresa tiene un efecto } \\
\text { positivo en el desempeño empresarial, es } \\
\text { decir, cuanto mayor es el tamaño, mayor es el } \\
\text { éxito empresarial. }\end{array}$ & 42 & Acepta \\
\hline \multirow[t]{3}{*}{ M II } & H11 & $\begin{array}{l}\text { El tamaño modera la relación entre la } \\
\text { innovación y el desempeño empresarial, de } \\
\text { manera que, cuanto más grande es una } \\
\text { empresa, mayor es la contribución de la } \\
\text { innovación al éxito empresarial. }\end{array}$ & $44 a$ y $44 b$ & Acepta parcialmente \\
\hline & $\mathrm{H} 11 \mathrm{a}$ & $\begin{array}{l}\text { El tamaño modera la relación entre la innovación } \\
\text { incremental y el desempeño empresarial. }\end{array}$ & $44 a$ & Acepta parcialmente \\
\hline & $\mathrm{H} 11 \mathrm{~b}$ & $\begin{array}{l}\text { El tamaño modera la relación entre la innovación } \\
\text { radical y el desempeño empresarial. }\end{array}$ & $44 b$ & Acepta parcialmente \\
\hline \multirow[t]{5}{*}{ M I y M II } & H12 & $\begin{array}{l}\text { El dinamismo del entorno tiene un efecto } \\
\text { positivo en la innovación empresarial, es } \\
\text { decir, cuanto mayor es el dinamismo del } \\
\text { entorno, mayor es la innovación empresarial. }\end{array}$ & $38 a$ y $38 b$ & Acepta parcialmente \\
\hline & $\mathrm{H} 12 \mathrm{a}$ & $\begin{array}{l}\text { La turbulencia del entorno está relacionada } \\
\text { positivamente con la innovación incremental. }\end{array}$ & $38 \mathrm{a}$ & Acepta \\
\hline & $\mathrm{H} 12 \mathrm{~b}$ & $\begin{array}{l}\text { La turbulencia del entorno está relacionada } \\
\text { positivamente con la innovación y radical. }\end{array}$ & $38 b$ & Acepta \\
\hline & $\mathrm{H} 12 \mathrm{C}$ & $\begin{array}{l}\text { La intensidad competitiva está relacionada } \\
\text { positivamente con la innovación incremental. }\end{array}$ & $38 a$ & Acepta parcialmente \\
\hline & $\mathrm{H} 12 \mathrm{~d}$ & $\begin{array}{l}\text { La intensidad competitiva está relacionada } \\
\text { positivamente con la innovación radical. }\end{array}$ & $38 b$ & Acepta parcialmente \\
\hline M II & H13 & $\begin{array}{l}\text { La turbulencia del entorno tiene un efecto } \\
\text { positivo en el desempeño empresarial, es } \\
\text { decir, cuanto mayor es la turbulencia del } \\
\text { entorno, mayor es el éxito empresarial. }\end{array}$ & 42 & Acepta \\
\hline M II & H14 & $\begin{array}{l}\text { La turbulencia del entorno modera la relación } \\
\text { entre la innovación y el desempeño } \\
\text { empresarial, de manera que, cuanto más } \\
\text { turbulento es el entorno, mayor es la } \\
\text { contribución de la innovación al éxito } \\
\text { empresarial. }\end{array}$ & $44 a$ y $44 b$ & Acepta parcialmente \\
\hline
\end{tabular}




\begin{tabular}{|c|c|c|c|c|}
\hline & $\mathrm{H} 14 \mathrm{a}$ & $\begin{array}{l}\text { La turbulencia del entorno modera la relación } \\
\text { entre la innovación incremental y el desempeño } \\
\text { empresarial. }\end{array}$ & $44 a$ & Acepta parcialmente \\
\hline & $\mathrm{H} 14 \mathrm{~b}$ & $\begin{array}{l}\text { La turbulencia del entorno modera la relación } \\
\text { entre la innovación radical y el desempeño } \\
\text { empresarial. }\end{array}$ & $44 b$ & Acepta parcialmente \\
\hline M II & H15 & $\begin{array}{l}\text { La intensidad competitiva tiene un efecto } \\
\text { positivo en el desempeño empresarial, es } \\
\text { decir, cuanto mayor es la intensidad } \\
\text { competitiva, mayor es el éxito empresarial. }\end{array}$ & 42 & Acepta parcialmente \\
\hline \multirow[t]{3}{*}{ M II } & H16 & $\begin{array}{l}\text { La intensidad competitiva modera la relación } \\
\text { entre la innovación y el desempeño } \\
\text { empresarial, de manera que, cuanto más } \\
\text { intensa sea la competencia, mayor es la } \\
\text { contribución de la innovación al éxito } \\
\text { empresarial. }\end{array}$ & $44 a$ y $44 b$ & Acepta parcialmente \\
\hline & $\mathrm{H} 16 \mathrm{a}$ & $\begin{array}{l}\text { La intensidad competitiva modera la relación entre } \\
\text { la innovación incremental y el desempeño } \\
\text { empresarial. }\end{array}$ & $44 a$ & Acepta parcialmente \\
\hline & $\mathrm{H} 16 \mathrm{~b}$ & $\begin{array}{l}\text { La intensidad competitiva modera la relación entre } \\
\text { la innovación radical y el desempeño empresarial. }\end{array}$ & $44 b$ & Acepta parcialmente \\
\hline \multirow[t]{5}{*}{ M III } & H17 & $\begin{array}{l}\text { La colaboración organizacional tiene un efecto } \\
\text { positivo en la innovación empresarial, es } \\
\text { decir, cuanto mayor es la colaboración } \\
\text { organizacional, mayor es la innovación } \\
\text { empresarial. }\end{array}$ & 45 & Acepta parcialmente \\
\hline & $\mathrm{H} 17 \mathrm{a}$ & $\begin{array}{l}\text { La colaboración del canal está relacionada } \\
\text { positivamente con la innovación incremental. }\end{array}$ & 45 & Acepta parcialmente \\
\hline & $\mathrm{H} 17 \mathrm{~b}$ & $\begin{array}{l}\text { La colaboración de asesoría está relacionada } \\
\text { positivamente con la innovación incremental. }\end{array}$ & 45 & Acepta parcialmente \\
\hline & $\mathrm{H} 17 \mathrm{c}$ & $\begin{array}{l}\text { La colaboración canal está relacionada } \\
\text { positivamente con la innovación radical. }\end{array}$ & 45 & Acepta parcialmente \\
\hline & $\mathrm{H} 17 \mathrm{~d}$ & $\begin{array}{l}\text { La colaboración asesoría está relacionada } \\
\text { positivamente con la innovación radical. }\end{array}$ & 45 & Acepta parcialmente \\
\hline \multirow[t]{3}{*}{ M III } & H18 & $\begin{array}{l}\text { La colaboración organizacional tiene un efecto } \\
\text { positivo en el desempeño empresarial, es } \\
\text { decir, cuanto mayor es la colaboración } \\
\text { organizacional, mayor es el éxito empresarial. }\end{array}$ & 46 & Acepta parcialmente \\
\hline & $\mathrm{H} 18 \mathrm{a}$ & $\begin{array}{l}\text { La colaboración del canal tiene un efecto positivo } \\
\text { en el desempeño empresarial. }\end{array}$ & 46 & Acepta parcialmente \\
\hline & $\mathrm{H} 18 \mathrm{~b}$ & $\begin{array}{l}\text { La colaboración de asesoría tiene un efecto } \\
\text { positivo en el desempeño empresarial. }\end{array}$ & 46 & Acepta parcialmente \\
\hline M III & H19 & $\begin{array}{l}\text { La colaboración organizacional modera la } \\
\text { relación entre innovación y desempeño } \\
\text { empresarial, de manera que, cuanto mayor es } \\
\text { la colaboración, mayor es la contribución de la } \\
\text { innovación al éxito empresarial. }\end{array}$ & $\begin{array}{r}49 a, 49 b \\
50 a, 50 b\end{array}$ & Acepta parcialmente \\
\hline
\end{tabular}




\begin{tabular}{|c|c|c|c|c|}
\hline & $\mathrm{H} 19 \mathrm{a}$ & $\begin{array}{l}\text { La colaboración del canal modera positivamente } \\
\text { la relación entre innovación incremental y el } \\
\text { desempeño empresarial. }\end{array}$ & $49 a, 49 b$ & Acepta parcialmente \\
\hline & $\mathrm{H} 19 \mathrm{~b}$ & $\begin{array}{l}\text { La colaboración del canal modera positivamente } \\
\text { la relación entre la innovación radical y el } \\
\text { desempeño empresarial. }\end{array}$ & $49 a, 49 b$ & Acepta parcialmente \\
\hline & $\mathrm{H} 19 \mathrm{c}$ & $\begin{array}{l}\text { La colaboración de asesoría modera } \\
\text { positivamente la relación entre la innovación } \\
\text { incremental y el desempeño empresarial. }\end{array}$ & $50 \mathrm{a}, 50 \mathrm{~b}$ & Acepta parcialmente \\
\hline & H19d & $\begin{array}{l}\text { La colaboración de asesoría modera } \\
\text { positivamente la relación entre la innovación } \\
\text { radical y el desempeño empresarial. }\end{array}$ & $50 \mathrm{a}, 50 \mathrm{~b}$ & Acepta parcialmente \\
\hline M III & $\mathrm{H} 2 \mathrm{O}$ & $\begin{array}{l}\text { La influencia de la colaboración } \\
\text { organizacional en el éxito innovador difiere } \\
\text { según el tamaño de la empresa. }\end{array}$ & $\begin{array}{r}49 a, 49 b \\
50 a, 50 b\end{array}$ & Acepta parcialmente \\
\hline & $\mathrm{H} 2 \mathrm{Oa}$ & $\begin{array}{l}\text { Las pequeñas empresas aprovechan mejor que } \\
\text { las grandes empresas la sinergia entre } \\
\text { colaboración del canal e innovación incremental } \\
\text { para alcanzar el éxito empresarial. }\end{array}$ & $49 a, 49 b$ & Acepta parcialmente \\
\hline & $\mathrm{H} 2 \mathrm{Ob}$ & $\begin{array}{l}\text { Las pequeñas empresas aprovechan mejor que } \\
\text { las grandes empresas la sinergia entre } \\
\text { colaboración del canal e innovación radical para } \\
\text { alcanzar el éxito empresarial. }\end{array}$ & $49 a, 49 b$ & Acepta parcialmente \\
\hline & $\mathrm{H} 20 \mathrm{C}$ & $\begin{array}{l}\text { Las grandes empresas aprovechan mejor que las } \\
\text { pequeñas empresas la sinergia entre colaboración } \\
\text { de asesoría y la innovación incremental para } \\
\text { alcanzar el éxito empresarial. }\end{array}$ & $50 \mathrm{a}, 50 \mathrm{~b}$ & Acepta parcialmente \\
\hline & $\mathrm{H} 20 \mathrm{~d}$ & $\begin{array}{l}\text { Las grandes empresas aprovechan mejor que las } \\
\text { pequeñas empresas la sinergia entre colaboración } \\
\text { de asesoría y la innovación radical para alcanzar } \\
\text { el éxito empresarial. }\end{array}$ & $50 a, 50 b$ & Acepta parcialmente \\
\hline
\end{tabular}



Quinto capítulo

Conclusiones 



\section{Conclusiones}

\subsection{Emprendedorismo y orientación al mercado como precursoras de la innovación: papel del tamaño empresarial (modelo explicativo I)}

Los resultados de este primer modelo explicativo aportan evidencia empírica acerca de distintas relaciones que conciernen a la cultura organizativa, a la innovación y al tamaño empresarial. Después de haber mostrado los resultados estadísticos en la sección anterior, se prosigue a exponer sobre las conclusiones más sobresalientes en el estudio y análisis del primer modelo explicativo.

Tanto la adopción de la orientación al mercado como de la orientación emprendedora como parte de la cultura organizativa proveen a las empresas capacidades para conocer las implicaciones e implementaciones que determinan la forma de promover acciones innovadoras. Por tanto, las empresas deben realizar un esfuerzo importante, indistintamente de su tamaño, para promover la cultura organizativa dentro de sus distintas funciones departamentales.

Los resultados obtenidos demuestran que una mejora en la cultura organizativa por parte de las empresas es un claro desencadenante de las acciones de innovación incremental y radical, y es probable que sea una premisa para la mejora de la actitud innovadora. Así es que cultura organizativa es determinante para que las pequeñas y grandes empresas promuevan y emprendan proyectos de innovación.

Las empresas más orientadas al mercado que utilizan la orientación al consumidor y la generación de inteligencia, están más atentas a los cambios del entorno y de las respuestas de sus clientes, lo que las hace más competitivas a la hora de responder a las amenazas del mercado y entender y adaptarse a los gustos y preferencias de sus clientes. Los resultados afirman que es el constructo que más influye en la disposición para poner en marcha las acciones de innovación incrementales, y puede que en primera instancia esta cultura incentiva más las acciones de innovación de marketing. De la misma manera, la orientación al mercado determi- 
na las acciones de innovación radical. Al parecer, esta cultura organizativa incentiva con mayor fuerza el desarrollo de nuevos productos y mercados, y estimula las actividades de I+D.

Por otro lado, la orientación emprendedora es el constructo que más influye en las acciones de innovación de producto y procesos. De la misma manera, las empresas procuran ser cada vez más emprendedoras, actuar proactiva y arriesgadamente a la hora de competir en el mercado con nuevas acciones de innovación incremental de organización, marketing, producto y procesos. Sin embargo los resultados que contrastaron la relación entre orientación emprendedora y las acciones innovadoras radicales, indican que la orientación emprendedora es el constructo que más influye en la disposición para poner en marcha acciones de innovación radicales.

Los resultados que contrastaron la relación entre orientación al mercado, orientación emprendedora y las acciones innovadoras, indican que todos los tipos de acciones de innovaciones progresivas y radicales quedan claramente identificadas por la influencia de los dos constructos de la cultura organizativa para las empresas de la muestra. Aunque la orientación al mercado es el constructo que más influye en la disposición para poner en marcha acciones de innovación progresiva, especialmente para las innovaciones incrementales de organización y marketing; y la orientación emprendedora para las acciones de producto y procesos. En el caso de la innovación radical, ambas orientaciones culturales potencian más el desarrollo de nuevos productos y mercados que las actividades de I+D o las patentes.

A modo de resumen para la primera cuestión de este modelo explicativo, se puede decir que la orientación al mercado y la orientación emprendedora pueden desencadenar en los perfiles de las acciones innovadoras (incremental y radical) y explicar la mayor parte de lo que ocurre con cada una de ellas, esto quiere decir, que tanto orientación al mercado como orientación emprendedora, influye en el impulso del comportamiento innovador de la empresa. De modo que cuanto mayores son los esfuerzos de una empresa por ser más orientada al mercado y más emprendedora, mayores son los resultados de la implantación de la acciones de innovación incremental y radical.

El entorno dinámico representa un dato de primer orden a la hora de que las empresas se sientan motivadas para poner en marcha acciones de innovaciones incrementales y/o 
radicales que persigan resultados exitosos. En consecuencia, las empresas que operan en sectores dinámicos o más turbulentos son los que mayor inclinación tendrán a poner en marcha acciones de innovadoras. Ahora bien, cuando los factores del entorno determinan si las empresas más orientadas al mercado o más emprendedoras son las que realizan mayores innovaciones, parece que la turbulencia del entorno es más fuerte para controlar los resultados innovadores que la intensidad competitiva. Cabe destacar que en medio de entornos con una alta intensidad competitiva no estimulan las actividades de I+D pero si la empresa está orientada al mercado y al emprendedorismo, es posible sacar adelante este tipo de innovaciones, a pesar de la hostilidad del entorno.

Respecto a la relación del tamaño con la innovación resulta que en situaciones con turbulencia las grandes empresas son más innovadoras (para cualquier tipo de acción innovadora) y en entornos de intensidad competitiva las acciones de innovación de organización son las más influenciadas. Las pequeñas empresas deben de utilizar sus ventajas competitivas respecto a las grandes empresas para potenciar sus acciones de innovación en marketing y actividades I+D cuando se encuentran en sectores de alta turbulencia y una intensidad competitiva moderada. Para potenciar esta dinámica, las políticas de apoyo a las pequeñas empresas pueden promover acciones en conjunto con otras empresas para aprovechar el dinamismo del entorno y potenciar las acciones emprendedoras.

Por otra parte, los resultados también son relevantes al mostrar una significativa relación entre el tamaño y la cultura organizativa con el dinamismo del entorno como controladores de la relación. Se llega a la conclusión que las empresas más grandes son las que mayor orientación al mercado y al emprendedorismo manifiestan, aún en medios turbulentos.

Anteriormente se planteaba si él tamaño condicionaba la cultura organizativa y la innovación incremental y radical, y si el tamaño podía ser la causa de la relación. Se concluye que la relación entre la cultura organizativa y la innovación (incremental y radical) persiste aunque se introduzca la variable tamaño, por lo tanto, el tamaño no explica necesariamente la relación. Por lo tanto, tanto las grandes y las pequeñas empresas pueden beneficiarse de los beneficios que aportan las orientaciones al mercado y la emprendedora para alcanzar la innovación incremental y radical. 
Por último, el efecto moderador del tamaño en la relación cultura organizativainnovación no se había estudiado ampliamente ni se han obtenido resultados concluyentes, por lo tanto, se aporta a la literatura una evidencia adicional respecto a la moderación del tamaño en otros escenarios. Los resultados mostraron que no existen efectos moderadores puros en la regresión. Solamente respecto a las acciones de innovación de organización y en marketing, el tamaño juega un rol cuasi-moderador. De manera que, las grandes empresas aprovechan mejor la innovación de organización, de marketing, de registro de patentes y actividades I+D, cuando están más orientadas al mercado, sin embargo, solamente se benefician mayormente de las ventajas de la orientación emprendedora cuando desarrollan nuevos productos y mercados.

A manera de conclusión final, la empresas que se ven envueltas en un ambiente económico turbulento y globalizador deben considerar la implantación de la innovación como un elemento obligatorio para aumentar la competitividad y ventajas largo-placistas, por lo tanto, la innovación empresarial debe estar incorporada dentro del diseño de la estrategia corporativa, atendiendo dispositivos que la faciliten y enfaticen una cultura organizativa adecuada, el desarrollo oportuno de habilidades, eficientes políticas de recursos humanos, una fuerte motivación y el desarrollo market-intelligence.

\subsubsection{Implicaciones en la práctica empresarial}

La mejora en la orientación al mercado y la orientación emprendedora por parte de las empresas es un claro desencadenante de las acciones de innovación incremental y radical, y es probablemente una premisa para la mejora de la actitud innovadora. La difusión de mejores prácticas, la formación directiva y un enfoque del negocio que no olvide estas capacidades organizativas, debe formar parte de la agenda de las propias empresas y organismos vinculados al desarrollo del tejido productivo. Más allá del conocimiento técnico que se precisa para la puesta en marcha de acciones de innovación.

La orientación al mercado pueden en primera instancia incentivar más las acciones de innovación de marketing, y la orientación emprendedora para explicar las acciones de innovación de producto y proceso; y las radicales. La puesta en marcha de acciones de innovación en cualquiera de estas direcciones parece verse acompañada por acciones del 
resto, por lo que el enfoque de la innovación en las empresas debe ser global ya que implica cambios en la organización en su conjunto.

\subsection{Factores organizacionales y del entorno como moderadores de la relación entre innovación multidimensional y desempeño empresarial (modelo explicativo II)}

Este segundo modelo explicativo ha pretendido aportar evidencia sobre la relación entre la innovación, el desempeño empresarial y los efectos moderadores de los factores organizacionales y del entorno. La necesidad de este estudio fue aportar pruebas que faciliten el diseño y la implantación de la estrategia innovadora así como su contribución al desempeño. Además, de identificar las principales prácticas que mejor se adecuan al entorno para enfocar con más acierto las estrategias de gestión, el apoyo regional y los fondos destinados a las mismas.

Como otros estudios han demostrado, y en nuestro caso también, los resultados obtenidos permiten concluir que existe una fuerte relación entre la innovación y el desempeño empresarial. Los resultados de las funciones de regresión explican diferencias en la forma en la que las acciones específicas de innovación incremental y radical afectan las cuatro variables de desempeño utilizadas en esta investigación. Las medidas son positivas tanto para las medidas de eficacia, eficiencia y adaptabilidad. En primera instancia, podemos concluir que las empresas de este estudio priorizan las actuaciones de innovación de marketing y organización, por su mayor capacidad explicativa, para mejorar los resultados financieros en el corto plazo y viabilidad futura a través de los resultados operativos.

Por parte de la innovación de organización se ven perjudicadas por los resultados relacionados al mercado y repercute en la eficiencia, conduciendo a un ahorro en costes. Todo parece indicar que los costes implicados en las acciones de innovación de marketing afectan la utilidad, los márgenes de venta y posicionamiento en el mercado, y afectan directamente el éxito de nuevos productos. En cambio las acciones de innovación de producto poseen un mayor énfasis en los resultados operativos a mediano y largo plazo. Cabe resaltar que las acciones de innovación de procesos no afectan significativamente a estos resultados una vez considerado el efecto de las otras acciones innovadoras. Debemos recordar que las 
innovaciones en procesos mantienen una correlación relevante con las acciones de innovación de producto.

Por parte de las acciones de la innovación radical se dilucida otro comportamiento. La medida que mejor explica las cuatro variables de desempeño es el desarrollo de nuevos productos y mercados, al parecer, es una de las acciones que las empresas deben esforzarse en recurrir puesto que aseguran beneficios y éxito empresarial en cualquier dimensión financiera u operativa. Estimular las actividad de I+D trae consigo mejores resultados financieros y de adaptabilidad en el mercado. Sin embargo, las empresas deben tomar en cuenta que la innovación basada en el registro de patentes afecta directamente los márgenes de utilidad financiera.

Se observa que los factores organizacionales y del entorno robustecen la relación entre la innovación incremental y radical y el desempeño empresarial. Respecto al tamaño como efecto directo, se concluye que cuando las empresas grandes alcanzan mejores resultados financieros y operativos que las pequeñas empresa. Por otro lado, consecuentemente y en línea con gran parte de los resultados empíricos publicados al respecto, la orientación al mercado potencia el desempeño empresarial. Cuando la orientación al mercado controla la relación promueven más tipos de innovación que dan margen de maniobra a las empresas. Por último, con la presencia de un entorno dinámico y altamente competitivo, las empresas incrementan su eficacia y viabilidad operativa a mediano y largo plazo.

La inclusión de efectos moderadores afectan los resultados modificando la importancia de las acciones innovadoras a la hora de explicar los resultados. Existen efectos moderadores significativos de los factores organizacionales. Cuanto más grande es la empresa mayor es el aporte de las innovaciones de organización y marketing en la eficiencia, eficacia y adaptabilidad empresarial. Sin embargo, cuanta más pequeña es la empresa mayores son los resultados operativos cuando innovan en producto y procesos. Respecto a la innovación radical las grandes empresas, aprovechan mejor de sus capacidades y recursos para registrar las innovaciones como patentes y además continuar en el desarrollo de nuevos productos y mercados. 
Del mismo modo, la orientación al mercado modera la relación. Las acciones de innovación de marketing y patentes desencadenan un aumento del desempeño financiero y operativo en las empresas más orientadas al mercado, sin embargo, son más eficaces cuando innovan en organización, y más adaptables al entorno cuando innovan en producto y procesos, y desarrollo de nuevos productos y mercados. La orientación al mercado es el único efecto moderador que potencia positivamente los resultados de los cuatro tipos de innovación incremental y dos tipos de radical. Esto parece estar asociado a que la clave de la orientación al mercado es la orientación al consumidor, por tanto, cuando las preferencias de los consumidores son inestables, la orientación al mercado facilita su seguimiento y el consecuente ajuste de la oferta y esfuerzos comerciales con el fin de alcanzar la satisfacción de los consumidores y obtener un mayor rendimiento. La innovación es más fructífera, cuando se incorpora la orientación al mercado dentro de la cultura organizativa de las empresas.

Respecto a los factores moderadores del entorno se encuentran evidencias a favor de que cuando se innova en entornos turbulentos, el desempeño operativo y financiero es más provechoso. Se concluye que en medio de turbulencia del entorno las empresas deben orientar sus iniciativas innovadoras de marketing para mejorar la eficiencia y eficacia; en innovaciones de producto y procesos para mejorar la adaptabilidad en el entorno; y en registro de patentes para potenciar los resultados operativos. Se deben evitar, en momentos de entornos hostiles y de alta incertidumbre, innovaciones de organización para no sufrir sus implicaciones negativas.

Por otro lado, los resultados corroboran las influencias positivas y negativas de la intensidad competitiva en la relación. Cuanta más alta es la intensidad competitiva, mayores serán los resultados empresariales cuando se opta por iniciativas innovadoras de marketing, producto y registro de patentes. Entonces, una mayor intensidad competitiva conlleva a un mayor esfuerzo por ser más agresivos con la competencia y anticiparse a sus acciones comerciales. Para ello es necesario emprender cambios significativos en marketing y aspectos relacionados al producto.

En cambio cuando la intensidad competitiva es alta, cualquier innovación de procesos y organización va en detrimento de la mejora de los resultados empresariales. Los efectos moderadores negativos de la intensidad competitiva en las innovaciones de organización y 
procesos podrían deberse a que cuando la intensidad competitiva es alta, la implantación de cambios en las estructuras organizativas y procesos productivos pueden conllevar demasiado esfuerzo y recursos por parte de la empresa. Lo que conlleva a una perdida de eficiencia financiera y eficacia operativa. Además, se corre el riesgo de hacerlo de manera errónea y distraer la atención de otras innovaciones más apropiadas en medio de este tipo de entornos hostiles.

Por tanto, el entorno percibido por la empresa, su dinámica o su turbulencia, afectan de manera significativa a los resultados empresariales bien de manera directa o bien a través de su incidencia en los resultados de las acciones de innovación que se pone en práctica. De hecho, la mayor turbulencia parece que es un factor desencadenante de las acciones de marketing que explican la rentabilidad, el crecimiento de las ventas y, en parte, de las acciones de marketing que acompañan el éxito lanzamiento de nuevos productos al mercado. En consecuencia, son los entornos dinámicos los que más favorecen las innovaciones en marketing.

No cabe duda que tanto la intensidad competitiva como la turbulencia del entorno inciden en la eficacia de las acciones de innovación y en la presencia de la orientación al mercado y orientación emprendedora; de forma que cuanto mayor sea una u otra, mayor será el valor que alcancen estas otras variables. Pero, mientras que la turbulencia del entorno provoca diferencias en los niveles de resultados y modifica la relación de estos con las acciones innovadoras, la intensidad competitiva tiende a ser más negativa. Cabe interpretar este resultado como una presencia menos cercana y amenazadora de los competidores tanto en la percepción de los clientes como en la de las propias empresas.

A manera de resumen, las empresas que incorporan innovaciones de organización sin evaluar los cambios en los procesos y no prevén las estrategias y actuaciones de sus competidores respecto a su negocio principal, dejan de ser eficientes, eficaces y adaptables a los cambios del entorno. No obstante, las empresas que valoran los cambios en la demanda de los consumidores, incorporan nuevos productos en el mercado, y registran patentes, tendrán más éxito a la hora de innovar. 


\subsubsection{Implicaciones en la práctica empresarial}

La contribución empírica de este modelo conlleva a importantes implicaciones empresariales. En primer lugar, se insta a las empresas a buscar activamente ideas innovadoras en marketing. Este tipo de adopción e implementación asegura resultados financieros y operativos tanto para las grandes empresas como a las pequeñas empresas. Además, son las únicas acciones de innovación que no se ven entorpecidas por factores organizacionales ni del entorno. Las pequeñas empresas deben considerar esta importante estrategia cuando operan en ambientes dinámicos y competitivos, normalmente dominados por las grandes empresas.

En segundo lugar, los resultados conducen a pensar que las consecuencias de implantar iniciativas innovadoras incrementales y radicales acarrean beneficios de la actividad comercial en consecución de los recursos empleados y la capacidad de responder a los cambios y oportunidades del entorno. Posiblemente porque la innovación incremental podría requerir mas habilidades comerciales (producto-marketing) y de organización, que de cambios en procesos productivos y organizativos para alcanzar un mejor desempeño empresarial.

Mientras la innovación radical acarreara mayores ventajas para la empresa al generar actividades de investigación que produzcan nuevos productos patentables. En este caso las pequeñas empresas pueden aprovechar de su potencial puesto que sus habilidades comerciales cuentan a su favor, estas les permiten comprender el entorno y reaccionar adecuadamente aprovechando los aciertos del mercado y anticipándose a sus amenazas. Por otra parte, las empresas grandes, deben aprovechar su gran volumen de recursos financieros y humanos para emprender más actividades de investigación y desarrollo de productos patentables y acompañados de una adecuada estrategia comercial.

En tercer lugar, la orientación al mercado y la orientación emprendedora son capacidades organizativas claves a la hora de explicar las estrategias y la bondad de los resultados obtenidos por las empresas. Cualquier mejora en la orientación al mercado por parte de las empresas dará como resultado excelentes implantaciones de las acciones de innovación y es probablemente una premisa para la mejora de la orientación innovadora. La 
difusión de mejores prácticas, la formación directiva y un enfoque del negocio que no olvide esta capacidad organizativa, debe formar parte de la agenda de las propias empresas y organismos vinculados al desarrollo del tejido productivo.

En cuarto lugar, los factores del entorno favorecen las innovaciones de marketing y producto. Las empresas deben potenciar al máximo esas acciones para contrarrestar las amenazas y aprovechar las oportunidades del entorno. La turbulencia del entorno representa un elemento prioritario a la hora de que las empresas se sientan motivadas para poner en marcha acciones de innovación que persigan obtener resultados en términos de rentabilidad, crecimiento de las ventas o mejorar la probabilidad de éxito en nuevos productos, al igual que influye en la intensidad con la que, en particular las acciones de innovación de marketing, influyen en estos resultados. En consecuencia, las empresas que operen en sectores dinámicos o más turbulentos son los que mayor inclinación tendrán a poner en marcha acciones de innovación. La influencia de intensidad competitiva, aunque no tan acertada como la turbulencia del entorno, también puede ser interpretada como una oportunidad para mejorar el grado de acierto de las acciones de innovación en el futuro en la medida en que estas lleguen a guardar más relación con los competidores directos. Es en estas líneas en los que más se podría centrar el apoyo público a la innovación si se quieren obtener resultados en un plazo breve de tiempo.

Finalmente, se justifican cualesquiera actuaciones de las administraciones públicas y Unión Europea en pro de aportar ayudas para la mejora de la capacidad competitiva y enriquecimiento del tejido productivo para las empresas localizadas en las zonas desfavorecidas y que mantienen un cierto atraso relativo en materia de capacidades organizativas y acciones de innovación.

\subsection{El papel de la colaboración en el éxito de la innovación: diferencias entre grandes y pequeñas empresas (modelo explicativo III)}

Este último modelo explicativo ha tratado de estudiar el papel de la colaboración y el tamaño en el éxito de la innovación radical e incremental. La colaboración se ha tipificado en dos áreas: colaboración del canal y colaboración de asesoría. También, se ha diferenciado el 
tamaño considerando dos submuestras: grandes y pequeñas empresas. La principal conclusión es que cuando se recurre a la colaboración para apoyar la innovación aumentan las probabilidades de éxito empresarial. Además, las empresas pequeñas sacan más ventajas de la colaboración del canal; y las grandes empresas de la colaboración de asesoría.

Este trabajo conlleva a importantes implicaciones empresariales y gubernamentales para potenciar aún más la relación entre innovación y resultados por medio de la colaboración. En primer lugar, los resultados conducen a pensar que las consecuencias de implantar iniciativas innovadoras acarrean beneficios de la actividad comercial y financiera, en consecución de los recursos empleados y la capacidad de responder a los cambios y oportunidades del entorno. Una vez más se constata que los esfuerzos de innovación son una de las claves para estimular el éxito empresarial y, consecuentemente, el bienestar económico.

En segundo lugar, puesto que la colaboración, tanto del canal como de asesoría, contribuye a una innovación más exitosa, el fomento de las redes de colaboración y asesoría debe ser una prioridad para promover la competitividad de las empresas. La innovación parece ser uno de los vehículos canalizadores de la contribución de la colaboración al éxito empresarial. Por tanto, una vía para potenciar el éxito innovador de las empresas es mejorar el aprovechamiento de las redes sociales. Disponer de relaciones de cooperación bajo una estructura abierta de intercambio de conocimiento y flujos de información promueven soluciones en conjunto sobre la reducción de los costes de desarrollo de la innovación (capacidades de fabricación y regulación know-how) y maximizar las oportunidades de comercialización (conocimiento del mercado y el acceso).

En tercer lugar, debe insistirse en el contexto económico-social que se plantea en este estudio, sobre todo para las pequeñas empresas. Los resultados obtenidos son de interés de cara a marcar pautas para la competitividad y viabilidad empresarial en regiones desfavorecidas dentro del entorno competitivo globalizado al que se enfrentan. Por eso las políticas gubernamentales de las regiones menos desarrolladas deben proveer a las pequeñas empresas facilidades de colaboración con entes externos para proveerles de herramientas tecnológicas y de aprendizaje que aceleren el desarrollo innovador y el éxito empresarial. Reforzando estos vínculos, las empresas pequeñas podrán aprovechar más de las redes de colaboración de asesoría y no solo de la colaboración del canal. De esta manera les permitiría 
disfrutar de un aumento de sus beneficios, obtener acceso y disponibilidad de recursos más complejos para la innovación y desarrollar el conocimiento y I+D.

Por otra parte, tal como lo resultados lo han demostrado, las grandes empresas aprovechan más de la colaboración de asesoría para desarrollar innovaciones radicales (patentes, actividades $\mathrm{I}+\mathrm{D}$, desarrollo de nuevos productos y mercados) es preciso que se siga fortaleciendo y facilitando, a nivel institucional, la oportunidad para colaborar con interlocutores y asesores externos, nacionales e internacionales, ya que las grandes empresas tienden a agotar el mercado local de colaboración, lo que limita a estas empresas a un bajo nivel de absorción del conocimiento y de los recursos.

\subsubsection{Implicaciones en la práctica empresarial}

En esta investigación se ha estudiado las relaciones entre la colaboración, la innovación y los resultados empresariales. Tal como se había previsto, los resultados evidencian que al introducir acuerdos de colaboración (tecnológica y no tecnológica) con cualquier tipo de agente externo, sean estos proveedores, clientes, competencia, universidades, etc. aumenta la probabilidad de mejorar los resultados de la innovación y las probabilidades de éxito empresarial tanto en la actividad comercial y financiera, y, por ende su ventaja competitiva. Por tanto, es necesario que las autoridades gubernamentales y regionales den prioridad y favorezcan las redes de colaboración empresariales bajo una estructura abierta para que las empresas aprovechen las ventajas de la cooperación para promover la competitividad de las empresas a través de la reducción de los costes de desarrollo e investigación en conjunto y de maximizar las oportunidades del mercado.

Por otra parte, se ha demostrado que tanto la colaboración del canal como de asesoría tiene un efecto positivo pero en distinto grado, pues la colaboración en el canal es más fructífera que la de asesoría para la pequeñas empresas en el éxito empresarial, estos resultados sugieren que la colaboración con los proveedores, los clientes y la competencia va más allá de ser un "recurso" para mejorar las capacidades empresariales sino que además, implican sobre todo el conjunto de la empresa. Es decir, la relación a largo plazo de las pequeñas empresas con los agentes del canal facilita la asimilación del conocimiento, 
promueve una cultura relacional y sobretodo, incentiva la complementariedad de los recursos, todo esto, genera en las empresas, capacidades significativas para el éxito empresarial, tal como lo proclama la Teoría de Recursos y Capacidades.

Partiendo de las diferencias, que antes citamos, entre la colaboración del canal y de asesoría, se pueden desgranar distintas enseñanzas prácticas. Los resultados de las regresiones sugieren que la colaboración del canal, tiene un efecto positivo en los resultados de innovación, por lo tanto, es una colaboración que aporta capacidades tecnológicas, como se mencionó anteriormente, pero también contribuye a la mejora de la posición competitiva, es decir, respecto a los clientes; los fideliza al responder a sus expectativas; respecto a los proveedores y competencia; llegar a acuerdos de colaboración para realizar inversiones en conjunto que incrementará los inputs. Estas estrategias en conjunto logran una posición competitiva de la empresa y también aumenta la imagen y reputación al asumir compromisos de gran valor, y esto es un recurso valioso, escaso e inimitable para lograr ventajas competitivas y el éxito empresarial.

Centrándose más bien en el segundo tipo de colaboración, por llamarlo de alguna manera, una colaboración de asesoría más institucional, se puede decir, que la colaboración con las universidades y con los centros tecnológicos siempre se había caracterizado por no culminar los procesos de innovación, porque su aporte ha radicado, primordialmente, en proveer a las empresas conocimiento, sea científico o tecnológico. No obstante, los resultados apuntan que la colaboración de asesoría "institucional" tiene un efecto positivo sobre la consecución de innovaciones, por lo que hace pensar que esta tendencia está cambiando puesto que cada vez se hace más patente el apoyo de colaboración innovadora de estas instituciones en el tejido empresarial. Posiblemente, este cambio se deba a las presiones que ejercen las autoridades públicas en la evaluación de políticas de innovación y $\mathrm{I}+\mathrm{D}$, con el fin de que la investigación tenga aplicación práctica e incentive la competitividad empresarial.

\subsection{Limitaciones de la investigación}

Se reconoce que existen diversas limitaciones en este estudio que deben ser tomadas en cuenta en futuras investigaciones. Por un lado, no se diferenció en la muestra los distintos 
sectores en juego. La muestra se pudo centrar en empresas de servicio e industria y lograr descifrar los distintos comportamientos diferenciadores y la forma de entender la estrategia orientada en la innovación según el sector. Con ello, se podría estudiar si las empresas enfocadas a los servicios o las industrias se orientan a un comportamiento diferenciador en los procesos organizativos o a los procesos productivos.

Además, no se tomó en cuenta los años de funcionamiento de la empresa. Esto puede avocar diferencias entre empresas jóvenes y maduras, puesto que su orientación estratégica y comportamiento innovador puede diferir con respecto a la edad de la misma.

Adicionalmente, la metodología empleada para medir los constructos estudiados puede generar relaciones ficticias debido a cierto 'efecto halo'. Puesto que las medidas correspondientes a una empresa se basan en la valoración de un único directivo, el estilo de respuesta puede traducirse en una relación aparente entre todos ellos. Sería importante abordar el fenómeno considerando distintas fuentes de información para medir los distintos constructos. La consideración de una medición más precisa de las distintas variables estudiadas permitiría un análisis más detallado de su relación con el la innovación.

También la medida de la innovación es débil porque aunque se siguió una aproximación multidimensional, cada dimensión se midió utilizando una sola pregunta. Además, la medición de los constructos considerados no ha sido todo lo ambiciosa que se hubiera deseado. Las limitaciones de espacio del cuestionario, debidas a la consideración de otros objetivos complementarios en el mismo estudio, impidieron una medición más precisa.

Por último, otra limitación latente es el tamaño de la muestra. Una muestra pequeña es especialmente vulnerable para lograr resultados óptimos. Cabe destacar, por un lado, el reducido tamaño muestral. Esto reduce la potencia de los contrastes y dificulta la detección de posibles efectos moderadores. El análisis de muestras mayores facilitaría la descripción del fenómeno con mayor precisión. 


\subsection{Futuras líneas de investigación}

Se pretende que este estudio pueda servir para la formulación de futuras investigaciones en esta área. Con un interés particular, como vías pendientes se encuentran:

(1) introducir nuevas variables y constructos al modelo como: el perfil del empresario, entidades que introducen innovación a las empresas, sector, edad y tamaño de la empresa.

(2) extender el modelo propuesto a otros contextos nacionales e internacionales y, también, ampliar la muestra a otras regiones objetivo 1 en España, concretamente Galicia y Andalucía, como zonas desfavorecidas y menos desarrolladas económicamente.

(3) investigar sobre el diseño y apoyo en la consecución de los planes de innovación en las pymes.

(4) estudiar el papel mediador de los resultados innovadores cuando se miden por el número de innovaciones en producto, proceso u organizativas, etc.

(5) tomar elementos claves de la innovación en la telefonía móvil y las redes sociales para el mejoramiento de la colaboración en el canal.

(6) explorar los métodos y sistemas del proceso innovador en la empresa como son la inteligencia competitiva, la prospectiva tecnológica, los estudios de posicionamiento competitivo, la definición de planes de innovación, el establecimiento de planes de $\mathrm{I}+\mathrm{D}$ (en base a equipos mixtos de desarrollo), la explotación de los resultados o la diversificación a partir de la capacitación tecnológica.

7) examinar acerca de la planeación y organización de la innovación relacionada a las actividades de los negocios internacionales. 
(8) indagar sobre la posibilidad de innovar a través de modelos de franquicia como vía de internacionalización en las pymes.

(9) incluir en el estudio otros comportamientos estratégicos no relacionados con la innovación tal como la estrategia de reducción de precios/costes. Por otro lado, vincular los resultados empresariales a partir de medidas de mercado, como el valor añadido de mercado.

(10) definir los modelos y metodologías orientadas a la gestión de la innovación colaborativa en las pymes.

(11) incorporar los motivos de una empresa para elegir un socio, y así analizaar los determinantes y las consecuencias de la colaboración tecnológica y no tecnológica.

(12) expandir la muestra para incluir más años, para crear un panel de datos que permita examinar con más detenimiento los aspectos dinámicos de la relación entre colaboración, la innovación y resultados empresariales.

(13) explotar la utilización de ecuaciones estructurales que aporten más claridad a los resultados. 
Sexto capítulo

Referencias bibliográficas y anexos 



\section{Referencias bibliográficas y anexos}

\subsection{Referencias bibliográficas}

Abernathy WJ and Utterback JM (1978) "Patterns of industrial innovation". Technology Review 80: 40-47.

Acha V, Gann DM and Salter AJ (2005) "Episodic innovation: R\&D strategies for project based environments". Industry and Innovation 12(2): 255-281.

Acs ZJ and Audretsch DB (1988) "Innovation in large and small firms: an empirical analysis". American Economic Review 78(4): 678-691.

Acs ZJ and Audretsch DB (1990) Innovation and small firms. Cambridge MA: The MIT Press.

Acs ZJ and Audretsch DB (1991) Innovation and technological change: an international comparison. R\&D firm size and innovative activity. In Acs ZJ and Audretsch DB (Eds). New York NY: Harvester Wheatsheaf.

Afuah A (1998) Innovation management: strategies implementation and profits. New York NY: Oxford University Press.

Ahuja G (2000) "Collaboration networks structural holes and innovation: a longitudinal study”. Administrative Science Quarterly 45(3): 425-455.

Ahuja G and Katila R (2001) "Technological acquisitions and the innovation performance of acquiring firms: a longitudinal study”. Strategic Management Journal 22(3): 197220.

Aiken LS and West SG (1991) Multiple regression: testing and interpreting interactions. Newbury Park CA: Sage.

Aiken M and Hage J (1971) “The organic organization and innovation”. Sociology 5(1): 6382.

Aldas-Manzano J, Küster I and Vila N (2005) "Market orientation and innovation: an interrelationship analysis". European Journal of Innovation Management 8(4): 437-452.

Almus M and Nerlinger E (1999) "Growth of new technology-based firms: which factors matter?” Small Business Economics 13: 141-154.

Ansoff HI (1965) La estrategia de la empresa. Pamplona: Eunsa.

Appiah-Adu K (1998) "Market orientation and performance: empirical tests in a transition economy". Journal of Strategic Marketing 6: 25-45. 
Appiah-Adu K and Ranchhod A (1998) "Market orientation and performance in the biotechnology industry: an exploratory empirical analysis”. Technology Analysis \& Strategic Management 10(2):197-210.

Appiah-Adu K and Singh S (1998) "Customer orientation and performance: a study of SMEs”. Management Decision 36(6): 385-394.

Aragón A y Sánchez G (2005) "Strategic orientation management characteristics and performance: a study of Spanish SME's". Journal of Small Business Management 43(3): 287-308.

Arbussà A, Bikfalvi A y Valls J (2004) "La I+D en las pymes: intensidad y estrategia". Universia Business Review, primer trimestre: 40-49.

Arceo MG (2010) "El impacto de la gestión del conocimiento y las tecnologías de información en la innovación: un estudio en las pyme del sector agroalimentario de Cataluña”. Edición electronica. [en línea]. www.eumed.net/tesis/2010/gam/. [Consultada: 18 enero de 2012].

Arias-Aranda D, Miguela-Rata B and Rodríguez-Duarte A (2001) "Innovation and firm size: an empirical study for Spanish engineering consulting companies”. European Journal of Innovation Management 4(3): 133-141.

Armstrong H and Taylor J (1985) Regional Economics and Policy, Oxford: Philip Allen Publishers.

Asebio (2010) Boletín de noticias 29. Revisado: 01 mayo de 2012. [en línea]: http://www.araclon.com/wp-content/files_mf/1291025807asebioESTUDIOEUROPEO.pdf. [Consultada: 19 abril de 2012].

Atuahene-Gima K (1995a) "Involving organizational buyers in new product development". Industrial Marketing Management 24: 215-226.

Atuahene-Gima K (1995b) "An exploratory analysis of the impact of market orientation on new product performance”. Journal of Product Innovation Management 12: 275-293.

Atuahene-Gima K (1996) "Market orientation and innovation". Journal of Business Research 35(2): 93-103.

Atuahene-Gima K and Ko A (2001) "An empirical investigation of the effect of market orientation and entrepreneurship orientation alignment on product innovation". Organization Science 12(1): 54-74.

Audretsch D (2002) "The dynamic role of small firms: evidence from the U.S.". Small Business Economics 18: 13-40. 
Avermaete T, Viaene J, Morgan E, et al. (2003) "Determinants of innovation in small food firms". European Journal of Innovation Management 6(1): 8-17.

Avlonitis GJ and Gounaris SP (1997) "Marketing orientation and company performance. industrial vs. consumer goods companies”. Industrial Marketing Management 26: $385-402$.

Avlonitis GJ and Salavou H (2007) "Entrepreneurial orientation of SMEs product innovativeness and performance”. Journal of Business Research 60(5): 566-575.

Baker WE and Sinkula JM (1999a) "The synergistic effect of market orientation and learning orientation on organizational peformance". Journal of the Academy of Marketing Science 27(4): 411-427.

Baker WE and Sinkula JM (1999b) "Learning orientation, market orientation and innovation: integrating and extending models of organizational performance". Journal of Market - Focused Management 4(4): 295-308.

Baker WE and Sinkula JM (2002) "Market orientation, learning orientation and product innovation: delving into the organization's black box". Journal of Market - Focused Management 5(1): 5-23.

Barau J and Osteryoung J (2001) "The determinants of successful micro-ipos: an analysis of issues made under the small corporate offering registration (SCOR) procedure". Journal of Small Business Management 39(3): 209-227.

Barceló M (1994) Innovación tecnológica en la industria: una perspectiva española. Barcelona: Beta.

Barney J (1991) "Firm resources and sustained competitive advantage". Journal of Management 17(1): 99-120.

Barrett H and Weinstein A (1998) "The effect of market orientation and organizational flexibility on corporate entrepreneurship". Entrepreneurship Theory and Practice 23(1): 57-70.

Barth H (2003) "Fit among competitive strategy, administrative mechanisms, and performance: a competitive study of small firms in mature and new industries". Journal of Small Business Management 41(2): 133-147.

Bathelt H (2003) 'In good faith?' The 'distanced neighbor' paradox: 'over-embedded' and 'under-socialized' economic relations in Leipzig's media industry. In: DRUID Summer Conference 2003, Copenhagen, Elsinore, 12-14 June, 2003, pp. 1-35.

Baum JC, Calabrese T and Silverman BS (2000) "Don't go it alone: alliance network composition and start-ups' performance in Canadian biotechnology". Strategic Management Journal 21(3): 267-294. 
Bean A (1995) "Why some R\&D organizations are more productive than others". Research Technology Management 1: 25-30.

Begley TM and Boyd DP (1986) "Executive and corporate correlates of financial performance in smaller firms". Journal of Small Business Management 24(2):8-15.

Belderbos R, Carree M and Lokshin B (2004) "Cooperative R\&D and firm performance". Research Policy 33: 1477-1492.

Bennett RJ and Robson PJ (2005) "The advisor-SME client relationship: impact satisfaction and commitment". Small Business Economics 25(3): 225-271.

Berthon P, Hulbert JM and Pitt L (2004) "Innovation or customer orientation? An empirical investigation”. European Journal of Marketing 38(9/10): 1065-1090.

Beugelsdijk S and Noorderhaven N (2003) "Personality characteristics of self-employed: an empirical study”. Small Business Economics 24: 159-167.

Bhaskaran S (2006) "Incremental innovation and business performance: small and mediumsize food enterprises concentrated industry environment”. Journal of Small Business Management 44(1): 64-80.

Biggadike R (1979) “The risk business of diversification”. Harvard Business Review 57(3): $103-111$.

Birley S and Westead P (1994) "A taxonomy of business star-up reasons and their impact on firm growth and size". Journal Business Venturing 2: 41-51.

Boer H and During WE (2001) "Innovation what innovation? A comparison between product process and organizational innovation". International Journal of Technology Management 22(1-3): 83-107.

Bond EU III, Walker BA, Hutt MD, et al. (2004) "Reputational effectiveness in crossfunctional working relationships". Journal of Product Innovation Management 21(1): $44-60$.

Boschma RA (2004) "The competitiveness of regions from an evolutionary perspective" Regional Studies 38(9): 1001-1014.

Boschma RA (2005) "Proximity and innovation: a critical assessment". Regional Studies 39(1): 61-74.

Boyd BK, Dess GG and Rasheed AM (1993) "Divergence between archival and perceptual measures of the environment: causes and consequences". Academy of Management Review 18(2): 204-226.

Burgelman RA (1991) "Intraorganizational ecology of strategy making and organizational adaptation: theory and field research”. Organization Science 2: 239-62. 
Burt RS (1992) Structural holes: the social structure of competitive. Cambridge Mass: Harvard University Press

Burt RS (2001) Structural holes versus network closure as social capital. In N. Lin, K. Cook and R. S. Burt: Social Capital: Theory and Research. Sociology and Economics: Controversy and Integration series. New York: Aldine de Gruyter, pp. 31-56.

Camison ZC (1997) La Competitividad de las pequeñas empresas Industrial Española: estrategia y Competencias Distintivas. Madrid: Civitas.

Camison ZC (2001) "La investigación sobre la pequeñas empresas y su competitividad. Balance de la cuestión desde las perspectivas narrativa y meta-analítica”. Papeles de Economía Española 65: 224-240.

Capon N, Farley JU and Hoenig S (1990) "Determinants of financial performance: a metaanalysis". Management Science 36(10): 1143-1159.

Carbonell P and Rodríguez A (2006) "The impact of market characteristics and innovation speed on perceptions of positional advantage and new product performance". International Journal of Research in Marketing 23(1): 1-12.

Caruana A, Ramaseshan B and Ewing MT (1998) "Do universities that are more marketoriented perform better?” International Journal of Public Sector Management 11(1): $55-70$.

Cassandra M (2004) "The dynamic nature of innovation partnering: a longitudinal study of collaborative inter-organizational relationships". European Journal of Innovation Management 7(2): 128-140.

Cescyl (2006) Situación económica y social de Castilla y León. Valladolid: Consejo Económico y Social de Castilla y León.

Cetindamar D and Ulusoy G (2008) "Innovation performance and partnerships in manufacturing firms in Turkey". Journal of Manufacturing Technology Management 19(3): 332-345.

Chaveerug A and Ussahawanitchakit P (2008) "Learning orientation, innovation capability and organizational performance in Thai audit firms: moderating effects of organization climate and uncertainty environment". Review of Business Research 8(2): 92-102.

Chesbrough HW (2003) Open innovation the new imperative for creating and profiting from technology. Boston MA: Harvard Business School Press.

Chesbrough HW (2006) Open Business Models: How to Thrive in the New Innovation Landscape. Boston, MA: Harvard Business School Press. 
Chesbrough HW and Appleyard MM (2007) "Open innovation and strategy". California Management Review 50(1): 57-76.

Chiesa V (2001) R\&D strategy and organization, managing technical change in dynamic contexts. London: Imperial College Press.

Christensen CM and Bower JL (1996) "Customer power strategic investments and the failure of leading firms”. Strategic Management Journal 17(3): 197-218.

Christensen CM and Rosenbloom R (1995) "Explaining the attacker's advantage: technological paradigms, organizational dynamics and the value network". Research Policy 23: 233-257.

Chudnovsky DA, López G y Rossi G (2004b) "Sobreviviendo en la convertibilidad Innovación empresas transnacionales y productividad en la industria manufacturera". Desarrollo Económico Revista de Ciencias Sociales 175(Octubre-Diciembre).

Chung L and Gibbons P (1997) "Corporate entrepreneurship: the roles of ideology and social capital”. Group Organ Manage 22(1): 10-30.

Cincera M, Kempen L, Pottelsberghe B, et al. (2004) "Productivity growth, R\&D and the role of international collaborativeagreements: some evidence for Belgian manufacturing companies". Brussels Economic Review 46(3): 107-140

Cohen WM and Klepper S (1996a) “A reprise of size and R\&D”. Economic Journal 106(July): 925-951.

Cohen WM and Klepper S (1996b) "Firm size and the nature of innovation within industries: the case of process and product R\&D”. Review of Economics and Statistics 78(2): 232-243.

Cohen WM and Levinthal D (1990) "Absorptive capacity: a new perspective on learning and innovation”. Administrative Science Quarterly 35(1): 128-152.

Coleman D (1999) Groupware: collaboration and knowledge sharing. En Knowledge management handbook, Liebowitz, J. (ed.). Florida, Boca Raton: CRC Press.

Collis D and Montgomery C (1995) "Competing on resources: strategy in the 1990's". Harvard Business Review 73(4): 119-128.

Combs JG and Ketchen DJ Jr (1999) "Explaining interfirm cooperation and performance: toward a reconciliation of predictions from the resource-based view and organizational economics". Strategic Management Journal 20(9): 867-888.

Comisión Europea (2011b) "Annual report on EU small and medium sized enterprises 2010/2011. Paris: OECD Publishing 
Cooper JR (1998) "A multidimensional approach to the adoption of innovation". Management Decision 36(8): 493-502.

Cooper RG (1984) "New product strategies: what distinguishes the top performance". Journal of Product Innovation Management 2(June): 151-164.

Cooper RG (1996) "Overhauling the new product process". Industrial Marketing Management 25(6): 465-482.

COTEC (2011) Informe sobre tecnología e innovación en España. Madrid: Fundación COTEC para la Innovación Tecnológica.

Covin JG and Miles MP (1999) "Corporate entrepreneurship and the pursuit of competitive advantage". Entrepreneurship Theory and Practice 23(3): 47-65.

Covin JG and Slevin DP (1988) "The influence of organization structure on the utility of an entrepreneurial top management style”. Journal of Management Studies 25(3): 217234.

Covin JG and Slevin DP (1989) "Strategic management of small firms in hostile and benign environments". Strategic Management Journal 10(1): 75-87.

Covin JG and Slevin DP (1991) “A conceptual model of entrepreneurship as firm behaviour". Entrepreneurship Theory and Practice 16(1): 7-24.

Criscuolo C and Haskel J (2003) Innovations and productivity growth in the UK: evidencefrom CIS2 and CIS3. Centre for Research into Business Activity (CeRiBa) Office for National Statistics, UK.

Cummings LL and Paramita B (1977) "Organizational performance as a function of organizational size and structure: a comparative analysis of Indonesian industry”. Academy of Management Proceedings: 317-321.

Currya, N and Webberb DJ (2012) "Economic Performance in Rural England". Regional Studies, 46(3): 279-291.

Czarnitzki D and Kraft K (2004) "Firm leadership and innovative performance: evidence from seven EU countries”. Small Business Economics 22(5): 325-332.

Czarnitzki D and Spielkamp A (2000) "Business services in Germany: bridges for innovation". Service Industries Journal 23(2): 1-31.

Daft R (1978) “A dual-core model of organizational innovation". Academy of Management Journal 21(2): 193-211.

Damanpour F (1990) Innovation effectiveness adoption and organizational performance. In West MA and Farr JL (Eds). Innovation and creativity at work. John Wiley \& Sons Chichester, pp.125-141. 
Damanpour F (1991) "Organizational innovation: a meta-analysis of effects of determinants and moderators". Academy of Management Journal 34(3): 555-590.

Damanpour F (1996) "Organizational complexity and innovation: developing and testing multiple contingency models”. Management Science 42(5): 693-716.

Damanpour F and Evan WM (1984) "Organizational innovation and performance: the problem of organizational lag”. Administrative Science Quarterly 29(3): 392-409.

Damanpour F, Walker R and Avellaneda C (2009) "Combinative effects of innovation types and organizational performance: a longitudinal study of services organizations". Journal of Management Studies 46(4): 650-675.

Das S, Sen PK and Sengupta S (1998) "Impact of strategic alliances on firm valuation". Academy of Management Journal 14(1): 27-41.

Das TK and Teng BS (2000) "A resource-based theory of strategic alliances". Journal of Management 26: 31-60.

Daugherty PJ, Richey RD, Roath AS, et al. (2006) "Is collaboration paying off for firms?" Business Horizons 49(1): 61-67.

Davenport TH (1996) Process innovation: reengineering work through information technology. Boston: Harvard Business School Press.

Davis D, Morris M and Allen J (1991) "Perceived environmental turbulence and its effect on selected entrepreneurship, marketing, and organizational characteristics in industrial firms". Journal of the Academy of Marketing Science 19(1): 43-51.

Day G (1994) “The capabilities of market driven organisations”. Journal of Marketing 58(3): $37-52$.

Day G and Nedungadi P (1994) "Managerial representations of competitive positioning". Journal of Marketing 58(2): 31-44.

de Luca LM, Gianmario V and Salvio V (2010) "Market orientation and R\&D effectiveness in high-technology firms: an empirical investigation in the biotechnology industry". Product Innovation Management 27(3): 299-320.

Deeks J (1973) “The small firm -asset or liability”. Journal of Management Studies 10(1): $25-47$.

Delaney JT and Huselid MA (1996) "The impact of human resource management practices on perceptions of organizational performance". Academy of Management Journal 39(4): 949-969.

Deshpandé R and Farley JU (1999a) "Corporate culture and market orientation: comparing Indian and Japanese firms". Journal ofInternational Marketing 7(4): 111-127. 
Deshpandé R and Farley JU (2000) "Market-focused organizational transformation in China". Journal of Market Focused Management 2: 213-232.

Deshpandé R, Farley JU and Webster FF Jr (1993) "Corporate culture, market orientation and innovativeness in Japanese firms: a quadra analysis”. Journal of Marketing 57(1): 2337.

Dess G, Lumpkin G and Covin J (1997) "Entrepreneurial strategy makig and firm performance: test of contingency and configurational models". Strategic Management Journal 18(9): 677-695.

Dhanaraj C and Parkhe A (2006) "Orchestrating innovation networks". Academy of Management Review 31(3): 659-669.

DIRCE (2011) Directorio central de empresas: explotación estadística. Instituto Nacional de Estadística, España. [enlínea]. http://www.ine.es/daco/daco42/daco424/sm0111.pdf [Consulta: 19 de abril de 2012].

Drejer I and Vinding A (2005) "Location and collaboration: manufacturing firms' use of knowledge intensive services in product innovation". European Planning Studies 13(6): 879-898.

Drejer I and Vinding A (2007) 'Searching near and far: determinants of innovative firms' propensity to collaborate across geographical distance". Industry and Innovation 14: $259-275$

Drucker PF (1985) Innovations and entrepreneurship. New York: Hamper and Row.

Dubois A (1998) Organising industrial activities across firm boundaries. London: Routledge.

Dunne P and Hughes A (1994) "Age, size, growth and survival: UK companies in the1980's". Journal of Industrial Economics 42: 115-141.

Dyer JH and Nobeoka K (2000) "Creating and managing a high performance knowledgesharing network: the Toyota case”. Strategic Management Journal 21: 345-367.

Dyer JH and Singh H (1998) "The relational view: Cooperative strategy and sources of interorganizational competitive advantage". Academy of Management Review 23(4): 660-679.

EIS (2006) European Innovation Scoreboard. Comparative Analysis of Innovation Performance. Maastricht Economic Research Institute on Innovation and Technology (MERIT) and the Joint Research Centre (Institute for the Protection and Security of the Citizen) of the European Commission. 
Eisenhardt K and Schoonhoven C (1996) "Resource based views of strategic alliance formation: strategic and social effects in entrepreneurial firms". Organization Science 7(2): 136-150.

Eisenhardt KM and Tabrizi BN (1995) "Accelerating adaptive processes: product innovation in the global computer industry". Administrative Science Quarterly 40(2): 84-110.

Entrialgo M, Fernández E and Vázquez C (2001) "The effect of the organizational context on SME's entrepreneurship: some Spanish evidence”. Small Business Economics 16(3): 223-236.

Ettlie JE, Bridges WP and O'Keefe RD (1984) “Organizational strategy and structural differences for radical versus incremental innovation". Management Science 30(6): $682-695$.

European Commission (2002) Innobarometer 2001. OPOCE. Luxembourg.

European Commission (2011) Innovation union scoreboard. Belgium: European Union. [enlínea]. http://www.proinno-europe.eu/inno-metrics/page/ius-2011. [Consulta: 08 abril de 2012].

EUROSTAT (2011) Eurostat yearbook 2011: Europe in figures. Bruselas: EUROSTAT.

Eustat (2012) “Gastos internos $(I+D)$ ". [enlínea]. http://www.eustat.es/documentos/opt_0/tema_179/elem_1697/definicion.html\#axzz1sU6 DMhsr. [Consulta: 19 de abril de 2012].

Evangelista R and Mastrostefano V (2006) "Firm size sectors and countries as sources of variety in innovation”. Economy Innovation New Technologies 15(3): 247-270.

Farinas J C and Moreno L (2000) "Firm's growth, size and age: a nonparametric approach". Review of Industrial Organisation 17: 249-265.

Fernández SE y Fernández CZ (1988) Manual de dirección estratégica de la tecnología. La producción como ventaja competitiva, Madrid: Ariel Economía.

Fethke GC and John BJ (1982) "Rivalry and the timing of innovation". Bell Journal of Economics 13(1): 272-279.

Fiol C (2001) "Revisiting an identity-based view of sustainable competitive advantage". Journal of Management 27(6): 691-699.

Fiol CM and Lyles M (1985) "Organizational learning". Acadamy of Management Review 10(4): 803-813.

Fotopoulos G and Louri H (2000) "Location and survival of new entry". Small Business Economics 14: 311-321. 
Frank L, Douglas FL, Narayanan VK, et al. (2010) "The case for entrepreneurship in R\&D in the pharmaceutical industry". Nature Reviews Drug Discovery 9: 683-689.

Freel MS (2000a) "Strategy and structure in innovative manufacturing SMEs: the case of an English region”. Small Business Economics 15(1): 27-45.

Freel MS (2000b) "Do small innovating firms outperform non-innovators". Small Business Economics 14(3): 195-210.

Freel MS (2005) "Perceived environmental uncertainty and innovation in small firms". Small Business Economics 25(1): 49-64.

Freeman C, Clark J and Soete L (1982) "Unemployment and technical innovation: a study of long waves in economic development. London: Frances Pinter.

Freeman CH (1975) La teoría de la innovación industrial. Madrid: Penguin Alianza.

Freeman R (1984) A Stakeholder approach: strategic management. Boston: Pitman.

Freeman S, Edwards R and Schroder B (2006) "How smaller born-global firms use networks and alliances to overcome constraints to rapid internationalization". Journal of International Marketing 14(3): 33-63.

Fritsch M and Lukas R (2001) “Who cooperates on R\&D?”. Research Policy 30(2): 297-312.

Fukagawa Y (2005) "Asia's new economic integration strategy: moving beyond the FTA" Asia Pacific Review 12(2): 10-29.

Galbraith JK (1956) American capitalism: the concept of countervailing power. Boston: Houghton Mifflin.

García-Romero A (2012) "Políticas de innovación eficaces para un país en crisis". Cuadernos de Gestión del Conocimiento Empresarial 33(Abril): 1-5.

García-Teruel PJ and Martínez-Solano P (2004) "Short term debt in Spanish SMEs". SSRN Working Paper Series, April. [en línea]. http://ssrncom/abstract=534503. [Consultada: 22 febrero de 2012].

Gatignon H and Xuereb J (1997) "Strategic orientation of the firm and new product performance”. Journal of Marketing Research 34(February): 77-90.

Gilsing V, Nooteboom B, van Haverbeke W, et al. (2008) "Network embeddedness and the exploration of novel technologies: technological distance betweenness centrality and density". Research Policy 37(10): 1717-1731.

Giner J and Santa M (2002) "Territorial systems of small firms in Spain: an analysis of productive and organizational characteristic in industrial districts". Entrepreneurial and Regional Development 14: 221-228. 
Golden PA, Doney PM, Johnson DM et al. (1995) “The dynamics of marketing orientation in transition economies: a study of Russian firms". Journal of International Marketing 3(2): 29-49.

Gómez-Villanueva J, Llonch-Andreu J y Rialp-Criado J (2010) “Orientación estratégica, innovación y resultados en PYMES de nueva creación: el rol del marketing”. Cuadernos de Gestión, 10: 85-110.

González A, Jiménez JJ y Sáez FJ (1997) "Comportamiento innovador de las pequeñas empresas". Investigaciones Europeas de Dirección y Economía de la Empresa 3(1): 93-112.

González-Benito O and González-Benito J (2005) "Cultural vs. operational market orientation and objective vs. subjective performance: perspective of production and operations". Industrial Marketing Management 34(8): 794-829.

González-Benito O, González-Benito J and Muñoz-Gallego P (2009) "Role of entrepreneurship and market orientation in firm's success". European Journal of Marketing 43(3/4): 500-522.

Grant RM (1991) "The resource-based theory of competitive advantage: implications for strategy formulation”. California Management Review 33(3): 114-135.

Grant RM (1996) "Toward a knowledge-based theory of the firm". Strategic Management Journal 17(winter special issue): 109-122.

Grant RM and Baden-Fuller C (2004) "A knowledge accessing theory of strategic alliances". Journal of Management Studies 41(1):61-84.

Greene P and Brown TE (1997) "Resources needs and the dynamic capitalism typology". Journal of Business Venturing 12(3): 161-173.

Griffin A and Hauser JR (1996) "Integrating Mechanisms for Marketing and R\&D". Journal of Product Innovation Management 13(3): 191-215.

Griffith R (1999) "Using the ARD establishment level data to look at foreign ownershipand productivity in the United Kingdom". Economic Journal 109: 416-442.

Griliches Z (1981) “Market value, R\&D and patents”. Economic Letters 7: 183-187.

Griliches Z and Mairesse J (1984) Productivity and $R \& D$ at the firm level In: Griliches, Z., R\&D, Patents and Productivity. University of Chicago Press, Chicago.

Guangzhou AH, Jefferson GH and Jinchang Q (2005) "R\&D and technology transfer in chinese industry". Review of Economics and Statistics 87(4): 780-786.

Gulati R (1998) “Alliances and networks”. Strategic Management Journal 19(4): 293-317. 
Gulati R (1999) "Network location and learning: the influence of network resources and firm capabilities on alliance formation". Strategic Management Journal 20(5): 397-420.

Gulati R and P Lawrence (1999) "Organizing vertical networks: a design perspective". Discusion paper: SMJ Special Issue Conference, Northwestern University, Evanston, IL.

Hair J, Anderson R, Tathan R et al. (2002) Análisis Multivariante. Madrid: Prentice Hall, $5^{\text {ta }}$ Ed.

Håkansson H (1987) Industrial technological development: a network approach. London: Croom Helm.

Håkansson H and Ford D (2002) "How should companies interact?" Journal of Business Research 55: 133-39.

Håkansson H and Snehota I (1995) Developing relationships in business networks. London: International Thomson.

Håkansson H and Waluszewski A (2002) "Path dependence: restricting or facilitating development?" Journal of Business Research 55(7): 561-570.

Hall BH (1993) "Industrial research in the 1980s: did the rate of return fall?" Brookings Papers on Economic Activity: Microeconomics 2: 289-331.

Hall BH and Mairesse J (1995) "Exploring the relationship between R\&D and productivity in French manufacturing firms". Journal of Econometrics 65: 263-293.

Hall M and Weiss L (1967) "Firm size and profitability". Review of Economics and Statistics 49(3): 319-331.

Hamberg D (1966) R\&D: Essays on the economics of research and development. New York: Randon House.

Hamel G (1991) "Competition for competence and inter-partner learning within internationalstrategic alliances”. Strategic Management Journal 12 (Summer Special Issue): 83-103.

Han JK, Kim N and Srivastava RK (1998) "Market orientation and organizational performance: is innovation a missing link?” Journal of Marketing 62(4): 30-45.

Hansen GS and Wernerfelt B (1989) "Determinants of firm performance: the relative importance of economic and organizational factors". Strategic Management Journal 10: 399-411.

Hargadon AB and Sutton RI (1997) "Technology brokering and innovation in a product development firm". Administrative Science Quarterly 42: 716-749. 
Harris R and Robinson C (2003) "Foreign ownership and productivity in the United Kingdom, estimates for U.K. manufacturing using the ARD”. Review of Industrial Organization 22(3): 207-223.

Harris RI and Trainor M (1995) "Innovations and R\&D in Northern Ireland manufacturing: a schumpeterian approach”. Regional Studies 29: 593-604.

Harrison D and Håkansson H (2006) "Activation in resource networks: a comparative study of ports". Journal of Business and Industrial Marketing 21(4): 231-238.

Headd B (2002) "Redefining Business Success: Distinguishing Between Closure and Failure". Small Business Economics 21: 51-61.

Hellmann T and Stiglitz J (2000) "Credit and equity rationing in markets with adverse selection”. European Economic Review (44):281-304.

Hernani JT (2009) "La estrategia estatal de innovación (E2i): una apuesta hacia el territorio. Colección Mediterráneo Económico: Innovación y Desarrollo Económico 17:175181.

Hernard DH and Szymanski DM (2001) "Customer satisfaction: a meta-analysis of the empirical evidence". Journal of the Academy of Marketing Science 29(1): 16-35.

Hess AM and Rothaermel FT (2011) "When are assets complementary? Star scientists strategic alliances and innovation in the pharmaceutical industry". Strategic Management Journal 32(8): 895-909.

Hewitt-Dundas N (2006) "Resource and capability constraints to innovation in small and large plants". Small Business Economics 26(3): 257-277.

Hills $G$ and LaForge $R$ (1992) "Research at the marketing interface to advance entrepreneurship theory". Entrepreneurship Theory and Practice 13(3) 33-59.

Hoang H and Antoncic B (2003) "Network based research in entrepreneurship: a critical review”. Journal of Business Venturing 18(2): 165-187.

Hoogstra G and Dijk J (2004) "Explaining firm employment growth: does location matter?" Small Business Economics 22: 179-192.

Hsueh L and Tu YY (2004) "Innovation and the operational performance of newly established small and medium enterprises in Taiwan". Small Business Economics 23(5): 99-113.

Hult GTM and Ketchen DJ Jr (2001) "Does market orientation matter? A test of relationship between positional advantage and performance”. Strategic Management Journal 22(9): 899-906. 
Hult GTM, Hurley RF and Knight G (2004) "Innovativeness: its antecedents and impact on business performance”. Industrial Marketing Management 33(5): 429- 438.

Hult GTM, Ketchen DJ Jr and Nichols EL Jr (2002) "An xamination of cultural competitiveness and order fulfillment cycle time within supply chains". Academy of Management Journal 45(3): 577-586.

Hult GTM, Snow C and Kandemir D (2003) "The role of entrepreneurship in building cultural competitiveness in different organizational types". Journal of Management 29(3): 401-426.

Hunt S and Morgan R (1996) "The comparative advantage theory of competition". Journal of Marketing 59(2): 1-15.

Hurley RF and Hult GTM (1998) "Innovation, market orientation and organizational learning: an integration and empirical examination". Journal of Marketing 62(3): 4254.

Iacobucci D (1996) Networks in marketing. Thousands Oaks, CA: Sage Publishing.

ICONO (2010) Indicadores del Sistema Español de Ciencia y Tecnología 2008. Madrid: FECYT.

Ingram P and Simons T (2002) "The transfer of experience in groups of organizations: Implications for performance and competition”. Management Science 48: 1517-1533.

Inkpen AC (1998) "Learning and knowledge acquisition through international strategic alliances". Academy of Management Executive 12(4): 69-80.

Jadesadalug V and Usshawanitchakit P (2008) "The impact of organizational synergy and autonomy on new product performance: moderating effects of corporate mindset and innovation". Journal of International Business Strategy 8(3): 118-128.

Janz N, Lööf H and Peters B (2003) "Firm level innovation and productivity - is there acommon story across countries?”. ZEW Discussion Paper No. 03-26.

Janz N, Lööf H and Peters B (2004) "Firm level innovation and productivity: is there a common story across countries?". Problems and Perspectives in Management 2: 184204.

Jassawalla AR and Sashittal HC (1998) "An examination of collaboration in high-technology new product development processes". Journal of Product Innovation Management 15(3): 237-25.

Jaworski BJ and Kohli AK (1993) "Market orientation: antecedents and consequences". Journal of Marketing 57(3): 53-70. 
Jaworski BJ, Kohli AK and Sahay A (2000) "Market-driven versus driving markets". Journal of the Academy of Marketing Science 28(1): 45-54.

Jensen JJ, van den Bosch FA and Volberda HW (2006) "Exploratory innovation, exploitative innovation and performance: effects of organizational antecedents and environmental moderator". Management Science 52: 1161-1174.

Jermias J (2006) "Competitive intensity as a quasi-moderator of the relationship between innovative efforts and performance". International Journal of Business 8(3): 281299.

Johannessen JA, Olsen B and Lumpkin GT (2001) "Innovation as newness: what is new how new and new to whom?” European journal of Innovation Management 4(1): 20-31.

Johanson J and Mattson LG (1992) Network positions and strategic action: an analytical framework. In Industrial Networks: A new view of reality, Axelsson B and Easton G. London: Routledge, pp. 205-217.

Johne FA and Snelson P (1988) "Success factors in product innovation: a selective review of the literature". Journal of product Innovation Management 5: 114-128.

Johnson P (2005) "Targeting firm births and economic regeneration in a lagging region". Small Business Economics 24: 451-464.

Jong JP and Freel M (2010) "Geographical distance of innovation collaborations". Report, EIM Research Reports, Zoetermee, February.

Julien P (1998) The State of the Art in Small Business and Entrepreneurship, London Brookfield: Ashgate.

Kafouros MI (2008) "Economic returns to industrial research". Journal of Business Research, 61: 868-876.

Kalleberg AL and Leicht KT (1991) "Gender and organizational performance: determinants of small business survival and success". Academy of Management Journal 34(1): $136-161$.

Kalwani M and Narayandas N (1995) "Long term manufacturer supplier relationships do they pay off for suppliers firms?” Journal of Marketing 59: 1-16.

Kanter RM (1989) When giants learn to dance: mastering the challenge of strategy management and careers in the 1990s. New York: Simon and Schuster.

Kanter RM (1994) "Collaborative advantage: the art of alliances". Harvard Business Review 72(7/8): 96-108.

Kanter RM (1995) "Thriving locally in the global economy". Harvard Business Review 73(5): 151-160. 
Kara A, Spillan J and DeShields O (2005) "The effect of a market orientation on business desempeño: a study of small-sized service retailers using MARKOR scale". Journal of Small Business Management 42(2): 105-118.

Kaynak E and Kara A (2004) "Market orientation and organizational performance: a comparison of industrial versus consumer companies in Mainland China using market orientation scale (MARKOR)". Industrial Marketing Management 33: 743-753.

Kemelgor BH (2002) "A comparative analysis of corporate entrepreneurial orientation between selected firms in the Netherlands and the USA". Entrepreneurship and Regional Development 14(1): 67-87.

Kemp RG, De Jongm PJ, Folkeringa MM et al. (2003) "Innovation and firm performance: differences between small and medium-sized firms". EIM Research Report, Zoetermeer.

Kenney M (2001) The temporal dynamics of knowledge creation in the information society. In Nonaka I and Nishiquchi T (Eds) Knowledge emergence social technical and evolutionary dimensions of knowledge creation. New York: Oxford University Press, pp. 93-110.

Keskin H (2006) "Market orientation, learning orientation and innovation capabilities in SMEs: an extended model". European Journal of Innovation Management 9(4): 396417.

Kickul J and Gundry L (2002) "Prospecting for strategic advantage: the proactive entrepreneurial personality and small firm innovation". Journal of Small Business Management 40(2): 85-97.

Kim CS and Inkpen AC (2005) "Cross-border, R\&D alliances, absorptive capacity and technological learning”. Journal of International Management 11(3): 313-329.

Kim CS and Park JH (2010) "R\&D network and its effect on innovation". Journal of International Marketing 18(4): 43-57.

Kirca AH, Jayachandran S and Bearden WO (2005) "Market orientation: a meta-analytic review and assessment of its antecedents and impact on performance". Journal of Marketing 69(2): 24-41.

Kitchell S (1995) "Corporate culture environmental adaptation and innovation adoption: qualitative/quantitative approach". Journal of the Academy of Marketing Science 23(3): 195-205.

Klomp LG and van Leeuwen (2001) "Linking innovation and firm performance: a new approach”. International Journal of the Economics of Business 8: 343-364. 
Knight RM (1986) “Corporate innovation and entrepreneurship: a Canadian study”. Product Innovation Management 4(4): 284-297.

Kogut B (2000) “The network as knowledge”. Strategic Management Journal 21(3): 405425.

Kogut B and Zander U (1992) "Knowledge of the firm combinative capabilities and the replication of technology". Organization Science 3(3): 383-397.

Kohli AK and Jaworski BJ (1990) "Market orientation: the construct research propositions and managerial implications". Journal of Marketing 54(2): 1-18.

Kotler P (1996) Dirección de mercadotecnia. México: Prentice Hall, $8^{\text {ta }}$ Ed.

Kotler P and Armstrong G (1997) Marketing: an introduction. New Jersey: Prentice-Hall.

Kumar K, Subramanian R and Strandholm K (2002) "Market orientation and performance: does organizatioal strategy matter?" Journal of Applied Business Research 18(1): 37 50 .

Kumar K, Subramanian R and Yauger C (1998) "Examining the market orientationperformance relationship: a context specific study". Journal of Management 24(2): 201-234.

Kumara N, Scheerb L and Kotler P (2000) "From market driven to market driving". European Management Journal 18(2):129-142.

Kwoka J and White L (2001) "The new industrial organization and small business". Small Business Economics 16: 21-30.

Laage-Hellman J (1997) Business networks in Japan supplier-customer interaction in product development. London: Routledge.

Lado N and Maydeu-Olivares A (2001) "Exploring the link between market orientation and innovation in the European and US insurance markets". International Marketing Review 18(2): 130-144.

Lado N, Maydeu-Olivares A and Rivera J (1998) "Measuring market orientation in several populations: a structural equations model". European Journal of Marketing 32(1/2): 23-39.

Lane PJ and Lubatkin M (1998) "Relative absorptive capacity and interorganizational learning”. Strategic Management Journal 19(5): 461-477.

Lane PJ, Salk JE and Lyles MA (2001) “Absorptive capacity learning and performance in international joint ventures”. Strategic Management Journal 22(12): 1139-1161. 
Langerak F (2001) "Effects of market orientation on the behaviors of salespersons and purchasers, channel relationships, and performance of manufacturers". International Journal of Research in Marketing 18: 221-234.

Langerak F (2003a) “An appraisal of research on the predictive power of market orientation”. European Management Journal 21(4): 447-464.

Langerak F (2003b) "The effect of market orientation on positional advantage and organizational performance”. Journal of Strategic Marketing 11(2): 93-115.

Lassen Gertsen and Ove-Riis (2006) "The nexus of corporate entrepreneurship and radical innovation”. Corporate Entrepreneurship and Radical Innovation 15(4): 359-372.

Lavie D and L Rosenkopf (2006) "Balancing exploration and exploitation in alliance formation". Academy of Management Journal 49: 797-818.

Lechler, T. (2001) "Social interaction: a determinant of entrepreneurial team venture success". Small Business Economics 16: 263-278.

Lee C and Tsai (2005) "The effects of business operation mode on market orientation, learning orientation and innovativeness". Industrial Management and Data Systems 105(3): 325-348.

Lee L and Sukoco B (2007) "The effects of entrepreneurial orientation and knowledge management capability on organizational effectiveness in Taiwan: the moderating role of social capital”. International Journal of Management 24(3): 540-572.

Lefebvre ET, Cassivi L, Lefebvre LA, et al. (2003) "E-collaboration within one supply chain and its impact on firms' innovativeness and performance". Journal of Information Systems and e-Business Management 1(2): 157-173.

Lehtoranta $\mathrm{O}$ (2010) Innovation collaboration in innovation and the growth performance of finnish firms. Finland: Julkaisija - Utgivare, VTT.

Leonard-Barton, D. (1995) Wellsprings of knowledge: building and sustaining the source of innovation. Boston: Harvard Business School Press.

Li H and Atuahene-Gima K (2001) "Product innovation strategy and the performance of new technology ventures in China". Academy of Management Journal 44(6): 1123-1134.

Li T and Calantone RJ (1998) "The impact of market knowledge competence on new product advantage: conceptualization and empirical examination". Journal of Marketing 62(October): 3-29.

Li Y and Hu J (2002) "Technical efficiency and location choice of small and medium-sized enterprise”. Small Business Economics 19: 1-12. 
Li Y, Liu Y and Zhao Y (2006) "The role of market and entrepreneurship orientation and internal control in the new product development of Chinese firms". Industrial Marketing Management 35: 336-347.

Liedholm C (2002) "Small Firm Dynamics: evidence from Africa and Latin America". Small Business Economics 18: 227-242.

Liedholm C and Mead D (1999) Small enterprise and economic development: the dynamic role of micro and small enterprises. London: Rutledge.

Lin YY and Chen YC (2007) "Does innovation lead to performance? An empirical study of SMEs in Taiwan". Management Research News 30(2): 115-132.

Link AN and Rees J (1990) "Firm size university based research and the returns to R\&D". Small Business Economics 2(1): 25-32.

Littunen H (2000) "Networks and local environmental characteristics in the survival of new firms". Small Business Economics 15(1): 59-71.

Littunen H and Nenonen T (1998) "The survival of firms over the critical first 3 years and the local environment”. Entrepreneurship and Regional Development 10(3): 189-202.

Liu H (1995) "Market orientation and firm size: an empirical examination in UK firms". European Journal of Marketing 29(1): 57-71.

Liu J, Dubinsky A and Shi Y (2000) "Change to survive: China's new state-owned enterprise". International Journal of Business Economics and Social Policy 12(2): 87-97.

Liu SS, Luo X and Shi YZ (2002) "Integrating customer orientation, corporate entrepreneurship and learning organization in organizations-in-transition: empirical study". International Journal of Research in Marketing 19(4): 367-382.

Liu SS, Luo X and Shi YZ (2003) "Market oriented organizations in an emerging economy: a study of missing links". Journal of Business Research 56(6): 481-491.

Llonch-Andreu J y López MP (1999) “Orientación al mercado, orientación estratégica y organización de las actividades de marketing: una investigación empírica". Investigaciones Europeas de Dirección y Economía de la Empresa 5(3): 77-94.

Lööf H and Heshmati A (2002) "Knowledge capital and performance heterogeneity: a firmlevel innovation study”. International Journal of Production Economics 76: 61-85.

Low Ch and Sloan (2007) "Inter-relationships between innovation and market orientation in SMEs”. Management Research News 30(12): 878-891.

Low M and MacMillan IC (1988) "Entrepreneurship: past research and future challenges". Journal of Management 14: 139-161. 
Lukas B and Ferrell O (2000) "The effect of market orientation on product innovation". Academy of Marketing Science Journal 28(2): 239-247.

Lummus RR, Vokurka RJ and Albert KL (1998) "Strategic supply chain planning". Production and Inventory Management Journal 39(3): 49-58.

Lumpkin GT and Dess GG (1996) "Clarifying the entrepreneurial orientation construct and linking it to performance”. Academy of Management Review 21(1): 135-172.

Lundvall BA and Nielsen P (2005) "Innovation organisational learning and job creation". European Journal of Economic and Social Systems 18(1): 79-97.

Lussier RN and Pfeifer S (2001) "A crossnational prediction model for business success" Journal of Small Business Management 39(3): 228-239.

Mahoney J and Pandian J (1992) "The resource-based view within the conversation of strategic management”. Strategic Management Journal 13(5): 363-380.

Majumdar SK (1997) "The impact of size and age on firm-level performance: some evidence from India”. Review of Industrial Organization 12(2): 231-241.

Mansfield E (1963) "Size of firm, market struture, and innovation". Joumal of Political Economy 71: 556-576.

Maravelakis E, Bilalis N, Antoniadis A, et al. (2006) "Measuring and benchmarking the innovativeness of SMEs: a three-dimensional fuzzy logic approach". Production Planning \& Control 17(3): 283-292.

Markides C (1997) “Strategic innovation”. MIT Sloan Management Review 38(3): 9-23.

Matear SH, Osborne P, Garrett T, et al. (2002) "How does market orientation contribute to service firm performance? An examination of alternatives mechanisms". European Journal of Marketing 36(9/10): 1058-1075.

Matsuno K, Mentzer JT and Özsomer A (2002) "The effects of entrepreneurial proclivity and market orientation on business performance”. Journal of Marketing 66: 18-32.

Mavondo FT and Farrell M (2003) "Cultural orientation: its relationship with market orientation innovation and organisational performance". Management Decision 41(3): 241-249.

Mavondo FT, Chimhanzi J and Stewart J (2005) "Learning orientation and market orientation relationship with innovation human resource practices and performance”. European Journal of Marketing 39 (11/12): 1235-1263.

Maydeu-Olivares A and Lado N (2003) "Market orientation and economic performance in the European insurance industry: a mediational model". International Journal of Service Industry Management 14: 284-309. 
McAdam R and Reid R (2004) "Innovation and organisational size in Irish SMEs: an empirical study". International Journal of Innovation Management 8(2): 147-165.

McCann J, León A and Harley J (2001) "Strategic goals and practices of innovative family business". Journal of Small Business Management 39(1): 50-59.

McEvily B and Zaheer A (1999) "Bridging ties: a source of firm heterogeneity in competitive capabilities” Strategic Management 20: 1133-1156.

McFadzean E, Ezineard J and Birchall D (2007) "Perception of risk and the strategic impact of existing IT on information security strategy at board level". Online Information Review Emerald 31(5): 622-660.

McKee D and Varadarajan P (1995) "Strategic adaptability and firm performance". Journal of Marketing 53(3): 21-35.

McPherson M (1992) "Growth and survival of small Southern African firms". PhD Dissertation, Michigan State University, East Lansing.

Melin (1986) "Entrepreneurship and strategic change". Frontiers of Entrepreneurial Research Babson College Wellesley Mass 725.

Menkveld A and Thurik R (1999) "Firm size and efficiency in innovation: reply". Small Business Economics 12: 97-101.

Mentzer JT, Dewitt W, Keebler JS, et al. (2000) "Defining supply chain management". Journal of Business Logistics 22(2): 1-25.

Messenghen K (2003) "Strategic entrepreneurship and managerial activities in SMEs". International Small Business Journal 21(2): 197-212.

Meuss M and Oerlemans L (2000) "Firm behaviour and innovative performance: an empirical exploration of the selection-adaptation debate". Research Policy 29(1): 4158.

Meyer MH and Utterback JM (1995) "Product development cycle time and commercial success”. IEEE Transactions on Engineering Management 42(4): 297-304.

Miles MP and Arnold DR (1991) "The relationship between marketing orientation and entrepreneurial orientation". Entrepreneurship Theory and Practice 15(4): 49-65.

Miles R and Snow C (1978) Organizational strategy structure and process. New York: McGraw-Hill.

Miller D (1983) “The correlates of entrepreneurship in three of firms". Management Science 29(7): 770-791. 
Miller D and Fiesen P (1982) "Innovation in conservative and entrepreneurial firms: two models of strategic momentum”. Strategic Management Journal 3(1): 1-25.

Minguella M y Balañá A (1989) "Diseño industrial e innovación tecnológica en la pequeña y mediana industria”. Barcelona: Treballs Gràfics, pp. 16 y 17.

Mintzberg HH (1989) Mintzberg on Management, New York: The Free Press.

Mintzberg HH and van Der L (1999) "Organigraphs: Drawing How Companies Really Work”. Harward Business Review, 77(5), 87-94.

Mitchell R and Smith B (2000) "Cross-cultural cognitions and the venture creation decision". Academy of Management Journal 43(5): 974-993.

Mole K and Worrel L (2001) "Innovation business performance and regional competitiveness in the West Midlands: evidence of the West Midlands survey". European Business Review 13(6): 353-364.

Molinero, F.; Baraja, E.; Rivilla, M. (2002) Inventario de productos agroalimentarios de calidad de Castilla y León. J, Valladolid: Junta de Castilla y León.

Mols NP (2002) "The impact of organizational and environmental factors on the implementation of internet-based marketing channels". Journal of Marketing Channels 9(3/4):103-131.

Monjon S and Waelbroeck P (2003) "Assessing spillovers from universities to firms: evidence from French firm-level data". International Journal of Industrial Organization 21: 1255-1270.

Moorman C and Miner AS (1997) "The impact of organizational memory on new product performance and creativity". Journal of Marketing Research 34(1): 91-106.

Morbey G (1989) "R\&D expenditures and profit growth". Research Technology Management 32: $20-23$.

Morgan K (2004) "The exaggerated death of geography: learning proximity and territorial innovation systems". Journal of Economic Geography 4(1): 3-21.

Morris MH and Paul GW (1987) "The relationship between entrepreneurship and marketing in established firms". Journal of Business Venturing 2(3): 247-259.

Morris MH and Sexton D (1996) "The concept of entrepreneurial intensity: implications for company performance”. Journal of Business Research 35: 5-13.

Morris R and Brennan G (2000) "Creating a seamless local government and small business interface for better regional economic development outcomes". paper presented at the ICSB World Conference, Brisbane, Australia, June. 
Morrison A, Breen J and Ali S (2003) "Small Business growth: intention, ability, and opportunity". Journal of Small business Management 41(4): 417-425.

Motohashi K (2005) "University-industry collaborations in Japan: the role of new technology-based firms in transforming the national innovation system". Research Policy 34(5): 583-594

Motohashi K and X Yun (2007) "China's innovation system reform and growing industry and science linkages”. Research Policy 36(8): 1251-1260.

Motohshi K (2008) "Licensing or not licensing?: empirical analysis on strategic use of patent in Japanese firms". Research Policy 37(9): 1548-1555.

Mowery DC, Oxley JE and Silverman BS (1996) "Strategic alliances and interfirm knowledge transfer”. Strategic Management Journal 17(winter special issue): 77-91.

Mowery DC, Oxley JE and Silverman BS (1998) "Technological overlap and interfirm cooperation: implications for the resource-based view of the firm". Research Policy 27(5): 507-524.

Muñoz-Gallego P (1992) “Aspectos Comerciales de la competitividad de la pequeñas empresas: algunas evidencias en Castilla y León”. Economía Industrial 284: 161-169.

Myers S and Marquis D (1969) Successful industrial innovation. Washington DC: National Science Foundation.

Naman JL and Slevin DP (1993) "Entrepreneurship and the concept of fit: a model and empirical test”. Strategic Management Journal 14(2): 137-157.

Narus J and Anderson J (1996) "Rethinking distribution: adaptive channels". Harvard Business Review 74(4): 112-120.

Narver JC and Slater SF (1990) "The effect of a market orientation on business profitability". Journal of Marketing 45(4): 20-35.

Narver JC, Slater SF and MacLachlan D (2004) "Responsive and proactive market orientation and new-product success". Journal of Product Innovation Management 21(5): 334-347.

Narver JC and Slater SF (1998) "Addtional thoughts on the measurement of market orientation: a commenton Deshpondé and Farley". Journal of Maket-Focused Management 2(3): 233-236.

Naude P and Turnbull PW (Eds.) (1998) Network dynamics in international marketing. Oxford: Pergamon.

Nieto M (2000) "Las innovaciones incrementales y su gestión en la empresa". Alta Dirección 212: $61-72$. 
Nieto M and Quevedo P (2005) “Absorptive capacity technological, opportunity knowledge, spillovers, and innovative effort". Technovation 25(10): 1141-1157.

Niosi J and Bas T (2001) "The competencies of Regions-Canada's clusters in biotechnology". Small Business Economics 17: 31-42.

Noble CH, Sinha RK and Kumar A (2002) "Market orientation and alternative strategic orientations: a longitudinal assessment of performance implications" Journal of Marketing 66(October): 25-39.

Nonaka I (1994) "Dynamic theory or organizational knowledge creation". Organization Science 5(1): 14-37.

Nooteboom B (1999) Inter-firm alliances: analysis and Design. New York: Routledge, London

Nooteboom B, van Haverbeke W, Duysters G, et al. (2005) "Optimal cognitive distance and absorptive capacity”. Research Policy 36(7): 1016-1034.

Norman R (1976) Creative management of firms. Lund, Sweden: Aldhus.

O'Gorman C, Bourke S and Murray J (2005) "The Nature of Managerial Work in Small Growth-Oriented Business". Small Business Economics 25: 1-16.

O'Cass A and Viet Ngo N (2007) "Market orientation versus innovative culture: two routes to superior brand performance”. European Journal of Marketing 41(7/8): 868-887.

OECD (2002) Frascati Manual. Paris: OECD Publishing. [en línea]. http://www.oecdbookshop.org/oecd/display.asp?sf1=identifiers\&lang=EN\&st1=9220 02081p1 [Consulta: 22 marzo de 2012].

OECD (2002) Science, technology and industry outlook. Paris: OECD Publishing.

OECD (2005) Manual de Oslo. Using Patent Data as Science and Technology Indicators, (EU/ Eurostat). Paris: OECD Publishing 3ra Ed. [en línea].

http://www.oecdbookshop.org/oecd/display.asp?sf1=identifiers\&lang=EN\&st1=9220 02081p1. [Consulta: 03 abril de 2012].

Olson EM, Walker OC, Ruekerf RW, et al. (2001) "Patterns of cooperation during new product development among marketing operations and R\&D: implications for project performance". Journal of Product Innovation Management 18(4): 258-271.

Osborn RN and Hagedoorn J (1997) "The institutional and evolutionary dynamics of interorganizational alliances and networks". Academy Management Journal 40(2): 261-278. 
Özsomer A, Calantone R and Di Benedetto A (1997) "What makes firms more innovative? A look at organizational and environmental factors". Journal of Business \& Industrial Marketing 12(6): 400-419.

Pakes A and Griliches Z (1980) "Patents and R\&D at the firm level: a first report". Economics Letters 5: 377-381.

Pavitt K, Robson M and Townsend J (1987) "The size distribution of innovating firms in the UK: 1945-1983”. Journal of Industrial Economics 35(3): 297-316.

Pedersen C and Dalum B (2004) Incremental versus radical change: the case of the digital North Denmark program. En 10th International Schumpeter Society Conference, Bocconi University, Milano.

Pelham AM (1997a) "Mediating influences on the relationship between market orientation and profitability in small industrial firms". Journal of Marketing Theory and Practice 5(2): $1-23$.

Pelham AM (1997b) "Market orientation and performance: the moderating effects of product and customer differentiation”. Journal of Business \& Industrial Marketing 12(5): 276296.

Pelham AM (1999) "Influence of environment, strategy, and market orientation on performance in small manufacturing firms". Journal of Business Research 45: 33-46.

Pelham AM (2000) "Market orientation and other potential influences on performance in small and medium-sized manufacturing firms". Journal of Small Business Management 38(1): 48-67.

Pelham AM and Wilson DT (1996) "A longitudinal study of the impact of market structure firm, structure strategy and market orientation culture on dimensions of small-firm performance". Journal of the Academy of Marketing Science 24(1): 27-43.

Peng MW and Luo Y (2001) "Managerial ties and firm performance in a transition economy: the nature of a micro-macro link". Academy of Management Journal 43(3): 486-501.

Pennings JM and Harianto F (1992) "Technological networking and innovation implementation". Organization Science 3(3): 356-382.

Perry S (2001) "The relationship between written business plans and the failure of small business in the U.S.". Journal of Small Business Management 39(3): 201-208

Peteraf M (1993) "The cornerstones of competitive advantage: a resource-based view". Strategic Management Journal 14(3): 179-191.

Petrakis P (1995) "Entrepreneurship and growth: creative and equilibrating events". Small Business Economics 9: 383-402. 
Phelps CC (2010) "A longitudinal study of the influence of alliance network structure and composition on firm exploratory innovation". Academy of Management Journal 53(4): 890-913.

Phillips BD and Kirchhoff BA (1989) "Formation growth and survival: small firm dynamics in the US economy”. Small Business Economics 1(1): 65-74.

Phromket C and Ussahawanitchakit P (2009) "Effects of organizational learning effectiveness on innovation outcomes and export performance of garments business in Thailand". International Journal of Business Research 9(7): 6-31.

Pitt L, Caruana A and Berthon P (1996) "Market orientation and business performance some European evidence". International Marketing Review 13(1): 5-18.

Podolny J and Stuart T (1995) "A role-based ecologyof technological change". American Journal of Sociology 100: 1224-1260.

Porter ME (1979) "How competitive forces shape strategy". Harvard Business Review 57(2): $137-145$.

Porter ME (1980) Competitive strategy, New York: The Free Press.

Porter ME (1985) "Competitive advantage: creating and sustaining superior performance. New York: The Free Press.

Portes A (1998) "Social capital: its origins and applications in modern sociology". Annual Review of Sociology 24: 1-24.

Powell WW, Koput KW and Smith-Doerr L (1996) "Inter-organizational collaboration and the locus of innovation: networks of learning in biotechnology". Administrative Science Quarterly 41(1): 116-145.

Prahalad CK and Hamel G (1990) "The core competence of the corporation". Harvard Business Review 68: 79-91.

Preiss K, Goldman SL and Nagel RN (1996) Cooperate to compete. New York: van Nostrand-Reinhold.

Psaltopoulos D, Stathopoulou S and Skuras D (2005) "The location of markets, perceived entrepreneurial risk, and start-up capital of micro rural firms". Small Business Economics 25: 147-158.

Quinn JB (1986) "La gestión de la innovación: un caos controlado". Harvard-Deusto Business Review primer trimestre: 44-56.

Raap A, Schillewaert N and Wei-Hao A (2008) "The influence of marketing orientation on ebusiness innovation and performance: the role of the top management team". Journal of Marketing Theory and Practice 16(1): 7-25. 
Rangone A (1998) "A resource-based approach to strategy analysis in small-medium sized enterprises”. Small Business Economics 12: 233-248.

Rangone A (1999) "A resource-based approach to strategy analysis in small-medium sized enterprises”. Small Business Economics 12(3): 233-248.

Ravichandran T (2000) "Swiftness and intensity of administrative innovation adoption: an empirical study of TQM in information systems". Decision Sciences 31(3): 691-724.

Reid G and Smith J (2000) "What makes a new business start-up successful?" Small Business Economics 14: 165-182.

Roberts G, Watson K and Oliver J (1990) "Larger and smaller firms compared". Journal of Organizational Change Management 2(3): 65-74.

Robson P and Bennett R (2000) "SME growth: the relationship with business advice and external collaboration”. Small Business Economics 15: 193-208.

Rodríguez-Cano C, Carrillat FA and Jaramillo F (2004) "A meta-analysis of the relationship between market orientation and business performance: evidence form five continents". International Journal of Research in Marketing 21(2): 179-200.

Rogers M (2004) "Networks firm size and innovation". Small Business Economics 22(2): $141-153$.

Roper S (1998) "Entrepreneurial characteristics, strategic choice and small business performance". Small Business Economics 11: 11-24.

Roper S and Love J (2002) "Innovation and export performance: evidence from the UK and German manufacturing plants". Research Policy 31(7): 1087-1102.

Rothaermel FT and Deeds DL (2004) "Exploration and exploitation alliances in biotechnology: a system of new product development". Strategic Management Journal 25(3): 201-221.

Rothaermel FT, Hitt MA and Jobe LA (2006) "Balancing vertical integration and strategic outsourcing: effects on product portfolios new product success and firm performance”. Strategic Management Journal 27(11): 1033-1056.

Rothwell R (1991) "External networking and innovation in small and medium-sized manufacturing firms in Europe". Technovation 11(2): 93-112.

Rothwell R (1994) "Towards the fifth-generation innovation process". International Marketing Review 11: 7-31.

Rothwell R and Dodgson M (1994) Innovation and size of firm. In Dodgson, M. (ed). Handbook of industrial innovation, Aldershot: Edward Elgar, pp 310-324. 
Ruekert R (1992) "Developing a market orientation: an organizational strategy perspective". International Journal of Research in Marketing 9: 225-245.

Russell R and Russell C (1992) "An examination of the effects of organizational norms, organizational structure and environmental uncertainty on entrepreneurial strategy". Journal of Management 18(4): 639-656.

Sakakibara M (1997) "Evaluating government-sponsored R\&D consortia in Japan: who benefits and how". Research Policy 26: 447-473.

Salavou H and Lioukas S (2003) "Innovativeness: its antecedents and impact on business performance”. Creativity and Innovation Management 12(2): 94-108.

Salavou H, Baltas G and Lioukas S (2004) "Organisational innovation in SMEs: the importance of strategic orientation and competitive structure". European Journal of Marketing 38(9/10): 1091-1112.

Sampson RC (2005) "Experience effects and collaborative returns in R\&D alliances". Strategic Management Journal 26(11): 1009-1031.

Sampson RC (2007) "R\&D alliances and firm performance: the impact of technological diversity and alliance organization on innovation". Academy of Management Journal 50(2): 364-386.

Sandberg and Hofer (1986) The effect of strategy and industrial structure on new venture performance. Frontiers of Entrepreneurial Research., Wellesley Mass: Babson College, pp. 244-266.

Sanders NR and Premus R (2005) "Modelling the relationship between firm it capability collaboration and performance". Journal of Business Logistics 26(1): 1-23.

Santamaría L, Nieto MJ y Barge-Gil A (2009) “Hay innovación más allá de la I+d? El papel de otras actividades innovadoras." Universia Business Review, Segundo trimestre: 102-117.

Santos ML and González-Benito O (2000) "Economic success factors in Spanish small retail business: An Analysis Based on Sector-Relative Definitions". Small Business Economics 15: 209-222.

Santos ML, Sanzo M, Álvarez L, et al. (2002) "El aprendizaje organizativo y la orientación al mercado como recursos empresariales: interacciones y efectos sobre la competitividad”. Revista Española de Investigación de Marketing 6(1): 7-37.

Santos ML y Vázquez R (1997) "Factores condicionantes del resultado del desarrollo de nuevos productos en las empresas de alta tecnología”. Revista Española de Investigación de Marketing 1: 165-189. 
Sanz Parra, B.; Fernández de Pedro, S. (2006) Mercado Laboral, Inspecciones de Trabajo, Seguridad Social y Plan de Empleo de Castilla y León. Valladolid: Secretaría de Empleo y Formación de la Unión Sindical de CC.OO.

Sargeant A and Mohamad M (1999) "Business performance in the UK hotel sector -does it pays to be market-orientated?" The Service Industrial Journal 19(3): 42-59.

Sarkar MB, Echambadi R and Harrison JS (2001) "Alliance entrepreneurship and firm market performance". Strategic Management Journal 22(6/7): 701-715.

Saxenian A (1994) Regional advantage: culture and competition in Silicon Valley and route 128. Cambridge Ma: Harvard University Press.

Scherer FM (1965) "Firm size, market structure, opportunity and the output of patented inventions". American Economic Review 55 (5): 1097-1125.

Scherer FM (1983) “The propensity to patent". International Journal of Industrial Organization 8(1): 107-128.

Schilling MA and Phelps CC (2007) "Interfirm collaboration networks: the impact of largescale network structure on firm innovation". Management Science 53(7): 1113-1126.

Schulze WS (1994) The two schools of thought in resource-based theory: definitions and implications for research. In Shrivastava P, Huff A and Dutton J (Eds). Resource based view of the firm. Greenwich CT: JAI Press, pp. 127-152

Schumpeter JA (1934) Theory of economic development. Cambridge MA: Harvard University Press.

Schumpeter JA (1944): La teoría del desenvolvimiento económico: una investigación sobre ganancias, capital, crédito, interés y ciclo economico. México: Fondo de Cultura Económica.

Sen AK and Haq K (2011) "Product innovation by small and medium sized firms through outsourcing and collaboration". International Journal of Management and Marketing Research 4(1): 63-74.

Sengupta S and Bushman FA (1998) "Organizational culture and new product performance: an exploratory investigation in high-technology firms". American Marketing Association Conference Proceedings 9: 391-398.

Shaffer S (2002) “Firm size and economic growth”. Economics Letters 76(2): 195-203.

Shan W, Walker G and Kogut B (1994) "Interfirm cooperation and startup innovation in the biotechnology industry”. Strategic Management Journal 15: 387-394.

Sheth JN and Parvatiyar A (2000) Handbook of relationship marketing. Thousand Oaks CA: Sage Publishing. 
Sidro-Cazador, V (1988) Gestión tecnológica de la empresa. Madrid: 1MPI.

Sin L, Tse A, Yau O et al. (2000) "Market orientation and business performance: an empirical study in Mainland China”. Journal of Global Marketing 143(3): 5-29.

Singh K and W Mitchell (1996) "Precarious collaboration: business survival after partners shut down or form new partnerships". Strategic Management Journal 17(Summer Special): 99-115.

Singh S (2003) "Effects of transition economy on the market orientation-business performance link: the empirical evidence from Indian industrial firms". Journal of Global Marketing 16(4): 73-96.

Skuras D, Dimara E and Vakrou A (2000) "The day after grant-aid: business development schemes for small rural firms in lagging areas of Greece". Small Business Economics 14: $125-136$.

Slater SF and Narver JC (1994a) "Does competitive environment moderate the market orientation-performance relationship?” Journal of Marketing 58(January): 46-55.

Slater SF and Narver JC (1994b) "Market orientation customer value and superior performance" Business Horizons 37(2): 22-28.

Slater SF and Narver JC (1995) "Market orientation and the learning organization". Journal of Marketing 59(3): 63-74.

Slater SF and Narver JC (1996) "Competitive strategy in the market-focused business". Journal of Market Focused Managernent 1: 159-174.

Slater SF and Narver JC (1998) "Customer-led and market-orientated: let's not confuse the two". Strategic Management Journal 19(10): 1001-1006.

Slater SF and Narver JC (1999) "Market-orientated is more than being customer-led". Strategic Management Journal 20: 1165-1168.

Slater SF and Narver JC (2000) "The positive effect of a market orientation on business profitability: a balanced replication”. Journal of Business Research 48(2): 69-73.

Smith KG, Guthrie JP and Chen MJ (1986) "Miles and Snow's typology of strategy organizational size and organizational performance". Academy of Management Proceedings 10(1): 45-49.

Smith-Doerr LJ, Owen-Smith KW, Koput WW et al. (1999) Networks and knowledge production: collaboration and patenting in biotechnology. In Leenders $\mathrm{R}$ and Gabbay S (Eds). Corporate Social Capital Kluwer, Academic Publishers Norwell MA, pp.331-350. 
Soete L (1979) "Firm size and inventive activity: the evidence reconsidered". European Economic Review 12: 319-340.

Soh PH (2003) "The role of networking alliances in information acquisition and its implication for new product performance". Journal of Business Venturing 18(6): $727-$ 744.

Soh PH and Roberts EB (2005) "Technology alliances and networks: an external link to research capability”. IEEE Transactions on Engineering Management 52(4): 419428.

Sorensen JB and Stuart TE (2000) “Aging obsolescence and organizational innovation". Administrative Science Quarterly 45(1): 81-112.

Souza G, Bayus B and Wagner H (2004) "New-product strategy and industry clock speed". Management Science 50(4): 537-549.

Spilling O (1996) "Regional variation of new firm formation: the Norwegian case". Entrepreneurship and Regional Development 8: 217-243.

Stoneman P (1983) The economic analysis of technological change. Oxford: Oxford University Press.

Storey DJ (1994) Understanding the small business sector. London: Rutledge.

Storey DJ and Wynarczyk P (1996) "The survival and non survival of micro firms in the UK" Review of Industrial Organization 11: 211-229.

Story V, O'Malley L and Hart S (2011) "Roles, role performance and radical innovation competences". Industrial Marketing Management 40(6): 952-966.

Stuart TE (1998) "Network positions and propensity to collaborate: An investigation of strategic alliance formation in high-technology industries". Administrative Science Quarterly 43: 668-698.

Stuart TE (2000) "Inter-organizational alliances and the performance of firms: a study of growth and innovation rates in a high-technology industry". Strategic Management Journal 21(8): 791-811.

Swaminathan V and Moorman C (2009) "Marketing alliances, firm networks and firm value creation". Journal of Marketing 73(5): 52-69.

Teece DJ, Pisano G and Shuen A (1997) "Dynamic capabilities and strategic management". Strategic Management Journal 18(7): 509-533.

Tether BS (2002a) "Identifying innovation, innovators and innovative behaviours: a critical assessment of the community innovation survey (CIS)". CRIC Discussion Paper No. 48, University of Manchester, UK. 
Tether BS (2002b) "Who co-operates for innovation and why: an empirical analysis". Research Policy 31(6): 947-967.

Thomas R (1995) New product success stories: lessons from leading innovators. New York NY: Wiley.

Tidd J, Bessant J and Pavitt K (2001) Managing innovation: integrating technological market and organizacional change. London: Wiley.

Torre A and Rallet A (2005) "Proximity and localization". Regional Studies Taylor and Francis Journals 39(1): 47-59.

Tsai KH, and Wang JC (2005) "Does R\&D performance decline with firm size? A reexamination in terms of elasticity". Research Policy 34: 966-976.

Tung-Zong Ch and Su-Jane Ch (1998) "Market orientation, service quality and business profitability: a conceptual model and empirical evidence". Journal of Services Marketing 12(4): 246-264.

Upton N, Teal E and Felan J (2001) "Strategy and business planning practices of fast growth family firms". Journal of Small Business Management 39(1): 60-72.

Utterback JM (1994) Mastering the Dynamics of innovation. Boston, MA: Harvard Business School Press.

van de Ven AH, Polley DE, Garud R, et al. (1999) The innovation journey. New York, NY: Oxford University Press.

van Egeren M and O'Connor S (1998) "Drivers of market orientation and performance in service firms". Journal of Services Marketing 12(1): 39-58.

van Gelderen M, Frese M and Thurik R (2000) "Strategies, Uncertainty and performance of Small Business Start-ups”. Small Business Economics 15: 165-181.

van Gelderen M, van der Sluis L and Jarsen P (2005) "Learning opportunities and learning behaviours of small business starters: relations with goal achievement, skill development and satisfaction”. Small Business Economics 25: 97-108.

van Leeuwen G (2002) "Linking innovation to productivity growth using two waves of CIS". CEREM Working Paper.

van Leeuwen G and Klomp L (2006) "On the contribution of innovation to multifactorproductivity growth”. Economics of Innovation and New Technology 15: 367390.

Vanhaverbeke WPM, Duysters GM and Beerkens BE (2002) "Technology capability building through networking strategies within high-tech industries". Academy of Management, Best Paper Proceedings, Denver, Colorado. 
Vázquez R, Santos ML and Álvarez LI (2001) "Market orientation innovation and competitive strategies in industrial firms". Journal Strategy Marketing 9: 69-90.

Vega-Vidal JA (2010) "La innovación efectiva: experiencia en el lanzamiento de una unidad de innovación”. Cuadernos de Gestión del Conocimiento Empresarial 23(Mayo): 1-5.

Venkatraman N and Ramanujam V (1986) "Measurement of business performance in strategy research: a comparison of approaches". Academy of Management Review 1(4): 801-808.

Venkatraman N and Ramanujam V (1987) "Measurement of business economic performance: an examination of method convergence". Journal of Management 13(1): 109-22.

Verhees F and Meulenberg M (2004) "Market orientation innovativeness product innovation and performance in small firm". Journal of Small Business Management 42(2): 134153.

Walker G, Kogut B and Shan WJ (1997) "Social capital structural holes and the formation of an industry network”. Organization Science 8(2): 109-125

Walker OC Jr and Ruekert RW (1987) “Marketing's role in the implementation of business strategies: a critical review and conceptual framework". Journal of Marketing 51(July): 15-33.

Wang CL (2008) "Entrepreneurial orientation, learning orientation and firm performance". Entrepreneurship Theory and Practice 32(4): 635-656.

Wilkinson I and Young L (2002) "On cooperating: firms, relations and networks". Journal of Business Research 55(2): 123-132.

Yagüe MJ (1992) "La actividad innovadora de la PYME industrial española". Economía Industrial 284: 137-149.

Yasuda H (2005) "Formation of strategic alliances in high technology industries: comparative study of the resourced based theory and the transaction-cost theory". Technovation 25(7): 763-770.

Yau OHM, McFetridge PR, Chow RPM et al. (2000) "Is relationship marketing for everyone?” European Journal of Marketing 34(9/10): 1111-1127.

Yin X and Zuscovitch E (1998) "Is firm size conducive to R\&D choice? A strategic analysis of product and process innovation". Journal of Economic Behaviour and Organization 35(2): 243-262.

Ying-Chieh C and Cipolla J (2007) "Relationships between goal setting innovation, project management, quality speed to market and new product success". Business Review Cambridge 9(1): 1-8. 
Zaheer A and Geoffrey GB (2005) "Benefiting from network position: firm capabilities, structural holes and performance". Strategic Management Journal 26(9): 809-825.

Zahra SA and Covin J (1995) "Contextual influences on the corporate entrepreneurshipperformance relationship: a longitudinal analysis". Journal of Business Venturing 10(1): 43-58.

Zahra SA, Neubaum D and Huse M (2000) "Entrepreneurship in medium-size companies: exploring the effects of ownership and governance systems". Journal of Management 26(5): 947-976.

Zaltman G, Duncan R and Holbek J (1973) Innovations and organisations. New York: John Wiley.

Zhou K, Yim Ch and Tse D (2005) "The effects of strategic orientations on technology and market based breakthrough innovations". Journal of Marketing 69(April): 42-60.

Zott, C. y Amit, R. (2009) "Innovación del modelo de negocio: creación de valor en tiempos de cambio". Universia Business Review, tercer trimestre: 108-121.

Zysman J (1993) "Bloques regionales, estrategias empresariales y el fin del libre comercio". Economía Industrial Enero-Febrero: 153-159. 


\subsection{Anexo: instrumento de medida los distintos variables implicadas en el análisis de la muestra}

Tabla 50

Instrumento de medida de las variables de la muestra

\begin{tabular}{|c|c|c|c|}
\hline Variables & \# & Ítems (escalas Likert de 7 puntos) & Fuente \\
\hline \multirow[t]{9}{*}{$\begin{array}{l}\text { Orientación al } \\
\text { mercado }\end{array}$} & V1 & $\begin{array}{l}\text { Información mercado } \\
\text { Continuamente estamos reuniendo información a cerca de } \\
\text { nuestro mercado objetivo. }\end{array}$ & \multirow[t]{9}{*}{$\begin{array}{l}\text { Jaworski y Kohli } \\
\text { (1990); Narver y } \\
\text { Slater (1990) }\end{array}$} \\
\hline & V2 & $\begin{array}{l}\text { Información competencia } \\
\text { Recogemos regularmente informaciones sobre las } \\
\text { estrategias de nuestros competidores. }\end{array}$ & \\
\hline & V3 & $\begin{array}{l}\text { Información clientes } \\
\text { Recogemos información sobre la satisfacción de nuestros } \\
\text { clientes. }\end{array}$ & \\
\hline & V4 & $\begin{array}{l}\text { Información interna } \\
\text { Utilizamos informes internos sobre la estructura y } \\
\text { tendencias del mercado. }\end{array}$ & \\
\hline & V5 & $\begin{array}{l}\text { Coordinación } \\
\text { Regularmente nos reunimos con los responsables de } \\
\text { marketing/ventas para discutir las tendencias del mercado. }\end{array}$ & \\
\hline & V6 & $\begin{array}{l}\text { Reclamaciones/ sugerencias } \\
\text { Se nos informa regularmente de las reclamaciones y } \\
\text { sugerencias de nuestros clientes. }\end{array}$ & \\
\hline & V7 & $\begin{array}{l}\text { Seguimiento } \\
\text { Los responsables de las distintas unidades funcionales se } \\
\text { reúnen regularmente para anticiparse a los cambios del } \\
\text { entorno. }\end{array}$ & \\
\hline & V8 & $\begin{array}{l}\text { Conocimiento mercado } \\
\text { Nuestra estrategia está más basada en el conocimiento } \\
\text { del mercado que en las capacidades productivas. }\end{array}$ & \\
\hline & V9 & $\begin{array}{l}\text { Satisfacción consumidor } \\
\text { Nuestra prioridad en el desarrollo de nuevos productos se } \\
\text { basa más en la satisfacción del consumidor que en la } \\
\text { obtención de ventajas de la capacidad productiva. }\end{array}$ & \\
\hline
\end{tabular}

La escala Likert para orientación al mercado ha sido: 1 = totalmente en desacuerdo/ 7 = totalmente de acuerdo 


\begin{tabular}{|c|c|c|c|}
\hline \multirow[t]{6}{*}{$\begin{array}{l}\text { Orientación } \\
\text { emprendedora }\end{array}$} & V10 & $\begin{array}{l}\text { Lanzamiento de productos } \\
\text { En los últimos cinco años hemos lanzado al mercado muchas } \\
\text { nuevas líneas de productos/ servicios. }\end{array}$ & \multirow[t]{6}{*}{$\begin{array}{l}\text { Naman y Slevin } \\
\text { (1993); Covin y } \\
\text { Miles (1999); } \\
\text { Slater y Narver } \\
(2000)\end{array}$} \\
\hline & V11 & $\begin{array}{l}\text { Cambios productos } \\
\text { Los cambios en nuestras líneas de productos/servicios } \\
\text { generalmente son considerables. }\end{array}$ & \\
\hline & $\begin{array}{ll}\text { V12 } \\
\end{array}$ & $\begin{array}{l}\text { Anticipación competidores } \\
\text { Nos anticipamos a las acciones de nuestros competidores al } \\
\text { introducir nuevos productos/servicios para desarrollar } \\
\text { técnicas administrativas, incorporar tecnologías operativas. }\end{array}$ & \\
\hline & \begin{tabular}{|l|} 
V13 \\
\end{tabular} & $\begin{array}{l}\text { Postura competitiva } \\
\text { Generalmente adoptamos una postura competitiva } \\
\text { deshaciéndonos de nuestros competidores. }\end{array}$ & \\
\hline & V14 & $\begin{array}{l}\text { Aversión al riesgo } \\
\text { Generalmente la dirección de mi empresa es propensa a } \\
\text { desarrollar proyectos de alto riesgo con oportunidades de } \\
\text { altos beneficios. }\end{array}$ & \\
\hline & \begin{tabular}{|l} 
V15 \\
\end{tabular} & $\begin{array}{l}\text { Postura valiente } \\
\text { En situaciones de tomas de decisión con incertidumbre, } \\
\text { generalmente la dirección de mi empresa adopta una postura } \\
\text { valiente y agresiva con el objetivo de maximizar la } \\
\text { probabilidad de explotar las posibles oportunidades. }\end{array}$ & \\
\hline
\end{tabular}

La escala Likert para orientación emprendedora ha sido: $1=$ totalmente en desacuerdo $7=$ totalmente de acuerdo.

\begin{tabular}{|c|c|c|c|}
\hline \multirow[t]{2}{*}{ Organización } & V16 & $\begin{array}{l}\text { Gestión } \\
\text { Implementación de técnicas de gestión avanzadas por parte } \\
\text { de las empresas. }\end{array}$ & \multirow[t]{5}{*}{ OECD, 2005} \\
\hline & V17 & $\begin{array}{l}\text { Organización } \\
\text { Implementación de estructuras organizacionales nuevas o } \\
\text { simplemente alteradas. }\end{array}$ & \\
\hline Marketing & V20 & $\begin{array}{l}\text { Cambios significativos en la fuerza de ventas, políticas de } \\
\text { comunicación y canales de distribución. }\end{array}$ & \\
\hline Producto & V19 & $\begin{array}{l}\text { Cambios en los aspectos relacionados al producto, como su } \\
\text { embalaje, volumen y presentación. }\end{array}$ & \\
\hline $\begin{array}{l}\text { Procesos } \\
\text { Productivos }\end{array}$ & V18 & $\begin{array}{l}\text { Cambios en el proceso de producción y en la distribución en } \\
\text { planta de los medios de producción. }\end{array}$ & \\
\hline
\end{tabular}

La escala Likert para organización, marketing, producto y procesos ha sido: 1 = ninguna innovación / 7 = muchas innovaciones. 


\begin{tabular}{|c|c|c|c|}
\hline $\begin{array}{l}\text { Patentes } \\
\text { registradas }\end{array}$ & V23 & $\begin{array}{l}\text { Indique el número de patentes registradas por su empresa en } \\
\text { los últimos cinco años. }\end{array}$ & \multirow{3}{*}{$\begin{array}{l}\text { OECD, 2002; } \\
\text { Kemp et al. } \\
(2003)\end{array}$} \\
\hline Actividades I+D & V27 & $\begin{array}{l}\text { Indique el número de personas claramente involucradas en } \\
\text { actividades de investigación, desarrollo e innovación en los } \\
\text { últimos cinco años. }\end{array}$ & \\
\hline $\begin{array}{l}\text { Desarrollo de } \\
\text { nuevos productos } \\
\text { y mercados }\end{array}$ & V30 & $\begin{array}{l}\text { Valore el grado en que su empresa ha estado involucrada, en } \\
\text { los últimos cinco años, en la desarrollo de nuevos productos y } \\
\text { mercados. }\end{array}$ & \\
\hline
\end{tabular}

La escala Likert para la medida de patentes ha sido: patentes registradas en los últimos cinco años $(0,1,2,3$, $4,5,>5)$; personas claramente involucradas en actividades $I+D+i(0,1$ y 3,4 y 7,8 y 11, 12 y 15, 16 y 19, >19); desarrollo de nuevos producto y mercados ( $1=$ nada involucrada $/ 7=$ muy involucrada)

\begin{tabular}{|c|c|c|c|}
\hline Rentabilidad & V35a & Rentabilidad. & \multirow{7}{*}{$\begin{array}{l}\text { Jaworski y Kohli } \\
\text { (1993); Slater y } \\
\text { Narver (1994); } \\
\text { Pelham y Wilson } \\
\text { (1996); Kotler y } \\
\text { Armstrong } \\
\text { (1997) }\end{array}$} \\
\hline $\begin{array}{l}\text { Crecimiento de las } \\
\text { ventas }\end{array}$ & V35b & Crecimiento de las ventas. & \\
\hline \multirow[t]{2}{*}{$\begin{array}{l}\text { Respuesta de } \\
\text { mercado }\end{array}$} & V35c & Crecimiento en las ventas & \\
\hline & V35d & Crecimiento de la cuota de mercado & \\
\hline \multirow{2}{*}{$\begin{array}{l}\text { Valor en el } \\
\text { mercado }\end{array}$} & V35e & Satisfacción del cliente & \\
\hline & V35f & Imagen/reputación de la empresa & \\
\hline $\begin{array}{l}\text { Éxito de nuevos } \\
\text { productos }\end{array}$ & V35g & Éxito de nuevos productos & \\
\hline
\end{tabular}

La escala Likert para la medida de resultados ha sido: $1=$ mucho peor que la competencia $/ 7=$ mucho mejor que la competencia.

\begin{tabular}{l|l|l|l}
\hline $\begin{array}{l}\text { Turbulencia del } \\
\text { entorno }\end{array}$ & V25 & $\begin{array}{l}\text { Procesos/ técnicas producción } \\
\text { Cambios en los procesos/técnicas de producción. }\end{array}$ & $\begin{array}{l}\text { Kohli y Jaworski } \\
\text { (1990); } \\
\text { Pelham y Wilson } \\
(1996) ; \\
\text { Hult et al. (2003) }\end{array}$ \\
\cline { 2 - 3 } & V26 & $\begin{array}{l}\text { Demanda } \\
\text { Cambios en la demanda de los consumidores. }\end{array}$ & $\begin{array}{l}\text { Nuevos Productos } \\
\text { Incorporación de nuevos productos. }\end{array}$ \\
\cline { 2 - 3 } & V27 & $\begin{array}{l}\text { Estrategias competitivas } \\
\text { Estrategias y actuaciones de los competidores. }\end{array}$ & \\
\hline
\end{tabular}

La escala Likert para turbulencia del entorno ha sido: 1 = muy estable $/ 7$ = cambios frecuentes y muy importantes. 


\begin{tabular}{l|l|l|l}
\hline $\begin{array}{l}\text { Intensidad } \\
\text { competitiva (IC) }\end{array}$ & V29 & $\begin{array}{l}\text { Bajos precios/ costes } \\
\text { Los competidores ofrecen precios muy agresivos a nuestros } \\
\text { clientes. }\end{array}$ & $\begin{array}{l}\text { Kohli y Jaworski } \\
\text { (1990); } \\
\text { Pelham y Wilson } \\
(1996) ; \\
\text { Hult et al. (2003) }\end{array}$ \\
\cline { 2 - 3 } & V30 & $\begin{array}{l}\text { Innovación } \\
\text { Los competidores ofrecen nuevos productos o productos } \\
\text { mejorados a nuestros clientes. }\end{array}$ & $\begin{array}{l}\text { Diferenciación comercial } \\
\text { Los competidores disponen de ofertas fácilmente sustitutivas } \\
\text { de la nuestra. }\end{array}$ \\
\cline { 2 - 3 } & V31 & $\begin{array}{l}\text { Tamaño } \\
\text { Los competidores son de mayor tamaño. }\end{array}$ & \\
\hline
\end{tabular}

La escala Likert para intensidad competitiva ha sido: $1=$ nada de acuerdo $/ 7=$ muy de acuerdo 